\title{
Multiphase Isolated DC-DC Converters for Low-Voltage High-Power Fuel Cell Applications
}

\author{
Seung-Ryul Moon \\ Thesis submitted to the faculty of the \\ Virginia Polytechnic Institute and State University \\ in partial fulfillment of the requirements for the degree of \\ Master of Science \\ in \\ Electrical and Computer Engineering
}

\author{
Jih-Sheng Lai, Chairman \\ Jamie De La Ree \\ Robert Hendricks
}

April 26, 2007

Blacksburg, Virginia

Keywords: Multiphase, DC-DC Converters, Fuel Cells, Soft Switching

Copyright 2007, Seung-Ryul Moon 


\title{
Multiphase Isolated DC-DC Converters for Low-Voltage High-Power Fuel Cell Applications
}

\author{
Seung-Ryul Moon
}

\begin{abstract}
Fuel cells provide a clean and highly efficient energy source for power generation; however, in order to efficiently utilize the energy from fuel cells, a power conditioning system is required. Typical fuel cell systems for stand-alone and utility grid-tied stationary power applications are found mostly with low nominal output voltages around $24 \mathrm{~V}$ and $48 \mathrm{~V}$, and power levels are found to be 3 to $10 \mathrm{~kW} \mathrm{[1][2].} \mathrm{A} \mathrm{power}$ conditioning system for such applications generally consists of a dc-dc converter and a dc-ac inverter, and the dc-dc converter for low-voltage, high-power fuel cells must deal with a high voltage step-up conversion ratio and high input currents. Although many dcdc converters have been proposed, most deal with high input voltage systems that focus on step-down applications, and such dc-dc converters are not suitable for low-voltage, high-power fuel cell applications.

Multiphase isolated dc-dc converters offer several advantages that are very desirable in low-voltage, high-power fuel cell applications. First, a multiphase is constructed with paralleled phases, which increase power rating and current handling capability for high input current. Second, an interleaving control scheme produces a high operating frequency with a low switching frequency, and the high operating frequency reduces size of passive components. Thirdly, use of a transformer provides electrical isolation and a high conversion ratio. Lastly, several multiphase converters are capable of soft-switching operation, which increases converter efficiency.

This thesis examines two highly efficient, soft-switching dc-dc converters that are targeted for fuel cell applications. The thesis also describes the converters' basic operating principles and analyzes performance for low-voltage, high-power fuel cell applications. 5-kW prototypes for each converter are built and tested with a fuel cell simulator. Experimental switching waveforms and efficiency profiles are shown to
\end{abstract}


support the described basic principles and the analysis. Major features and differences between these two converters are also discussed. 


\section{ACKNOWLEDGMENTS}

First, I would like to express my most sincere gratitude and appreciation to my advisor and mentor, Dr. Jih-Sheng Lai, for giving me the opportunity to study under him. Dr. Lai taught me much in my undergraduate and graduate years at Virginia Tech, and his rigorous attitude toward research, valuable expertise, and extensive vision will guide me through my engineering profession for the rest of my life.

I next want to thank Dr. Jaime De La Ree and Dr. Robert Hendricks for serving on my committee and for helping to make the Bradley Department of Electrical and Computer Engineering at Virginia Tech the excellent program that it is.

Classes I took under many professors, especially Dr. William Baumann, Dr. Dushan Boroyevich, and Dr. Fred Lee, were sources of valuable knowledge, without which my graduate work could not been completed.

My gratitude extends to my Future Energy Electronics Center (FEEC) colleagues, Dr. Changrong Liu, Mr. Gary Kerr, Mr. Sung-Yeul Park, Mr. Rae-Young Kim, Ms. Junhong Zhang, Mr. Jian-Liang Chen, Mr. Ken Stanton, Dr. Konstantin Louganski, Dr. Yu Wensong, Mr. Neil Savio D’Souza, Mr. Hao Qian, Mr. Greg Malone, Mr. Brennen Ball, Mr. Brad Tomlinson, Mr. Alexander Miller, Mr. Wei-han Lai, Mr. Hidekazu Miwa, Mr. Joseph Amato, Mr. Edward Jones, Ms. Amy Johnson and Mr. Heath Kouns, for their valuable assistants. Also I also thank visiting scholars, Dr. Ju-Won Baek, Dr. Tae-Won Chun, Dr. Gyu-Ha Choe and Dr. In-Dong Kim, for their helpful insights.

I also thank my fellow graduate students, especially Mr. Tim Thacker and Mr. Jerry Francis, for their help when I was despaired with overdue homework and projects.

Most importantly, I would like to thank my family. My deepest gratitude belongs to my parents, Mr. Young-Chul Moon and Ms. Hyun-Sook Kim, for their endless love, care, and sacrifice. I know they take as much pride in this accomplishment as I do. Thanks to 
my sister, Ms. Seung-Hee Moon, who showed her love and encouraged me many times. Thanks to my uncle, Mr. Gerard Thompson, and his wife, Ms. Ok-Hui Thompson. They are like my second parents, who taught values and merits to me. Thanks to all my cousins for their support. Without them, my life would not have been as enjoyable as it has been.

I owe a great deal to professors, colleagues, friends and members of my family who have helped through my years at Virginia Tech. My apologies if I have inadvertently omitted anyone to whom acknowledgement is due. 
This work is sponsored by the U.S. department of Energy (DOE) National Energy Technology Laboratory (NETL) Solid-State Energy Alliance Program (SECA) under award number DE-FC26-02NT41567. 


\section{TABLE OF CONTENTS}

1 INTRODUCTION

1.1 Fuel Cell Power Conditioning System For Distributed Power GeNERATion

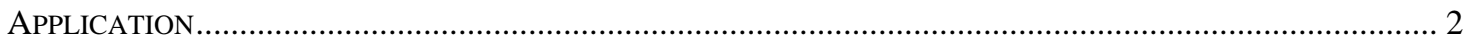

1.2 LinE FREQUENCY TRANSFORMER VERSUS High FREQUENCY TRANSFORMER .............................. 3

1.3 TRANSFORMER ISOLATED DC-DC CONVERTERS ..................................................................... 5

1.3.1 High conversion ratio and current handling capability ....................................................... 5

1.3.2 High efficiency .............................................................................................................. 5

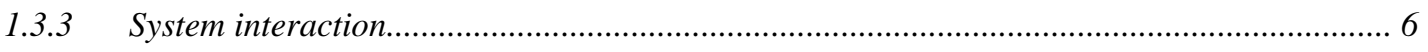

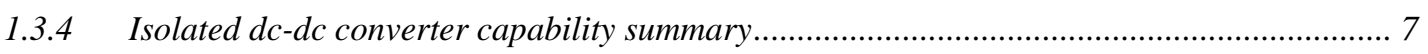

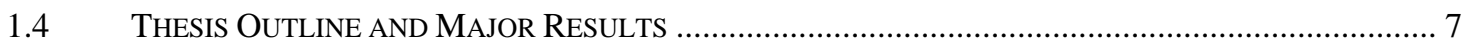

2 TOPOLOGY SURVEY OF HIGH POWER DC-DC CONVERTERS ........................................ 10

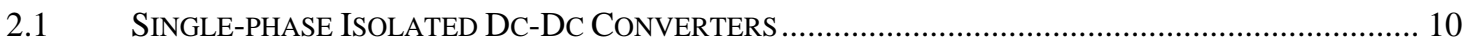

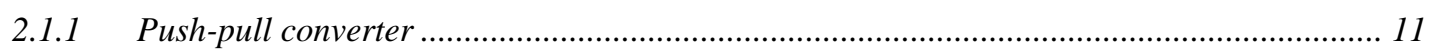

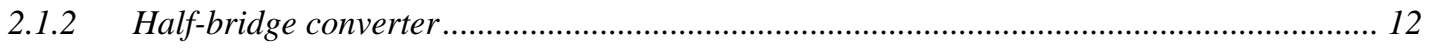

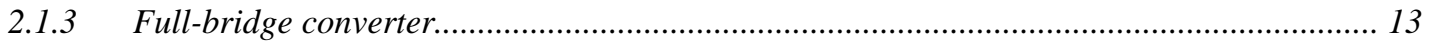

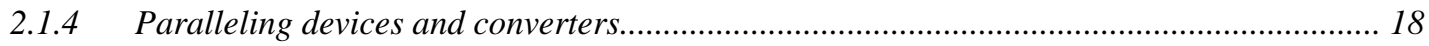

2.1.5 Single-phase isolated dc-dc converters summary ................................................................ 18

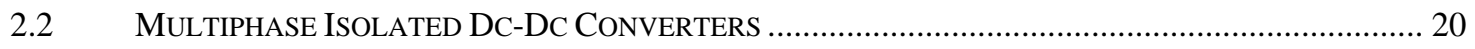

2.2.1 Three-phase PWM dc-dc converter with a $\Delta$ - $\Delta$ transformer ................................................... 20

2.2.2 Three-phase dc resonant PWM dc-dc converter with a $Y$-Y transformer .............................. 21

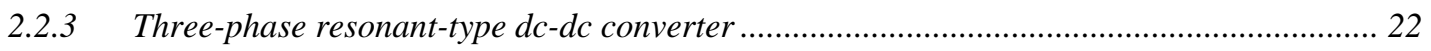

2.2.4 Hybridge rectifier converter and current-tripler converter............................................... 24

2.2.5 Three-phase asymmetrical PWM dc-dc converter with a Y-Y transformer ........................... 25

2.2.6 Three-phase phase-shift modulation PWM dc-dc converter with a $\Delta$-Y transformer ............ 26

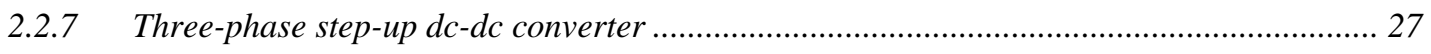

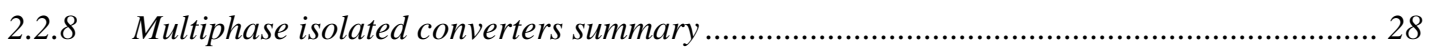

3 BASIC OPERATION OF MULTIPHASE DC-DC CONVERTERS........................................... 31

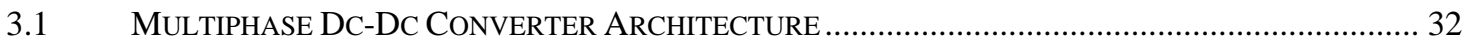

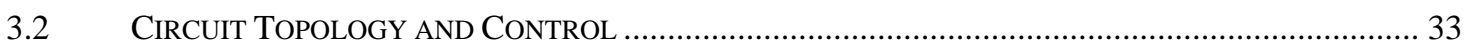

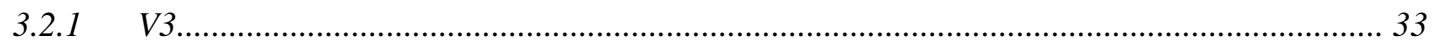

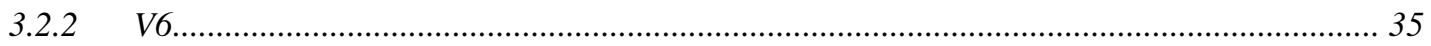

3.2.3 Multiphase coupled transformer VS. single-phase non-coupled transformers...................... 37

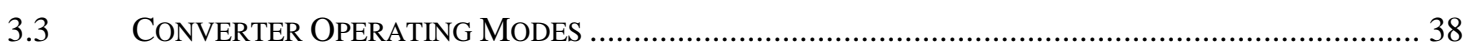




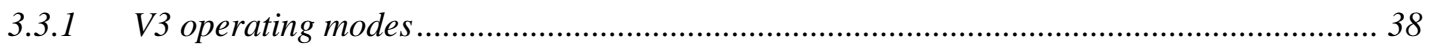

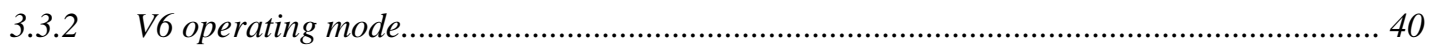

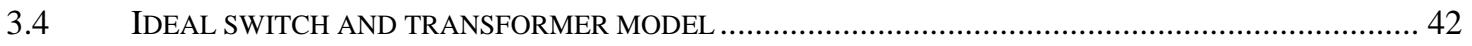

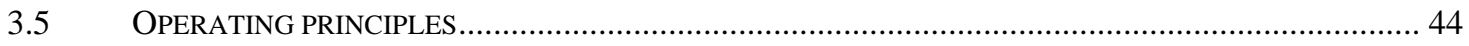

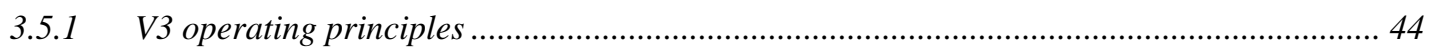

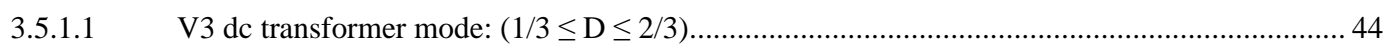

1) V3 dc transformer mode - Cycle 1, Stage 1: switch vector (101)...................................... 46

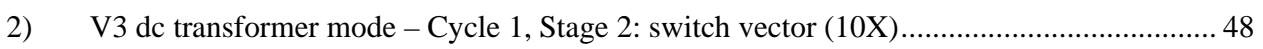

3) V3 dc transformer mode - Cycle 1, Stage 3: switch vector (100)....................................... 50

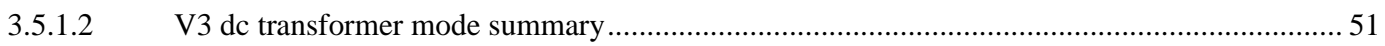

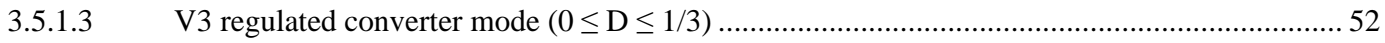

1) V3 regulated converter mode - Cycle 1, Stage 1: switch vector (100) .................................5 53

2) V3 regulated converter mode - Cycle 1, Stage 2: switch vector (X00) ............................... 54

3) V3 regulated converter mode - Cycle 1, Stage 3: switch vector $(000)$................................... 55

4) V3 regulated converter mode - Cycle 1, Stage 4: switch vector (0X0) ............................... 56

5) V3 regulated converter mode - Cycle 2, Stage 1: switch vector (010) ............................... 57

3.5.1.4 V3 regulated converter mode summary ….......................................................................... 57

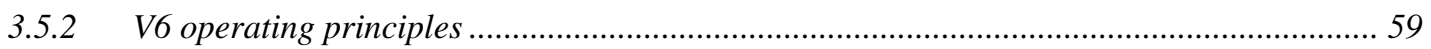

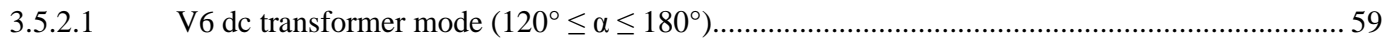

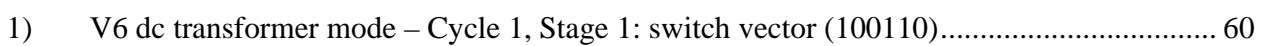

2) V6 dc transformer mode - Cycle 1, Stage 2: switch vector (10011X) ................................. 62

3) V6 dc transformer mode - Cycle 1, Stage 3: switch vector (100111)................................... 63

4) V6 dc transformer mode - Cycle 1, Stage 4: switch vector (1001X1) ................................ 64

5) V6 dc transformer mode - Cycle 2, Stage 1: switch vector (100101).................................... 65

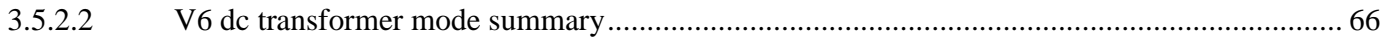

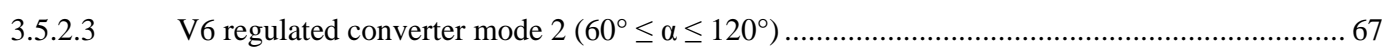

1) V6 regulated converter mode 2 - Cycle 1, Stage 1: switch vector (100111) ........................ 68

2) V6 regulated converter mode 2 - Cycle 1, Stage 2: switch vector (100X11) .......................69 69

3) V6 regulated converter mode 2 - Cycle 1, Stage 3: switch vector (100011) ....................... 70

4) V6 regulated converter mode 2 - Cycle 1, Stage 4: switch vector $(1000 \mathrm{X} 1)$....................... 71

5) V6 regulated converter mode 2 - Cycle 2, Stage 1: switch vector (100001) ....................... 72

3.5.2.4 V6 regulated converter mode 2 summary ................................................................................ 73

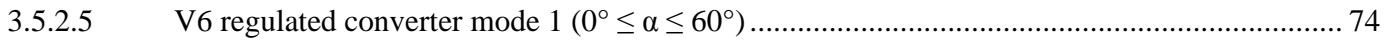

1) V6 regulated converter mode 1 - Cycle 1, Stage 1: switch vector (100011) ........................ 75

2) V6 regulated converter mode 1 - Cycle 1, Stage 2: switch vector (1X0011) ....................... 76

3) V6 regulated converter mode 1 - Cycle 1, Stage 3: switch vector (110011) ........................ 77

4) V6 regulated converter mode 1 - Cycle 1, Stage 4: switch vector (1100X1) ...................... 78

5) V6 regulated converter mode 1 - Cycle 2, Stage 1: switch vector (110001) ....................... 79

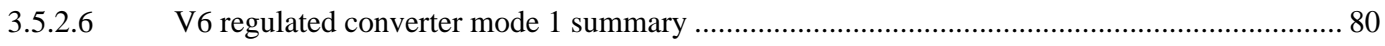

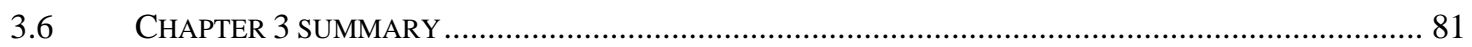


T.1 TRANSFORMER SETTING COMPARISON .......................................................................... 83

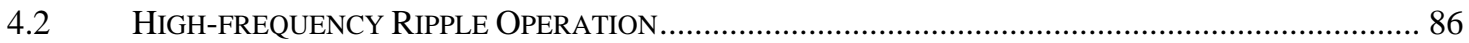

4.2.1 High-frequency operation in the regulated converter mode ..........................................87

4.2.2 High-frequency operation in the dc transformer mode ................................................. 90

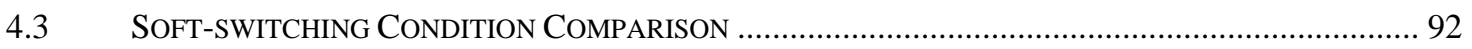

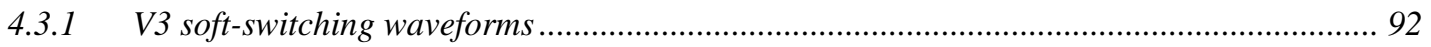

4.3.1.1 V3 soft-switching waveforms: de transformer mode ........................................................... 94

4.3.1.2 V3 soft-switching waveforms: regulated converter mode ...................................................... 97

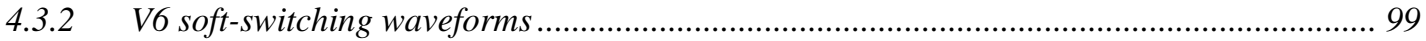

4.3.2.1 V6 soft-switching waveforms: dc transformer mode ......................................................... 102

4.3.2.2 V6 soft-switching waveforms: regulated converter mode 2 ................................................. 105

4.3.2.3 V6 soft-switching waveforms: regulated converter mode 1 ................................................... 108

4.3.3 Soft-switching condition summary............................................................................ 110

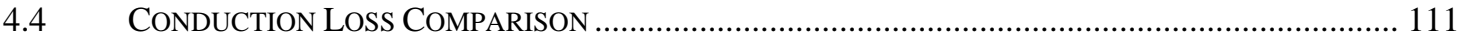

4.4.1 Conduction loss in dc transformer mode ................................................................. 111

4.4.2 Conduction loss in regulated converter mode ........................................................... 114

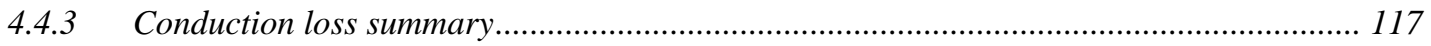

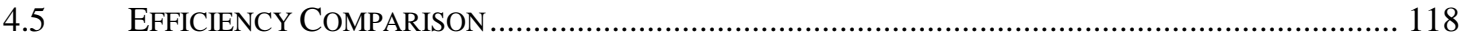

4.5.1 Dc transformer mode efficiency............................................................................ 118

4.5.2 Regulated converter mode efficiency ....................................................................... 119

$5 \quad$ CONCLUSION AND FUTURE RESEARCH DIRECTION.................................................. 122

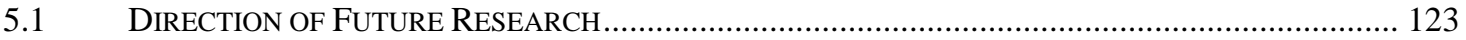

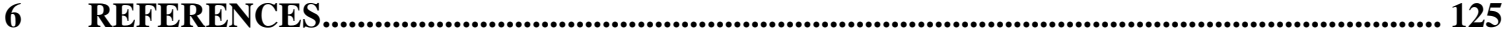

$7 \quad$ VITA 


\section{LIST OF FIGURES}

FIGURE 1.1 - ELECTRICAL ISOLATION VIA LINE FREQUENCY TRANSFORMER

FIGURE 1.2 - ELECTRICAL ISOLATION VIA ISOLATED DC-DC CONVERTER WITHIN POWER CONDITIONING

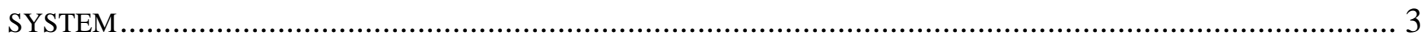

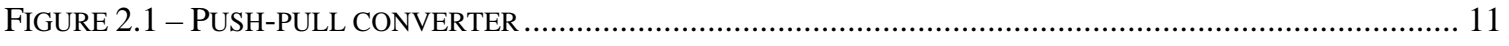

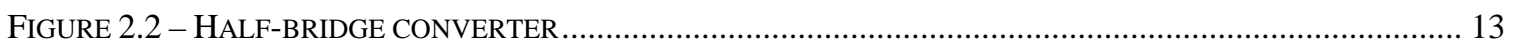

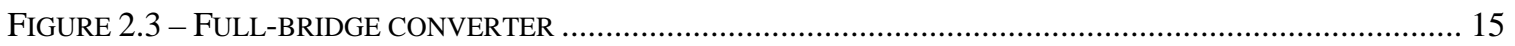

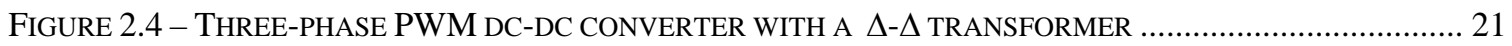

FIGURE 2.5 - THREE-PHASE DC RESONANT PWM DC-DC CONVERTER WITH A Y-Y TRANSFORMER .............. 22

FIGURE 2.6 - THREE-PHASE SERIES-PARALLEL RESONANT CONVERTER WITH A Y-Y TRANSFORMER............ 23

FIGURE 2.7 - THREE-PHASE SERIES RESONANT CONVERTER WITH A Y-Y TRANSFORMER ........................... 23

FIGURE 2.8 - THREE-PHASE DC-DC CONVERTER WITH A HYBRIDGE RECTIFIER WITH A Y-Y TRANSFORMER 25

FIGURE 2.9 - THREE-PHASE CURRENT-TRIPLER DC-DC CONVERTER WITH A $\Delta$ - $\Delta$ TRANSFORMER.................. 25

FIGURE 2.10 - THREE-PHASE ASYMMETRICAL PWM DC-DC CONVERTER WITH A Y-Y TRANSFORMER ......... 26

FIGURE 2.11 - THREE-PHASE PHASE-SHIFT MODULATION PWM DC-DC CONVERTER WITH A $\Delta$-Y

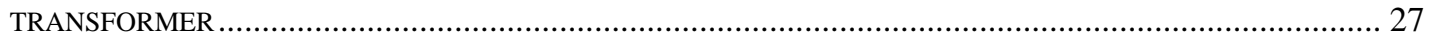

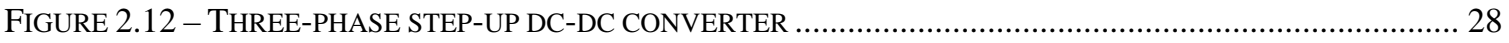

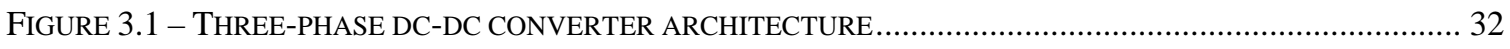

FIGURE 3.2 - V3 CONVERTER: THREE HALF-BRIDGE, Y-Y TRANSFORMER ISOLATED CONVERTER ............... 33

FIGURE 3.3 - INTERLEAVING ASYMMETRICAL DUTY CYCLE CONTROL SIGNAL FOR V3 ............................. 33

FIGURE 3.4 - V6 CONVERTER: THREE FULL-BRIDGE, $\Delta$-Y TRANSFORMER ISOLATED CONVERTER ................ 35

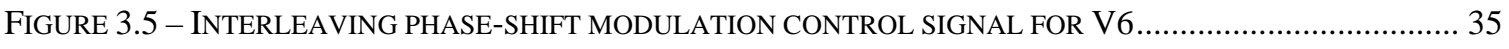

FIGURE 3.6 - COMPARISON BETWEEN SYMMETRICAL AND ASYMMETRICAL DUTY CYCLE............................ 39

FIGURE 3.7 - V3 CONVERSION RATIO AND OPERATING MODES.......................................................... 40

FIGURE 3.8 - PHASE-SHIFT MODULATION LEADING AND LAGGING LEG DEFINITION .................................. 41

FIGURE 3.9 - V6 CONVERSION RATIO AND OPERATING MODES ........................................................ 41

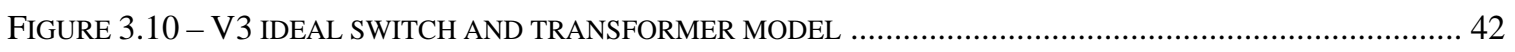

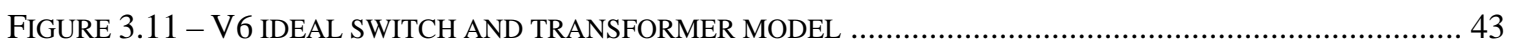

FIGURE 3.12 - V3 GATE SIGNALS AND SWITCHING VECTORS FOR DC TRANSFORMER MODE ....................... 45

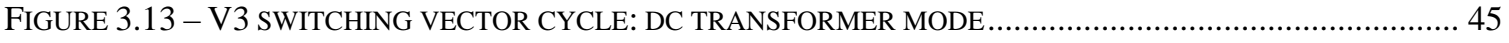

FIGURE 3.14 - V3 EQUIVALENT CIRCUIT: DC TRANSFORMER MODE - CYCLE 1, STAGE 1...........................46

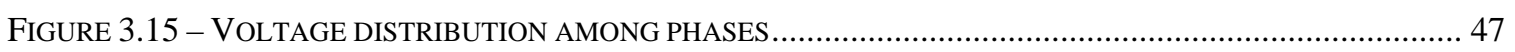

FIGURE 3.16 - V3 EQUIVALENT CIRCUIT: DC TRANSFORMER MODE - CYCLE 1, STAGE 2 ...........................48

FIGURE 3.17 - V3 EQUIVALENT CIRCUIT: DC TRANSFORMER MODE - CYCLE 1, STAGE 2, INTERMEDIATE STAGE 
FIGURE 3.18 - V3 EQUIVALENT CIRCUIT: DC TRANSFORMER MODE - CYCLE, STAGE 3

FIGURE 3.19 - V3 WAVEFORMS OF THREE-PHASE OUTPUT VOLTAGES AND RECTIFIER OUTPUT VOLTAGE,

$\mathrm{V}_{\text {RECT }}$, IN DC TRANSFORMER MODE 51

FIGURE 3.20 - V3 GATE SIGNALS AND SWITCHING VECTORS FOR REGULATED CONVERTER MODE ................ 52

FIGURE 3.21 - V3 SWITCHING VECTOR CYCLE: REGULATED CONVERTER MODE....................................... 52

FIGURE 3.22 - V3 EQUIVALENT CIRCUIT: REGULATED CONVERTER MODE - CYCLE 1, STAGE 1 .................... 53

FIGURE 3.23 - V3 EQUIVALENT CIRCUIT: REGULATED CONVERTER MODE - CYCLE 1, STAGE 2 ................... 54

FIGURE 3.24 - V3 EQUIVALENT CIRCUIT: REGULATED CONVERTER MODE - CYCLE 1, STAGE 3 ................... 55

FIGURE 3.25 - V3 EQUIVALENT CIRCUIT: REGULATED CONVERTER MODE - CYCLE 1, STAGE 4 ................... 56

FIGURE 3.26 - V3 EQUIVALENT CIRCUIT: REGULATED CONVERTER MODE - CYCLE 2, STAGE 1 ................... 57

FIGURE 3.27 - V3 WAVEFORMS OF THREE-PHASE OUTPUT VOLTAGES AND RECTIFIER OUTPUT VOLTAGE,

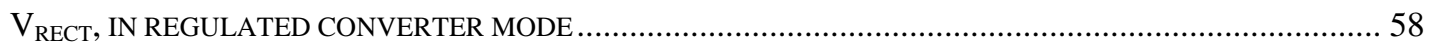

FIGURE 3.28 - V6 GATE SIGNALS AND SWITCHING VECTORS FOR DC TRANSFORMER MODE ........................ 59

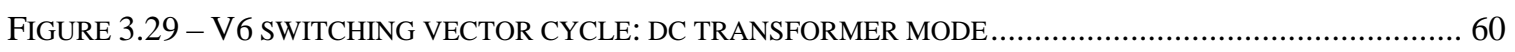

FIGURE 3.30 - V6 EQUIVALENT CIRCUIT: DC TRANSFORMER MODE - CYCLE 1 STAGE 1 ...............................60

FIGURE 3.31 - V6 EQUIVALENT CIRCUIT: DC TRANSFORMER MODE - CYCLE 1 STAGE 2 ..............................62

FIGURE 3.32 - V6 EQUIVALENT CIRCUIT: DC TRANSFORMER MODE - CYCLE 1 STAGE 3.............................63

FIGURE 3.33 - V6 EQUIVALENT CIRCUIT: DC TRANSFORMER MODE - CYCLE 1 STAGE 4..............................64

FIGURE 3.34 - V6 EQUIVALENT CIRCUIT: DC TRANSFORMER MODE - CYCLE 2 STAGE 1 ..............................65

FIGURE 3.35 - V6 WAVEFORMS OF THREE-PHASE OUTPUT VOLTAGES AND RECTIFIER OUTPUT VOLTAGE,

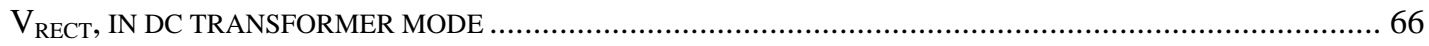

FIGURE 3.36 - V6 GATE SIGNALS AND SWITCHING VECTORS FOR REGULATED CONVERTER MODE 2 ............67

FIGURE 3.37 - V6 SWITCHING VECTOR CYCLE: REGULATED CONVERTER MODE 2 ......................................67

FIGURE 3.38 - V6 EQUIVALENT CIRCUIT: REGULATED CONVERTER MODE 2 - CYCLE 1 STAGE 1 ..................68

FIGURE 3.39 - V6 EQUIVALENT CIRCUIT: REGULATED CONVERTER MODE 2 - CYCLE 1 STAGE 2................. 69

FIGURE 3.40 - V6 EQUIVALENT CIRCUIT: REGULATED CONVERTER MODE 2 - CYCLE 1 STAGE 3.................. 70

FIGURE 3.41 - V6 EQUIVALENT CIRCUIT: REGULATED CONVERTER MODE 2 - CYCLE 1 STAGE 4.................. 71

FIGURE 3.42 - V6 EQUIVALENT CIRCUIT: REGULATED CONVERTER MODE 2 - CYCLE 2 STAGE $1 \ldots \ldots \ldots \ldots \ldots \ldots . . . . . . . . .72$

FIGURE 3.43 - V6 WAVEFORMS OF THREE-PHASE OUTPUT VOLTAGES AND RECTIFIER OUTPUT VOLTAGE,

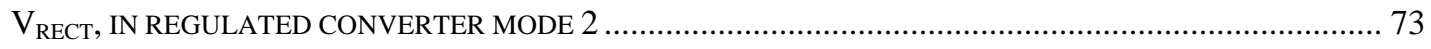

FIGURE 3.44 - V6 SWITCHING VECTOR CYCLE: REGULATED CONVERTER MODE 1.................................... 74

FIGURE 3.45 - V6 SWITCHING VECTOR CYCLE: REGULATED CONVERTER MODE 1.................................... 74

FIGURE 3.46 - V6 EQUIVALENT CIRCUIT: REGULATED CONVERTER MODE 1 - CYCLE 1 STAGE 1.................. 75

FIGURE 3.47 - V6 EQUIVALENT CIRCUIT: REGULATED CONVERTER MODE 1 - CYCLE 1 STAGE 2.................. 76

FIGURE 3.48 - V6 EQUIVALENT CIRCUIT: REGULATED CONVERTER MODE 1 - CYCLE 1 STAGE 3.................. 77

FIGURE 3.49 - V6 EQUIVALENT CIRCUIT: REGULATED CONVERTER MODE 1 - CYCLE 1 STAGE 4.................. 78

FIGURE 3.50 - V6 EQUIVALENT CIRCUIT: REGULATED CONVERTER MODE 1 - CYCLE 2 STAGE 1.................. 79 
FIGURE 3.51 - V6 WAVEFORMS OF THREE-PHASE OUTPUT VOLTAGES AND RECTIFIER OUTPUT VOLTAGE,

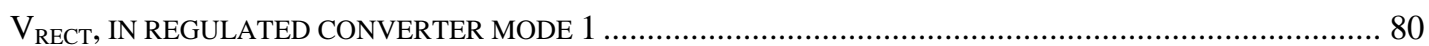

FIGURE 4.1 - V3 (LEFT) AND V6 (RIGHT) CONVERTER PROTOTYPES ........................................................... 82

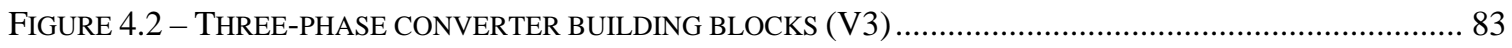

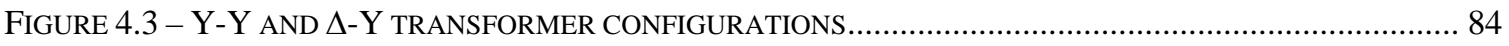

FIGURE 4.4 - HIGH-FREQUENCY RIPPLE OPERATION WITH THE THREE-PHASE INTERLEAVING CONTROL

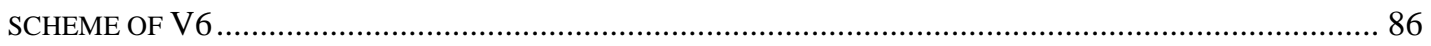

FIGURE 4.5 - V3 HIGH-FREQUENCY OPERATION IN REGULATED CONVERTER MODE ...................................... 87

FIGURE 4.6 - V6 HIGH-FREQUENCY OPERATION IN REGULATED CONVERTER MODE 1 ................................... 88

FIGURE 4.7 - V6 HIGH-FREQUENCY OPERATION IN REGULATED CONVERTER MODE 2 ..................................... 88

FIGURE 4.8 - V3 HIGH-FREQUENCY OPERATION IN DC TRANSFORMER CONVERTER MODE ............................. 90

FIGURE 4.9 - V6 HIGH-FREQUENCY OPERATION IN DC TRANSFORMER CONVERTER MODE ............................. 90

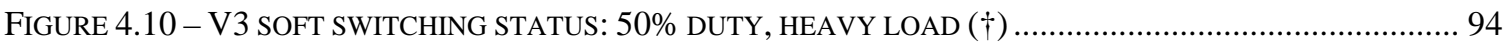

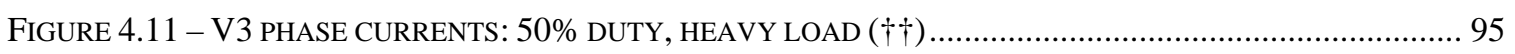

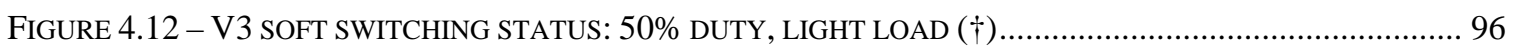

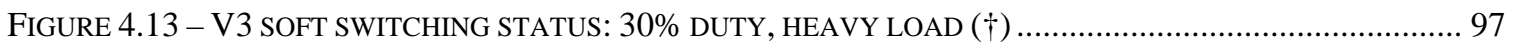

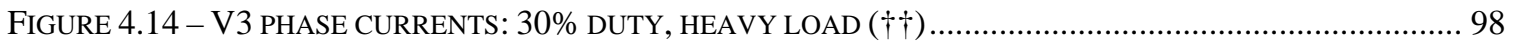

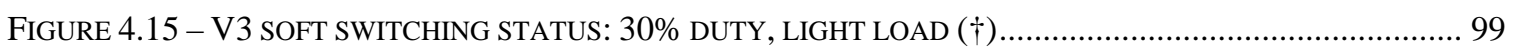

FIGURE 4.16 - V6 SOFT SWITCHING STATUS: DC TRANSFORMER MODE $\left(150^{\circ}\right)$, LEADING LEG, HEAVY LOAD(\#)

FIGURE 4.17 - V6 SOFT SWITCHING STATUS: DC TRANSFORMER MODE (150), LAGGING LEG, HEAVY

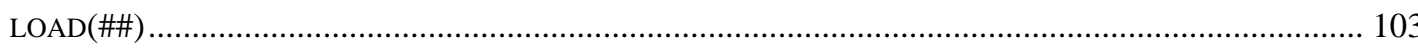

FIGURE 4.18 - V6 SOFT SWITCHING STATUS: DC TRANSFORMER MODE (150), LAGGING LEG, LIGHT LOAD(\#\#) 104

FIGURE 4.19 - V6 SOFT-SWITCHING STATUS: REGULATED CONVERTER MODE $2\left(110^{\circ}\right)$, LEADING LEG, HEAVY

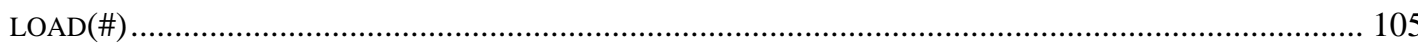

FIGURE 4.20 - V6 SOFT-SWITCHING STATUS: REGULATED CONVERTER MODE $2\left(110^{\circ}\right)$,, LAGGING LEG, HEAVY $\operatorname{LOAD}(\# \#)$ 106

FIGURE 4.21 - V6 SOFT-SWITCHING STATUS: REGULATED CONVERTER MODE $2\left(110^{\circ}\right)$,, LAGGING LEG, LIGHT

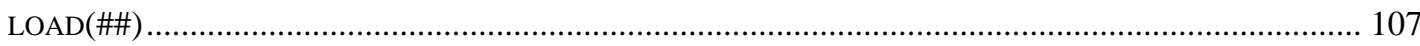

FIGURE 4.22 - V6 SOFT-SWITCHING STATUS: REGULATED CONVERTER MODE 1 (50), LEADING LEG, HEAVY $\operatorname{LOAD}(\#)$ 108

FIGURE 4.23 - V6 SOFT-SWITCHING STATUS: REGULATED CONVERTER MODE $1\left(50^{\circ}\right)$, LAGGING LEG, HEAVY

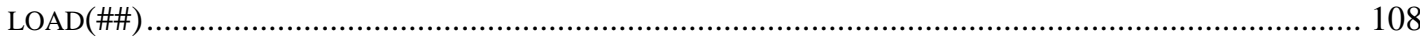

FIGURE 4.24 - V6 SOFT-SWITCHING STATUS: REGULATED CONVERTER MODE 1 (50²), LAGGING LEG, LIGHT $\operatorname{LOAD}(\# \#)$ 109

FIGURE 4.25 - V3 PHASE CURRENT IN DC TRANSFORMER MODE 111 


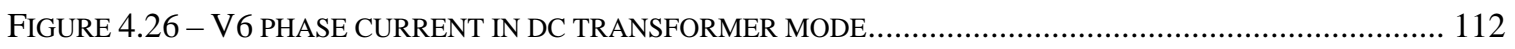

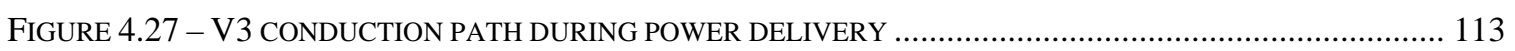

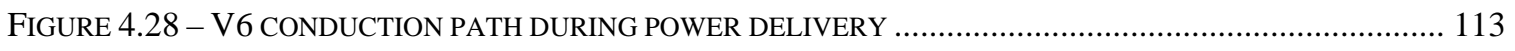

FIGURE 4.29 - V3 PHASE CURRENT IN REGULATED CONVERTER MODE .................................................... 114

FIGURE 4.30 - V6 PHASE CURRENT IN REGULATED CONVERTER MODE .................................................... 115

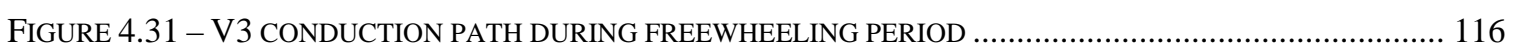

FIGURE 4.32 - V6 CONDUCTION PATH DURING FREEWHEELING PERIOD ................................................... 116

FIGURE 4.33 - PROTOTYPE CONVERTER EFFICIENCY IN DC TRANSFORMER MODE ..................................... 119

FIGURE 4.34 - PROTOTYPE CONVERTER EFFICIENCY IN REGULATED CONVERTER MODE .............................. 121 


\section{LISTS OF TABLES}

TABLE 4.1 - TRANSFORMER TURNS RATIO FOR V3 AND V6 ………………............................................. 85

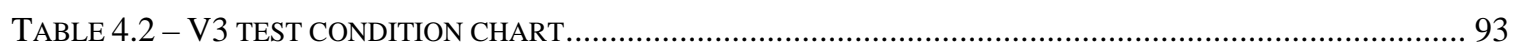

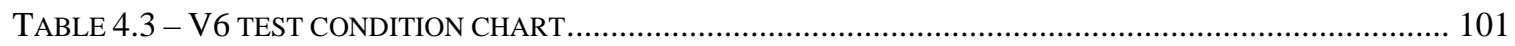

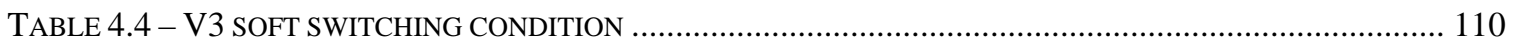

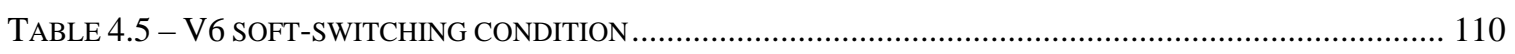




\section{INTRODUCTION}

Fuel cells, which utilize reaction between hydrogen and oxygen to produce electricity, provide a clean and highly efficient energy source for power generation. As fuel cell technology matures, it will become a viable option for power generation and distribution. As an effort to develop a reliable fuel cell technology, the U.S. Department of Energy (DOE) National Energy Technology Laboratory (NETL) started the SolidState Energy Alliance (SECA) program to develop a $5 \mathrm{~kW}$ solid-oxide fuel cell (SOFC) for distributed power generation.

In order to efficiently deliver electrical power from fuel cells to end-use applications, a power conditioning system (PCS) is necessary. A PCS for distributed power generation generally consists of a dc-dc converter and a dc-ac inverter, and through power conditioning, unregulated dc electrical power from fuel cells is converted into usable power, such as ac power for standalone load and electric utility grid-tie. The Virginia Tech's Future Energy Electronics Center (FEEC), as a core technology team member, is developing a low-cost dc-dc converter as the standard interface between the SOFC source and a load-side dc-ac inverter.

The SECA's SOFC produces low-voltage dc, which ranges from $20 \mathrm{~V}$ to $60 \mathrm{~V}$. The output voltage level depends on load condition, and a lower voltage is generated with a heavier load. For such a low-voltage source to deliver $5 \mathrm{~kW}$ power, the current level may exceed $250 \mathrm{~A}$ at the full-load condition. Most existing dc-dc power converters are developed for high-voltages, such as $300 \mathrm{~V}$ and higher, and are not equipped to handle such a high-current condition. The purpose of this thesis is to evaluate different advanced dc-dc converters that are suitable for low-voltage, high-power fuel cells. Among different advanced dc-dc converters, multiphase and soft-switching have been the major focus to increase the converter efficiency. Power semiconductor devices and converter circuit topology need to be optimally selected to achieve a high efficiency power conversion, and the high efficiency is considered to be the most important performance index in all the energy related applications.

Multiphase converters offer several advantages, and the major advantages are that currents are shared among phases to reduce current stress on devices, and that an 
interleaving control scheme reduces size of passive components with an increased effective frequency and a lower ripple current amplitude. On the other hand, softswitching allows higher efficiency with reduced switching losses, which is a key to high efficiency power conversion. A range of dc-dc converters are examined for fuel cell applications, and two types of multiphase isolated soft-switching dc-dc converters are selected for detailed analysis and performance evaluation. Major content in this thesis includes topological studies, computer simulations, and hardware implementation. Experimental results of two multiphase dc-dc converters are compared.

\subsection{Fuel Cell Power Conditioning System for Distributed Power Generation Application}

Fuel cells can be applied to diverse applications in a very wide range of power levels. Among those applications, this thesis particularly considers dc-dc converters for distributed power generation applications, i.e. stand-alone and utility grid-tied stationary power applications. For these applications, fuel cells are found mostly with low nominal output voltages around 24 and $48 \mathrm{~V}$, and power levels are found to be 3 to $10 \mathrm{~kW}$ [1][2].

Stationary power applications and utility lines operate at 50/60 Hz, 120/240 $\mathrm{V}_{\mathrm{AC}}$ RMS. However, a fuel cell is a non-ideal dc source, and for fuel cells to be practically utilized, a power conditioning system (PCS) must be utilized to generate the desired ac output. In such applications where a PCS is utilized to supply power to consumer electronics, household appliances, and/or utility lines, regulatory agencies usually require electrical isolation for safety reasons. Generally, electrical isolation is obtained using a transformer, and there are two typical ways to achieve electrical isolation via a transformer: a) a line frequency $(50 / 60 \mathrm{~Hz})$ transformer utilized between a power conditioning system and appliances/utility lines, or b) a high-frequency transformer utilized within a dc-dc converter of a power conditioning system.

The block diagram in Figure 1.1 illustrates how electrical isolation is achieved with a line frequency transformer. An unregulated fuel cell output is converted to a regulated dc output by a non-isolated dc-dc converter, i.e. a boost converter, and a dc-ac inverter generates a low-voltage sinusoidal $35 \mathrm{~V}_{\mathrm{AC}}$ RMS output. Then a line frequency 
transformer provides electrical isolation, and a turns ratio of 1:3.5:3.5 generates a $120 / 240$ V AC $_{\text {AMS output. }}$

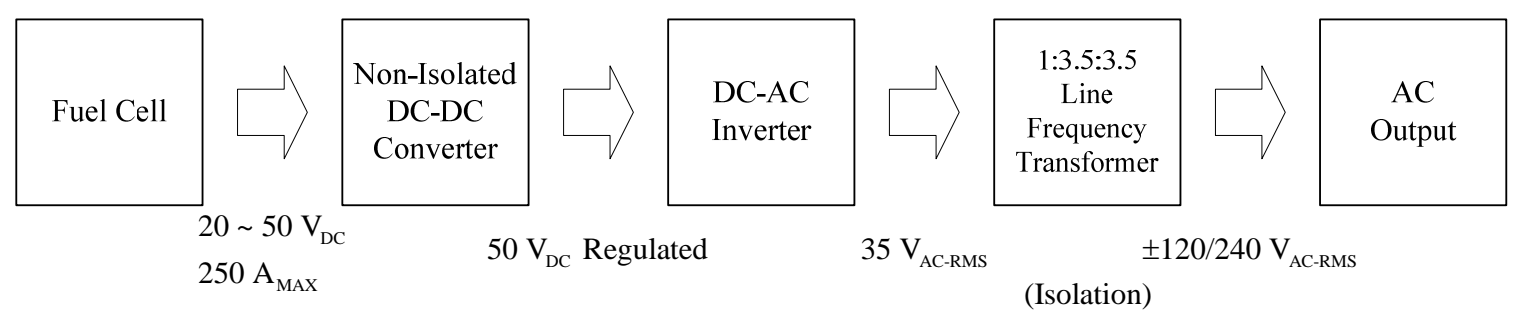

Figure 1.1 - Electrical isolation via line frequency transformer

On the other hand, Figure 1.2 illustrates how electrical isolation is achieved with a high-frequency transformer within a dc-dc converter of a power conditioning system. The dc-dc converter takes a low-voltage fuel cell output and boosts it to 200/400 $\mathrm{V}_{\mathrm{DC}}$ while providing electrical isolation, and a dc-ac inverter generates 120/240 $\mathrm{V}_{\mathrm{AC}} \mathrm{RMS}$ output.

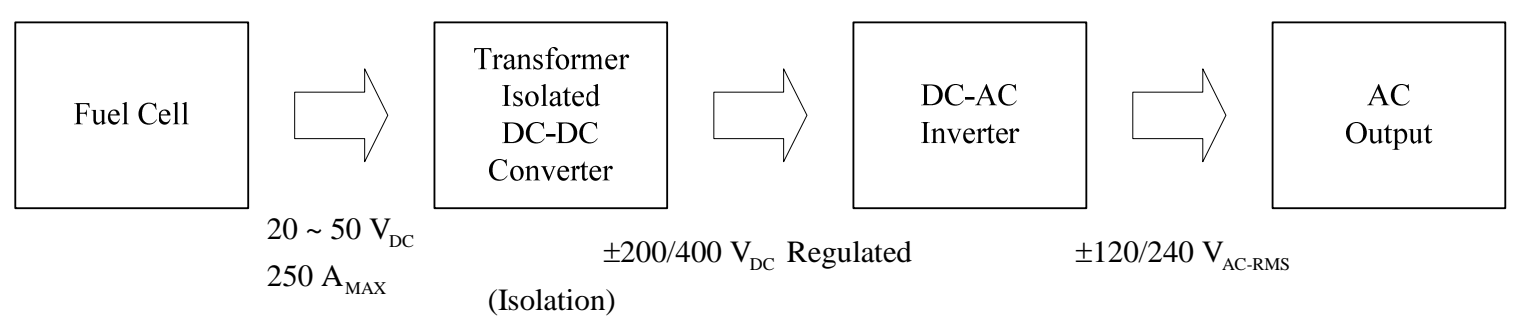

Figure 1.2 - Electrical isolation via isolated dc-dc converter within power conditioning system

\subsection{Line Frequency Transformer versus High Frequency Transformer}

In addition to the electrical isolation, transformers offer other advantages, such as noise decoupling and multiple outputs with multiple secondary windings. Typical disadvantages are that a) design and costs of transformers are non-trivial, b) unbalanced input can cause transformer saturation, c) difficulty in cross regulation between multiple outputs and d) a transformer introduces additional losses. Nevertheless, transformers are 
required to provide the electrical isolation, and the high-frequency transformers offers several additional advantages over the line frequency transformers.

Advantages of the high-frequency transformers can be evaluated from a systematic point of view. First, a transformer's size and weight vary inversely with frequency, thus the line frequency transformers, which operate at $50 / 60 \mathrm{~Hz}$, are large in size and weight. However, dc-dc converters operate in frequency range of tens or hundreds of kilohertz, therefore a significant improvement in size, weight, and cost can be made by incorporating a high-frequency transformer into a dc-dc converter stage. Secondly, incorporating a line frequency transformer at the end of power conversion system tends to cause lower efficiency. Transformers are utilized to boost low-voltage to high-voltage, thus all the stages before transformer must operate in a low-voltage condition. When a line frequency transformer is used, the entire power conditioning system operates in lowvoltage. Assuming the same power rating, a lower voltage translates to a higher current, and the high current results a higher conduction losses and a lower overall efficiency.

Advantages of the high-frequency transformer can be also evaluated from a dc-dc converter point of view. First, a transformer in the dc-dc converter stage enables a better device optimization and lowers voltage and/or current stresses on switching devices. Second, lower voltage and/or current rated devices cost less. Third, the better device utilization and optimization enable use of better devices with a lower on-resistance, which leads to less conduction losses and a higher efficiency.

Overall, when the advantages and the disadvantages of the line frequency transformers and the high-frequency transformers are weighted against each other, it becomes obvious that use of the high-frequency transformers is a better choice than use of the line frequency transformers. Therefore, this thesis focuses on isolated dc-dc converters, and non-isolated dc-dc converters are excluded from further consideration due to its many disadvantages. 


\subsection{Transformer Isolated Dc-Dc Converters}

This section discusses challenges that the isolated dc-dc converters face in lowvoltage, high-power fuel cell applications, and sets loose specifications for the dc-dc converter in such a environment.

\subsubsection{High conversion ratio and current handling capability}

In a fuel cell power system, a dc-dc converter is an interface between the fuel cell power system and a load side dc-ac inverter. Its main responsibility is to convert a lowvoltage input from the fuel cells, which ranges from 20 to $60 \mathrm{~V}_{\mathrm{DC}}$, to a regulated highvoltage 200/400 $\mathrm{V}_{\mathrm{DC}}$ output. The dc-dc converter output is then connected to the dc-ac inverter to obtain a $120 / 240 \mathrm{~V}_{\mathrm{AC}} \mathrm{RMS}$ output.

Within such a power conditioning system, the dc-dc converter must be concerned with two points, a) a high conversion ratio from a nominal $25 \mathrm{~V}$ input to a $400 \mathrm{~V}$ output, and b) a high-current condition, due to the low input voltage. For an instance, when a 5 kW solid-oxide fuel cell (SOFC) is heavily loaded, the fuel cell output can be decreased as low as to $22 \mathrm{~V}$ [4], which translates to a conversion ratio greater than 18 and over 200 A input currents for the dc-dc converter. Therefore, the converter must be capable of handling a very high current, along with a high conversion ratio.

\subsubsection{High efficiency}

The dc-dc converter should also be able to convert power efficiently. In all the energy related applications, the efficiency is considered to be the most important performance index. Increased efficiency can reduce fuel consumption and save operating cost. Quoted by Mr. Don Collins from National Energy Technology Laboratory (NETL), each $1 \%$ increase in converter system efficiency is worth $\$ 75$ / $\mathrm{kWe}$, which is equivalent to $\$ 6.50$ / mbtu gas cost for a SOFC power plant of the size about $150 \mathrm{~kW}$ [5]. Increased

efficiency can not only save the operating cost, but also save manufacturing cost. For an example, thermal management components are big contributors in cost, size, and weight. 
With increased efficiency, less heat is generated, and size and cost for thermal management can be significantly reduced.

In order to increase efficiency, power loss components must be identified and improved. Generally, converter power losses can be attributed to conduction losses, switching losses, and magnetic losses. Properly designed transformers and inductors can minimize the magnetic losses, and the properly designed magnetic components can be utilized for several different circuit topologies, assuming specification remains similar. However, a choice of converter topology can significantly affect amount of switching losses and conduction losses. For an example, switching losses can be significantly reduced by choosing a soft-switching converter over a hard-switching converter.

Among the three major loss attributions, conduction losses are the dominant loss factor in high-current applications, as with low-voltage, high-power fuel cells, thus a topology with low conduction loss should be chosen. In order to increase efficiency, power semiconductor devices and the converter topology need to be optimally selected to minimize switching and conduction losses.

\subsubsection{System interaction}

When a power conditioning system is designed for a fuel cell system, a special design consideration should be given for an interaction between the fuel cells and a dc-dc converter, particularly for negative currents and low frequency ripple currents. First, fuel cells can only source currents, and are incapable of sinking any currents back. In other word, fuel cells should not experience any negative currents, since fuel cells can not reproduce hydrogen from electricity, and the negative currents may damage the fuel cells [6][7]. For an instant, certain converter topologies can generate instantaneous negative currents back to source, thus a diode and filters are typically used to prevent any negative currents. However, such topologies should be avoided, and appropriate topologies without possibility of negative currents should be selected for fuel cells.

Secondly, fuel cells are very sensitive to low-frequency ripple currents, and the ripple current should be limited within the specification. When a fuel cell power system is tied to a single-phase $50 / 60 \mathrm{~Hz}$ application, the system experiences low-frequency current 
ripples that are twice of the line frequency. Reference [7] suggests that such ripple currents should be limited to less than $10 \%$ of load current for proton exchange membrane (PEM) fuel cells. For solid-oxide fuel cells (SOFC), the control system of balance of plant (BOP) is more sensitive to ripple currents, and $2 \%$ RMS ripple current is specified to avoid BOP controller instability [8]. The dc-dc converter should be able to limit and control the amount of low-frequency ripple current propagate through the converter to the fuel cells, and this can be achieved using an advanced control technique specially designed for a single-phase fuel cell application. However, the advanced control design is out of scope for this thesis, and reference [8] should be referred for more information.

\subsubsection{Isolated dc-dc converter capability summary}

To summarize, the dc-dc converter for low-voltage, high-power fuel cells should be capable of:

- High conversion ratio - from $20 \sim 60 \mathrm{~V}$ to $400 \mathrm{~V}$

- High current handling capability - up to 250 A @ 20 V, 5 kW operation

- High efficiency - optimal selection of power semiconductor devices and a converter topology to lower switching and conduction losses. High efficiency also lowers operating cost.

- High power density - lower manufacturing cost

- Electrical isolation - via transformer

- Stable interaction with fuel cell - minimize low-frequency current ripple and no negative current into fuel cell

\subsection{Thesis Outline and Major Results}

This chapter briefly discusses fuel cell distributed power generation, and its need for a power conditioning system with an advanced dc-dc converter. The chapter also addresses the requirements of the dc-dc converter in low-voltage, high-power fuel cell applications. 
In chapter 2, a range of isolated dc-dc converters are surveyed for fuel cell applications. Advantages and disadvantages of popular single-phase converters are discussed in relation to the fuel cell applications. Then, several multiphase dc-dc converters are surveyed. Multiphase converters offer several advantages over singlephase converters. First, a multiphase is constructed with paralleled phases, instead of paralleled multiple devices. Multiple phases share overall currents to increase power rating and current handling capability, which is required in low-voltage, high current fuel cell applications. Consequently, the multiphase configuration reduces RMS current per phase, which lowers devices stresses and utilizes devices better. Second, an interleaving control scheme produces a high operating frequency with a low switching frequency, and the high operating frequency reduces size of passive components. Third, multiphase transformers can be configured various ways to meet a high conversion ratio with a lower turn ratio. Lastly, several multiphase converters are capable of soft-switching operation, which increases converter efficiency.

In chapter 3, two advanced multiphase isolated dc-dc converters are selected from the surveyed multiphase converters in chapter 2 and are analyzed in detail. First converter is a three-phase, three-leg, Y-Y transformer isolated, asymmetrical duty cycle pulse width modulation converter, which is named "V3". Second converter is a three-phase, six-leg, $\Delta$-Y transformer isolated, phase-shift modulation converter, which is named "V6". This chapter examines operation modes and operating principles of each converter in detail.

In chapter 4, 5-kW prototypes for each converter are built and tested with a fuel cell simulator. Experimental switching waveforms and efficiency profiles are shown to support the described basic principles and analysis. Major features and differences between these two converters are also discussed. Both V3 and V6 converters achieved high efficiency, such that V3 reached peak $96.8 \%$ efficiency at $1.8 \mathrm{~kW}$ while maintaining over $95 \%$ efficiency over wide load range, and V6 reached peak $97.2 \%$ efficiency at $2.5 \mathrm{~kW}$ while maintaining over $96 \%$ efficiency over wide load range.

Chapter 5 gives conclusions of this thesis and suggests future work for the further developments on high power converters for low-voltage, high-power fuel cell applications. 
The purpose of this thesis is to evaluate different advanced dc-dc converters that can efficiently deliver power to the load. Two previously proposed dc-dc converters, V3 and V6, are analyzed in great detail and tested for fuel cell applications. Both converters exhibit excellent attributes, and are highly recommended for fuel cell application. 


\section{Topology SuRVey of High POWER DC-DC CONVERTERS}

A number of high-frequency transformer isolated dc-dc converters are analyzed in literatures. However, most past researches deal with high-voltage input, such as $300 \mathrm{~V}$ and higher, and focus on high to low voltage, step-down conversion. Only a limited number of literatures are devoted to low to high voltage, step-up conversion, and even less number of literatures talk about high-current applications, such as fuel cells. This chapter surveys past literatures and searches for suitable topologies for low-voltage, highpower fuel cell applications.

\subsection{Single-phase Isolated Dc-Dc Converters}

Single-phase transformer isolated converters are employed in a range of applications. Popular topologies are flyback, forward, push-pull, half-bridge, and full-bridge.

A flyback converter is a simple buck-boost based converter. The topology is popular and is advantageous when multiple outputs are required at a relatively low power, in the range of 50 to $100 \mathrm{~W}$. On the disadvantageous side, the topology suffers from high voltage stresses on switching devices, and the flyback transformer core is poorly utilized and it needs to be oversized.

Similarly, a forward converter is a simple buck based converter. The power handling capability is higher than flyback, and it ranges from 500 to $1000 \mathrm{~W}$. The forward converter exhibits a better transformer utilization when compared to the flyback converter, but the transformer magnetizing current must operate in discontinuous conduction mode to prevent the transformer from saturation.

Overall, the flyback and the forward converters are popular in relative low-power applications because these are simple and easy to build. However, their transformer cores are not effectively utilized, and both suffer from high voltage and/or current stresses on switching devices, such that the stresses become excessive during high power. Thus, these can not handle high power, and are ruled out from high power applications. On the other hand, push-pull, half-bridge, and full-bridge converters are able to handle higher power, and these deserve closer consideration for high-power fuel cell application. 


\subsubsection{Push-pull converter}

Figure 2.1 shows a typical push-pull converter with a full-bridge diode rectifier. One main advantage of this topology is that only one device is connected in series with a input source at any given instant, and only one switching device is responsible for conduction loss. Due to its low conduction loss, the push-pull topology can be very attractive for high-current applications. However, it is prone to transformer saturation, and exhibits a poor transformer utilization due to transformer primary-side center tap configuration. Additionally, the center tap configuration causes a higher voltage stress on switching devices, and the higher voltage stress requires devices with higher breakdown voltage. Typically, MOSFETs are preferred over IGBTs in low-voltage applications, and if MOSFETs are used in the application, devices with a higher drain-to-source breakdown voltage ( $\left.\mathrm{V}_{\mathrm{DSS}}\right)$ and a higher on-resistance are required. As a consequence, the advantage gained from single device conduction loss is offset by higher on-resistance of the single device.

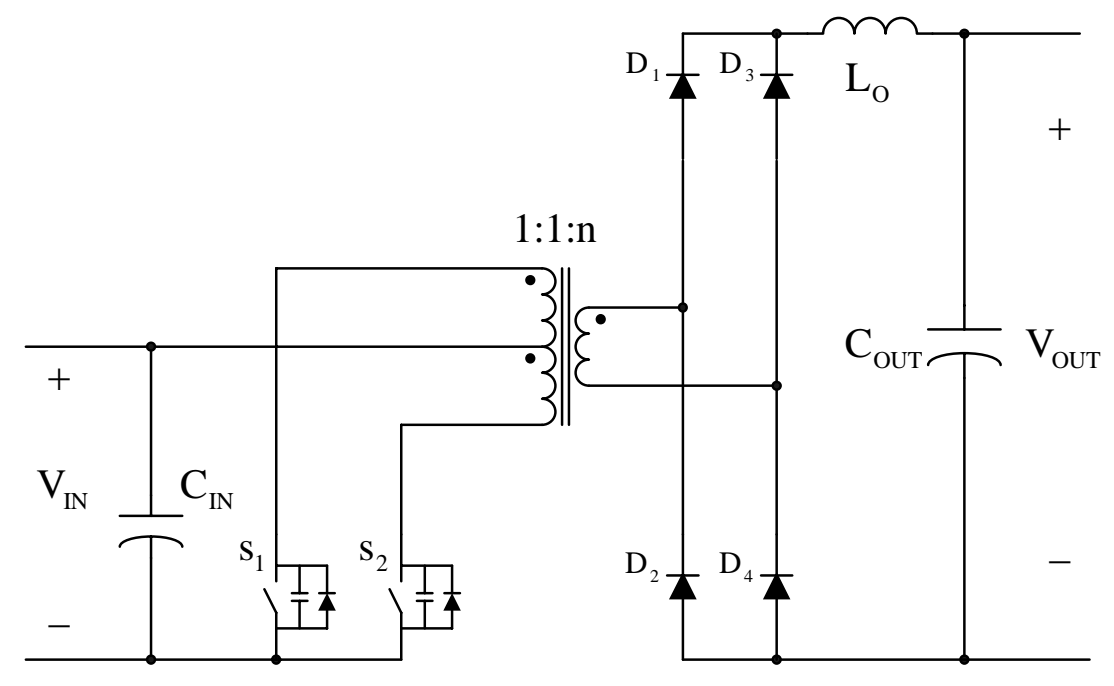

Figure 2.1 - Push-pull converter 


\subsubsection{Half-bridge converter}

Figure 2.2 shows a typical half-bridge dc-dc converter with a single-phase transformer and a full-bridge diode rectifier. The half-bridge tolopogy is one of the simplest topology, and is popular in low to medium power system due to its simplicity.

The half-bridge topology is usually employed in voltage step-down application, since it utilizes only a half of input voltage. In the primary side of the transformer, one end is connected to the midpoint of the half-bridge, and the other end is connected to the midpoint of split dc capacitors. The average voltage of the split dc capacitors at the midpoint is one half of the input voltage; therefore, the transformer can only utilize one half of the input voltage. As a consequence of utilizing only one half of the input voltage, all the primary side components, such as the split dc capacitors, switching devices, and the transformer, experience double amount of input current. For an instance, if an average current of $100 \mathrm{~A}$ is being supplied from fuel cell, then the capacitors and the switching devices must be able to handle approximately 200 A current ripples. In addition to the high current stress, the transformer turns ratio has to be doubled to compensate for utilizing only one half of the input voltage. As a consequence of the higher turns ratio, the transformer suffers from higher leakage inductance, and a higher leakage inductance causes more energy losses and more duty cycle losses than a lower leakage inductance. Considering all these factors, the half-bridge topology is more suitable for low-current, step-down application than for high-current, and step-up application, such as fuel cell application. 


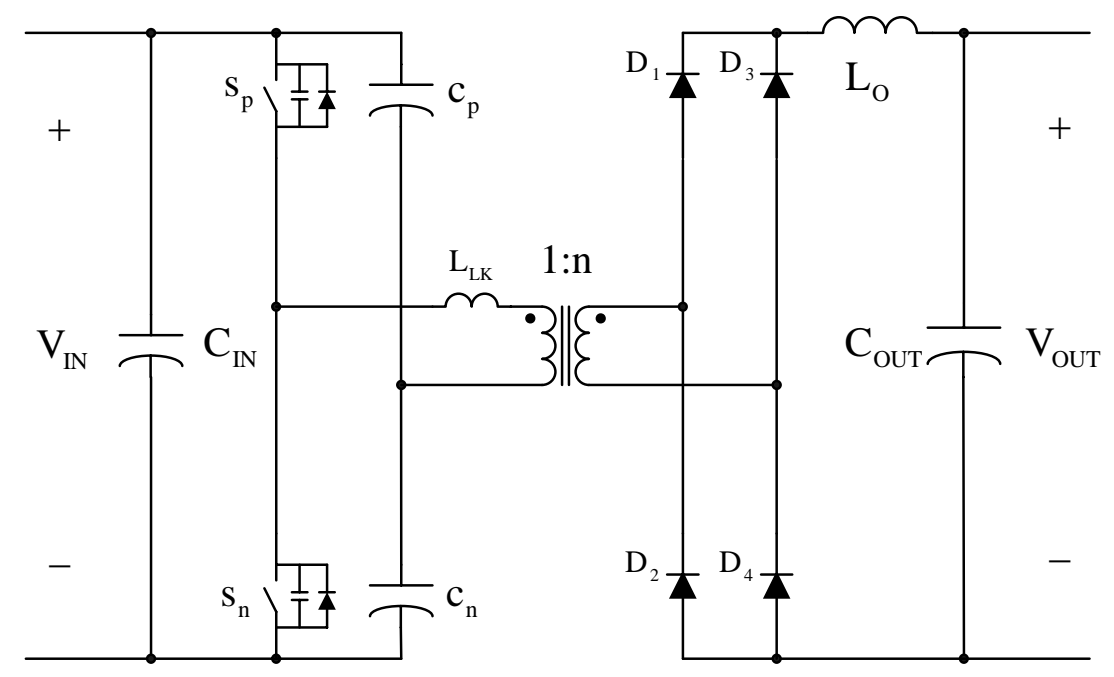

Figure 2.2 - Half-bridge converter

\subsubsection{Full-bridge converter}

Figure 2.3 illustrates a conventional full-bridge converter with a single-phase transformer and a full-bridge diode rectifier, and the full-bridge topology could be the most popular and preferred single-phase isolated dc-dc converter topology for many high-power applications. Unlike the half-bridge topology, the full-bridge topology utilizes the entire input voltage. Also in the full-bridge topology, the current stresses in the primary side components do not double, while voltage stresses remains the same as the half-bridge topology.

One of advantages of the full-bridge topology is the ability to apply different control schemes with little to no modification and achieve desired results. The fundamental control scheme of the full-bridge topology is a constant frequency pulse-widthmodulation (PWM). This control strategy is highlighted by minimal circulating current and current stress. However, it operates under a hard-switching condition, and this causes large switching losses. Also, parasitic parameters, such as transformer leakage inductance and output rectifier reverse recovery spikes, cause parasitic ringings, which increase voltage and current stresses. Typically, snubbers and voltage clamps are used to limit the voltage stress, but they cause additional energy losses. Large switching losses restrict switching frequency from increasing, and the low switching frequency puts a limit on power density in this constant frequency PWM control strategy. 
Many resonant-type converters are proposed in literature to deal with one or more of the hard-switching PWM control limitation. Conventional resonant converters improve switching losses by incorporating a soft-switching technique and increases power density by reducing the size of transformers and passive filter elements with higher frequency operation. However, resonant-type soft-switching and high frequency operation are typically achieved at the expense of substantially higher component stresses [10]. When the resonant-type converter is implemented for high current application, i.e. the fuel cell system, the current stress may become unacceptably high to be practically implemented. These also require a variable frequency control. The variable frequency control scheme makes control implementation challenging and filter component optimization becomes difficult.

An alternative method to the PWM or the resonant-type control scheme is the fullbridge converter using a phase-shift modulation (PSM) control. The PSM control scheme takes strong points from both the PWM control technique and the resonant-type converters. First, switching losses are reduced with a soft-switching technique. Resonant elements needed for soft-switching is provided by the parasitic elements of switch output capacitance and transformer leakage inductance. Secondly, unlike the resonant-type converters, the soft-switching can be achieved while maintaining constant frequency operation [12][13]. Although this control scheme offers several advantages, there are several undesirable traits:

- Limited soft-switching range in leading leg

- High circulating energy in the transformer primary side during free-wheeling period

- Loss of duty cycle due to large leakage inductance

- Load dependent dc characteristics 


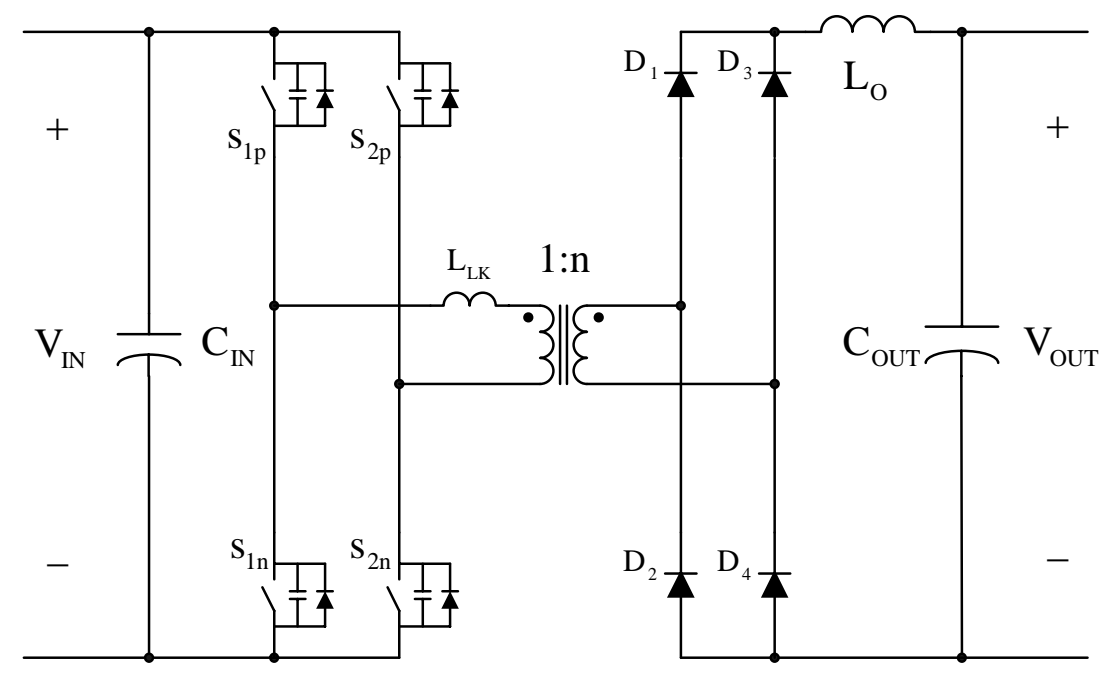

Figure 2.3 - Full-bridge converter

Many full-bridge topology variations are proposed in literature to improve one or more shortcomings. A quick survey of the full-bridge topology variations is presented here:

\section{- Zero-voltage transition (ZVT) PWM converter [14]}

- ZVT is provided by the addition of an auxiliary network, which consists of two small switches and one small inductor, to a full-bridge topology. The ZVT enables zero-voltage switching (ZVS) for the entire line and load range without increasing device voltage and current stresses. Also, duty cycle loss is minimized.

- However, large circulating current still remains to be a problem, and the circulating current should be minimized in high-current fuel cell application.

- Experimental circuit: $380 \mathrm{~V}$ input voltage, $48 \mathrm{~V}$ output voltage, $1.8 \mathrm{~kW}$ output, and $83 \mathrm{kHz}$ switching frequency.

- This variation is advantageous with high voltage, high power application. 90 $\%$ efficiency at full load is reported, but the efficiency rapidly drops to $60 \%$ at light load, due to constant energy consumption of auxiliary circuit. 
- Zero-voltage zero-current switching (ZVZCS) PWM converter using transformer auxiliary windings [15]

- In a ZVZCS circuit, the zero-voltage switching (ZVS) of lagging leg switches is achieved by the same manner as the ZVS in the phase-shift full-bridge topology. Leading leg switches achieve zero-current switching (ZCS) by resetting the current in the transformer primary during the freewheeling period.

- In this circuit, the current in the transformer primary is reset by using the transformer auxiliary windings. No lossy components are involved and no additional active switch is added. All active and passive devices are operated under a minimum voltage and current stresses. Also, no large circulating current is generated.

- Experimental circuit: $480 \mathrm{~V}$ input, $50 \mathrm{~V}$ output, $2.5 \mathrm{~kW}, 100 \mathrm{kHz}$, IGBT

- A maximum efficiency at full load is $94.5 \%$ is reported. One disadvantage of this variation is that the realization of the auxiliary circuit, which consists of transformer auxiliary windings, rectifier diodes, a holding capacitor and a discharging diode, is a bit complex.

- Zero-voltage zero-current switching (ZVZCS) PWM converter with a dc blocking capacitor and a saturable core [16]

- The ZVZCS is achieved by resetting the current in transformer primary with a dc blocking capacitor and a saturable reactor.

- Soft-switching is achieved in a wide range, and circulating current is reduced to lower conduction losses.

- Experimental circuit: $400 \mathrm{~V}$ input, $48 \mathrm{~V}$ output, $2 \mathrm{~kW}$ output power, $100 \mathrm{kHz}$ switching frequency.

- $94 \%$ efficiency at full load is reported.

- In low-voltage, high-power fuel cell applications, a high-current condition takes a place. The dc blocking capacitor, which is in series with the primary transformer windings, is in the path of main power delivery; therefore the capacitor must be able to handle high current. Such capacitors would be hard 
to manufacture, and its cost would be very high, which makes this topology variation impractical for high-current applications. Also the saturable reactor loss limits the maximum power level.

- Zero-voltage zero-current switching (ZVZCS) PWM converter with secondary clamps [17][18]

- ZVZCS is achieved by resetting the current in primary transformer windings with a clamp in the transformer secondary side. Additional auxiliary circuits, however, adds additional cost, control complexity, and switching losses due to its hard-switching characteristic,

- Experimental circuit: $480 \mathrm{~V}$ input, $48 \mathrm{~V}$ output, $3 \mathrm{~kW}$ output power, $100 \mathrm{kHz}$ switching frequency, and $94 \%$ maximum efficiency.

Many full-bridge variant topologies are proposed; however, most literature focus on voltage step-down applications, where a high-current condition does not pose a major concern. Although many topologies report excess of $94 \%$ efficiency in step-down applications with high input voltage, if the same topologies are to be implemented with fuel cell applications, where a low fuel cell output voltage causes a high current stress, then efficiency would drop significantly due to higher conduction losses.

Above topologies focus on the reduction of switching losses, and not on conduction losses. In high voltage applications, device switching losses are usually higher than conduction losses. However, when input voltage is low, i.e. fuel cell applications, input current becomes very high, and the conduction losses may overcome the switching losses and become the dominant factor in overall losses. In order to reduce the conduction losses, either the resistance in current path or the current through resistive path must be lowered. Paralleled devices lower the resistance in the path, and paralleled converters lower the current of the path. Two methods are discussed in more detail in next section. 


\subsubsection{Paralleling devices and converters}

As power level increases and components face more stresses, the components within converters or the converters themselves can be paralleled to reduce component stress and achieve a higher power rating.

For low-voltage, high-power fuel cell applications, large current causes significant conduction losses along the path it flows, and the conduction loss is the main cause of lower efficiency. A simple power loss calculation, $I^{2} \cdot R$, indicates that conduction loss can be reduced by decreasing the amount of current through each lossy components and/or by reduce the component resistance. When components are paralleled, the resistance in current path is reduced, and average current flow through each component is also reduced, thus it lowers conduction losses and achieves higher power rating. However, paralleled components increase the complexity of circuit layout, and unbalanced dynamic and static current sharing among the components may cause a problem. Especially, if the current does not equally shared by each component, one component faces more stress and may fail faster than others.

Converters are often paralleled when higher power rating is desired. Paralleled converters reduce average current in individual converter and increase overall power rating; however, the paralleled converters cause redundancy in power components, control circuits, and gate drivers; therefore, cost and size of the system increase linearly with the power rating. Also converter current sharing and interaction must be considered as well.

- While paralleled devices and converters can achieve better efficiency and higher power rating, it is not necessarily the best solution, and better solutions and topologies should be sought after.

\subsubsection{Single-phase isolated dc-dc converters summary}

Single-phase isolated dc-dc converters are very popular and often used in many applications. Most of previously reported topologies focus on step-down applications where the reduction of switching losses with soft-switching techniques is the main topic. However, fuel cell applications face a very high current condition, where the current may 
go up to $250 \mathrm{~A}$ and even higher in the future. Most of previously reported single-phase isolated dc-dc converters seem inadequate and insufficient, as these can not deal with the high current condition, and also sufficiently rated components are not readily available. These converters can be the baseline technology for realizing many other converters, such as multi-phase dc-dc converters, which is discussed in next section. 


\subsection{Multiphase Isolated Dc-Dc Converters}

As the power rating of dc-dc converters increase, single-phase converters face severe component stresses. Especially in fuel cell applications, high current stress limits the power rating from further increase. Thus, the use of multiphase converter circuits is proposed to reduce the high current stress on devices and components. This section surveys the literature of multiphase dc-dc topology for fuel cell applications.

\subsubsection{Three-phase PWM dc-dc converter with a $\Delta-\Delta$ transformer}

Shown in Figure 2.4, a three-phase isolated dc-dc converter is introduced in 1988 by A. R. Prasad, et al., in reference [19].

This topology is considered to be the first multiphase converter to demonstrate all the key attributes of multiphase converters. First, control signals are interleaved with $120^{\circ}$ shift among phases. As a result, converter effective frequency appears to be three times greater than actual switching frequency. In other words, the voltage and the current of input port and output port have three times greater chopping frequency than switching frequency. Secondly, as a consequence of higher effective frequency, the size of passive filter components, i.e. capacitors and inductors, are significantly reduced. Furthermore, if a three-phase transformer is used instead of three single-phase transformers, transformer size reduction is possible, since flux can couple among phases inside the transformer magnetic core. However, the design and the implementation of three-phase transformer can be challenging. Thirdly, lower RMS currents go through individual power switches, since each phase shares overall currents. Therefore, higher power level can be achieved with lower device stresses.

In the reference, a $2 \mathrm{kVA}$ prototype experimental converter is reported using power MOSFETs with the following circuit parameters: $20 \mathrm{kHz}$ operating frequency, 185.5 260 $\mathrm{V}$ input source voltage, and $2100 \mathrm{~W}$ output power. It reports high $96 \%$ efficiency; however, the experiment is conducted with high input voltage under very ideal condition, where nearly zero line inductance or nearly zero transformer leakage inductance is included. In a setting where inductance can not be minimized, the converter suffers from 
high circulating current and high conduction loss. Also this topology employs symmetrical PWM control signal, which causes high commutating loss due to hardswitching. If this topology is implemented for fuel cell applications, it is very likely that efficiency will be reduced significantly.

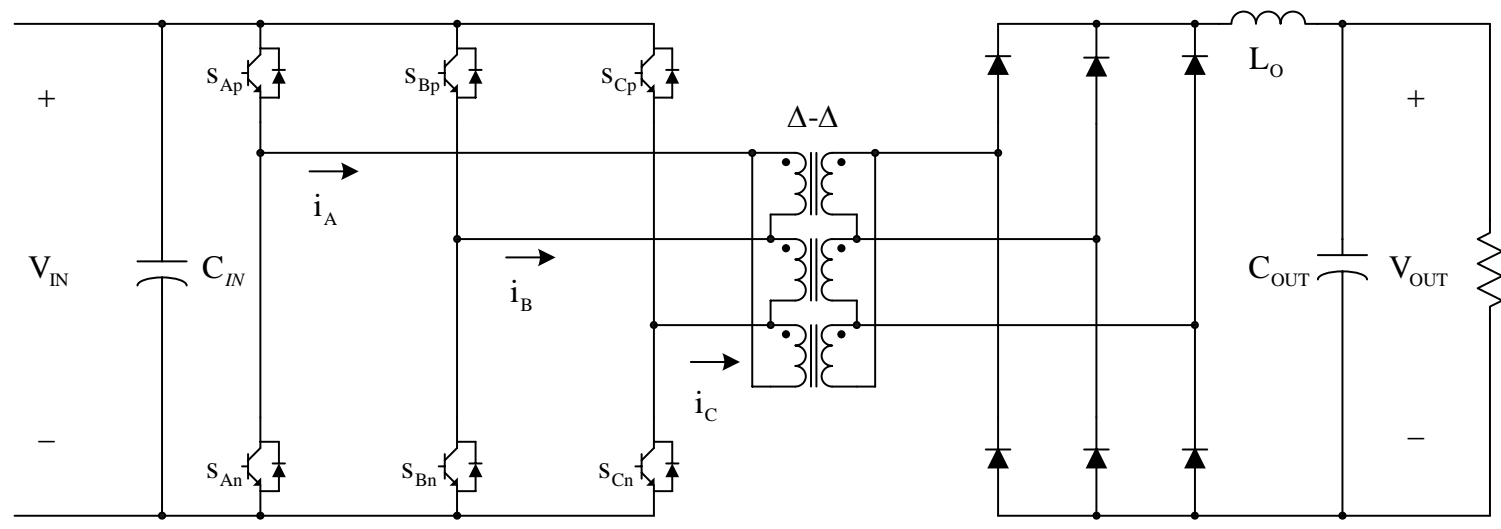

Figure 2.4 - Three-phase PWM dc-dc converter with a $\Delta$ - $\Delta$ transformer

\subsubsection{Three-phase dc resonant PWM dc-dc converter with a Y-Y transformer}

Figure 2.5 illustrates a three-phase dc resonant PWM dc-dc converter with Y-Y transformer. The same authors of the dc-dc converter in section 2.2.1, Prasad, et al., introduced a soft-switching version of the same converter in 1991 in reference [20]. Main differences are change of three-phase transformer configuration from $\Delta-\Delta$ to $\mathrm{Y}-\mathrm{Y}$ and the addition of resonant network. The resonant inductor, $\mathrm{L}_{\mathrm{RES}}$, is added to the primary side of transformer and the resonant capacitor, $\mathrm{C}_{\mathrm{RES}}$, is added immediately after the output of three-phase diode rectifier.

The control method remains the same as the previous work, symmetrical PWM control with $120^{\circ}$ interleave among phases. The combination of resonant network and PWM control methods are used to regulate output voltage from no load to full load with low switching losses. It should be noted that constant switching frequency control is employed instead of usual variable frequency control associated with resonant converters.

A 1.5 kVA experimental three-phase dc resonant PWM dc-dc converter is reported with the following circuit parameter: $110 \mathrm{~V}$ and $12.5 \mathrm{~A}$ input, $100 \mathrm{~V}$ and $12.5 \mathrm{~A}$ output, 
and $90.9 \%$ efficiency. This topology not only shows low efficiency, but the resonant network also makes power devices suffer from high voltage and current stress, and the converter requires higher rated devices to be used. Also, the large size of resonant network components, $\mathrm{L}_{\mathrm{RES}}$ and $\mathrm{C}_{\mathrm{RES}}$, offset the benefit of transformer and filter size reduction.

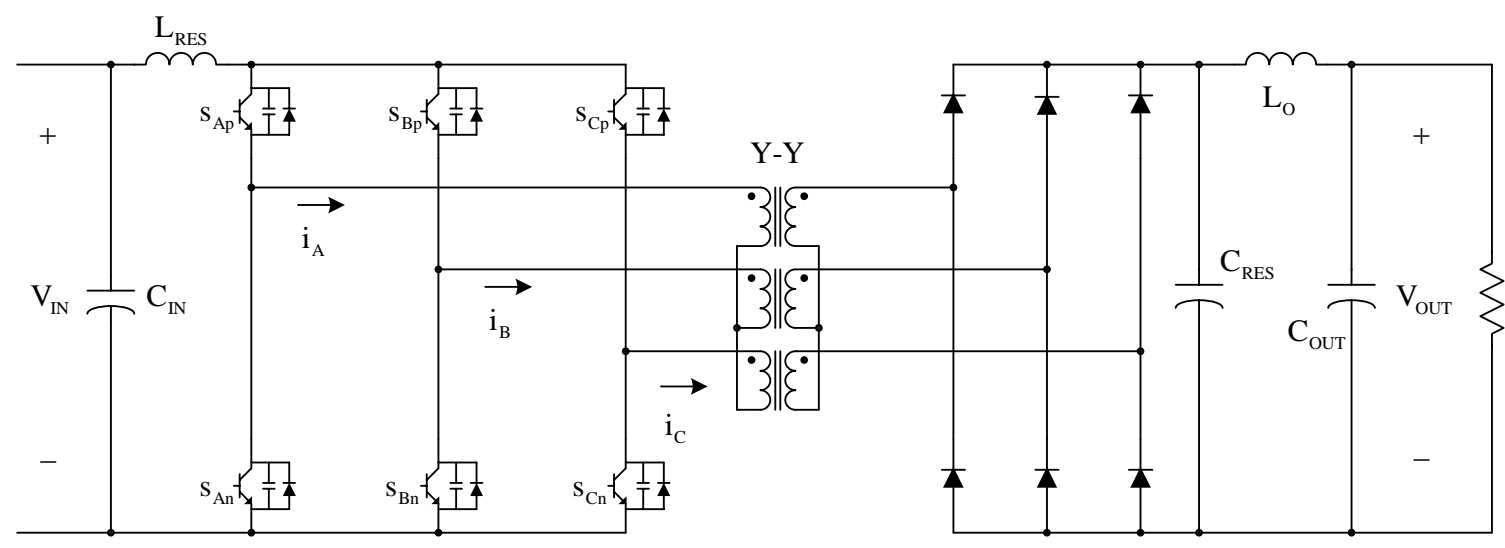

Figure 2.5 - Three-phase dc resonant PWM dc-dc converter with a Y-Y transformer

\subsubsection{Three-phase resonant-type dc-dc converter}

Figure 2.6 and Figure 2.7 illustrate a three-phase series-parallel resonant converter and a three-phase series resonant converter reported in reference [21] and [22], respectively. Both resonant-type converters are similar and are discussed together.

Resonant tank are created with three-phase transformer leakage inductance and resonant capacitors. The resonance creates a soft-switching condition, which helps to improve system efficiency and to increase switching frequency; however, high voltage and current stresses are imposed on power devices. Also control scheme utilizes a variable frequency operation, thus filter optimization can present some difficulty.

A $5 \mathrm{~kW}$ experimental three-phase series resonant converter circuit is reported with following circuit parameters: $400 \mathrm{~V}$ input, $400 \mathrm{~V}$ output, $100 \mathrm{kHz}$ resonant frequency with variable switching frequency. It reports a very high conversion efficiency of $98.2 \%$ in high voltage applications; however, in low-voltage high-power applications, efficiency could drop significantly. 
The main drawback of the resonant-type dc-dc converter with low-voltage highpower applications is the presence of the resonant capacitor in the path of main power delivery. In both resonant-type converters, the resonant capacitor is in series with the three-phase transformer in primary side. Since high-current condition in the primary is associated with low-voltage fuel cell applications, the resonant capacitor must be able to process very high current. Not only high current resonant capacitors are very expensive, but also their availability is very limited. Additionally, the primary side already experiences very high current stress in low-voltage high-power application, and the resonant network would add more stress to already high current stress.

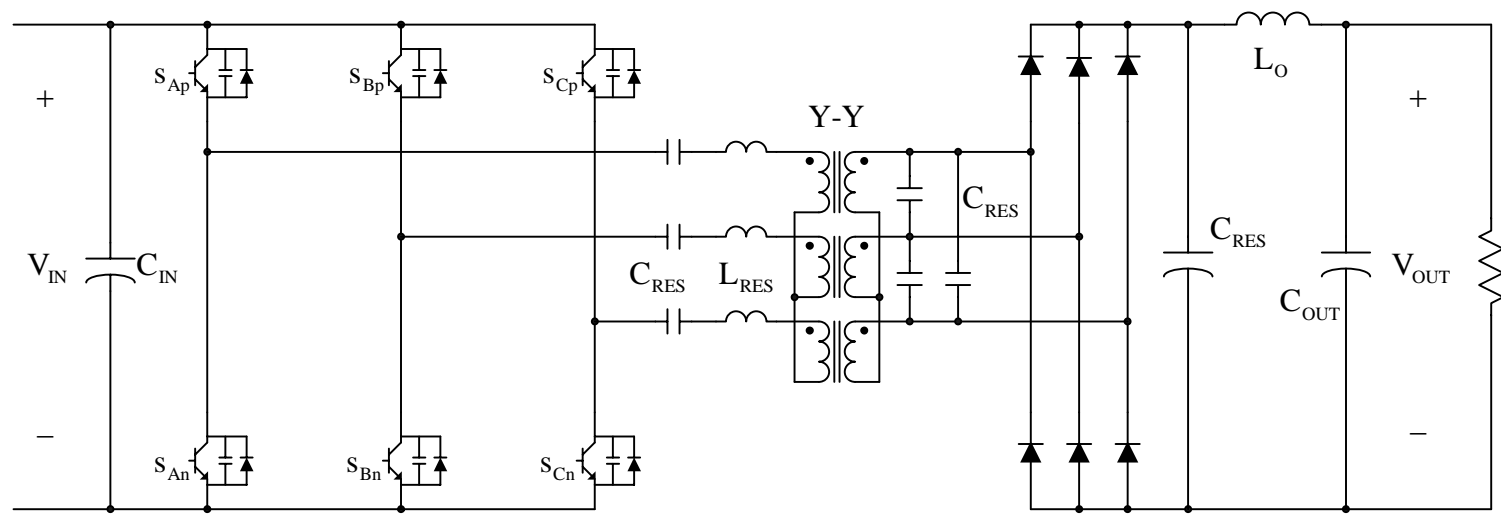

Figure 2.6 - Three-phase series-parallel resonant converter with a Y-Y transformer

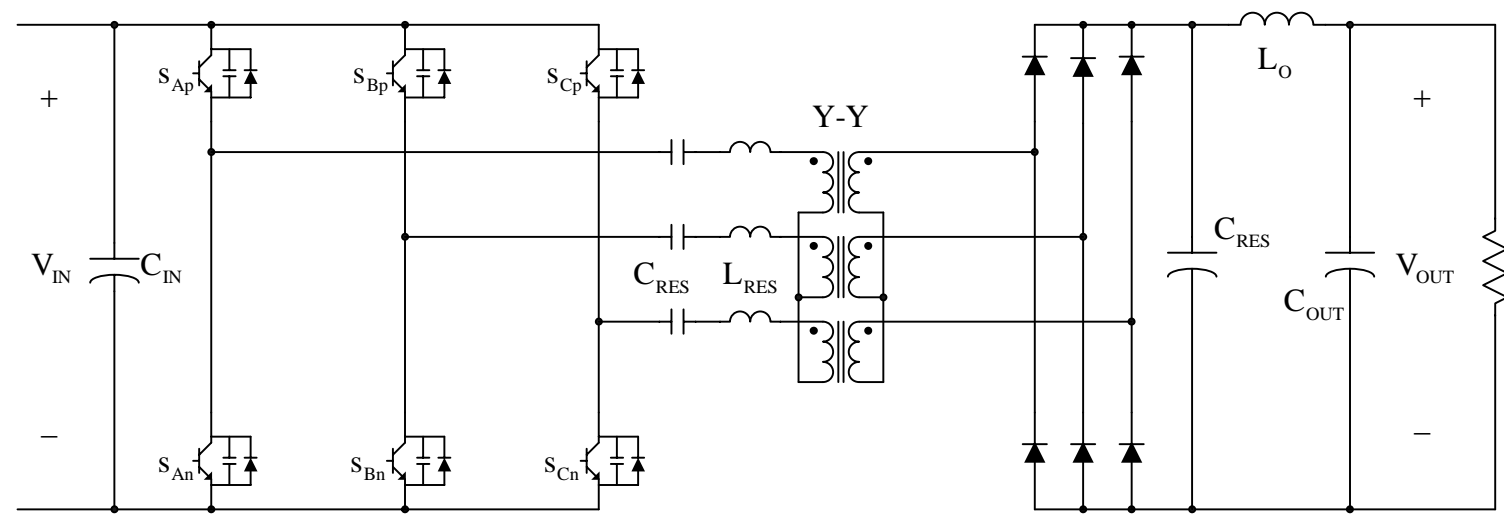

Figure 2.7 - Three-phase series resonant converter with a Y-Y transformer 


\subsubsection{Hybridge rectifier converter and current-tripler converter}

Figure 2.8 shows a three-phase dc-dc converter with a hybridge rectifier with a Y-Y transformer. This topology is introduced by Oliveira, et al., in 2003 [23]. Figure 2.9 shows a three-phase current-tripler dc-dc converter with a $\Delta-\Delta$ transformer. This topology is introduced by Zhou, et al., in 2003 for low-voltage high-current microprocessor voltage regulation module (VRM) [24].

Both topologies are for step-down applications where improvements are focused on secondary side to increase efficiency. Secondary-side power losses have a major impact on efficiency in step-down applications, thus when a less number of components, such as diodes or MOSFETs, are responsible for conduction losses, efficiency can be improved significantly.

Main changes are that rectifier is formed with three inductors and three diodes/MOSFETs, instead of six diodes of a full-bridge rectifier. The three inductors are positioned in the place of three diodes, and a usual filter inductor is removed, since the three inductors take the responsibility of current filter. As a result, overall output inductor volume is increased, but output capacitor volume is decreased, if the same output current ripple is to be maintained. It should be also noted that both topologies are capable of soft-switching.

An experimental hybridge rectifier circuit is reported with following specification: $420 \mathrm{~V}$ input, $60 \mathrm{~V}$ output, $6 \mathrm{~kW}$ output, and $46 \mathrm{kHz}$ switching frequency. It reports $95 \%$ efficiency at $2 \mathrm{~kW}$ and $93 \%$ at $6 \mathrm{~kW}$. Also an experimental current-tripler circuit is reported with following specification: $48 \mathrm{~V}$ input, $1.0 \mathrm{~V}$ output, $100 \mathrm{~A}$ output, and 300 kHz switching frequency. It reports $87 \%$ efficiency at full load.

Both topologies report approximately 2 4 \% efficiency increase compared to threephase full-bridge rectifier counterpart. However, in step-up application, such as fuel cells, the conduction loss in transformer secondary side is comparatively small, thus efficiency improvement in the secondary side is minimum with these topologies. 


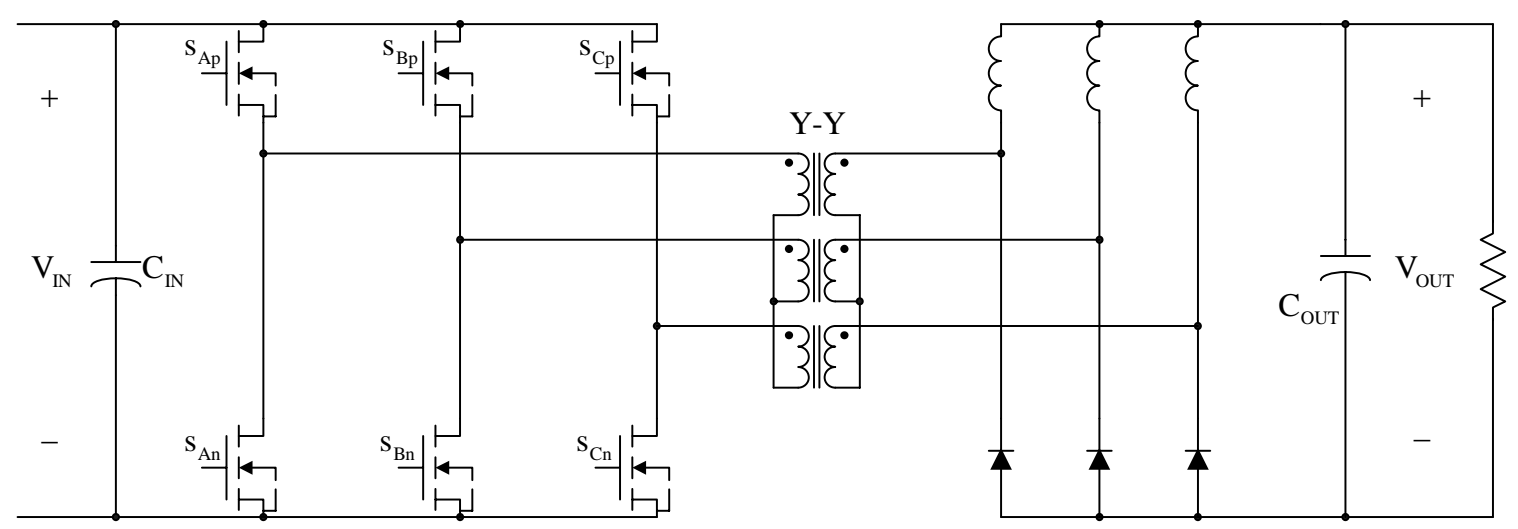

Figure 2.8 - Three-phase dc-dc converter with a hybridge rectifier with a Y-Y transformer

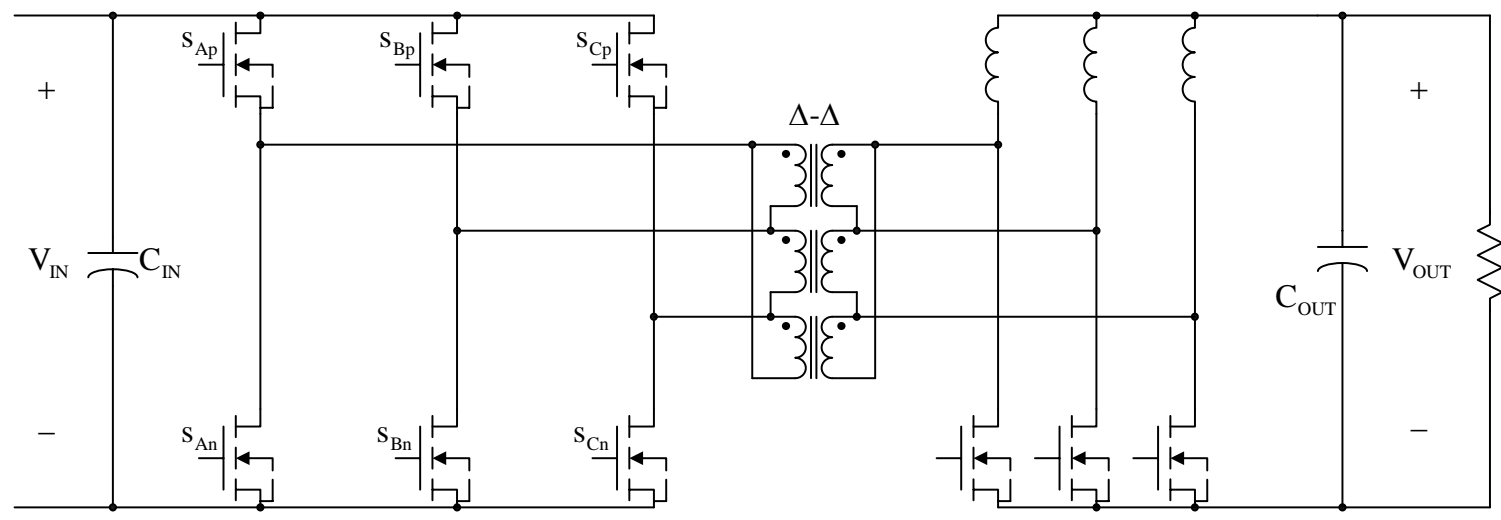

Figure 2.9 - Three-phase current-tripler dc-dc converter with a $\Delta-\Delta$ transformer

\subsubsection{Three-phase asymmetrical PWM dc-dc converter with a Y-Y transformer}

Figure 2.10 shows a three-phase asymmetrical PWM dc-dc converter with a Y-Y transformer. This topology is introduced by Oliveira, et al., in 2003 [25]. Asymmetrical duty cycle control scheme is proposed to achieve zero-voltage switching (ZVS). The asymmetrical duty cycle allows the resonant network of three-phase transformer leakage inductance and switching devices' output capacitance to resonate, and the resonance discharges a switching device output voltage to zero before turning on the corresponding switch. The utilization of the intrinsic resonant elements within the converter eliminates the need for adding extra resonant components. In high-power applications, adding resonant component can impose size and cost constraints. 
The zero-voltage switching mechanism is very similar to the single-phase full-bridge phase shift modulation topology of section 2.1.3, because the converter inherits the same traits. For the same reason, this topology also suffers from limited zero-voltage switching range, high circulating energy in the primary during free-wheeling period, and loss of duty cycle due to large leakage inductance.

An experimental circuit is reported with following parameters: $420 \mathrm{~V}$ input, $60 \mathrm{~V}$ output, $6 \mathrm{~kW}$ output power, and $46 \mathrm{kHz}$ operating frequency. It reported $93.5 \%$ in $3 \mathrm{~kW}$ and $91.4 \%$ in $6 \mathrm{~kW}$ output power.

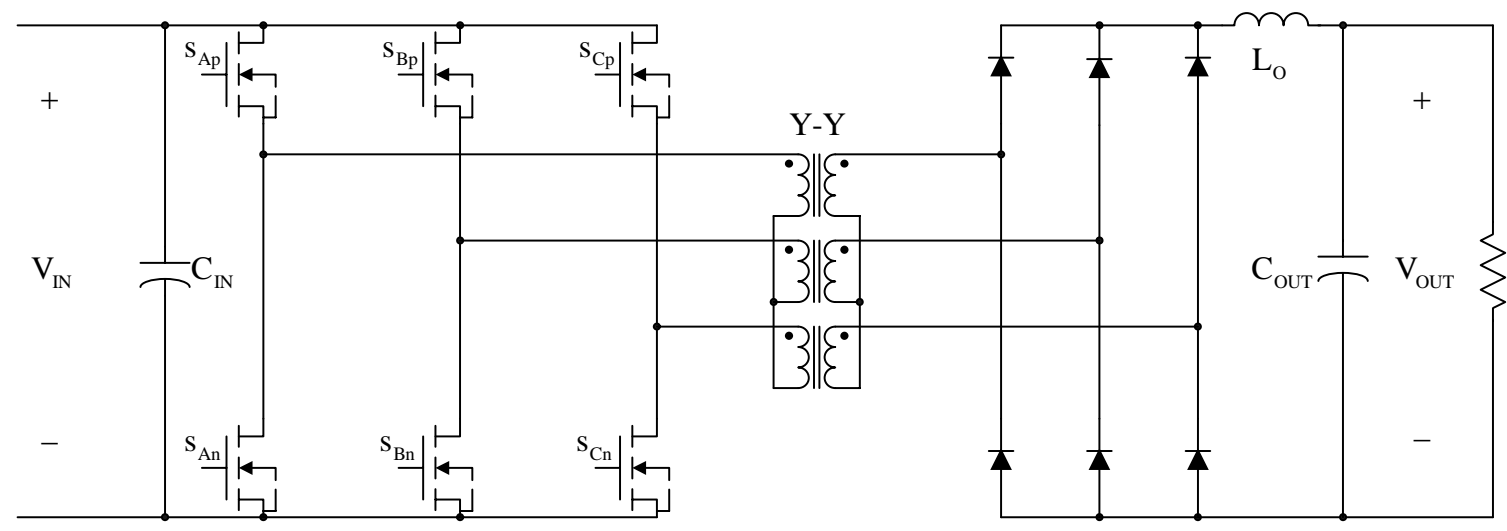

Figure 2.10 - Three-phase asymmetrical PWM dc-dc converter with a Y-Y transformer

\subsubsection{Three-phase phase-shift modulation PWM dc-dc converter with a $\Delta-Y$ transformer}

Figure 2.11 shows a three-phase phase-shift modulation PWM dc-dc converter with a $\Delta$-Y transformer. This topology is proposed by Liu, et al., in 2004 [26].

The topology consists of three full-bridge converters, and each phase is controlled with a phase-shift modulation control scheme. Three-phase transformers are configured in $\Delta$-Y setting, and it boosts the output voltage without increasing transformer turns ratio. The converter is also capable of zero-voltage zero-current switching (ZVZCS) over a wide load range without an auxiliary circuitry. One drawback of this topology is that it is the most complex topology among the surveyed topologies.

All the previous topologies are targeted for step-down applications, but this topology is intended for step-up applications, such as fuel cell applications. An experimental 
circuit is reported with following parameters: $25 \mathrm{~V}$ input, $300 \mathrm{~V}$ output, $3 \mathrm{~kW}$ output, and $50 \mathrm{kHz}$ operating frequency. It reported $96 \%$ efficiency at $3 \mathrm{~kW}$.

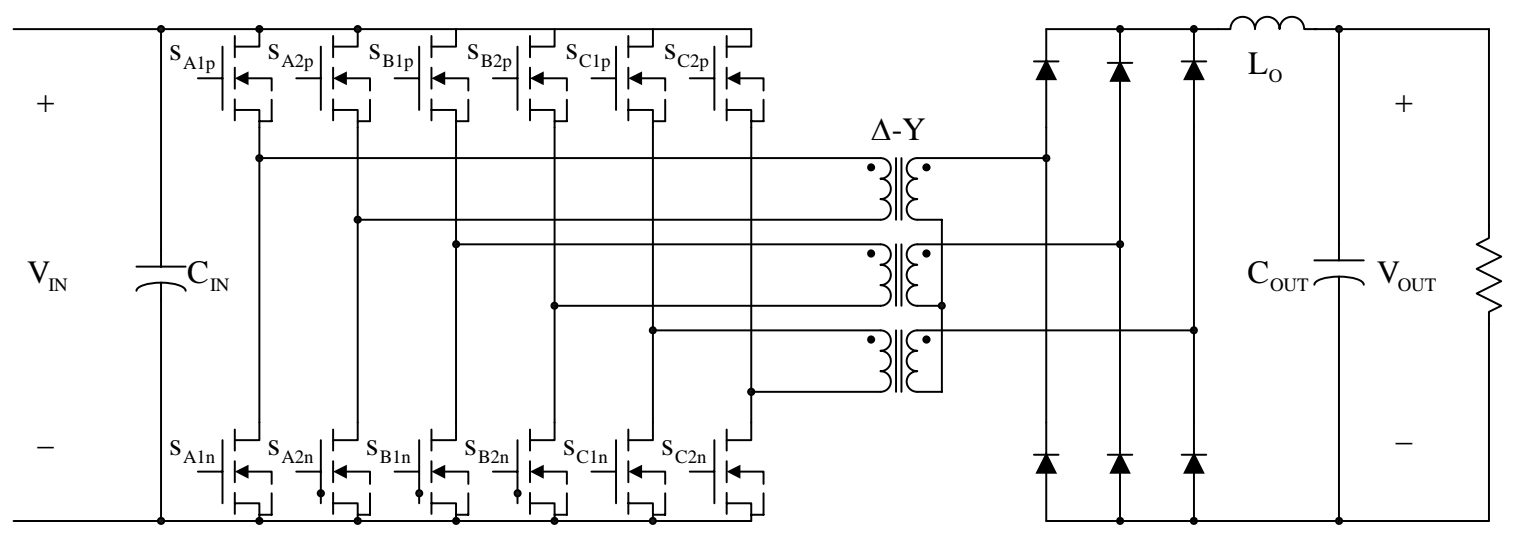

Figure 2.11 - Three-phase phase-shift modulation PWM dc-dc converter with a $\Delta$-Y transformer

\subsubsection{Three-phase step-up dc-dc converter}

Figure 2.12 shows a three-phase step-up dc-dc converter, which is proposed by Oliveira, et al., in 2005 [27]. Like the circuit in section 2.2.6, the topology is also intended for step-up applications, such as photovoltaic or fuel cell systems.

The topology is a boost-type topology that consists of three boost converters in parallel. The outputs of the boost converters are connected to a three-phase Y-Y transformer, and the outputs of the Y-Y transformer are connected to a three-phase full bridge rectifier. Compared to other multi-phase topologies which utilizes minimum of six switches in the transformer primary, this topology only utilizes three switches and replace other three switches with inductors. This configuration is very similar to the hybridge rectifier converter of section 2.2.4, where the three-phase full bridge rectifier is replaced with network of three MOSFETs/diodes and three inductors. As a matter of a fact, the step-up converter is the same as the hybridge converter with input terminal swapped with output terminal.

One main advantage of the boost-type converters is that these are current source inverters. As mentioned in the section 1.3.1, the fuel cells are very sensitive to negative currents, and the boost derived topologies are current source inverters which provide integrated input filter and prevent input current from pulsating. On the other hand, 
voltage source inverters, such as buck converters, typically require input filters to eliminate a significant amount of high frequency input current ripples.

In contrast, the circuit exhibits several disadvantages. First, the circuit must not operate under $1 / 3$ of duty cycle. Since inductor current can not change instantaneously, the duty cycle must be kept above 1/3 to maintain continuous flow of current. Secondly, it operates under hard-switching commutation, and high switching loss occurs. Thirdly, a snubber circuit is required, due to the hard-commutation causing high noise and rinings.

An experimental circuit is reported with following parameters: $47 \mathrm{~V}$ input, $450 \mathrm{~V}$ output, $6.8 \mathrm{~kW}$ output power, and $20 \mathrm{kHz}$ operating frequency. $88 \%$ efficiency is reported under full load.

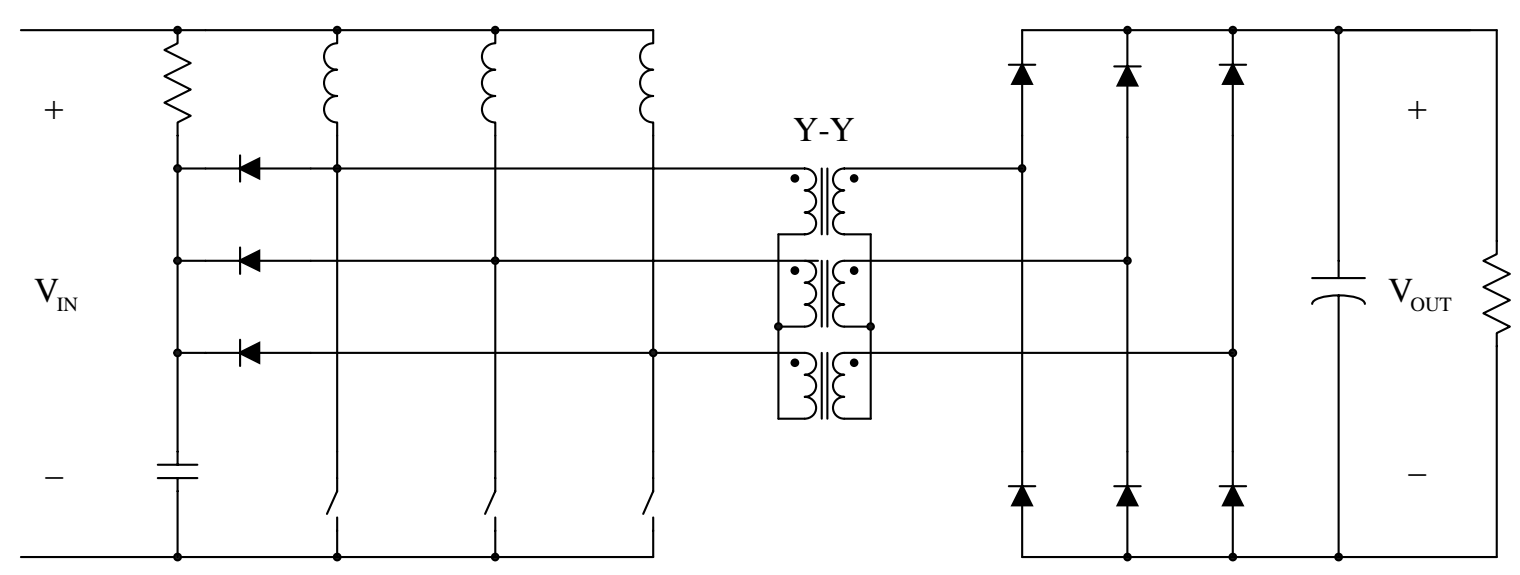

Figure 2.12 - Three-phase step-up dc-dc converter

\subsubsection{Multiphase isolated converters summary}

Multiphase converters offer several advantages over single-phase converters. The main differences are that phases are paralleled and control signals are interleaved with some designated degree shift among phases. For an example, amount of phase shift in three-phase system is $360^{\circ} / 3=120^{\circ}$. The advantages are following:

- Interleaving control signal enables higher effective frequency while switching frequency remains at lower frequency. For an instance, if switching frequency is $50 \mathrm{kHz}$ in a three-phase converter, resulting effective frequency on the voltage 
and the current of input and output is multiplied by a number of phases, which results in $150 \mathrm{kHz}$, i.e..

$50 \mathrm{kHz}$ switching frequency $\cdot 3$ phases $=150 \mathrm{kHz}$ effective frequency

- As a result of the high effective frequency, the size of passive filter components, i.e. capacitors and inductors, are significantly reduced.

- If a multiphase, coupled transformer is utilized instead of individual single-phase transformers, overall transformer size reduction is possible, since flux can couple among phases inside the transformer magnetic core.

- Higher power rating and/or density is possible, since each phase shares a portion of total current, and a lower RMS current goes through individual power switches.

All the converters reviewed above are three-phase types. The three-phase type is popular since it can easily utilize three-phase transformer configurations. It also should be noted that three-phase converters allow the transformers to be configured in $\Delta-\Delta, \Delta-\mathrm{Y}$, $\mathrm{Y}-\mathrm{Y}$, or $\mathrm{Y}-\Delta$ to match a particular topology setting and to obtain different output voltage levels without adjusting the transformer turns ratio.

While multiphase converters offer several advantages, one of the obvious drawback is its complexity in both topology and its control. Typically analog control offers simple and cost effective design in single-phase converter. However, multiphase converter analog control implementation could be complex and costly [28]. Recent popularity and significant cost reduction of digital signal processor (DSP), the digital control can offer lower cost and smarter control.

Overall, potential cost saving on passive components through ripple cancellation and efficiency improvements are very attractive, despite topology complexity. For lowvoltage, high-power fuel cell applications, potential saving is even more significant, because of large input current involved.

Most multiphase converters are able to achieve soft-switching with relatively high switching frequency and high efficiency. With promising performance of multiphase dcdc converters, it is worth looking into the similarities and difference between suitable candidates. The best candidates are converters of section 2.2.5 and 2.2.6. In following 
chapters, two converters are examined for their basic operation, and performances are evaluated for fuel cell applications. 


\section{Basic Operation OF MULTIPHASE DC-DC CONVERTERS}

As the demand for a high power rating and high power density increases, single-phase converters face severe component stresses; thus, it has become more difficult to meet the demand without paralleling components and/or increasing operating frequency. Paralleled components enable converters to have a higher power rating, but this solution presents problems of its own, which are pointed out in section 2.1.4. To increase power density, switching frequency is often increased to reduce the size of passive components; however, increasing switching frequency is limited by switching losses and its stress on the switches. These problems must be dealt with before converters can be practically utilized.

Multiphase converters improve on the limitations that are present in the single-phase converters. Main differences from single-phase converters are a) phases are paralleled, instead of paralleling components, and b) the control signal for each phase is applied with interleaving method. Interleaved phases increase a power rating by lowering RMS current through individual components and increase power density by increasing effective operating frequency and reducing size of passive components, i.e. capacitors and inductors.

Several multiphase topologies are reviewed in chapter 2. Among those, two of multiphase converters appear appropriate for low-voltage, high-power fuel cell applications. The first converter is the three-phase, three-leg, Y-Y transformer isolated, asymmetrical duty cycle, pulse-width-modulation (PWM) converter of section 2.2.5, and it is referred as "V3" from this point on. The second converter is the three-phase, six-leg, $\Delta$-Y transformer isolated, phase-shift modulation (PSM) converter of section 2.2.6, and it is referred as "V6" from this point on.

This chapter outlines the architecture of multiphase dc-dc converters. Then, the circuit topology and the control of V3 and V6 are analyzed in detail. Lastly, steady-state operating modes and operating principles are discussed. 


\subsection{Multiphase Dc-Dc Converter Architecture}

Figure 3.1 illustrates how a general three-phase dc-dc converter is constructed, which is used as an example to explain multiphase converter architectures.

Input can be either a voltage or a current source. In the case of fuel cell power systems, a fuel cell stack is a dc voltage source, and converters deal with dc voltage to dc voltage conversion. A input filter is often required to reduce to noise and disturbance from converters. Many renewable energy sources, such as batteries, photovoltaics, and especially fuel cells, are sensitive and vulnerable to disturbances, such as negative currents and current ripples, and the input filter lessens such disturbances.

After the input filter, a power stage chops and inverts the dc input into high-frequency three-phase interleaved ac signals. Interleaving phase control schemes allow higher effective frequency operations and offer several benefits, which are mentioned in section 2.2.8. The ac signals then excite a high-frequency multiphase transformer, and the transformer either steps-up or steps-down the ac signals to an appropriate level. One advantage of three-phase transformers is its flexibility of transformer configuration. Three-phase transformers can be configured in one of $\Delta-\Delta, \Delta-\mathrm{Y}, \mathrm{Y}-\mathrm{Y}$, and $\mathrm{Y}-\Delta$ to obtain different output voltage levels along with turns-ratio adjustment. Different three-phase transformer configurations and their advantages are considered in detail in section 4.1.

Once the transformer outputs attain an appropriate output level, the output is rectified with a suitable three-phase rectifier, such as a three-phase full-bridge rectifier, a current tripler, or a hybridge rectifier. The rectified signal is filtered and supplied to output sinks.

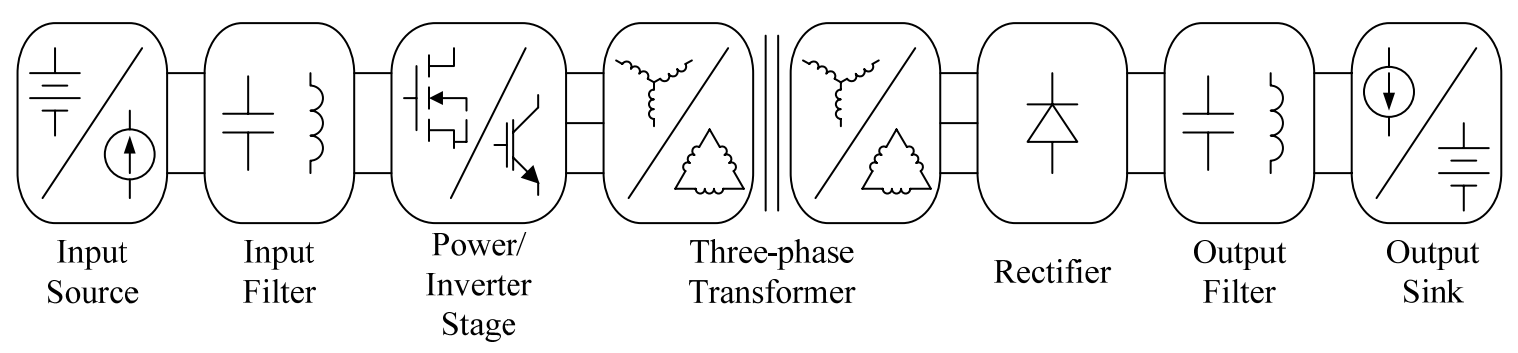

Figure 3.1 - Three-phase dc-dc converter architecture 


\subsection{Circuit Topology and Control}

\subsubsection{V3}

V3 is a three-phase, three-leg, Y-Y transformer isolated, asymmetrical duty cycle, pulse width modulation (PWM) converter, and the V3 converter circuit topology and its control signals are shown in Figure 3.2 and Figure 3.3, respectively.

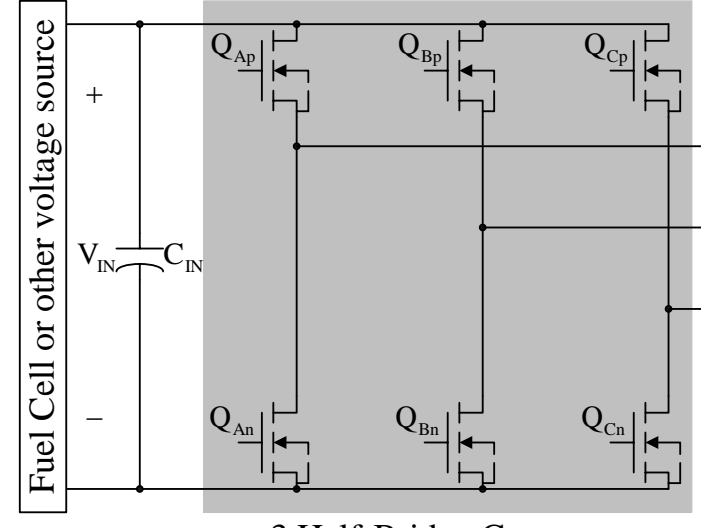

3 Half-Bridge Converter

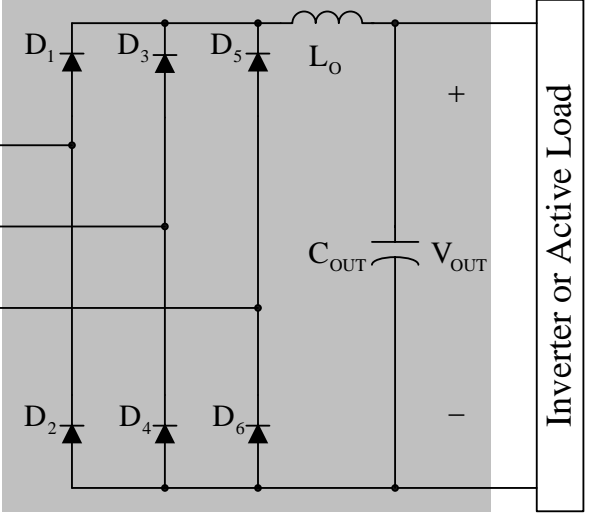

Rectifier + LC filter

Figure 3.2 - V3 converter: three half-bridge, Y-Y transformer isolated converter

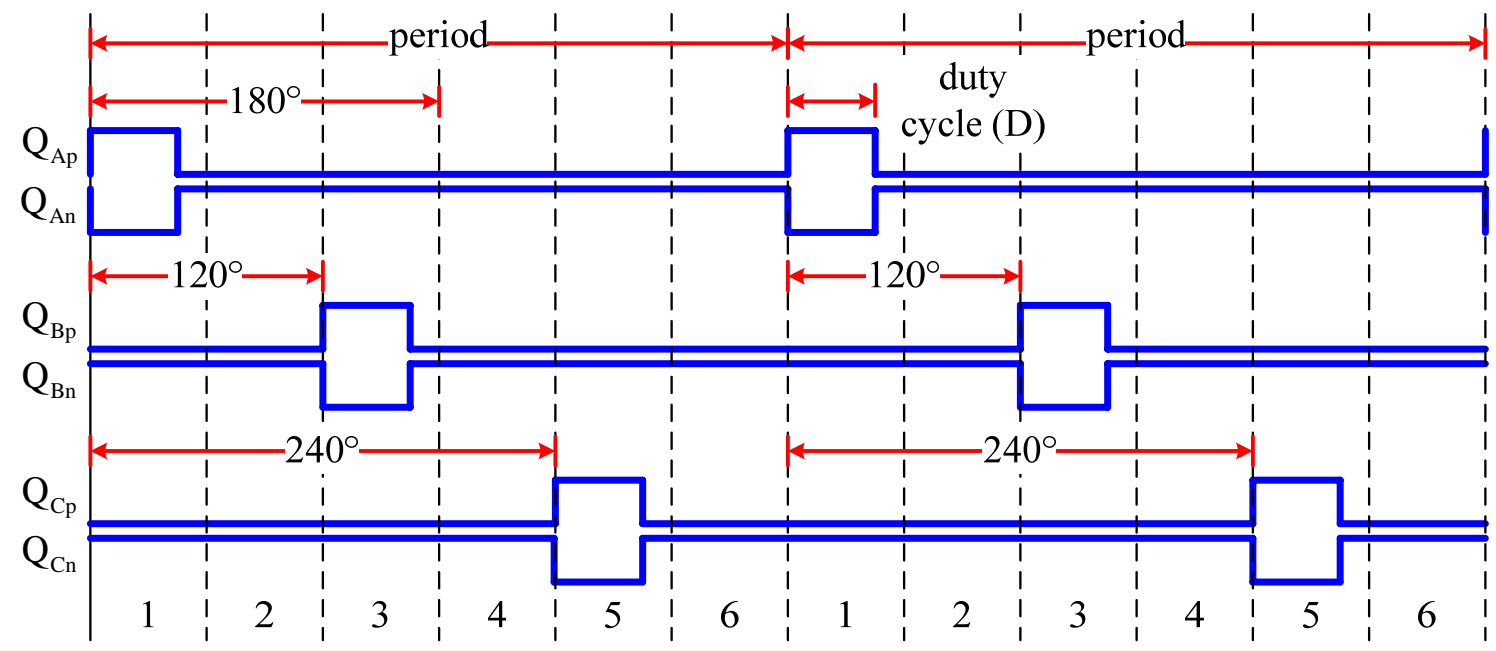

Figure 3.3 - Interleaving asymmetrical duty cycle control signal for V3

The V3 converter consists of six switches, three single-phase transformers, six diodes, and a LC filter. Six switches form three phase-legs, and the midpoints of each phase-leg are connected to one end of each primay transformer windings. The other ends of the 
primary transformer windings are gathered and connected to a single node to form a Yconnection. The transformer secondary side is also configured in a Y-connection. Since both primary and secondary is in the Y-connection, the three single-phase transformers can be said to be in a Y-Y configuration. Once the transformers convert voltage to a desired level, the transformer outputs are rectified with a three-phase full-bridge rectifier, which is formed with six diodes. Then, the rectified output is filtered with the LC filters, and DC output voltage is generated.

Each phase-leg, a.k.a. half-bridge, represents a phase, and three phase-legs form three phases. The phases are denoted as A, B, and C. For each phase-leg, a upper device is indicated with $\mathrm{p}$, while a lower device is indicated with $\mathrm{n}$. Therefore, the upper device of phase $A$ is denoted as $\mathrm{Q}_{\mathrm{Ap}}$. Other devices follow the same naming convention.

Figure 3.3 illustrates the interleaved asymmetrical duty cycle control signal for V3. Each phase is controlled with asymmetrical pulse width modulation (PWM). In the asymmetrical PWM, complementary signals controls a upper switch and a lower switch. The upper switch is in on-state for the duration of duty cycle, D, and the lower switch is in on-state for remaining time in a period. Other phases are governed with the identical asymmetrical PWM signals with $120^{\circ}$ and $240^{\circ}$ phase shift with respect to the first phase. In other words, phase control signals are interleaved with $120^{\circ}$ phase shift among them.

If a conventional PWM using symmetrical duty cycle is employed, then the V3 converter would operate in hard-switching conditions. However, the three-phase asymmetrical PWM control signal is adopted in order to achieve soft-switching and to reduce switching loss. Detailed soft-switching mechanism is described in section 3.5.1. Additionally, difference features between the symmetrical and the asymmetrical duty cycle are explained in detail in section 3.3.1. 


\subsubsection{V6}

V6 is a three-phase, six-legs, $\Delta$-Y transformer isolated, phase-shift modulated (PSM) converter, and the V6 converter and its control signals are shown in Figure 3.4 and Figure 3.5 , respectively.

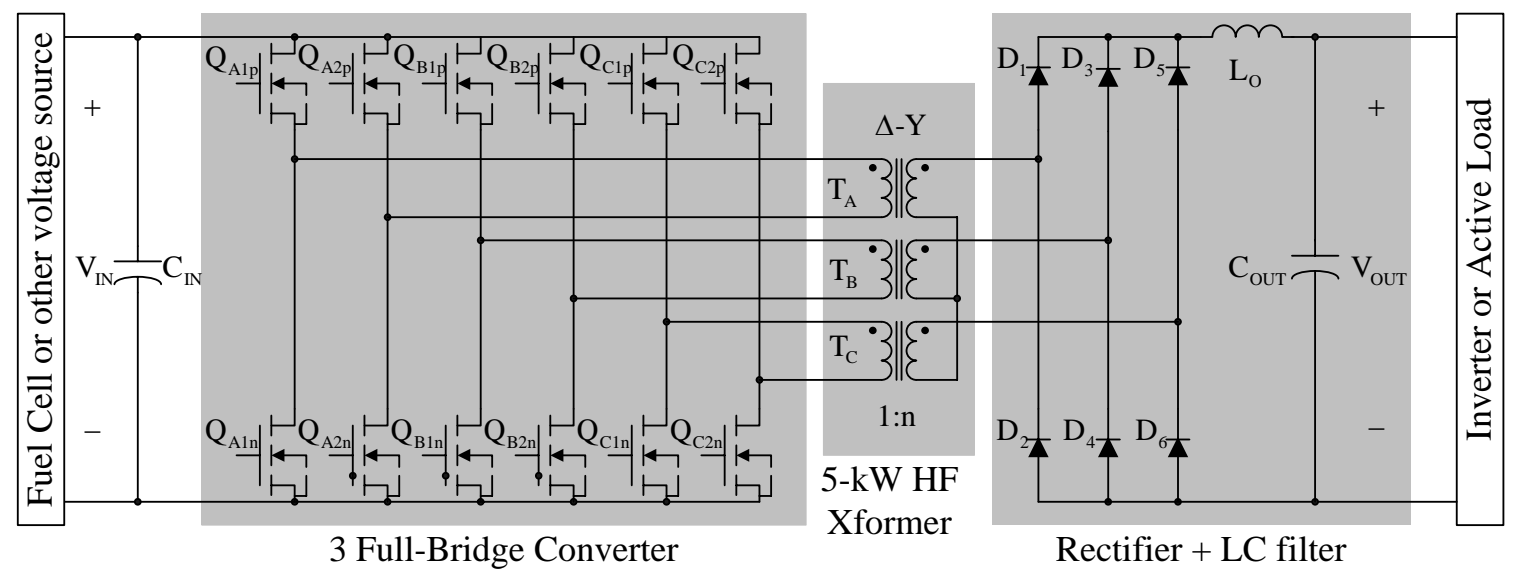

Figure 3.4 - V6 converter: three full-bridge, $\Delta$-Y transformer isolated converter

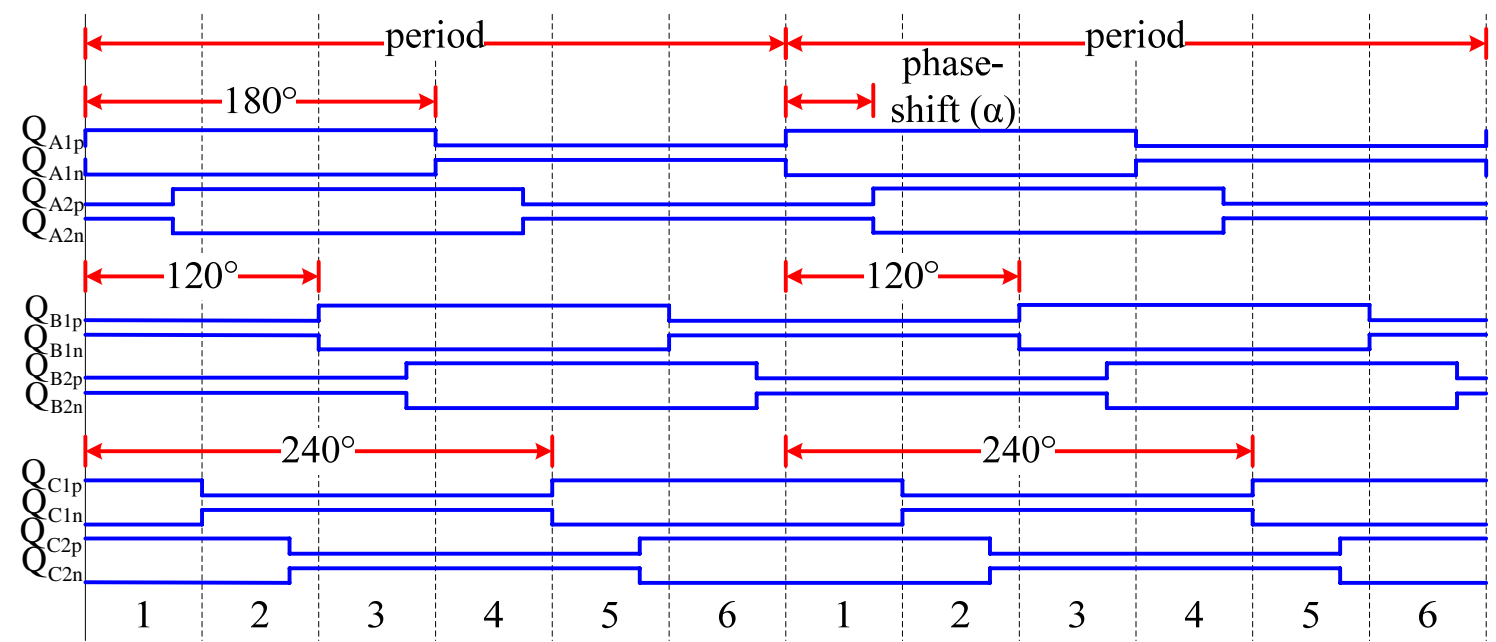

Figure 3.5 - Interleaving phase-shift modulation control signal for V6

The V6 converter consists of twelve switches, three single-phase transformers, six diodes, and a LC filter. Twelve power switches form six phase-legs. A pair of these phase-legs and a single-phase transformer form a full-bridge; therefore, three phases of full-bridges are constructed with the six phase-legs and the three transformers. Also, the 
three single-phase transformers are configured to form an open $\Delta$-connection. Each transformer is separated from other transformers in open $\Delta$-connection, and a total of six terminals are accessible. In a conventional closed $\Delta$-connection, three transformers form an enclosure and only three terminals are accessible. The secondary side is configured in a Y-connection, thus the three single-phase transformers can be said to be in an open $\Delta$-Y configuration. Once the transformers convert voltage to a desired level, the transformer outputs are rectified with a three-phase full-bridge rectifier, which is formed with six diodes. Then, the rectified output is filtered with the LC filters, and DC output voltage is generated.

Three full-bridges represent three phases, and phases are denoted as A, B and C. Leading leg is referred as leg 1 , and lagging leg is referred as leg 2. For each leg, the upper device is indicated with $\mathrm{p}$, while the lower device is indicated with $\mathrm{n}$. Therefore, the upper device in leading leg of phase $A$ is denoted as $Q_{A 1 p}$. Other devices follow the same naming convention.

Figure 3.5 illustrates the interleaving phase-shift modulation control signal for V6. A phase-shift modulation (PSM) is used to control each phase. In PSM, the switches of each leg turn on and off alternately with $50 \%$ duty ratio, and the phase-shift, $\alpha$, is introduced between a leading leg and a lagging leg to control the operating duty cycle of the converter. A definition of the leading and the lagging leg is given in section 3.3.2. Other phases are governed with the identical PSM signals with $120^{\circ}$ and $240^{\circ}$ phase shift with respect to the first phase. It is also said that control signals are interleaved with $120^{\circ}$ phase shift among them.

A conventional single-phase full-bridge PSM is capable of zero-voltage switching (ZVS) operation. V6 inherits ZVS operation and additionally achieves zero-current switching (ZCS) operation. Detailed soft-switching mechanism is covered in section.3.5.2 


\subsubsection{Multiphase coupled transformer VS. single-phase non-coupled transformers}

In both V3 and V6, three single-phase transformers are used to configure a threephase transformer, instead of using one coupled three-phase transformer. Coupled transformers certainly offer several advantages:

- Flux is coupled among phases inside a magnetic core. Since the flux is coupled, the flux from different phases can cancel each other out. This means that the coppers and cores of a transformer are used more effectively, and the transformer can be made smaller and light for the same power handling capability.

- A smaller transformer structure reduces the core loss, because the total volume of the core is reduced.

- If there is any circulating current, the flux coupling can be utilized to minimize the circulating current.

However, the construction of a three-phase transformer from several single-phase transformers offers different types of advantages:

- Single-phase transformers can be versatile and configured to one's need on the spot. For an instance, three single-phase transformers can be configured to any of three-phase setting, $\Delta-\Delta, \Delta-\mathrm{Y}, \mathrm{Y}-\mathrm{Y}$, or $\mathrm{Y}-\Delta$. Meanwhile, coupled transformers must be constructed to the desired configuration.

- The design and the construction of a single-phase transformer is much simpler than a multiphase transformer.

- Analysis of steady-state operating mode is also easier with non-coupled transformers.

Although coupled three-phase transformers offer advantages listed above, a lack of appropriate three-phase transformers and design difficulty restrained from its usage. Also, the flexibility of single-phase transformer was attractive. Such reasons influenced 
to construct three-phase transformers from separate individual transformers, rather than using coupled multiphase transformer.

\subsection{Converter Operating Modes}

Single-phase converters, such as buck converters, generally only have one mode of operation regardless of duty cycle, assuming these only operate under a continuous conduction mode (CCM). However, when multiphase dc-dc converters are implemented using an interleaving control scheme, more than one mode of operation can occur. As duty cycle or phase shift angle crosses operating mode boundaries, the converter's operating principles change and different phenomenon may result.

In this section, the operating mode boundaries are identified, and the steady-state operating principal of each mode is examined and evaluated in section 3.5.

\subsubsection{V3 operating modes}

A three-phase interleaved asymmetrical PWM duty cycle controls the V3. The individual phase of V3 can be viewed as a half-bridge, and typically a symmetrical duty cycle is utilized in a single-phase half-bridge topology. In the single-phase half-bridge topology, such as shown in section 2.1.2, an asymmetrical duty cycle causes volt-second to unbalance, which causes transformer magnetizing current to saturate. Additionally, the saturating current causes unbalanced voltage in split dc capacitors as well. However, the asymmetrical duty cycle does not cause the volt-second to unbalance in the transformers in V3. Figure 3.19 in section 3.5.1.2 and Figure 3.27 in section 3.5.1.4 illustrate voltage across transformers, and it can be easily seen that the volt-second across transformer is balanced.

The symmetrical duty cycle and the asymmetrical duty cycle are briefly compared in Figure 3.6. In symmetrical duty cycle, one of two switches in a phase-leg is in on-state for the duration of duty cycle. At the end of duty cycle, the switch turns off, and both switches in the phase-leg is in off-state. At the half of the period, the opposite side device turns on and operate the same manner as previously. In the asymmetrical duty 
cycle, when the upper switch in a phase-leg is in on-state, the lower switch is in off-state, and vice versa. Therefore, one and only one switch is in on-state at any time.

The asymmetrical PWM control allows duty cycle control from 0 to 1 , unlike the symmetrical PWM control, which only allows duty cycle control from 0 to $1 / 2$. When duty cycle exceeds $1 / 2$ with the symmetrical PWM control, a shoot-through condition, where both upper and lower switching devices in a phase-leg turn on at the same time, occurs. However, the asymmetrical duty cycle does not shoot-through regardless of duty cycle, since opposite side device in a phase-leg always complements the other.

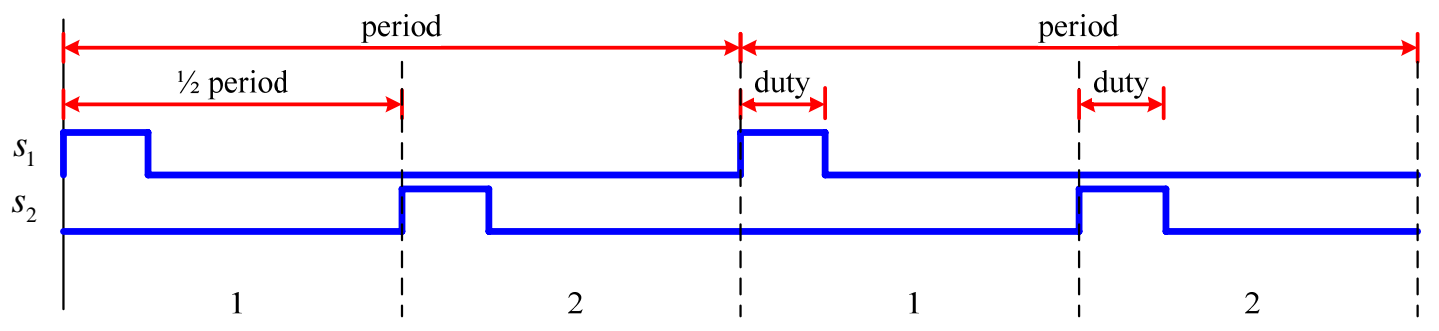

(a) Symmetrical duty cycle

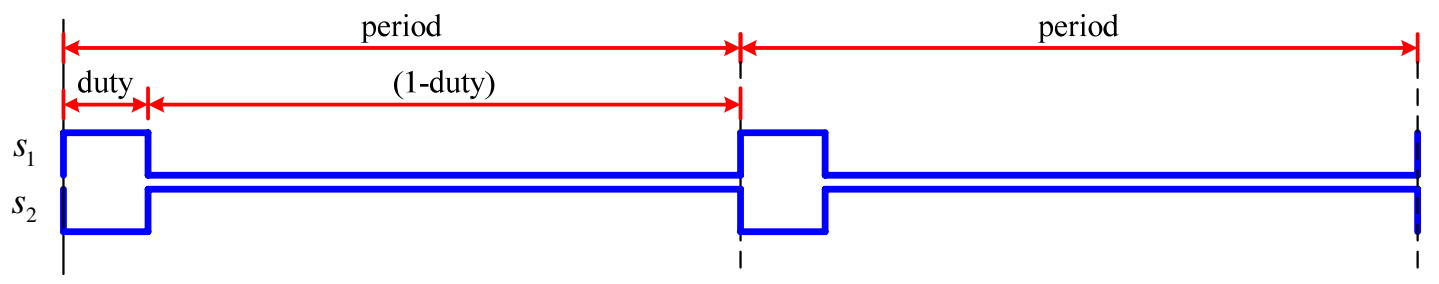

(b) Asymmetrical duty cycle

Figure 3.6 - Comparison between symmetrical and asymmetrical duty cycle

As the asymmetrical duty cycle of V3 changes from 0 to 1 , three operating regions can be identified based on the duty cycle: $0<\mathrm{D}<1 / 3,1 / 3<\mathrm{D}<2 / 3$, and $2 / 3<\mathrm{D}<1$. In the first operating region, $0<\mathrm{D}<1 / 3$, output voltage increases linearly from $0 \mathrm{~V}$ to $\mathrm{n} \cdot \mathrm{V}_{\mathrm{IN}}$ as the duty cycle increases from 0 to $1 / 3$, where $n$ is transformer turns ratio and $V_{\text {IN }}$ is input voltage. In the second operating region, $1 / 3<D<2 / 3$, the output voltage remains at $n \cdot V_{\text {IN }}$ regardless of the duty cycle. In the third operating region, $2 / 3<D<1$, the output voltage decreases linearly from $n \cdot V_{\text {IN }}$ to 0 as the duty cycle increases from $2 / 3$ to 1 . The first region and the third region, where the output voltage can be regulated with the duty cycle control can be called "regulated converter mode." The second region, where the output 
voltage remains the same regardless of the duty cycle can be called "dc transformer mode."

The operating principal of the regulated converter mode is the same in both first region and third region. Operating in the third region, where the output voltage decreases as the duty cycle increases, makes control design different from convention. Therefore, the duty cycle is typically limited to 0.5 , and the converter is prevented from entering the third region. Figure 3.7 illustrates conversion ratio and operating modes of V3.
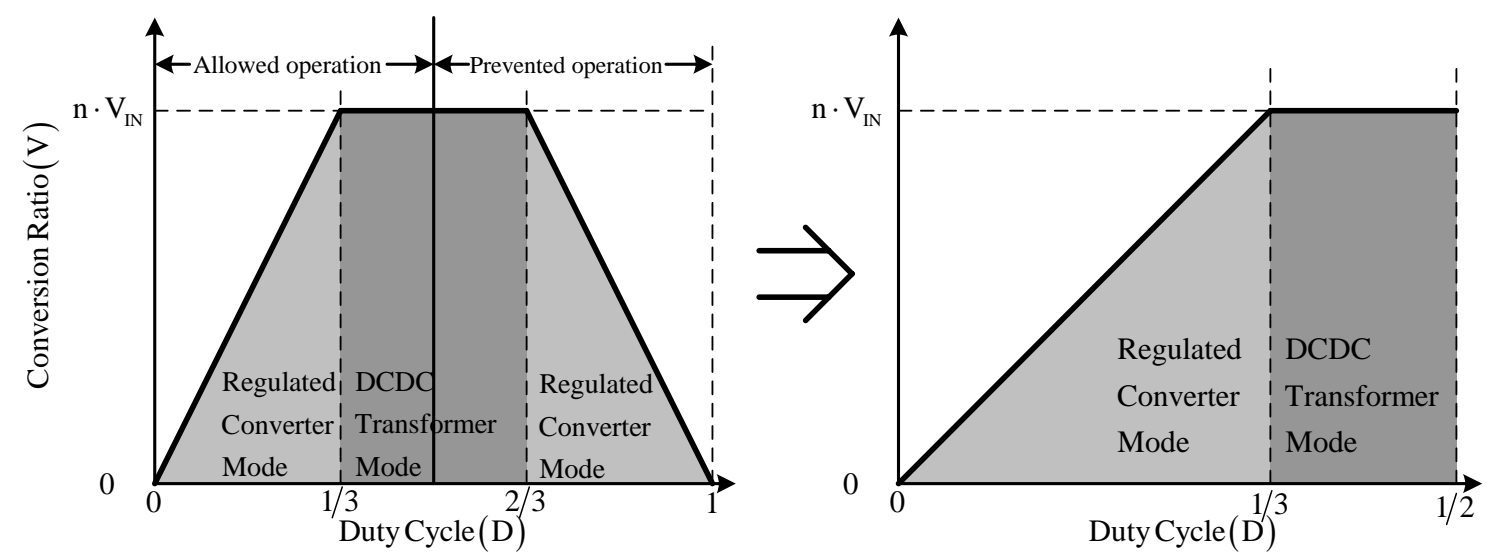

Figure 3.7 - V3 conversion ratio and operating modes

\subsubsection{V6 operating mode}

A three-phase interleaved phase-shift modulation (PSM) controls V6. In the PSM control, the definition of a leading leg and a lagging leg is often differ in different literatures. Therefore, Figure 3.8 defines the convention of the leading leg and the lagging leg for this thesis.

As time travels from left to right in Figure 3.8, the leading leg starts or "leads" switching actions at the beginning of the period. Then the lagging leg follows or "lags" the switching actions of the leading leg. Some literatures, such as [12], uses opposite definition. 


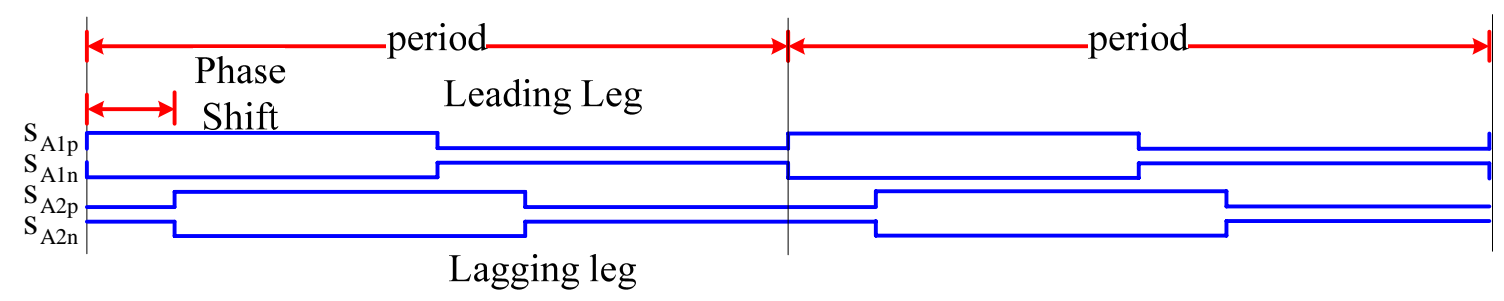

Figure 3.8 - Phase-shift modulation leading and lagging leg definition

PSM is capable of phase-shift modulation angle from $0^{\circ}$ to $360^{\circ}$; however, for the same reason as V3, modulation angle is limited to $180^{\circ}$. Figure 3.9 illustrates conversion ratio and operating modes of $\mathrm{V} 6$, and the conversion ratio mirror at the $180^{\circ}$ modulation angle, and the control of the modulation angle is typically limited to below $180^{\circ}$.

Operating mode of V6 can be analyzed for three cases based on the phase shift modulation angle, $\alpha$ : $0^{\circ}<\alpha<60^{\circ}, 60^{\circ}<\alpha<120^{\circ}$, and $120^{\circ}<\alpha<180^{\circ}$. In the $0^{\circ}<\alpha<60^{\circ}$ case, output voltage increases linearly from $0 \mathrm{~V}$ to $\mathrm{n} \cdot \mathrm{V}_{\mathrm{IN}}$ as the modulation angle increases from $0^{\circ}$ to $60^{\circ}$, where $\mathrm{n}$ is transformer turns ratio and $\mathrm{V}_{\mathrm{IN}}$ is input voltage. In the $60^{\circ}<\alpha<120^{\circ}$ case, the output voltage increases linearly from $n \cdot V_{\text {IN }}$ to $2 \cdot n \cdot V_{\text {IN }}$ as the modulation angle increases from $60^{\circ}$ to $120^{\circ}$. In the $120^{\circ}<\alpha<180^{\circ}$ case, the output voltage remains at $2 \cdot n \cdot V_{\text {IN }}$ regardless of the modulation angle. The first and the second regions are referred as "regulated converter mode 1" and "regulated converter mode 2", respectively. The third region is referred as "dc transformer mode".
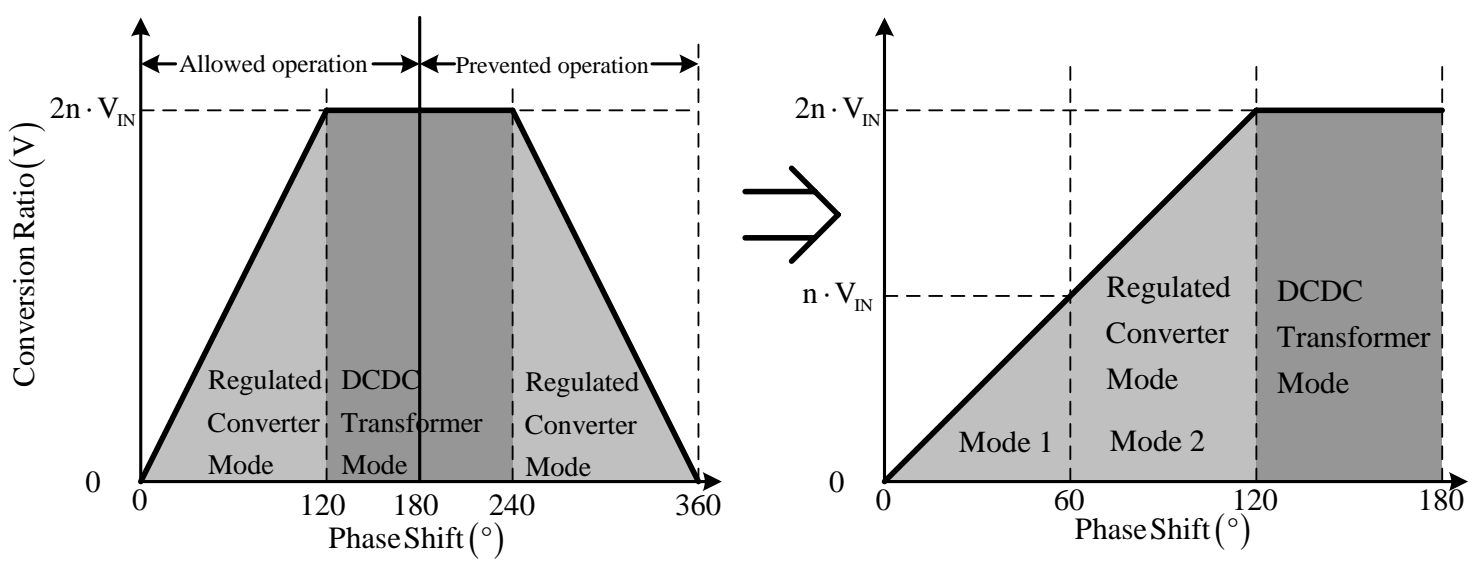

Figure 3.9 - V6 conversion ratio and operating modes 


\subsection{Ideal switch and transformer model}

To analyze steady-state operation, several assumptions are made:

- All components are ideal;

- A MOSFET is modeled with an ideal switch, an anti-parallel body-diode, and a device output capacitor;

- A transformer is modeled with an ideal transformer and a leakage inductor; and

- The inductor in output stage is large enough to be treated as a constant current source during a switching period.

V3 switch model of Figure 3.2 is modeled as Figure 3.10, with ideal switch and transformer models.

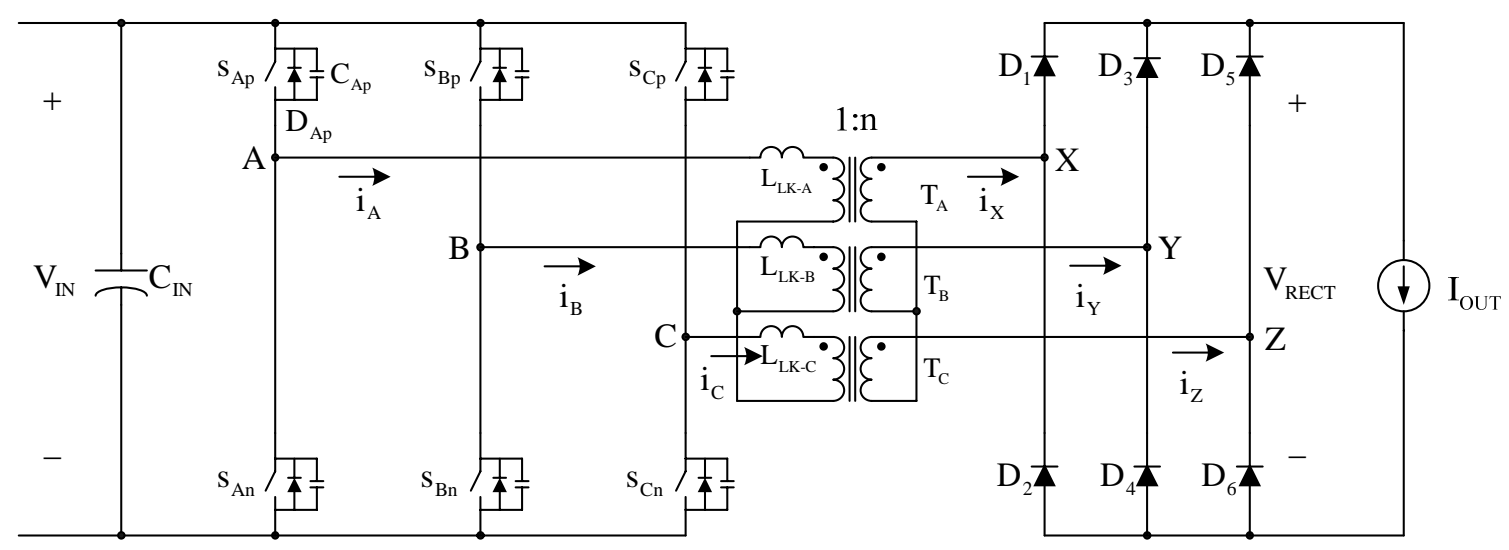

Figure 3.10 - V3 ideal switch and transformer model

MOSFET $\mathrm{Q}_{\mathrm{Ap}}$ is replaced with an ideal switch $\mathrm{s}_{\mathrm{Ap}}$, a body diode $\mathrm{D}_{\mathrm{Ap}}$, and a device output capacitor $\mathrm{C}_{\mathrm{Ap}}$, and remaining switches follow the case. The midpoints of phaselegs are labeled $A, B$ and $C$, and the currents $i_{A}, i_{B}$ and $i_{C}$ flow out from the midpoints into the transformers. Phase A transformer consists of an ideal transformer, $\mathrm{T}_{\mathrm{A}}$, and a leakage inductor, $\mathrm{L}_{\mathrm{LK}-\mathrm{A}}$, and remaining transformer also follow the case. Transformer outputs are labeled X, Y, and Z, and are rectified with a full bridge diodes, which consists of diodes $\mathrm{D}_{1}$ through $\mathrm{D}_{6}$. $\mathrm{V}_{\mathrm{RECT}}$ is the voltage after the rectifier, and $\mathrm{I}_{\mathrm{OUT}}$ is load current. 
V6 switch model of Figure 3.4 is modeled as Figure 3.11 with ideal switch and transformer models.

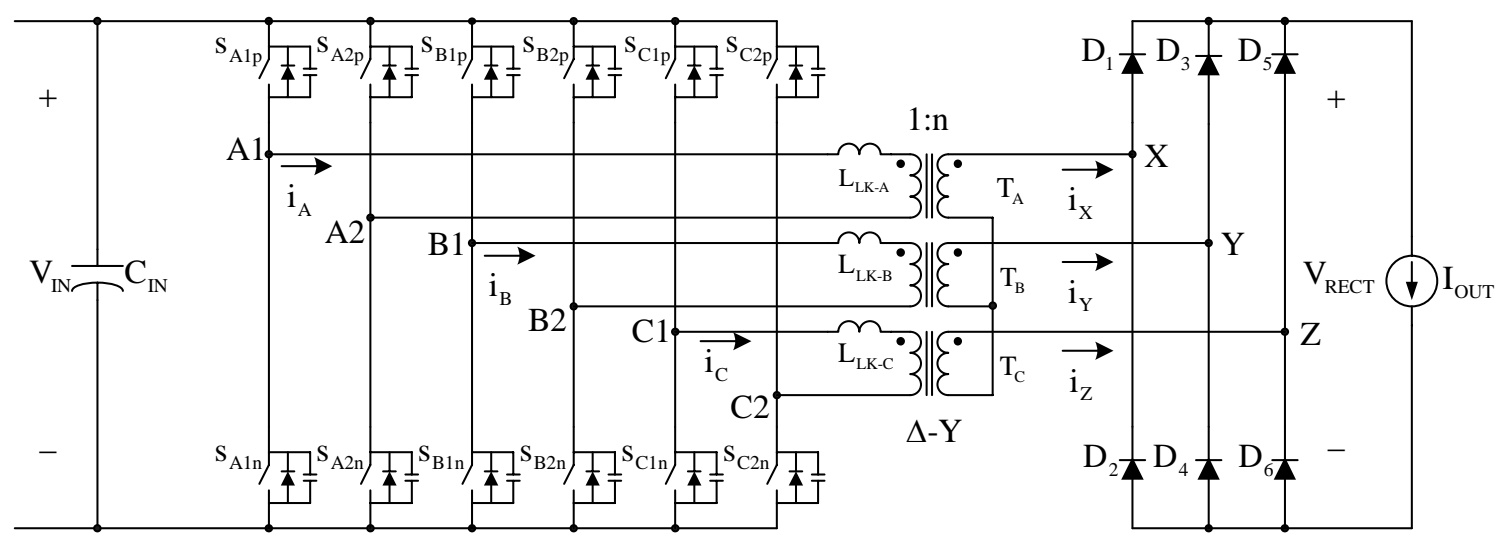

Figure 3.11 - V6 ideal switch and transformer model

MOSFET $\mathrm{Q}_{\mathrm{A1p}}$ is replaced with an ideal switch $\mathrm{s}_{\mathrm{A} 1 \mathrm{p}}$, a body diode $\mathrm{D}_{\mathrm{A} 1 \mathrm{p}}$, and a device output capacitor $\mathrm{C}_{\mathrm{A} 1 \mathrm{p}}$, and remaining switches follow the case. The midpoints of the leading and the lagging legs in phase $A$ are labeled $A_{1}$ and $A_{2}$, respectively, and current $\mathrm{i}_{\mathrm{A}}$ flows from $\mathrm{A}_{1}$ to $\mathrm{A}_{2}$. Remaining phases follow the case. Phase A transformer consists of an ideal transformer, $\mathrm{T}_{\mathrm{A}}$, and a leakage inductor, $\mathrm{L}_{\mathrm{LK}-\mathrm{A}}$, and remaining transformers follow the case. Transformer outputs are labeled X, Y, and Z, and are rectified with a full bridge diodes, which consists of $\mathrm{D}_{1}$ through $\mathrm{D}_{6}$. $\mathrm{V}_{\mathrm{RECT}}$ is the voltage after the rectifier, and $\mathrm{I}_{\mathrm{OUT}}$ is load current. 


\subsection{Operating principles}

When transformer windings are connected together in multiphase converters, current and/or voltage coupling between the windings causes interactions among phases. The interactions are determined by the duty cycle or the phase-shift angle of V3 or V6, respectively.

In order to easily identify how the duty cycle or the phase-shift angle determines the converter status and the phase interaction, a switching vector is assigned. Both V3 and V6 utilize complementary gate signals for each phase-leg. When a upper switch is in onstate, the leg switching status is defined as 1, and when a lower switch is in on-state, the leg switching status is defined as 0 . The leg switching status when both upper and lower switches are in on-state is prohibited, since a shoot-through condition occurs. The status of both switches are in off-state is defined as deadtime, and the leg switching status is defined as $\mathrm{X}$.

\subsubsection{V3 operating principles}

V3 can operate in two different operating modes, dc transformer mode and regulated converter mode. The operating principles in each mode is different and is explained in following sections.

\subsubsection{V3 dc transformer mode: $(1 / 3 \leq \mathrm{D} \leq 2 / 3)$}

Figure 3.12 illustrates V3 gate signals and switching vectors for the dc transformer mode. Along with nominal switching states, deadtime switching states are included to reflect transitions between nominal states. A period can be divided into a total of 12 stages, which consist of 3 cycles of 4 stages, and each stage starts and ends with a switch either turns on or turns off. Figure 3.13 partitions the switching vectors into cycles and stages for the dc transformer mode. The operating principles of each cycle are identical. The difference between cycles is that phase current and voltage status is shifted to next phase during following cycles. 


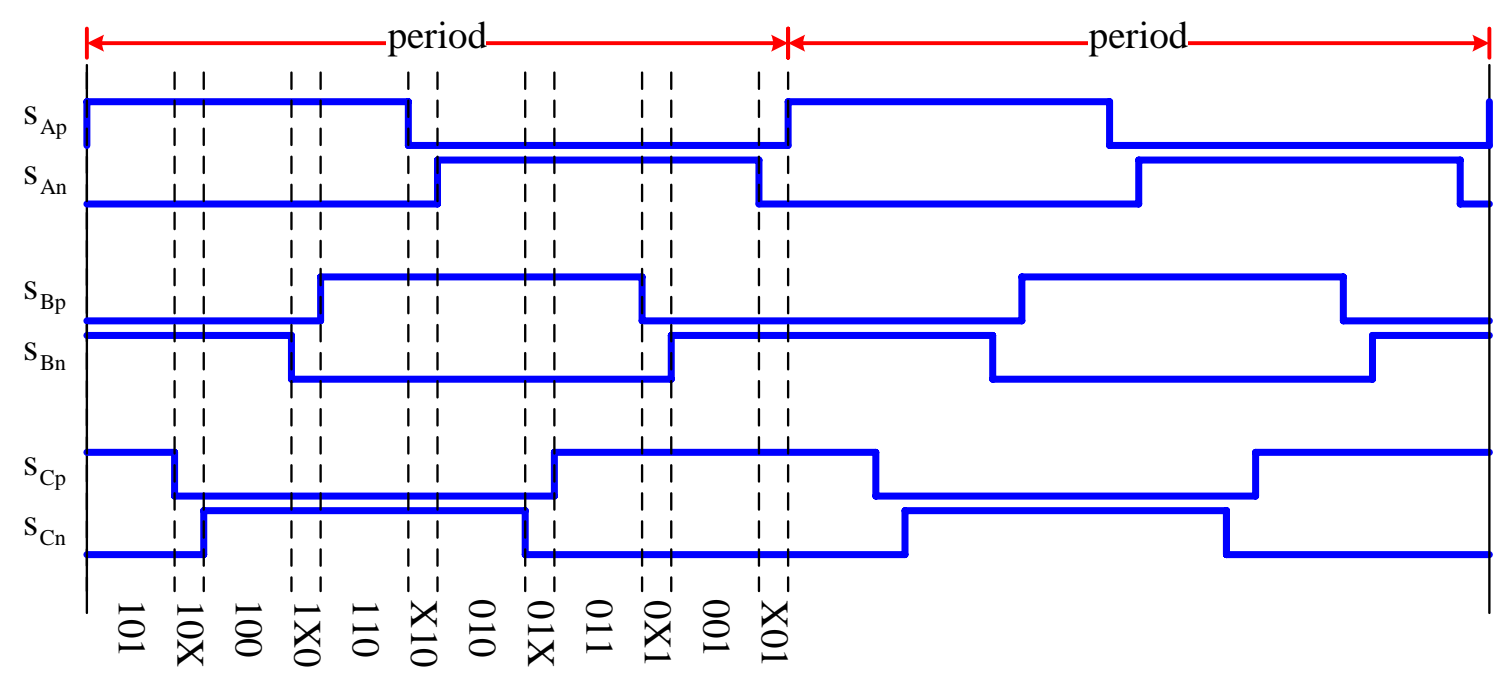

Figure 3.12 - V3 gate signals and switching vectors for dc transformer mode

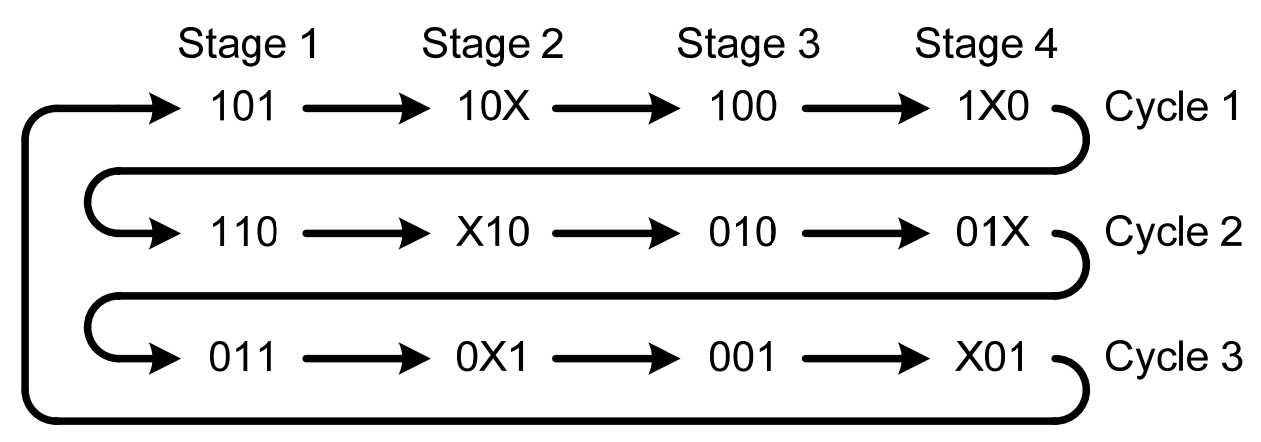

Figure 3.13 - V3 switching vector cycle: dc transformer mode 
1) V3 dc transformer mode - Cycle 1, Stage 1: switch vector (101)

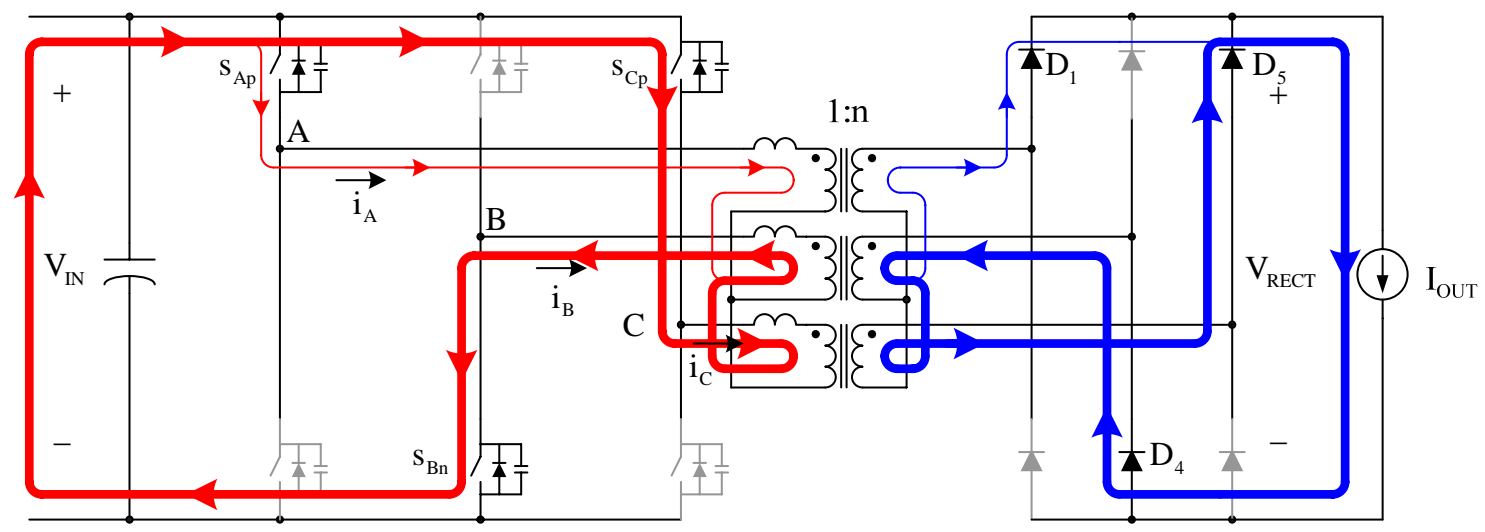

Figure 3.14 - V3 equivalent circuit: dc transformer mode - cycle 1, stage 1

- As shown in the equivalent circuit of Figure 3.14, two phases (phase A and C) are connected to the positive dc input rail, and current $\left(\mathrm{i}_{\mathrm{A}}\right)$ and $\left(\mathrm{i}_{\mathrm{C}}\right)$ flow in the positive direction. The remaining phase (phase B) is connected to the negative dc input rail and current $\left(i_{B}\right)$ flows in the negative direction.

- The phase that is connected to dc rail by itself (phase B) must let the entire reflected load current $\left(\mathrm{I}_{\mathrm{OUT}} / \mathrm{n}\right)$ through the switch connected to the dc rail $\left(\mathrm{s}_{\mathrm{Bn}}\right)$. The other two phases (phase A and C) are connected to the other side of dc rail in parallel, and the parallel conduction paths are provided through two switches ( $\mathrm{s}_{\mathrm{Ap}}$ and $\left.\mathrm{s}_{\mathrm{Cp}}\right)$.

- The paralleled paths suggest that the reflected output current could be equally shared between two paths; however, it is usually not the case. In the previous stage, the switch vector was (001), and the phase $C$ was connected to the positive dc rail by itself, and the phase $\mathrm{C}$ was conducting the entire reflected output current. Also, phase A was conducting in the negative direction through a lower switch $\left(\mathrm{s}_{\mathrm{An}}\right)$. When vector changes from (001) to (101) of the present stage, the transformer leakage inductance maintains full reflected phase currents from the previous stage in the phase $\mathrm{C}$. Meanwhile, the negative current in the phase $\mathrm{A}$ is reset to zero.

- Therefore, in the beginning of the present stage, the currents are unbalanced between two phases (phase A and C), where the phase A conducts a negligible 
amount of currents and the phase C conducts majority of currents. However, if the value of the leakage inductance is sufficiently small, the current between phase $\mathrm{A}$ and $\mathrm{C}$ can balance out by the end of the stage.

- During this stage, one phase is connected to one side of the dc input rail, and other two phases are connected to the opposite side dc input rail. This state causes uneven voltage distributions between phases, and Figure 3.15 illustrates the voltage distributions among phases during this condition. The phases that share the dc rail see one-third of input voltage, while the remaining one phase sees twothird of the input voltage.

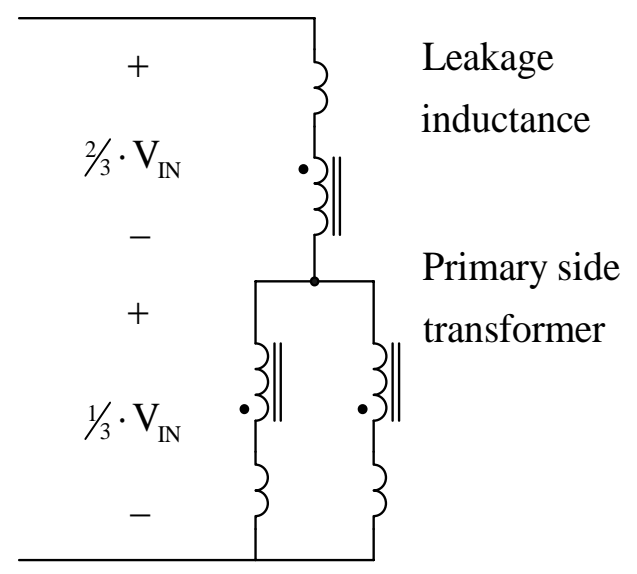

Figure 3.15 - Voltage distribution among phases

- As a result of the uneven distribution of voltage and current, the phase that is connected to the dc rail by itself (phase B) transmits two-third of input power, and the remaining two phases (phase $\mathrm{A}$ and $\mathrm{C}$ ) transmit the remaining third. If the phase A only conducts a negligible amount of currents, then the phase $\mathrm{C}$ transmits majority of one third.

- Input voltage $\left(\mathrm{V}_{\mathrm{IN}}\right)$ is applied across the primary side of Y-connection transformer, and the induced voltage on the secondary side of the Y-connection transformer causes $D_{1}, D_{4}$ and $D_{5}$ to be forward biased, and produces $n \cdot V_{\text {IN }}$ at the rectified output, $\mathrm{V}_{\mathrm{RECT}}$. 
2) V3 dc transformer mode - Cycle 1, Stage 2: switch vector (10X)

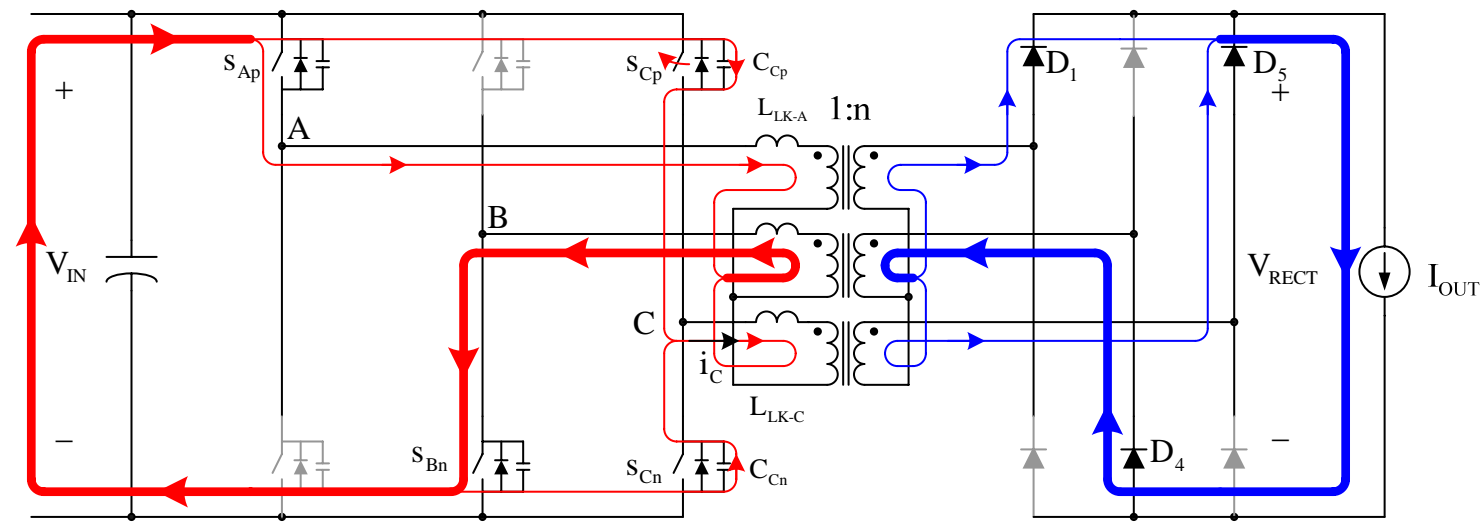

Figure 3.16 - V3 equivalent circuit: dc transformer mode - cycle 1, stage 2

- At the beginning of the stage, the upper switch $\left(\mathrm{s}_{\mathrm{Cp}}\right)$ turns off. The phase current (ic) continues to flow while the switch turns off, and the switching condition is considered to be hard turn-off.

- When the upper switch $\left(\mathrm{s}_{\mathrm{Cp}}\right)$ is turned off, equivalent transformer leakage inductances $\left(\mathrm{L}_{\mathrm{eq}}\right)$ start to resonate with equivalent switch output capacitances $\left(\mathrm{C}_{\mathrm{eq}}\right)$, and the resonance discharges the opposite side device output capacitance $\left(\mathrm{C}_{\mathrm{Cn}}\right)$. This causes the phase midpoint voltage $\left(\mathrm{V}_{\mathrm{C}}\right)$ to fall from $\mathrm{V}_{\text {IN }}$ to $0 \mathrm{~V}$.

- Resonant elements are the equivalent switch output capacitances, which are the sum of the upper and the lower device output capacitance of the phase $\left(\mathrm{C}_{\mathrm{eq}}=\mathrm{C}_{\mathrm{Cp}}\right.$ $+\mathrm{C}_{\mathrm{Cn}}$ ), and the equivalent transformer leakage inductance, which are the sum of the transformer leakage inductance in the phase A and the phase $\mathrm{C}\left(\mathrm{L}_{\mathrm{eq}}=\mathrm{L}_{\mathrm{LK}-\mathrm{A}}+\right.$ $\left.\mathrm{L}_{\mathrm{LK}-\mathrm{C}} \approx 2 \cdot \mathrm{L}_{\mathrm{LK}}\right)$.

- When the phase midpoint voltage $\left(\mathrm{V}_{\mathrm{C}}\right)$ reaches the ground potential, the remaining current flows through the body diode $\left(D_{C n}\right)$, as shown in the intermediate equivalent circuit in Figure 3.17. 


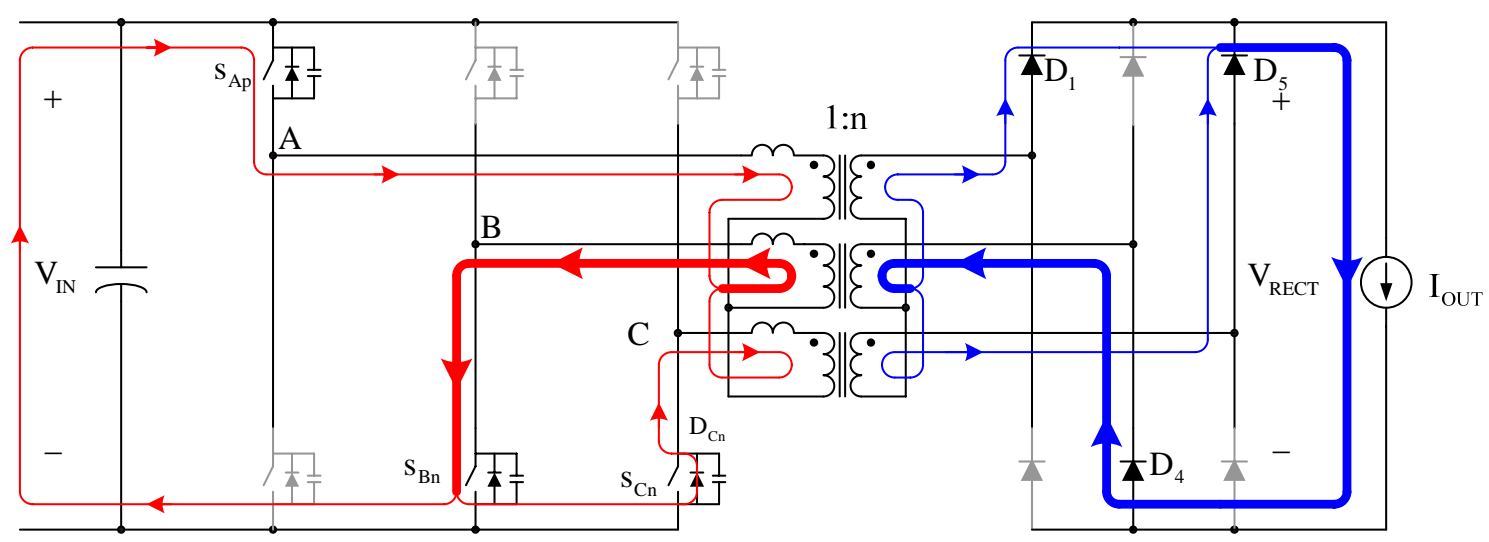

Figure 3.17 - V3 equivalent circuit: dc transformer mode - cycle 1, stage 2, intermediate stage

- During this intermediate transition stage, the rectified output, $\mathrm{V}_{\mathrm{RECT}}$, momentarily falls as low as one-half of $n \cdot V_{\text {IN }}$. This is considered as loss of duty cycle. Because of this occurrence, continual constant output at $\mathrm{V}_{\mathrm{RECT}}$ is momentarily broken. Duration of this low voltage period is determined by the value of leakage inductance. Typically, relative small value of the leakage inductance keeps this period very short, and this condition has negligible impact to the output voltage. 
3) V3 dc transformer mode - Cycle 1, Stage 3: switch vector (100)

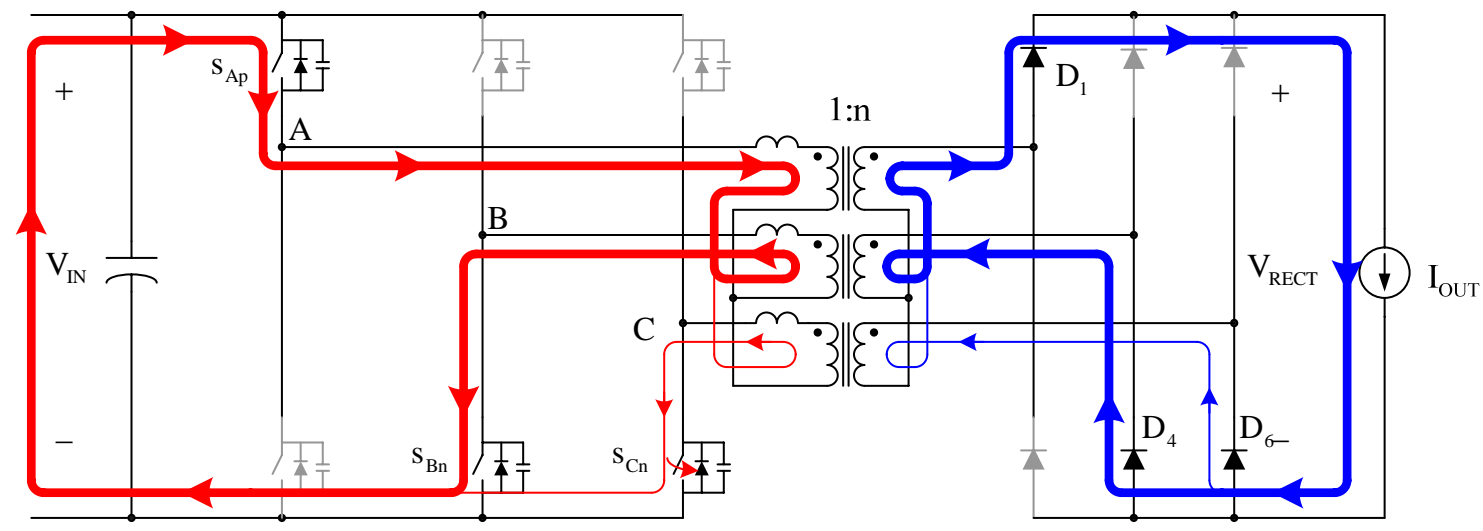

Figure 3.18 - V3 equivalent circuit: dc transformer mode - cycle, stage 3

- At the beginning of the stage, the lower switch $\left(\mathrm{s}_{\mathrm{Cn}}\right)$ turns on. At this time, the voltage across the switch is zero, thus zero-voltage switching (ZVS) turn-on is achieved.

- At this time, the phase A is connected to the positive dc rail, and the other two phases (phase $\mathrm{B}$ and $\mathrm{C}$ ) are connected to the negative dc input rail. The phase $\mathrm{C}$ current ( $\mathrm{i}_{\mathrm{C}}$ ) is reset to zero and the phase A conducts full reflected output currents.

- The condition in this stage is very similar to the stage 1 . Difference is that voltage and current is shifted from one phase to next phase. The switching transition of cycle 1 , stage 3 and cycle 1 , stage 4 follow the identical principles of cycle 1 , stage 1 and cycle 1 , stage 2 , respectively.

- Also cycle 2 follows the identical principle of cycle 1 . In other words, each cycle is identical in the operating principle. 


\subsubsection{V3 dc transformer mode summary}

- Dc transformer mode is present when duty cycle is between $1 / 3$ and $2 / 3$. During this mode, at least one pair of transformer transmits input voltage to output voltage throughout a period, and rectified output is constant voltage, $n \cdot V_{\text {IN }}$, regardless of the duty cycle. Therefore, V3 behaves like a dc-dc transformer. Figure 3.19 shows waveforms during the dc transformer mode.

- ZVS turn-on is achieved on both upper and lower switches.

- The ZVS turn-on is achieved by using the energy stored in the leakage inductance of the transformer to discharge the output capacitance of the switches before turning on. It should be noted that the energy stored in output filter inductor is not used. Therefore, the ZVS condition can be lost during a light load condition.

- Resonant elements are sum of upper and lower device output capacitance of phase (i.e. $\mathrm{C}_{\mathrm{eq}}=\mathrm{C}_{\mathrm{Cp}}+\mathrm{C}_{\mathrm{Cn}}$ ) and equivalent transformer leakage inductance, which includes leakage inductance of two phases (i.e. $\mathrm{L}_{\mathrm{eq}}=\mathrm{L}_{\mathrm{LK}-\mathrm{A}}+\mathrm{L}_{\mathrm{LK}-\mathrm{C}} \approx 2 \cdot \mathrm{L}_{\mathrm{LK}}$ ).

- The switches turn off under hard-switching, and achieve no soft-switching.

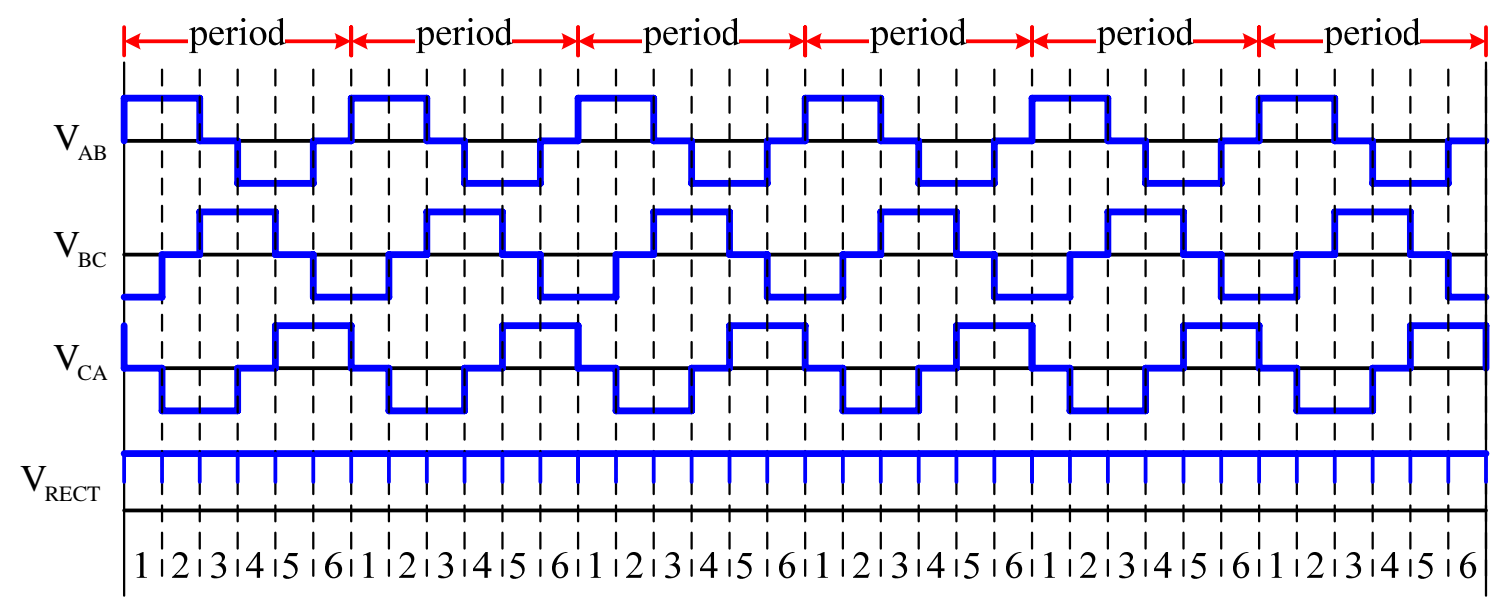

Figure 3.19 - V3 waveforms of three-phase output voltages and rectifier output voltage, $\mathrm{V}_{\mathrm{RECT}}$, in dc transformer mode 


\subsubsection{V3 regulated converter mode $(0 \leq \mathrm{D} \leq 1 / 3)$}

Figure 3.20 illustrates V3 gate signals and switching vectors for the regulated converter mode. Along with nominal switching states, deadtime switching states are included to reflect transitions between nominal states. A period can be divided into a total of 12 stages, which consist of 3 cycles of 4 stages, and each stage starts and ends with a switch either turns on or turns off. Figure 3.21 partitions the switching vectors into cycles and stages for the regulated converter mode. The operating principles in each cycle is. The difference between cycles is that phase current and voltage status is shifted to next phase during following cycles.

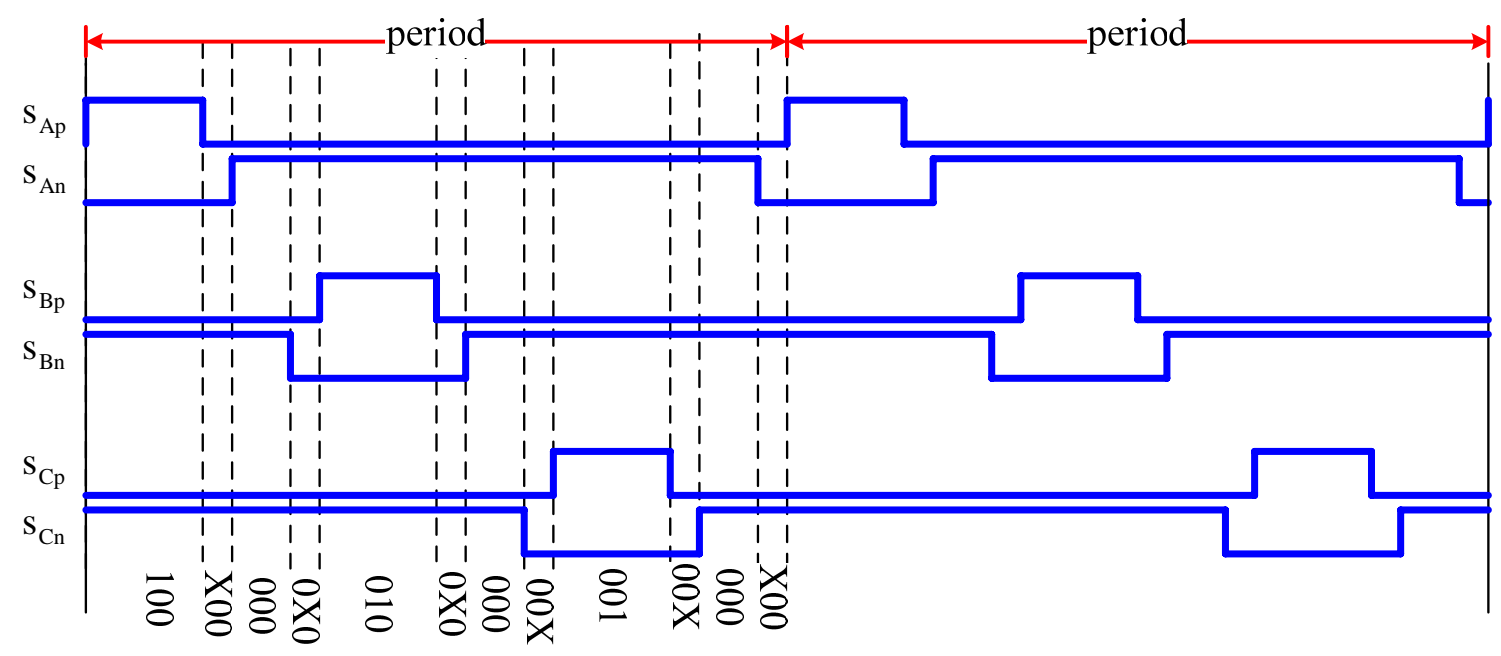

Figure 3.20 - V3 gate signals and switching vectors for regulated converter mode

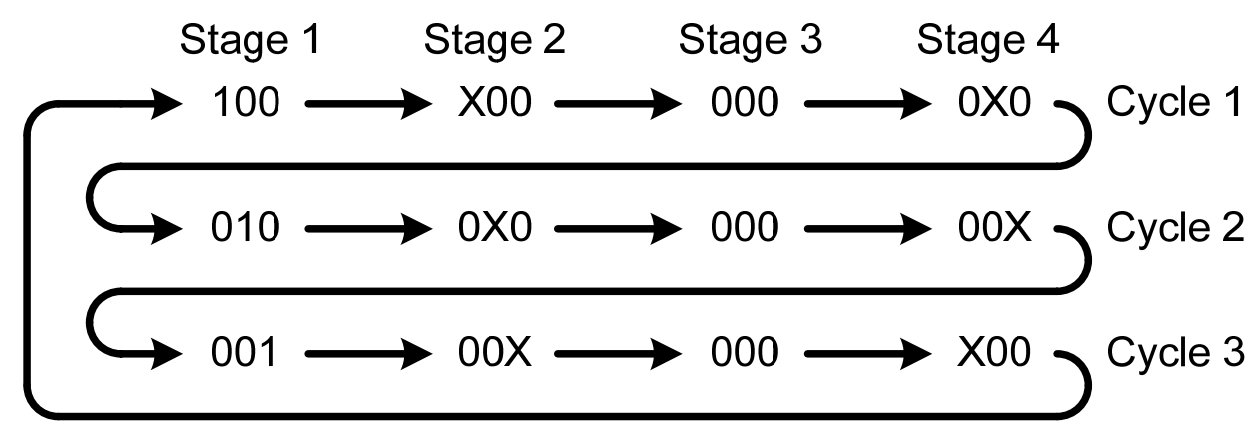

Figure 3.21 - V3 switching vector cycle: regulated converter mode 
1) V3 regulated converter mode - Cycle 1, Stage 1: switch vector (100)

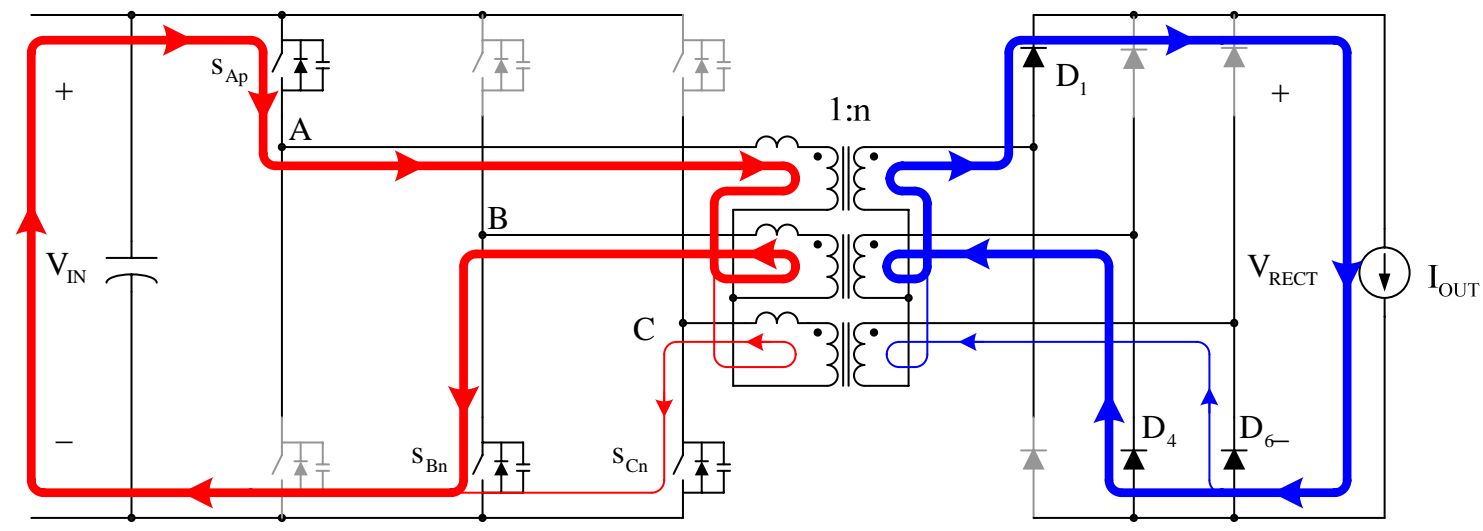

Figure 3.22 - V3 equivalent circuit: regulated converter mode - cycle 1, stage 1

- The equivalent circuit of Figure 3.22 indicates that one phase (phase A) is connected to the positive dc rail, and the other two phases (phase B and C) are connected to the negative dc input rail. (The present status is identical as in dc transformer mode during stage 1 and stage 3.)

- Depends on the amount of transformer leakage inductance, the paralleled paths (phase B and C) may or may not share the reflected current. In the case of small leakage inductance, the phase current is shared. On the other case of large leakage inductance, the phase current is unbalanced such that phase B conducts most of the current.

- The stage sees uneven voltage distribution between phases (see Figure 3.15). As a result of uneven distribution of voltage and current, individual phase delivers different amount power.

- $\quad D_{1}, D_{4}$ and $D_{6}$ are forward biased and conducting, and rectified output, $V_{R E C T}$, is $n \cdot V_{\text {IN }}$. 
2) V3 regulated converter mode - Cycle 1, Stage 2: switch vector (X00)

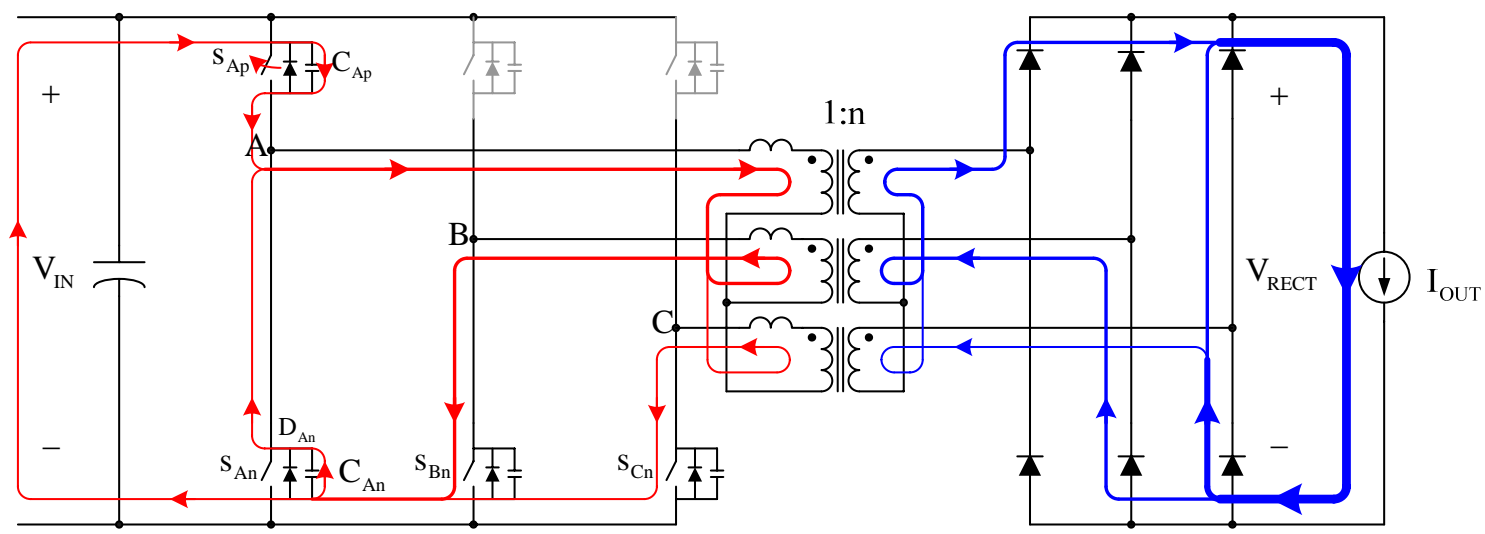

Figure 3.23 - V3 equivalent circuit: regulated converter mode - cycle 1, stage 2

- At the beginning of the stage, an upper switch $\left(\mathrm{s}_{\mathrm{Ap}}\right)$ turns off. The phase current continues to flow while the switch turns off, and soft-switching can not be achieved.

- When the upper switch $\left(\mathrm{s}_{\mathrm{Ap}}\right)$ is turned off, the current through the transformer primary is the output current reflected to the primary. Therefore, the energy of the large filter inductor in the secondary is used to discharge the opposite side device output capacitance $\left(\mathrm{C}_{\mathrm{An}}\right)$. The midpoint voltage $\left(\mathrm{V}_{\mathrm{A}}\right)$ drops from $\mathrm{V}_{\mathrm{IN}}$ to 0 V.

- When the switch output capacitances are fully discharged, circulating current continues to flow through body diode $\left(\mathrm{D}_{\mathrm{An}}\right)$. At this time, voltage across all the primary side transformers becomes zero, and power does not transfer to output. 
3) V3 regulated converter mode - Cycle 1, Stage 3: switch vector (000)

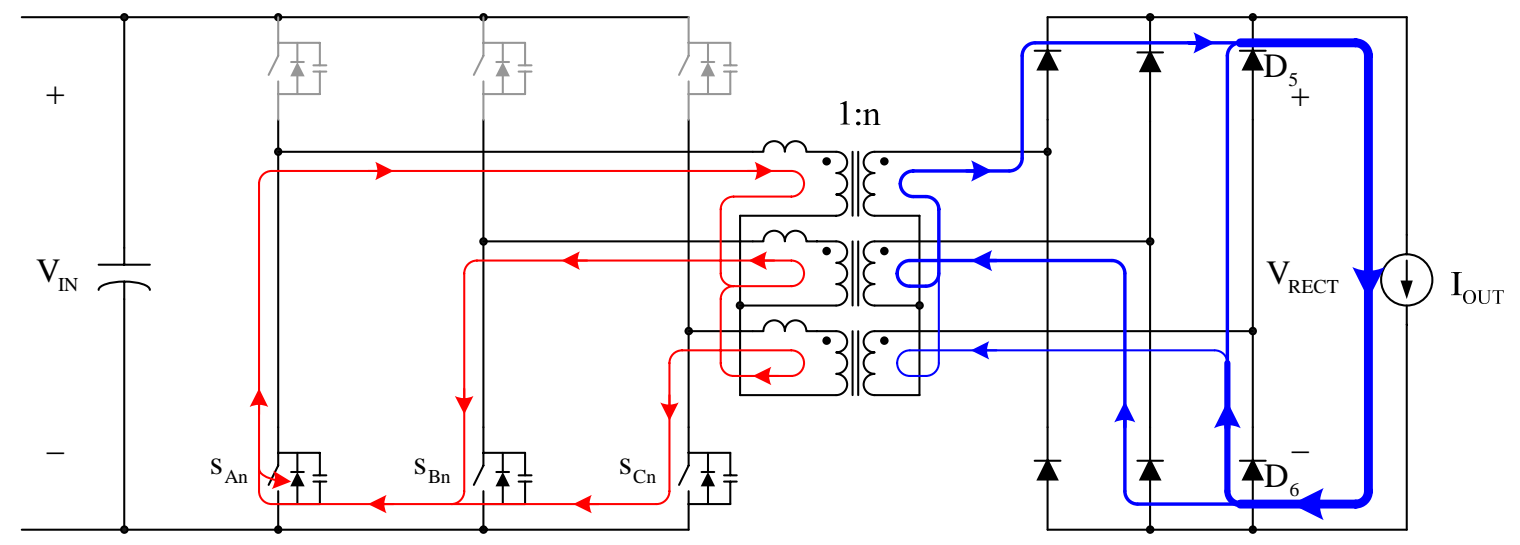

Figure 3.24 - V3 equivalent circuit: regulated converter mode - cycle 1, stage 3

- At the beginning of the stage, a lower switch ( $\left.\mathrm{s}_{\mathrm{An}}\right)$ turns on. Voltage across the switch is zero, and zero-voltage switching (ZVS) turn-on is achieved.

- The transformer leakage inductance holds the reflected output current during freewheeling period. Conduction loss dissipates energy without delivering power to the load.

- All the rectifier diodes are forward biased. Circulating current in the primary reflects to secondary through transformers, and it forces more current through some of rectifier diodes than others. The difference between the reflected circulating current and output current, Iout, freewheels through $\mathrm{D}_{5}$ and $\mathrm{D}_{6}$. Rectified output voltage, $\mathrm{V}_{\mathrm{RECT}}$, is $0 \mathrm{~V}$. 
4) V3 regulated converter mode - Cycle 1, Stage 4: switch vector (0X0)

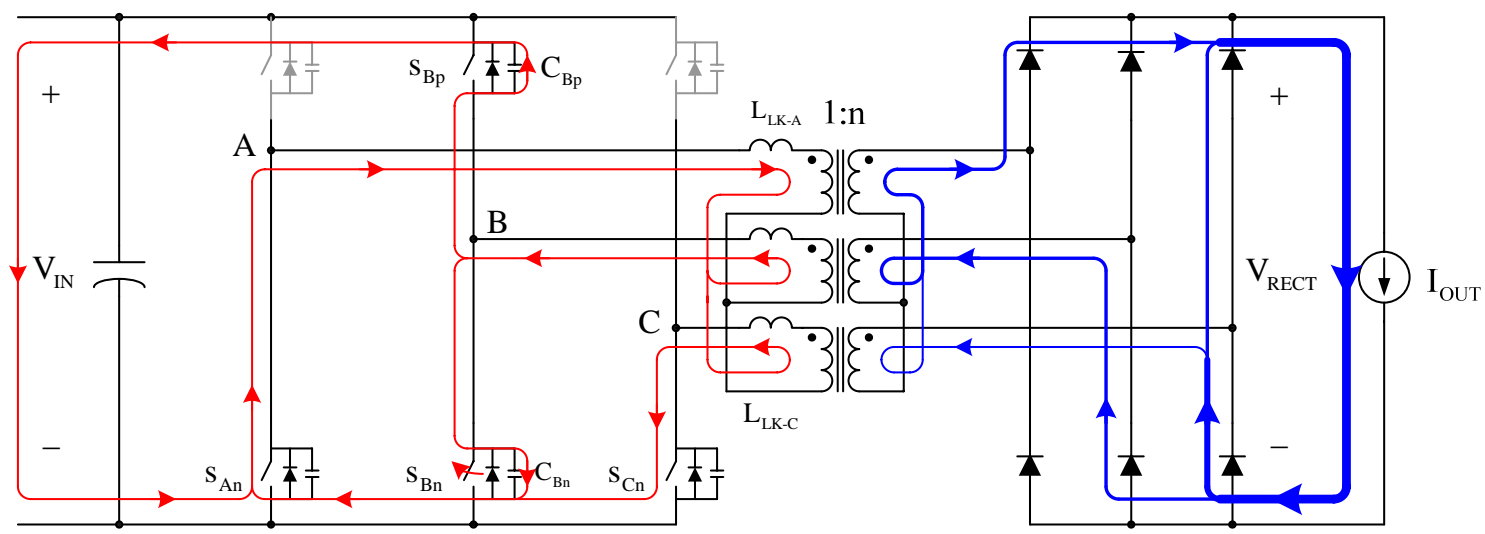

Figure 3.25 - V3 equivalent circuit: regulated converter mode - cycle 1, stage 4

- At the beginning of the stage, a lower switch $\left(\mathrm{s}_{\mathrm{Bn}}\right)$ turns off. The phase current continues to flow while the switch turns off, and soft-switching can not be achieved.

- When the switch $\left(\mathrm{s}_{\mathrm{Bn}}\right)$ is turned off, the transformer equivalent leakage inductances $\left(\mathrm{L}_{\mathrm{eq}}\right)$ start to resonate with switch output capacitances $\left(\mathrm{C}_{\mathrm{eq}}\right)$, and the resonance discharges the opposite side device output capacitance $\left(\mathrm{C}_{\mathrm{Bp}}\right)$. This causes the phase midpoint voltage $\left(\mathrm{V}_{\mathrm{B}}\right)$ to rise from $0 \mathrm{~V}$ to $\mathrm{V}_{\mathrm{IN}}$.

- Resonant elements are capacitance sum of upper and lower device output capacitor $\left(\mathrm{C}_{\mathrm{eq}}=\mathrm{C}_{\mathrm{Bp}}+\mathrm{C}_{\mathrm{Bn}}\right)$ and equivalent transformer leakage inductance $\left(\mathrm{L}_{\mathrm{eq}}=\right.$ $\left.\mathrm{L}_{\mathrm{LK}-\mathrm{B}}+\left(\mathrm{L}_{\mathrm{LK}-\mathrm{C}} \| \mathrm{L}_{\mathrm{LK}-\mathrm{C}}\right) \approx 1.5 \cdot \mathrm{L}_{\mathrm{LK}}\right)$. 
5) V3 regulated converter mode - Cycle 2, Stage 1: switch vector (010)

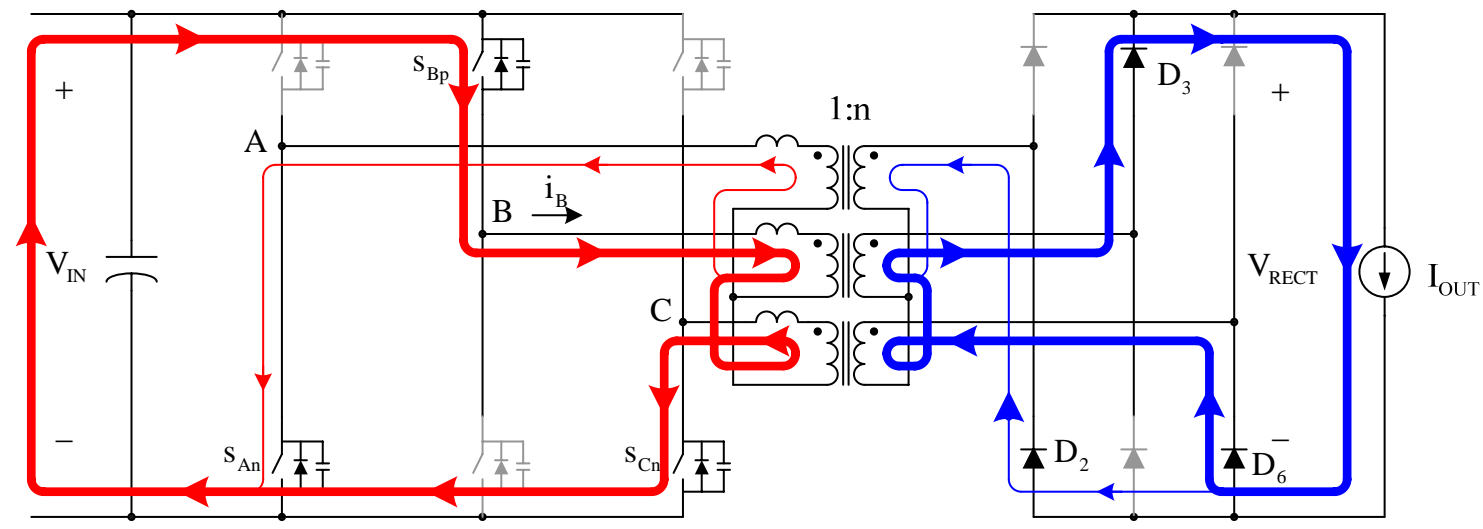

Figure 3.26 - V3 equivalent circuit: regulated converter mode - cycle 2, stage 1

- At the beginning of the stage, an upper switch $\left(\mathrm{s}_{\mathrm{Bp}}\right)$ turns on. Voltage across the switch is zero, and zero-voltage switching (ZVS) turn-on is achieved.

- The switch $\left(\mathrm{s}_{\mathrm{Bp}}\right)$ must be turned on before the phase current $\left(\mathrm{i}_{\mathrm{B}}\right)$ reverses direction. Otherwise, the reverse current charges the device output capacitance $\left(\mathrm{C}_{\mathrm{Bp}}\right)$ and ZVS is lost.

- When switch is turned on, the phase currents continue to increase until its current equals the reflected output current $\left(n \cdot \mathrm{i}_{\mathrm{L}}\right)$.

- $\quad D_{2}, D_{3}$ and $D_{6}$ are forward biased and conducting, and rectified output, $V_{R E C T}$, is $n \cdot V_{\text {IN }}$.

- When the phase current $\left(i_{B}\right)$ reaches $n \cdot i_{L}$, current sum of the other two phase (phase $A$ and C) also reach $-n \cdot i_{L}$. This stage is equivalent to the stage 1 of cycle 1 . The only difference is that the current flow has shifted from one phase to next phase. Each cycle is identical in operating principle.

\subsubsection{V3 regulated converter mode summary}

- Regulated converter mode is present when duty cycle is either between 0 and $1 / 3$ or between $2 / 3$ and 1 . Only the operating principal during $0 \leq \mathrm{D} \leq 1 / 3$ is examined, since the duty cycle beyond $50 \%$ is avoided. However, the operating principal is identical in both $0 \leq \mathrm{D} \leq 1 / 3$ and $2 / 3 \leq \mathrm{D} \leq 1$. 
- Asymmetrical duty cycle produces rectangular waveforms at the $\mathrm{V}_{\mathrm{RECT}}$. At some portions of period, a combination of switches imposes voltage across a pair of transformers, and causes $\mathrm{V}_{\mathrm{RECT}}=\mathrm{n} \cdot \mathrm{V}_{\mathrm{IN}}$, where $\mathrm{n}$ is transformer turn ratio and $\mathrm{V}_{\text {IN }}$ is input voltage. During other times of the period, either all upper or all lower switches are on, which impose zero voltage across all the transformers, and cause $\mathrm{V}_{\mathrm{RECT}}=0 \mathrm{~V}$. Figure 3.27 shows waveforms during the regulated converter mode.

- ZVS turn-on is achieved on both upper and lower switches.

- When duty cycle is below 1/3, the upper switch ZVS is achieved using only the energy stored in the transformer leakage inductance. Thus, ZVS condition can be lost during light load conditions. The lower switch ZVS is achieved using the energy in both the leakage and output filter inductance. Therefore, ZVS can be easily achieved even during light load conditions.

- Resonant elements are capacitance sum of upper and lower device output capacitor (i.e. $\mathrm{C}_{\mathrm{eq}}=\mathrm{C}_{\mathrm{Bp}}+\mathrm{C}_{\mathrm{Bn}}$ ) and equivalent transformer leakage inductance (i.e. $\left.\mathrm{L}_{\mathrm{eq}}=\mathrm{L}_{\mathrm{LK}-\mathrm{B}}+\left(\mathrm{L}_{\mathrm{LK}-\mathrm{C}} \| \mathrm{L}_{\mathrm{LK}-\mathrm{C}}\right) \approx 1.5 \cdot \mathrm{L}_{\mathrm{LK}}\right)$.

- $\quad$ Switch turn-off takes place under hard-switching.

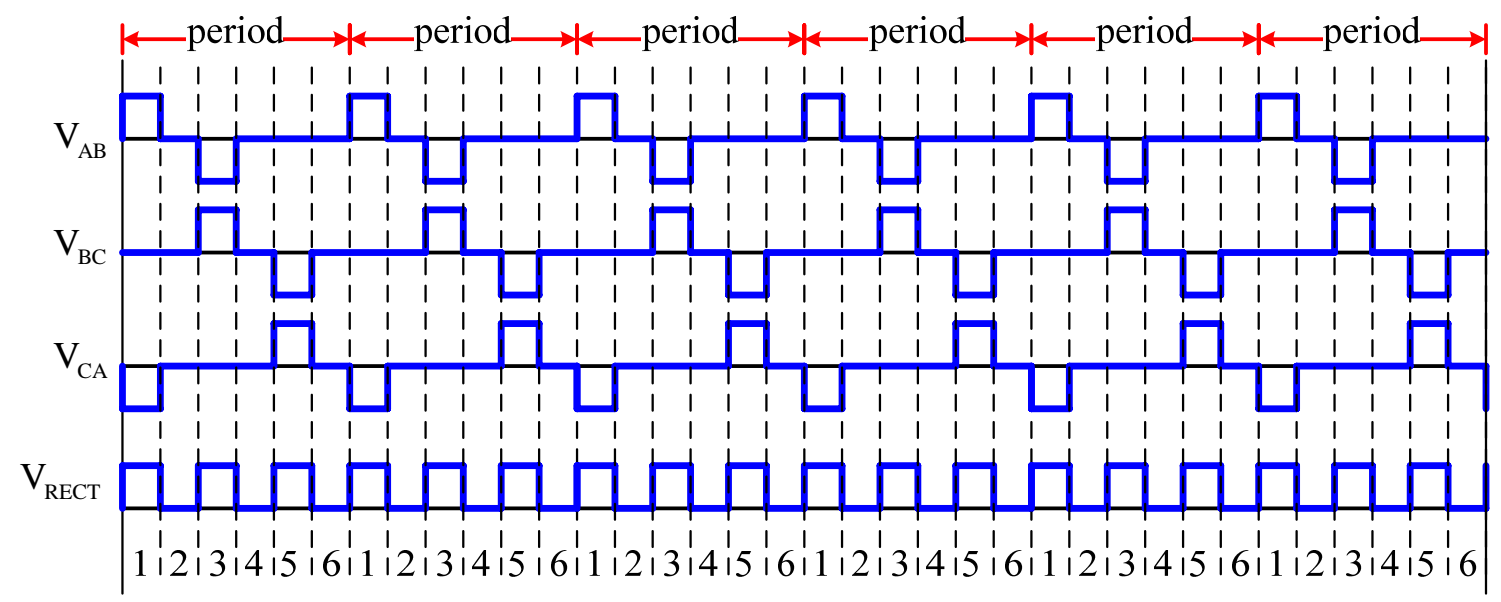

Figure 3.27 - V3 waveforms of three-phase output voltages and rectifier output voltage, $V_{\text {RECT }}$, in regulated converter mode 


\subsubsection{V6 operating principles}

V6 can operate in three different modes: dc transformer mode, and regulated converter mode 2 and mode 1 . The operating principle in each mode is different and is explained in following sections.

\subsubsection{V6 dc transformer mode $\left(120^{\circ} \leq \alpha \leq 180^{\circ}\right)$}

Figure 3.28 illustrates V6 gate signals and switching vectors for dc transformer mode. Along with nominal switching states, deadtime switching states are included to reflect transition between nominal states. A period can be divided into total of 24 stages, which consist of 6 cycles of 4 stages, and each stage starts and ends with a switch either turns on or turns off. Figure 3.29 partitions the switching vectors into cycles and stages for dc transformer mode. Each cycle is identical in operating principle. The difference between cycles is that phase current and voltage status is shifted to next phase during the following cycle.

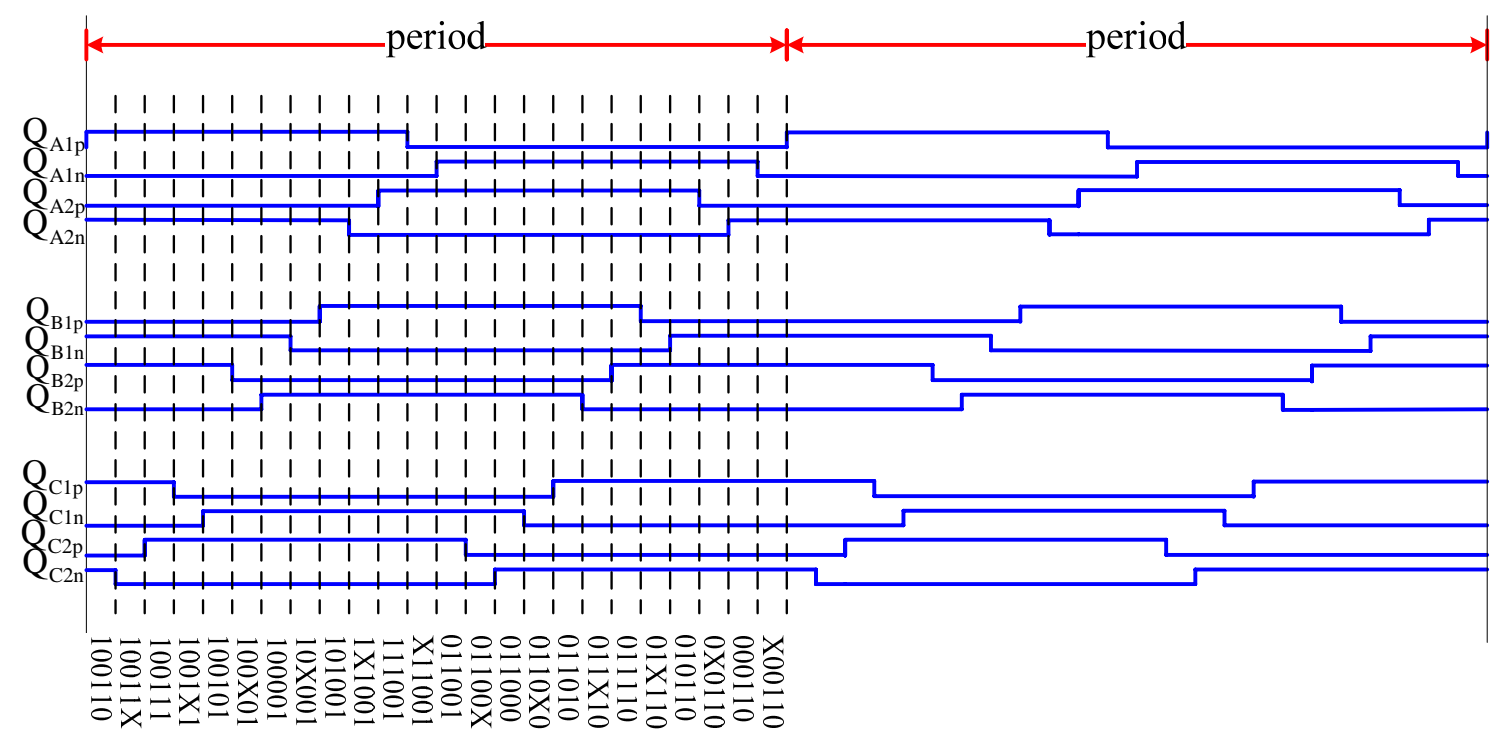

Figure 3.28 - V6 gate signals and switching vectors for dc transformer mode 


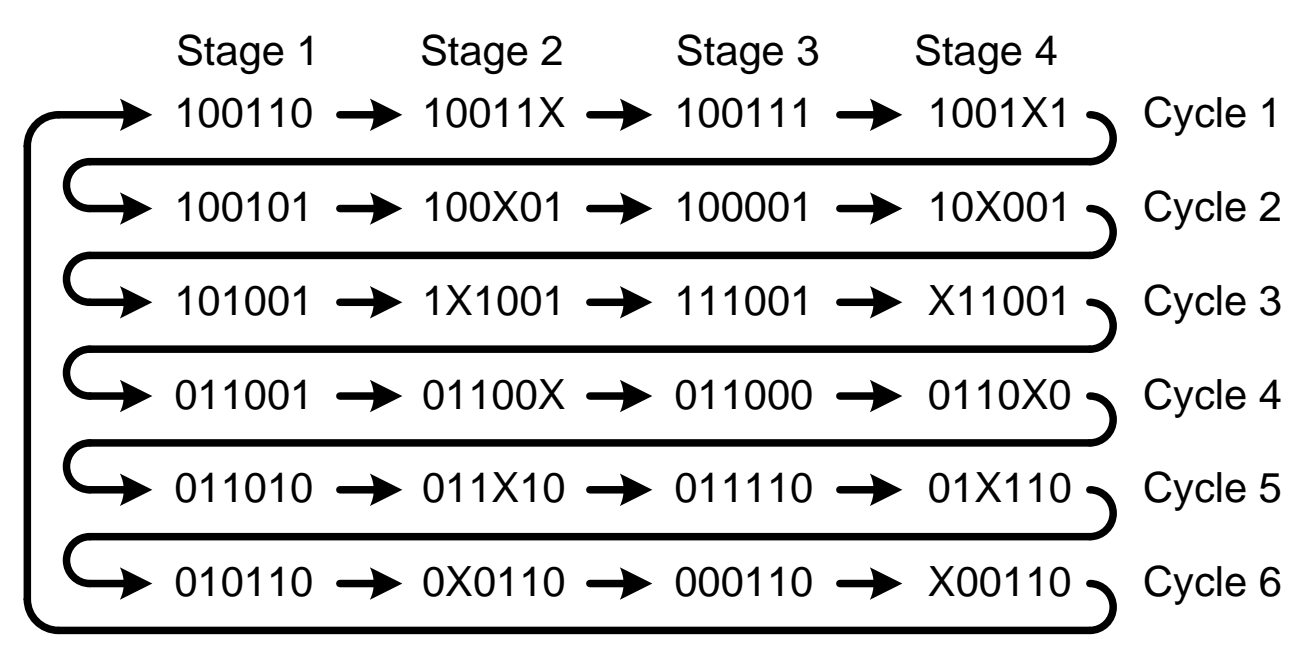

Figure 3.29 - V6 switching vector cycle: dc transformer mode

1) V6 dc transformer mode - Cycle 1, Stage 1: switch vector (100110)

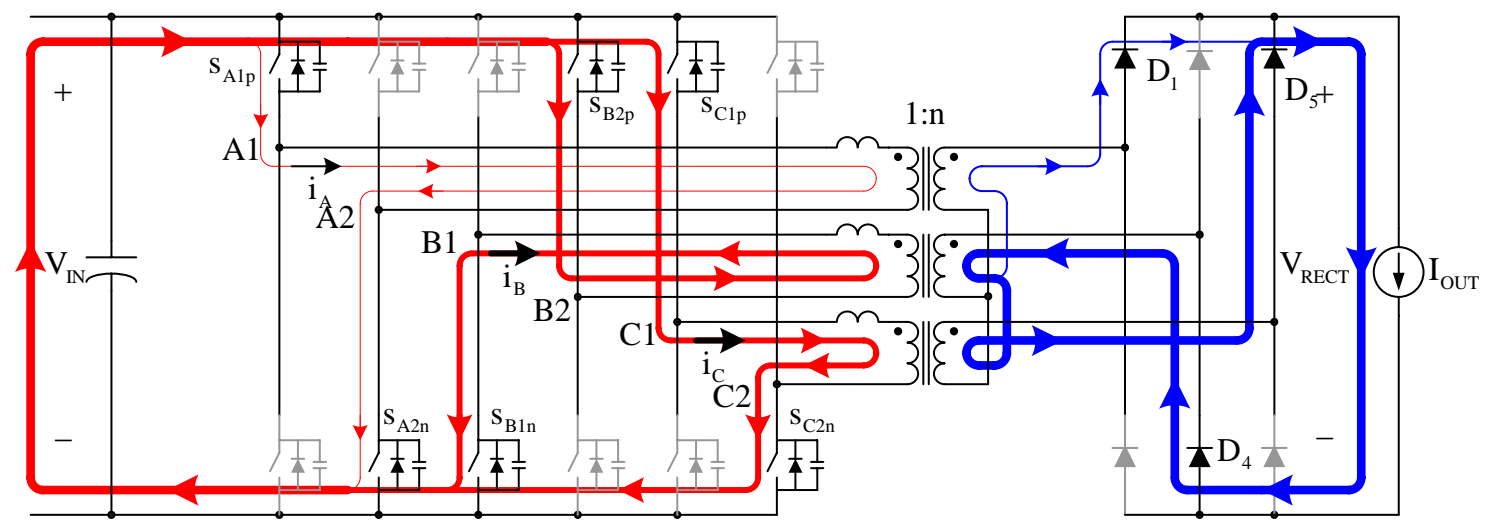

Figure 3.30 - V6 equivalent circuit: dc transformer mode - cycle 1 stage 1

- As shown in the equivalent circuit of Figure 3.30, the input currents ( $\left.i_{I N}\right)$ flow through all three phases. Currents in phase $A$ and $C\left(i_{A}\right.$ and $i_{C}$ ) flow in positive current direction, while the currents of remaining phase $\left(\mathrm{i}_{\mathrm{B}}\right)$ flow in negative direction.

- Although phase A and C provide paralleled paths for positive directional current flow, phase A current $\left(\mathrm{i}_{\mathrm{A}}\right)$ is at near zero, while phase C current ( $\left.\mathrm{i}_{\mathrm{C}}\right)$ is at near full reflected output current. In previous stages, phase A current $\left(\mathrm{i}_{\mathrm{A}}\right)$ was reset to zero 
and the phase C current $\left(\mathrm{i}_{\mathrm{C}}\right)$ was conducting fully reflected load current. Even though phases $\mathrm{A}$ and $\mathrm{C}$ in present stage provide paralleled current paths, the transformer leakage inductance $\left(\mathrm{L}_{\mathrm{LK}}\right)$ tends to maintain the initial phase current in the beginning of the stage. Due to lack of any significant voltage to balance out current between two phases, phase A maintains near-zero current, and phase $\mathrm{C}$ continues to conduct nearly fully reflected load current. However, if the value of the leakage inductance is sufficiently small, the current between phase A and C can balance out and share the positive directional current.

- All three phases contribute in power transmission to the load. Phase B transmits one-half of power to the load, and phase A and C transmit the other half; however, since phase A current $\left(\mathrm{i}_{\mathrm{A}}\right)$ is near zero, this phase transmits very small amount of power to the load. Phase $\mathrm{C}$ transmits remaining power to the load.

- Positive input voltage $\left(\mathrm{V}_{\mathrm{IN}}\right)$ is applied across transformer $\mathrm{T}_{\mathrm{A}}$ and $\mathrm{T}_{\mathrm{C}}$, and negative input voltage $\left(-\mathrm{V}_{\mathrm{IN}}\right)$ is applied across transformer $\mathrm{T}_{\mathrm{B}}$. The induced voltages on Y-connection of secondary side transformer cause $\mathrm{D}_{1}, \mathrm{D}_{4}$ and $\mathrm{D}_{5}$ to be forward biased and produce $2 \cdot n \cdot V_{\text {IN }}$ at the rectified output, $V_{\text {RECT }}$. 
2) V6 dc transformer mode - Cycle 1, Stage 2: switch vector (10011X)

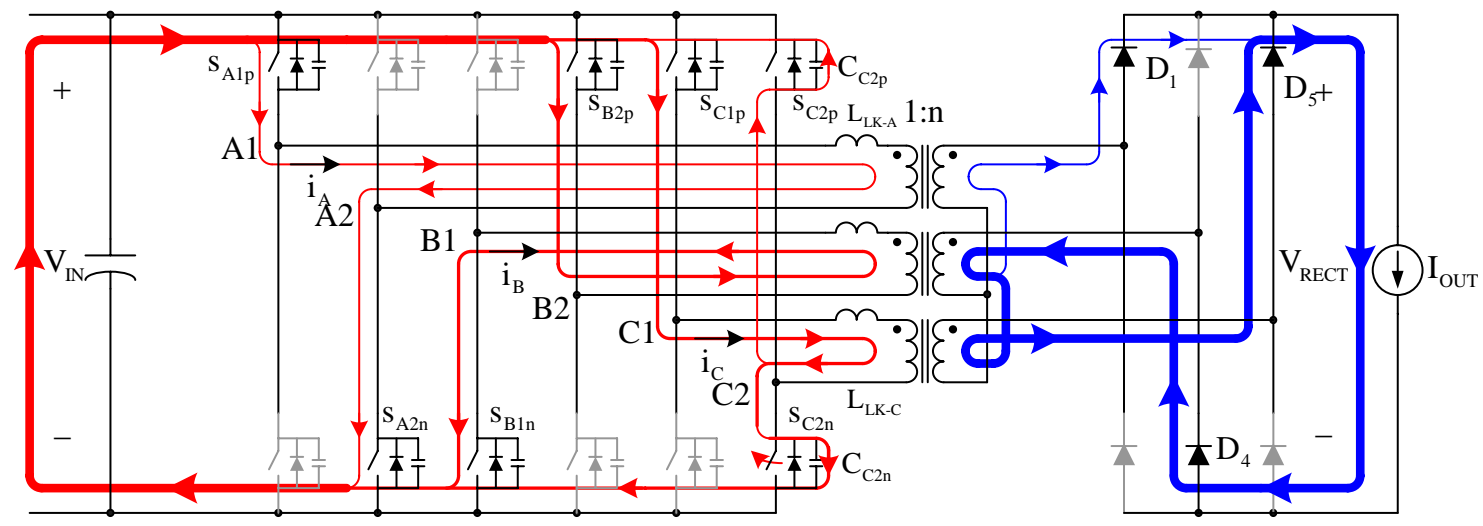

Figure 3.31 - V6 equivalent circuit: dc transformer mode - cycle 1 stage 2

- At the beginning of the stage, a lagging leg switch $\left(\mathrm{s}_{\mathrm{C} 2 \mathrm{n}}\right)$ turns off. The phase current $\left(\mathrm{i}_{\mathrm{C}}\right)$ continues to flow while switch turns off, so the switch turns off at hard-switching condition.

- When the lagging leg switch is turned off, the transformer leakage inductance ( $\left.\mathrm{L}_{\mathrm{eq}}\right)$ start to resonate with device output capacitance $\left(\mathrm{C}_{\mathrm{eq}}\right)$, and the resonance discharges the opposite side device output capacitance $\left(\mathrm{C}_{\mathrm{C2p}}\right)$. This causes the lagging leg midpoint voltage $\left(\mathrm{V}_{\mathrm{C} 2}\right)$ to rise from $0 \mathrm{~V}$ to $\mathrm{V}_{\mathrm{IN}}$.

- The resonant elements are capacitance sum of upper and lower device output capacitor $\left(\mathrm{C}_{\mathrm{eq}}=\mathrm{C}_{\mathrm{C} 2 \mathrm{p}}+\mathrm{C}_{\mathrm{C} 2 \mathrm{p}}\right)$ and equivalent transformer leakage inductance ( $\mathrm{L}_{\mathrm{eq}}$ $\left.=\mathrm{L}_{\mathrm{LK}-\mathrm{A}}+\mathrm{L}_{\mathrm{LK}-\mathrm{C}} \approx 2 \cdot \mathrm{L}_{\mathrm{LK}}\right)$. 
3) V6 dc transformer mode - Cycle 1, Stage 3: switch vector (100111)

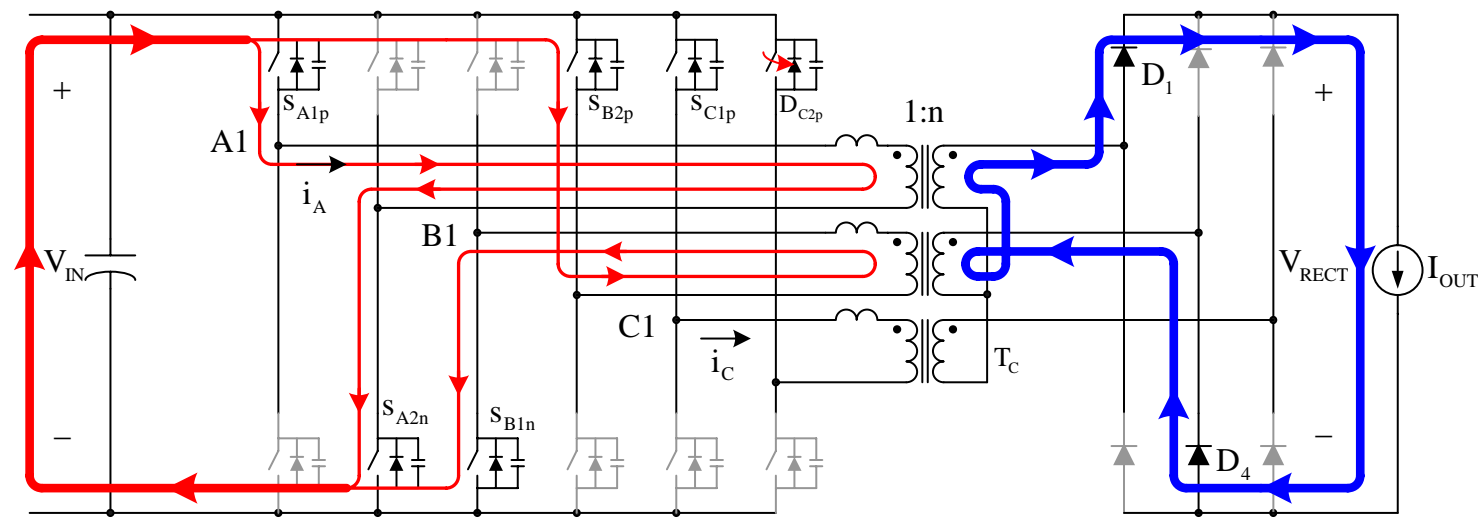

Figure 3.32 - V6 equivalent circuit: dc transformer mode - cycle 1 stage 3

- At the beginning of the stage, a lagging leg switch ( $\left.\mathrm{s}_{\mathrm{C} 2 \mathrm{p}}\right)$ turns on. Voltage across the switch is zero, thus zero-voltage switching (ZVS) turn-on is achieved.

- When the lagging leg switch ( $\left.\mathrm{s}_{\mathrm{C}_{2} \mathrm{p}}\right)$ is turned on, the phase current $\left(\mathrm{i}_{\mathrm{C}}\right)$ is reset to zero, and phase A current rises from near zero to fully reflected output current (I $\left.\mathrm{I}_{\mathrm{OUT}} / \mathrm{n}\right)$. Meanwhile, the phase B current maintains the full reflected output current.

- Since phase $C$ transformer $\left(T_{C}\right)$ voltage and current is reduced to zero, and power is discontinued from transmitting to load through this phase. However, phase A takes over the power transmission task from phase C. Phase B continues to transmit power. Two phases conduct equal halves of input current, and each phase transmits one-half power to the load.

- $\mathrm{D}_{1}$ and $\mathrm{D}_{4}$ are forward biased and conducting, and rectified output, $\mathrm{V}_{\mathrm{RECT}}$, is $2 \cdot n \cdot V_{\text {IN }}$. 
4) V6 dc transformer mode - Cycle 1, Stage 4: switch vector (1001X1)

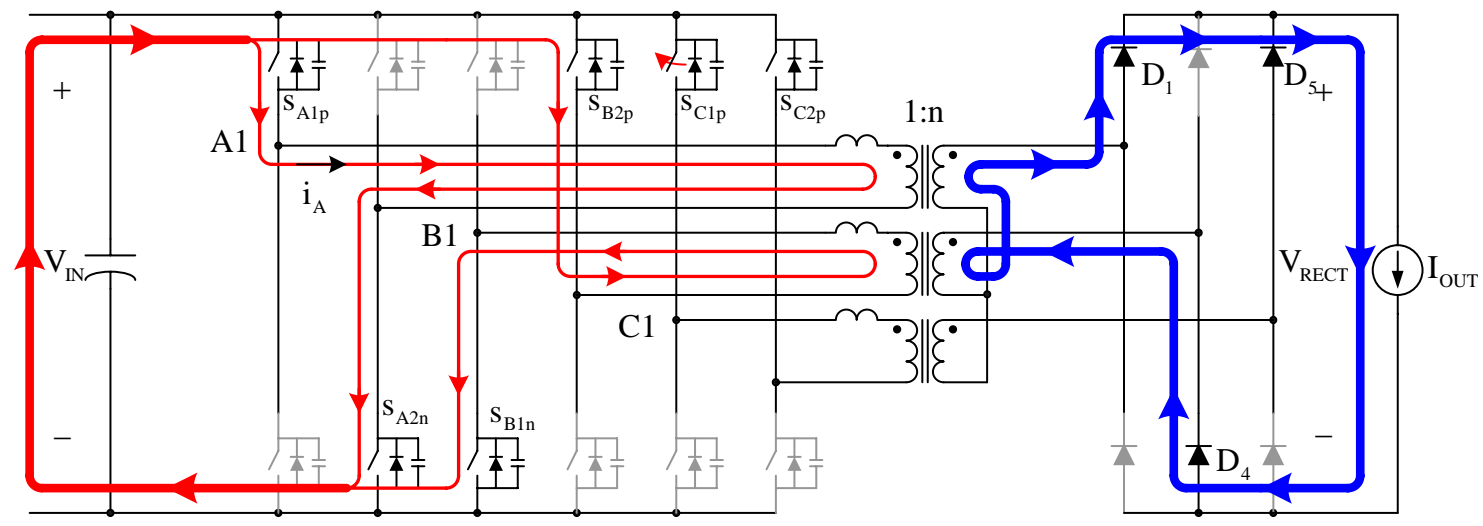

Figure 3.33 - V6 equivalent circuit: dc transformer mode - cycle 1 stage 4

- At the beginning of the stage, a leading leg switch $\left(\mathrm{s}_{\mathrm{C} 1 \mathrm{p}}\right)$ turns off. The phase current $\left(\mathrm{i}_{\mathrm{C}}\right)$ is zero, and zero-current switching (ZCS) turn-off is achieved.

- $\quad$ The stage condition remains the same as previous stage. 
5) V6 dc transformer mode - Cycle 2, Stage 1: switch vector (100101)

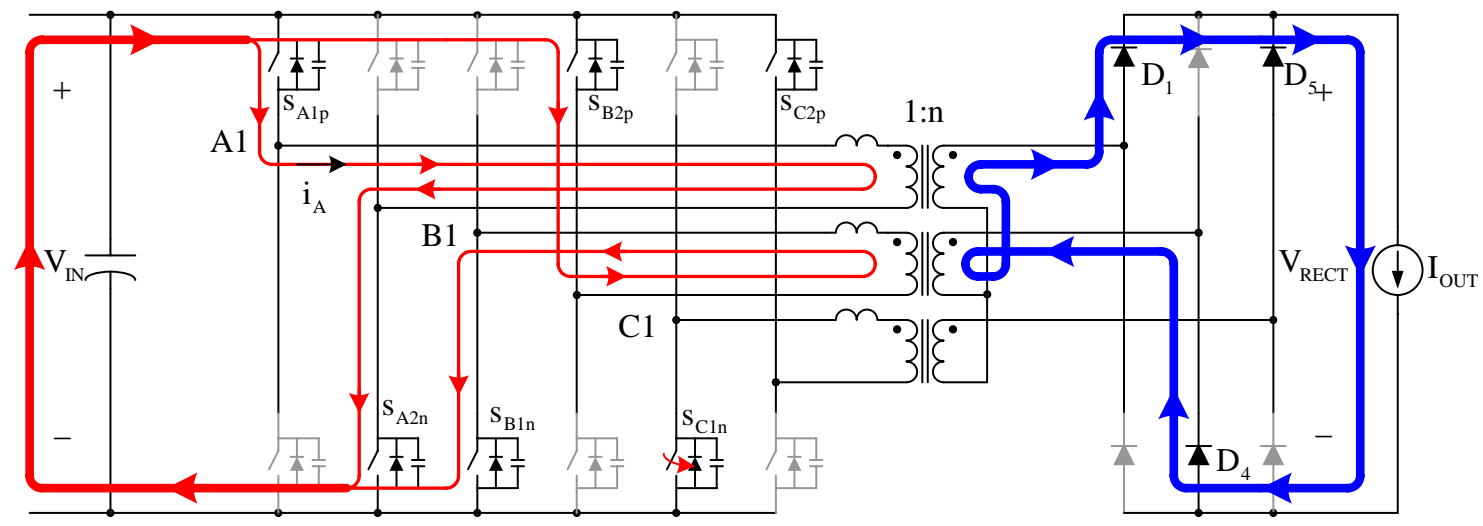

Figure 3.34 - V6 equivalent circuit: dc transformer mode - cycle 2 stage 1

- At the beginning of the stage, a leading leg switch $\left(\mathrm{s}_{\mathrm{C} 1 \mathrm{n}}\right)$ turns on. The phase current $\left(\mathrm{i}_{\mathrm{C}}\right.$ ) remains zero throughout the turn-on period, and zero-current switching (ZCS) turn-on is achieved.

- This stage is equivalent to the stage 1 of cycle 1 . The only difference is that the current flow has shifted from phase to next phase. Each cycle is identical in operating principle. 


\subsubsection{V6 dc transformer mode summary}

- Dc transformer mode is present when phase-shift modulation angle is between $120^{\circ}$ and $180^{\circ}$. During this mode, at least two phases and at most three phases transfer input voltage to output side throughout a period, and the rectified output is constant voltage, $2 \cdot n \cdot V_{\text {IN }}$, regardless of duty cycle. Therefore, the converter behaves like a dc transformer.

- ZVS turn-on is achieved on lagging leg switches. The ZVS turn-on is achieved with the energy stored in the leakage inductance of the transformer, and the energy discharge the device output capacitance voltage to zero before turning on. It should be noted that energy stored in the output filter inductor is not used. Therefore, ZVS condition can be lost during light load condition.

- Resonant elements are capacitance sum of upper and lower device output capacitor (i.e. $\mathrm{C}_{\mathrm{eq}}=\mathrm{C}_{\mathrm{Cp}}+\mathrm{C}_{\mathrm{Cn}}$ ) and equivalent transformer leakage inductance, which includes leakage inductance of two phases (i.e. $\mathrm{L}_{\mathrm{eq}}=\mathrm{L}_{\mathrm{LK}-\mathrm{A}}+\mathrm{L}_{\mathrm{LK}-\mathrm{C}} \approx$ $\left.2 \cdot \mathrm{L}_{\mathrm{LK}}\right)$.

- Lagging leg switch turn-off takes place under hard-switching.

- ZCS turn-on and turn-off is achieved on leading leg switches. ZCS is achieved through resetting the phase current to zero with other phase.

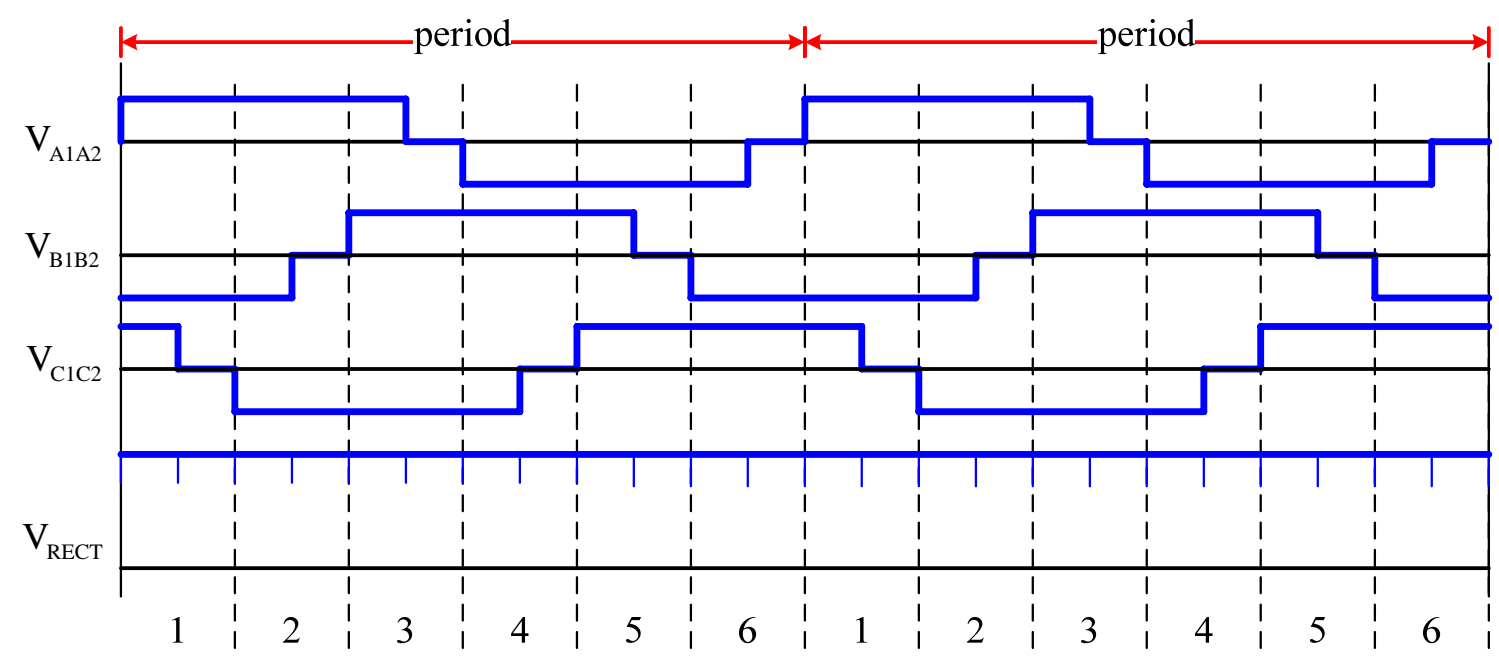

Figure 3.35 - V6 waveforms of three-phase output voltages and rectifier output voltage, $\mathrm{V}_{\mathrm{RECT}}$, in dc transformer mode 


\subsubsection{V6 regulated converter mode $2\left(60^{\circ} \leq \alpha \leq 120^{\circ}\right)$}

Figure 3.36 illustrates V6 gate signals and switching vectors for regulated converter mode 2. Along with nominal switching states, deadtime switching states are included to reflect transition between nominal states. A period can be divided into a total of 24 stages, which consist of 6 cycles of 4 stages, and each stage starts and ends with a switch either turn-on or turn-off. Figure 3.37 partitions the switching vectors into cycles and stages for regulated converter mode 2. Each cycle is identical in operating principle. The difference between cycles is that phase current and voltage status is shifted to next phase during following cycle.

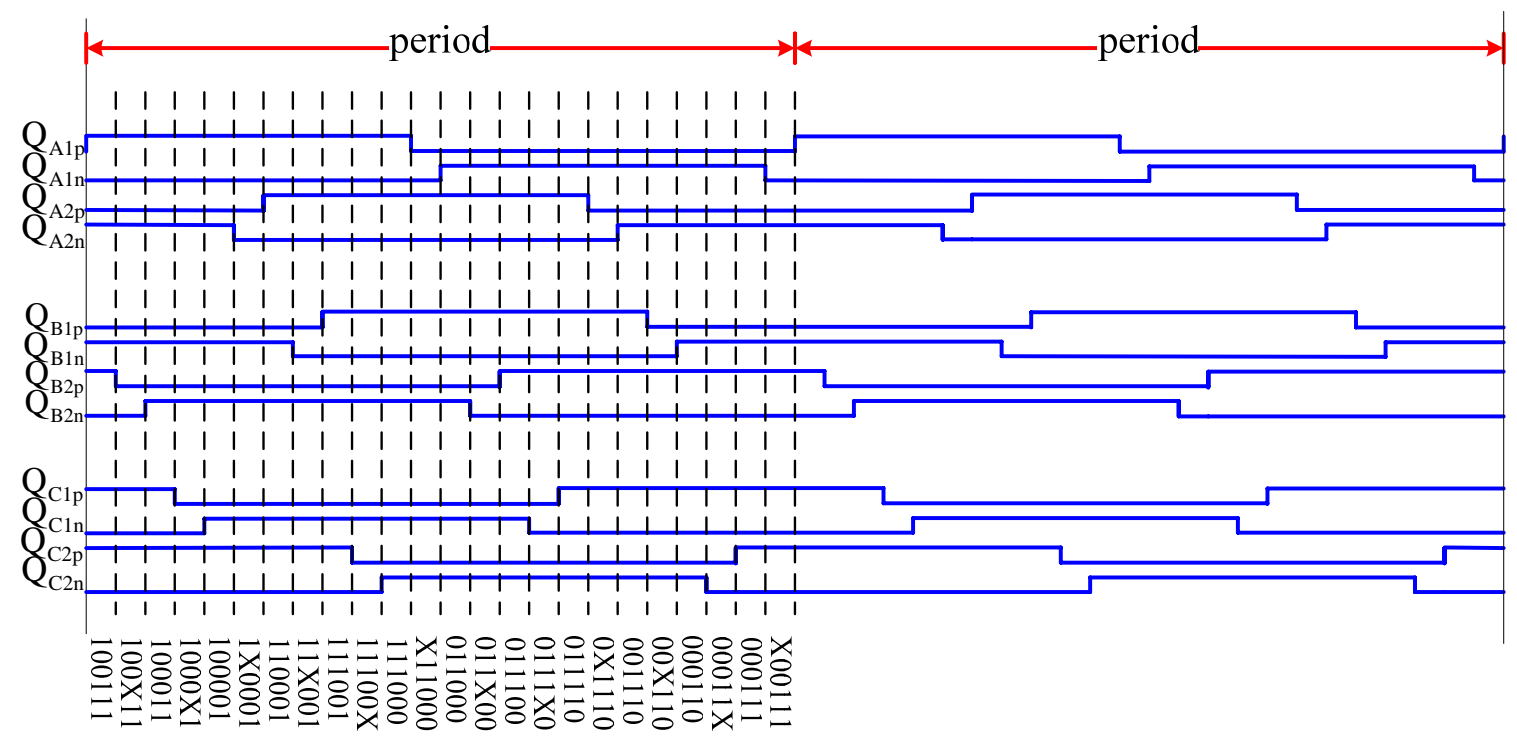

Figure 3.36 - V6 gate signals and switching vectors for regulated converter mode 2

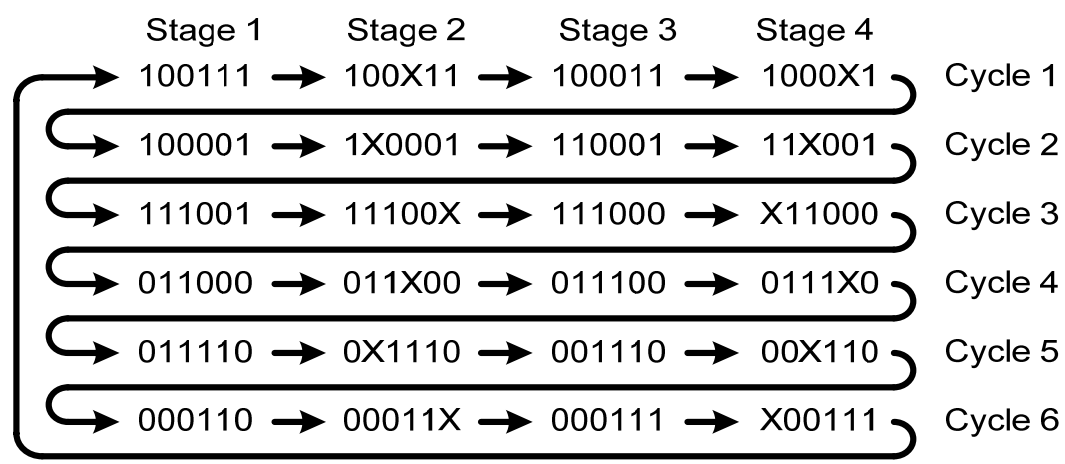

Figure 3.37 - V6 switching vector cycle: regulated converter mode 2 
1) V6 regulated converter mode 2 - Cycle 1, Stage 1: switch vector (100111)

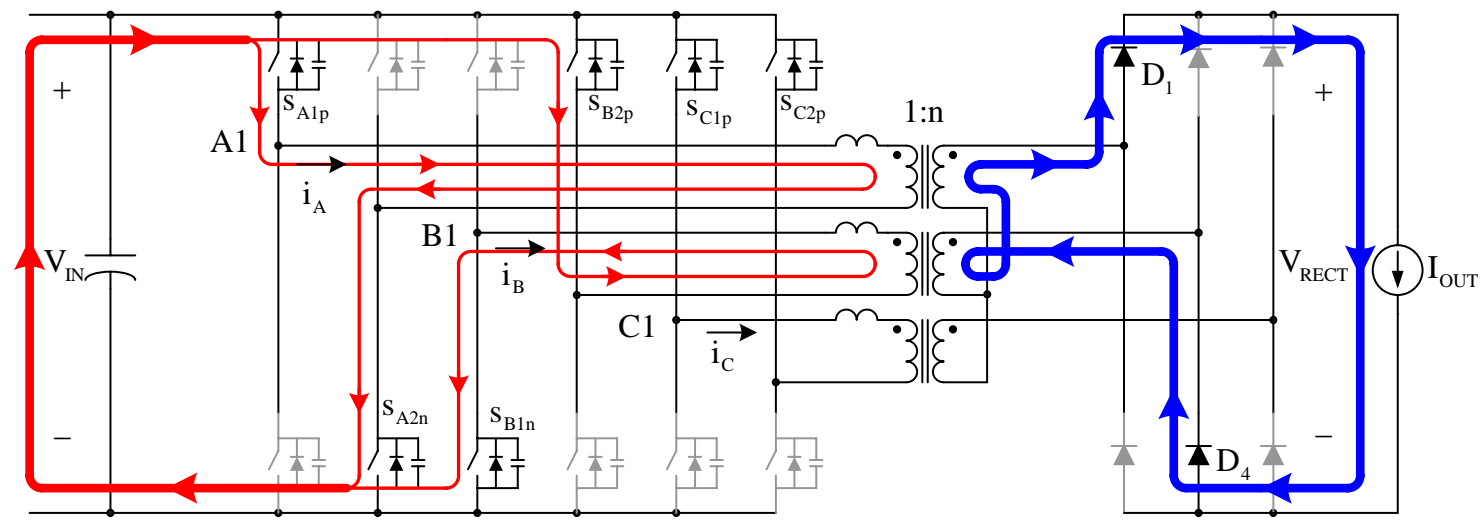

Figure 3.38 - V6 equivalent circuit: regulated converter mode 2 - cycle 1 stage 1

- As shown in the equivalent circuit of Figure 3.38, the input current ( $\mathrm{i}_{\mathrm{IN}}$ ) is split between two phases $\left(\mathrm{i}_{\mathrm{A}}\right.$ and $\mathrm{i}_{\mathrm{B}}$ ). The current of remaining phase ( $\mathrm{i}_{\mathrm{C}}$ ) was reset to zero and does not have any circulating current.

- Two phases conduct equal halves of input current, and each phase transmits onehalf power to the load.

- Positive input voltage $\left(\mathrm{V}_{\mathrm{IN}}\right)$ is applied across transformer $\mathrm{T}_{\mathrm{A}}$, and negative input voltage $\left(-\mathrm{V}_{\mathrm{IN}}\right)$ is applied across transformer $\mathrm{T}_{\mathrm{B}}$. The induced voltages on secondary side transformer are stacked in series, which causes $\mathrm{D}_{1}$ and $\mathrm{D}_{4}$ to be forward biased and produces $2 \cdot n \cdot V_{\text {IN }}$ at the rectified output, $V_{\text {RECT }}$. 
2) V6 regulated converter mode 2 - Cycle 1, Stage 2: switch vector (100X11)

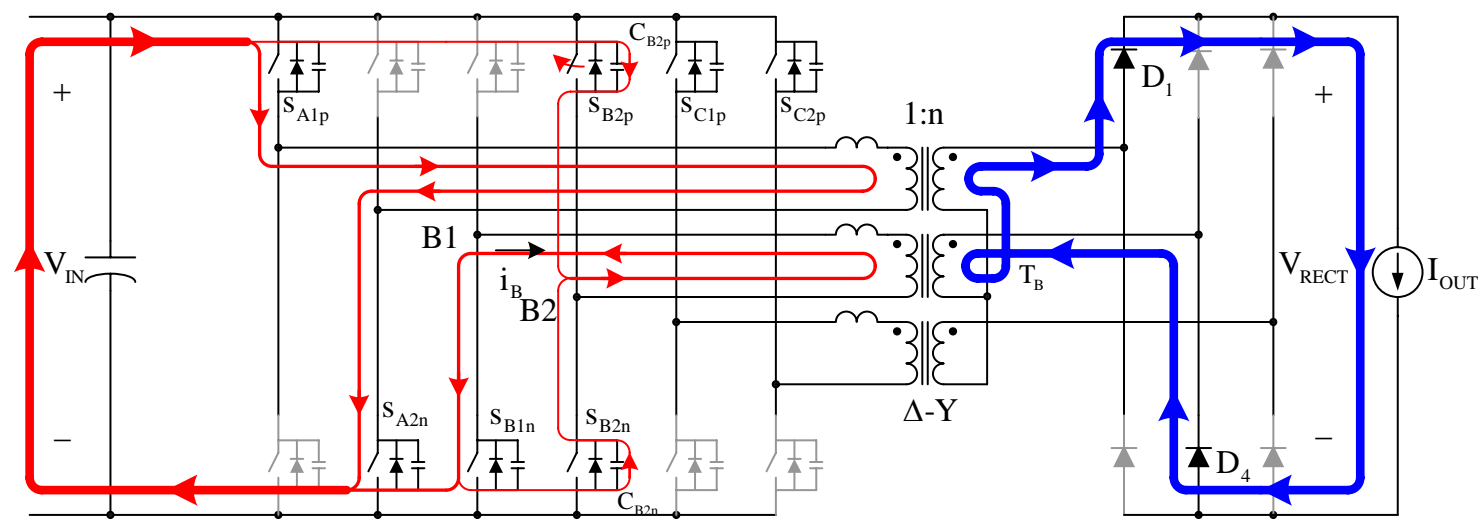

Figure 3.39 - V6 equivalent circuit: regulated converter mode 2 - cycle 1 stage 2

- At the beginning of the stage, a lagging leg switch $\left(\mathrm{s}_{\mathrm{B} 2 \mathrm{p}}\right)$ turns off. The phase current $\left(\mathrm{i}_{\mathrm{B}}\right)$ continues to flow while switch turns off, and soft-switching can not be achieved.

- When the lagging leg switch $\left(\mathrm{s}_{\mathrm{B} 2 \mathrm{p}}\right)$ is turned off, the energy of the large output filter inductor is used to discharge the opposite side device output capacitance $\left(\mathrm{C}_{\mathrm{B} 2 \mathrm{n}}\right)$. The midpoint voltage of the lagging leg $\left(\mathrm{V}_{\mathrm{B} 2}\right)$ drops from $\mathrm{V}_{\mathrm{IN}}$ to $0 \mathrm{~V}$.

- When the reflected output current fully discharges the switch output capacitance $\left(\mathrm{C}_{\mathrm{B} 2 \mathrm{n}}\right)$, it continues to flow through body diode $\left(\mathrm{D}_{\mathrm{B} 2 \mathrm{n}}\right)$ and circulates in phase $\mathrm{B}$. At this time, voltage across the phase transformer $\left(T_{B}\right)$ becomes zero, and power is discontinued from transmitting to load through this phase. 
3) V6 regulated converter mode 2 - Cycle 1, Stage 3: switch vector (100011)

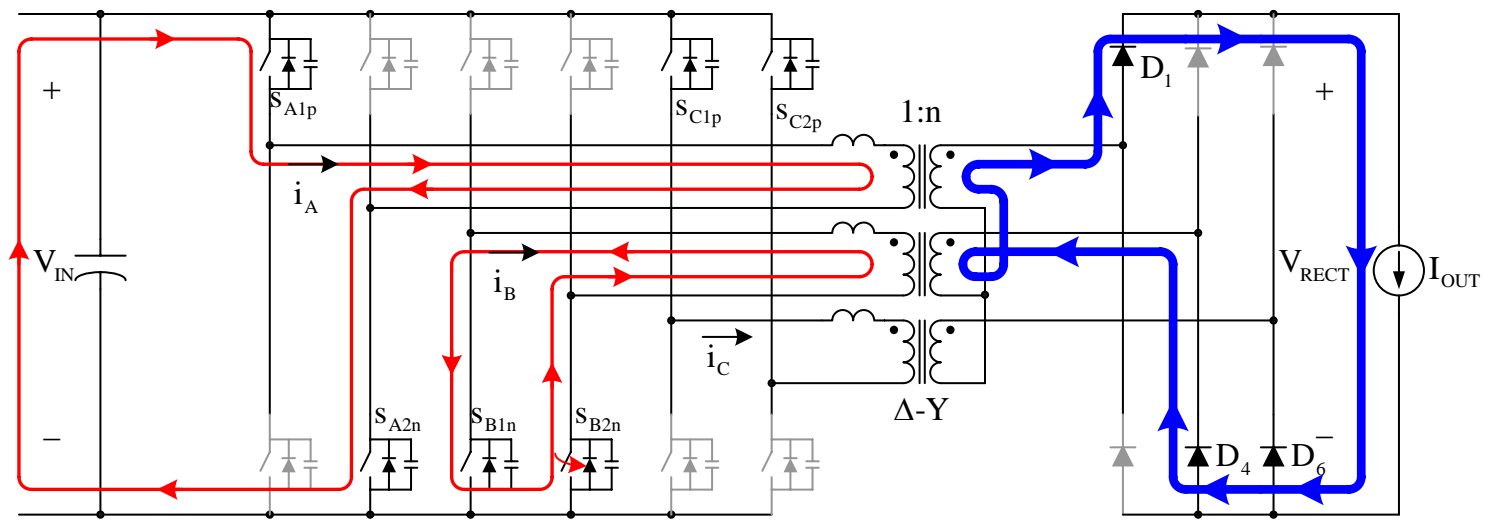

Figure 3.40 - V6 equivalent circuit: regulated converter mode 2 - cycle 1 stage 3

- At the beginning of the stage, a lagging leg switch $\left(\mathrm{s}_{\mathrm{B} 2 \mathrm{n}}\right)$ turns on. Voltage across the switch is zero, and zero-voltage switching (ZVS) turn-on is achieved.

- Typically, circulating current is caused when leakage inductance maintains freewheeling current in primary, and V3's regulated converter mode is an example of such case. However, circulating current of V6 in this mode is resulted from different mechanism. Secondary side of three-phase transformer is configured in Y-connection, which stacks phase A in series with phase B and C in parallel. In other words, the load current must conduct through phase $\mathrm{A}$, and it forces the current to also conduct through other two phases in series. Therefore, the circulating current is due to the reflected load current, rather than leakage inductance.

- Although phases B and C each has formed a loop, phase C has a negligible amount of circulating current. In the previous stage, the phase $\mathrm{C}$ current $\left(\mathrm{i}_{\mathrm{C}}\right.$ ) was reset to zero, and the transformer leakage inductance maintains zero current in phase $\mathrm{C}$ and continual current conduction in phase B. However, if the value of the leakage inductance is small, the current between phase B and C can balance out and share the circulating current.

- Phase A transmits power to the load, while remaining two phases (phase B and C) do not. 
- $\quad D_{1}, D_{4}$ and $D_{6}$ are forward biased and conducting, and rectified output, $V_{R E C T}$, is $n \cdot V_{\text {IN }}$

4) V6 regulated converter mode 2 - Cycle 1, Stage 4: switch vector (1000X1)

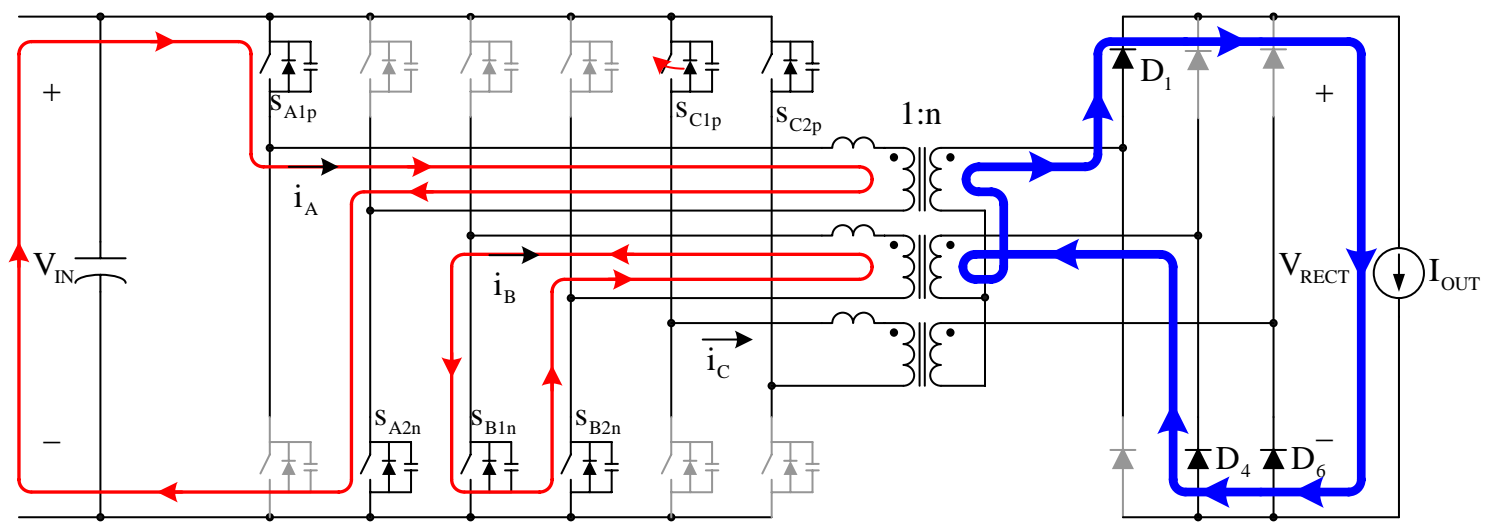

Figure 3.41 - V6 equivalent circuit: regulated converter mode 2 - cycle 1 stage 4

- At the beginning of the stage, a leading leg switch ( $\left.\mathrm{s}_{\mathrm{C} 1 \mathrm{p}}\right)$ turns off. The phase current $\left(\mathrm{i}_{\mathrm{C}}\right)$ is zero or near zero, and zero-current switching (ZCS) turn-off is achieved.

- The stage condition remains the same as previous stage. 
5) V6 regulated converter mode 2 - Cycle 2, Stage 1: switch vector (100001)

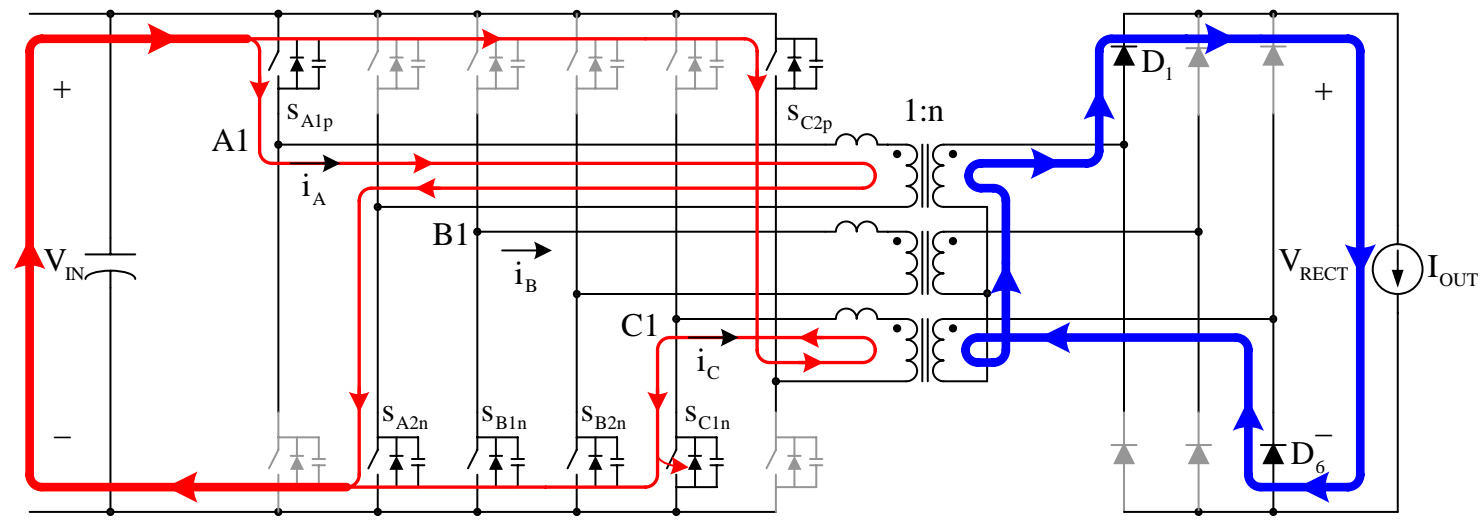

Figure 3.42 - V6 equivalent circuit: regulated converter mode 2 - cycle 2 stage 1

- At the beginning of the stage, a leading leg switch $\left(\mathrm{s}_{\mathrm{C} 1 \mathrm{n}}\right)$ turns on. Initial voltage across the device is $\mathrm{V}_{\mathrm{IN}}$, and initial current in phase $\mathrm{C}\left(\mathrm{i}_{\mathrm{C}}\right)$ is zero or near-zero. Although initial current is zero, as switch turns on, the phase current $\left(\mathrm{i}_{\mathrm{C}}\right)$ starts to rapidly rise, and the leading leg switch turn-on takes place under hard-switching.

- When the leading leg switch $\left(\mathrm{s}_{\mathrm{C} 1 \mathrm{n}}\right)$ is turn on, the input voltage $\left(\mathrm{V}_{\mathrm{IN}}\right)$ is applied to the transformer leakage inductance in phase $\mathrm{B}$ and $\mathrm{C}$, and it causes the circulating current in phase $\mathrm{B}\left(\mathrm{i}_{\mathrm{B}}\right)$ is reset to zero, and phase $\mathrm{C}$ current ( $\mathrm{i}_{\mathrm{C}}$ ) rises to match the reflected load current $\left(\mathrm{I}_{\mathrm{OUT}} / \mathrm{n}\right)$.

- Two phases conduct equal halves of input current, and each phase transmits onehalf power to the load.

- Positive input voltage $\left(\mathrm{V}_{\mathrm{IN}}\right)$ is applied across transformer $\mathrm{T}_{\mathrm{A}}$, and negative input voltage $\left(-\mathrm{V}_{\mathrm{IN}}\right)$ is applied across transformer $\mathrm{T}_{\mathrm{C}}$. The induced voltages on secondary side transformer are stacked in series, which causes $\mathrm{D}_{1}$ and $\mathrm{D}_{6}$ to be forward biased and produces $2 \cdot n \cdot V_{\text {IN }}$ at the rectified output, $V_{\text {RECT }}$.

- This stage is equivalent to the stage 1 of cycle 1 . The only difference is that the current flow has shifted from phase to next phase. Each cycle is identical in operating principle. 


\subsubsection{V6 regulated converter mode 2 summary}

- Regulated converter mode 2 is present when phase-shift modulation angle is between $60^{\circ}$ and $120^{\circ}$. During this mode, at least one phase and at most two phases transfer input voltage to output side.

- When two phases are transferring input voltage to output side, rectified output voltage is $2 \cdot n \cdot V_{\text {IN. }}$. When one phase is transferring, rectified output voltage is $\mathrm{n} \cdot \mathrm{V}_{\text {IN }}$. Rectangular waveform of given two voltage is produced, and phase-shift modulation controls the width of rectangle and regulates output voltage.

- ZVS turn-on is achieved on lagging leg switches. The ZVS is achieved using energy in both the leakage and output filter inductance. Therefore, ZVS can be easily achieved even during light load condition.

- Lagging leg switch turn-off takes place under hard-switching.

- Leading leg switch turn-on takes place under hard-switching.

- ZCS turn-off is achieved on leading leg switches. ZCS is achieved through resetting the phase current to zero with other phase.

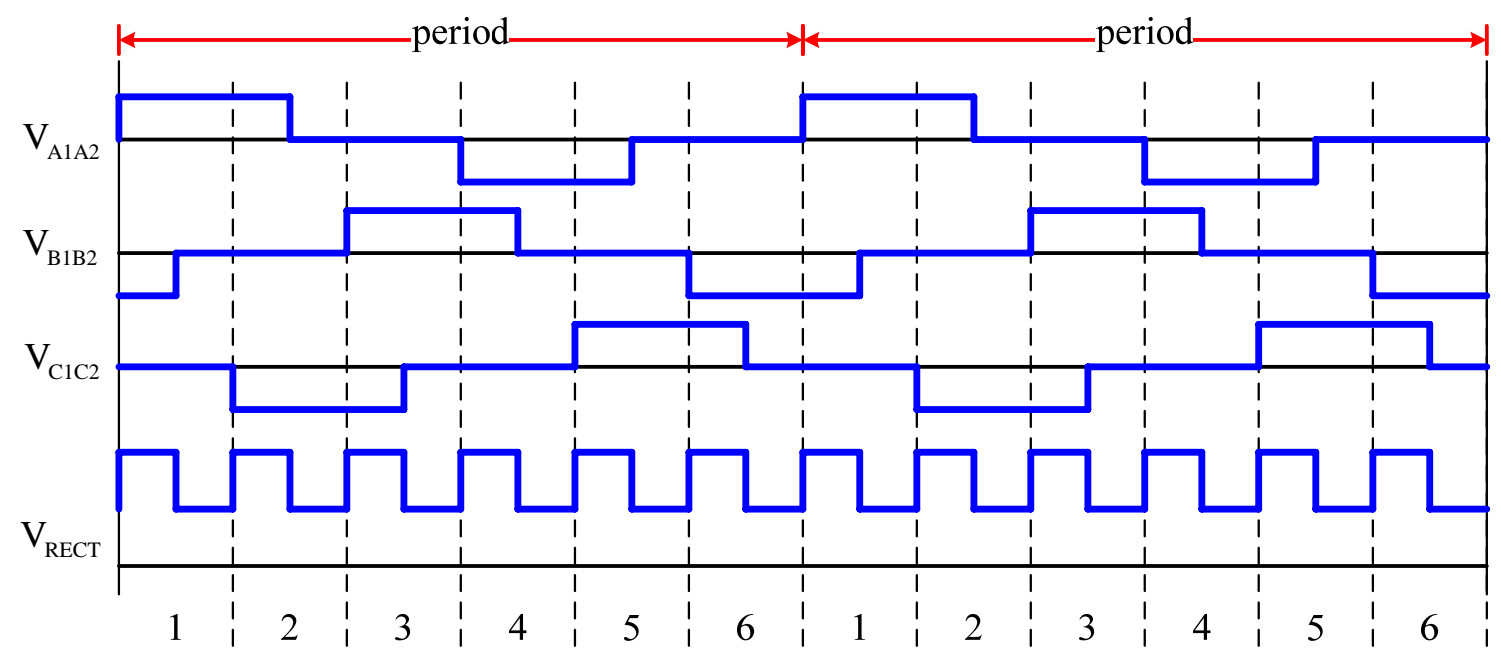

Figure 3.43 - V6 waveforms of three-phase output voltages and rectifier output voltage, $\mathrm{V}_{\mathrm{RECT}}$, in regulated converter mode 2 


\subsubsection{V6 regulated converter mode $1\left(0^{\circ} \leq \alpha \leq 60^{\circ}\right)$}

Figure 3.44 illustrates V6 gate signals and switching vectors for regulated converter mode 1. Along with nominal switching states, deadtime switching states are included to reflect transition between nominal states. A period can be divided into total of 24 stages, which consist of 6 cycles of 4 stages, and each stage starts and ends with a switch either turns on or turns off. Figure 3.45 partitions the switching vectors into cycles and stages for regulated converter mode 1. Each cycle is identical in operating principle. The difference between cycles is that phase current and voltage status is shifted to next phase during following cycle.

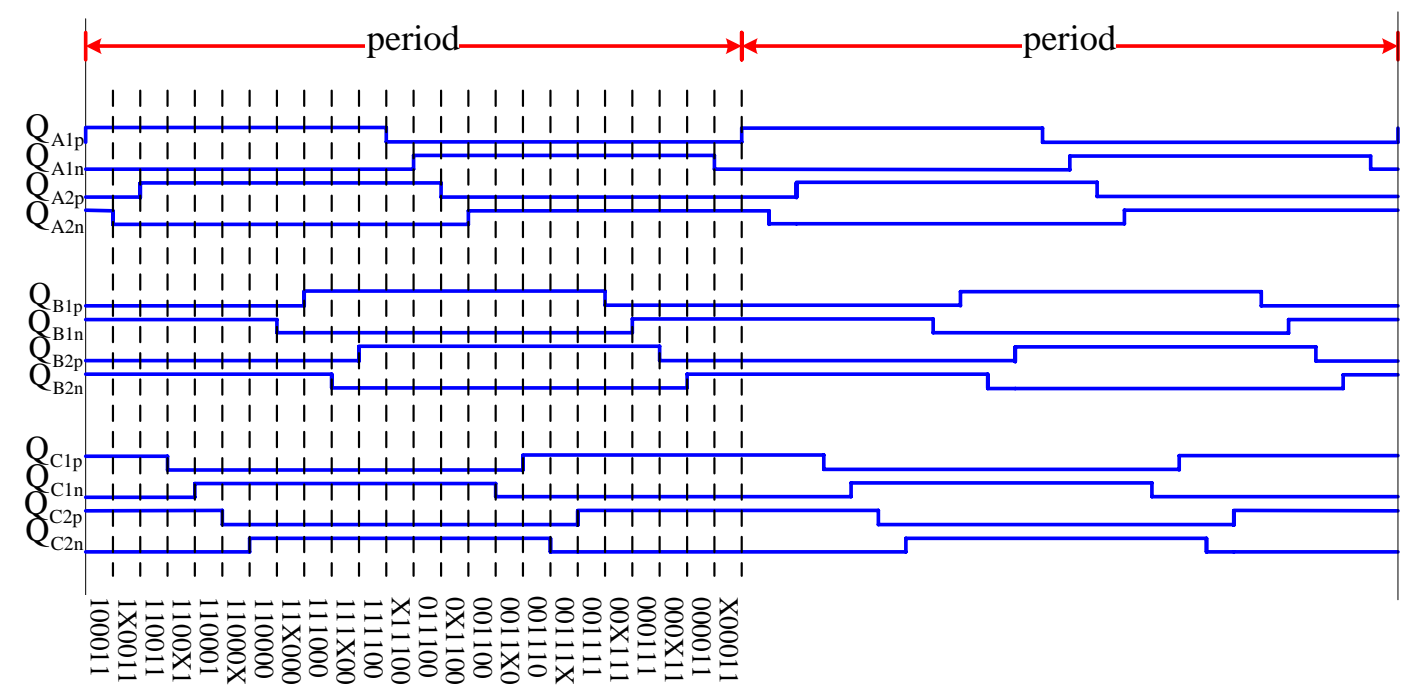

Figure 3.44 - V6 switching vector cycle: regulated converter mode 1

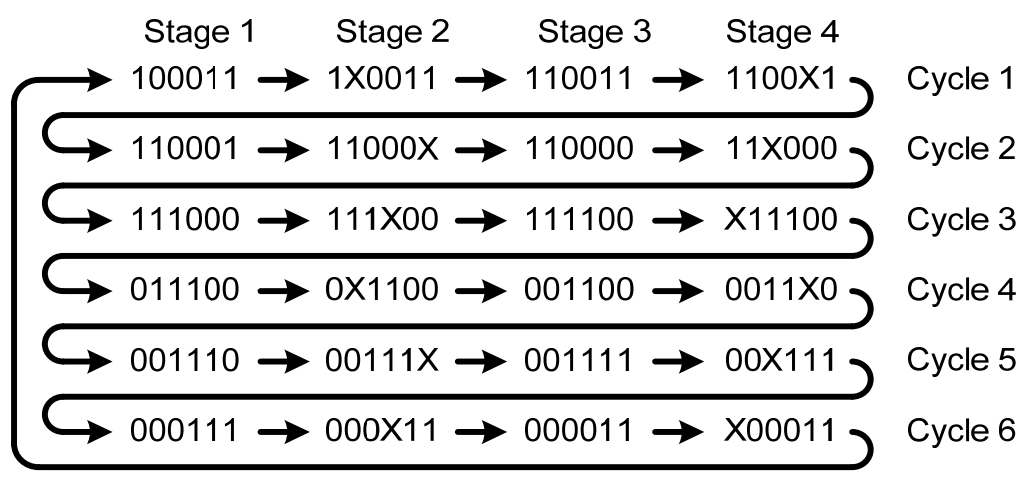

Figure 3.45 - V6 switching vector cycle: regulated converter mode 1 
1) V6 regulated converter mode 1 - Cycle 1, Stage 1: switch vector (100011)

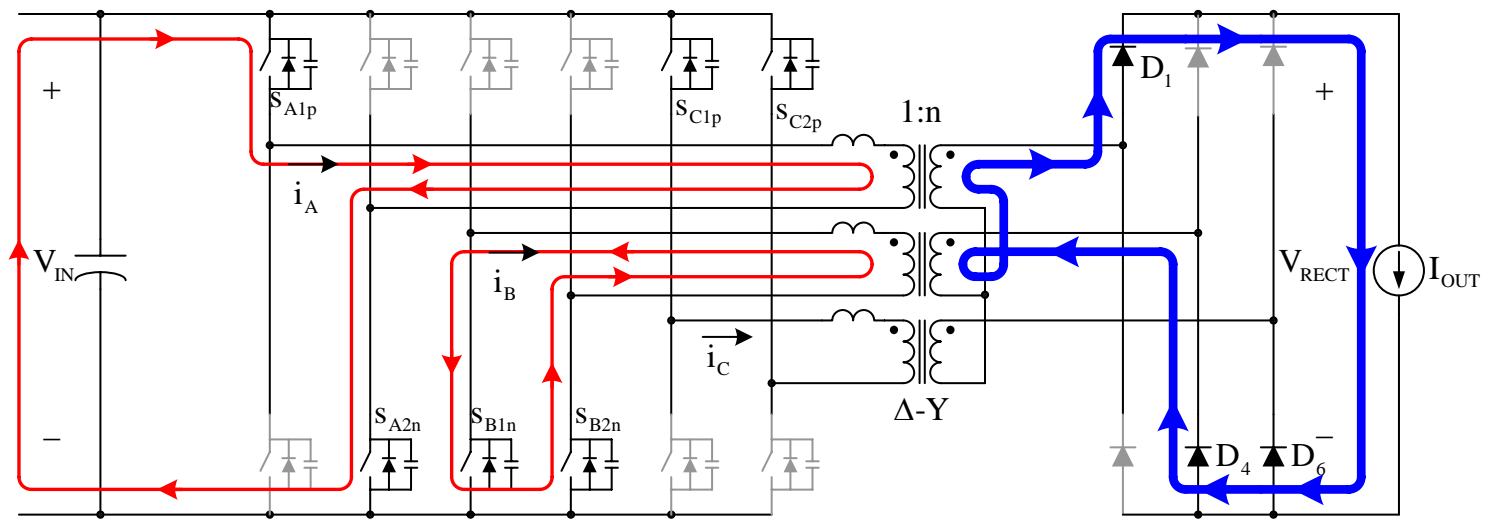

Figure 3.46 - V6 equivalent circuit: regulated converter mode 1 - cycle 1 stage 1

- As shown in the equivalent circuit of Figure 3.46, the input current ( $\mathrm{i}_{\mathrm{IN}}$ ) flows through phase $A$, while phase B current $\left(\mathrm{i}_{\mathrm{B}}\right)$ circulates in a loop. The circulating current in phase $\mathrm{C}\left(\mathrm{i}_{\mathrm{C}}\right)$ is at near zero. The current sum of phase $\mathrm{B}$ and $\mathrm{C}\left(\mathrm{i}_{\mathrm{B}}+\mathrm{i}_{\mathrm{C}}\right)$ is equal to negative of phase $A$ current $\left(i_{A}\right)$.

- Phase A applies input voltage $\left(\mathrm{V}_{\mathrm{IN}}\right)$ to the phase transformer $\left(\mathrm{T}_{\mathrm{A}}\right)$ and transmits power to the load. Meanwhile, other two phases (phase B and C) applies $0 \mathrm{~V}$ to their phase transformers $\left(T_{B}\right.$ and $\left.T_{C}\right)$ and do not transmits power to the load.

- $\quad D_{1}, D_{4}$ and $D_{6}$ are forward biased and conducting, and rectified output, $V_{R E C T}$, is $n \cdot V_{\text {IN }}$. 
2) V6 regulated converter mode 1 - Cycle 1, Stage 2: switch vector (1X0011)

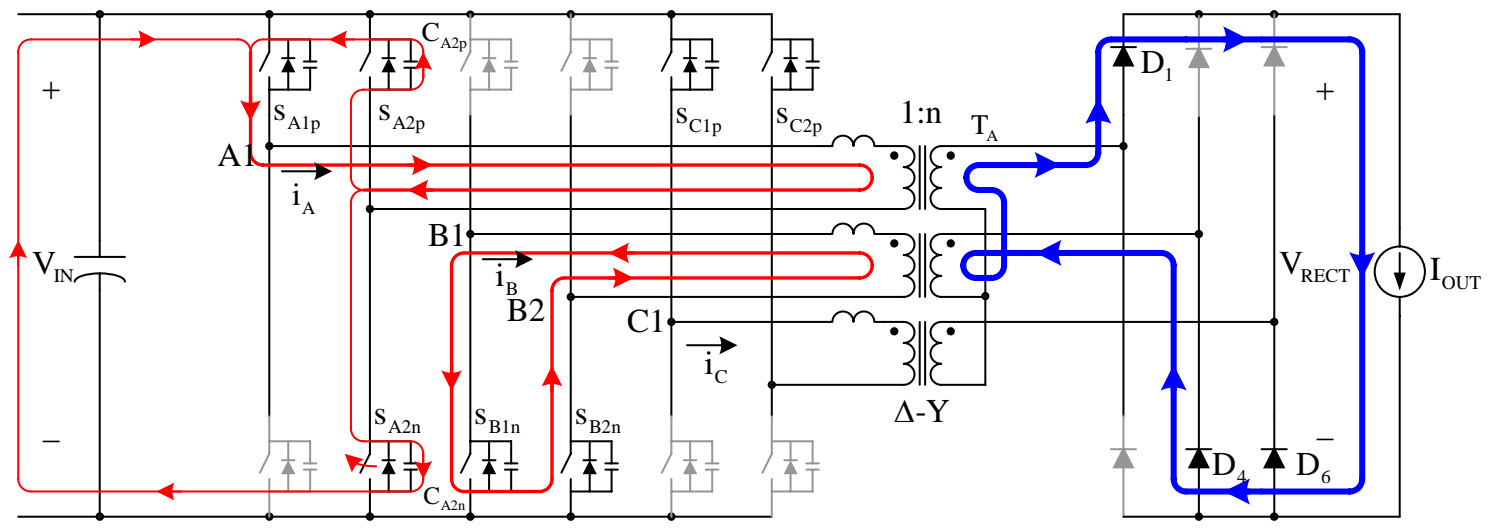

Figure 3.47 - V6 equivalent circuit: regulated converter mode 1 - cycle 1 stage 2

- At the beginning of the stage, a lagging leg switch $\left(\mathrm{s}_{\mathrm{A} 2 \mathrm{n}}\right)$ turns off. The phase current $\left(\mathrm{i}_{\mathrm{A}}\right)$ continues to flow while switch turns off, and soft-switching can not be achieved.

- When the lagging leg switch $\left(\mathrm{s}_{\mathrm{A} 2 \mathrm{n}}\right)$ is turned off, the current through the transformer primary is the output current reflected to the primary. Therefore, the energy of the large output filter inductor is used to discharge the opposite side device output capacitance $\left(\mathrm{C}_{\mathrm{A} 2 \mathrm{p}}\right)$. The midpoint voltage of the lagging leg $\left(\mathrm{V}_{\mathrm{A} 2}\right)$ rises from $0 \mathrm{~V}$ to $\mathrm{V}_{\mathrm{IN}}$.

- When the reflected output current fully discharges the switch output capacitance $\left(\mathrm{C}_{\mathrm{A} 2 \mathrm{p}}\right)$, it continues to flow through body diode $\left(\mathrm{D}_{\mathrm{A} 2 \mathrm{p}}\right)$ and circulates in phase $\mathrm{A}$. At this time, voltage across the phase transformer $\left(\mathrm{T}_{\mathrm{A}}\right)$ becomes zero, and power is discontinued from transmitting to load through this phase. 
3) V6 regulated converter mode 1 - Cycle 1, Stage 3: switch vector (110011)

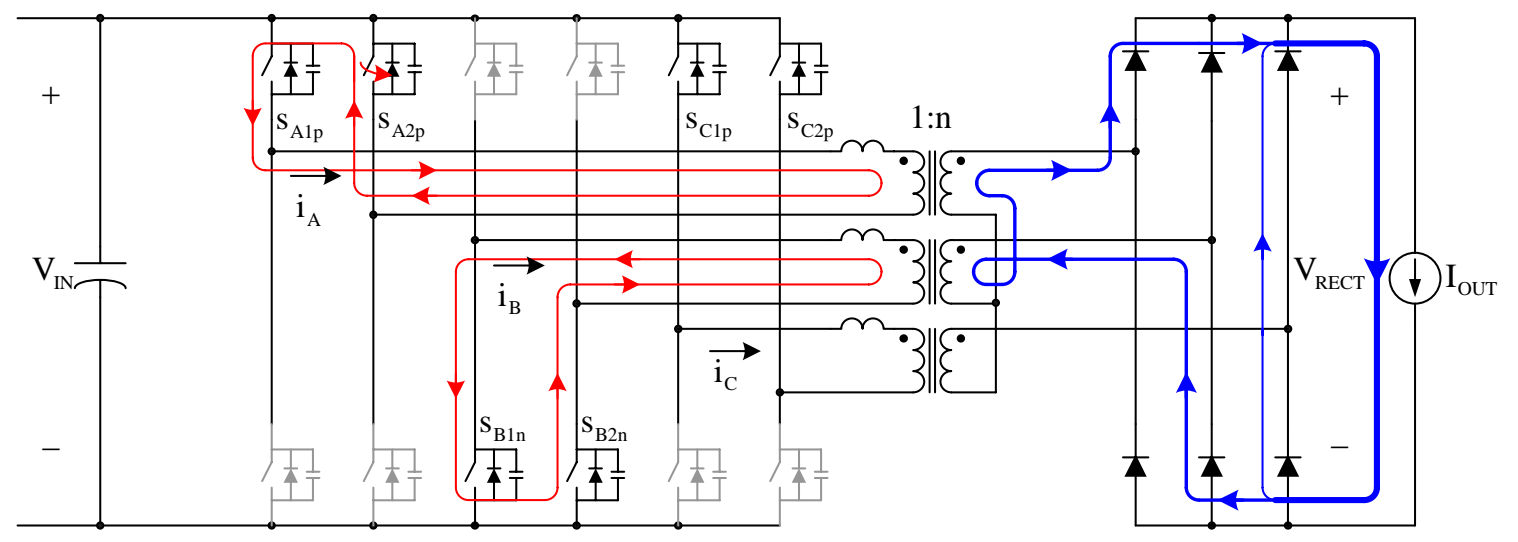

Figure 3.48 - V6 equivalent circuit: regulated converter mode 1 - cycle 1 stage 3

- At the beginning of the stage, a lagging leg switch $\left(\mathrm{s}_{\mathrm{A} 2 \mathrm{p}}\right)$ turns on. Voltage across the switch is zero, thus zero-voltage switching (ZVS) turn-on is achieved.

- Due to leakage inductance in phases, current continues to circulate in the primary. In the previous stage, the phase $\mathrm{C}$ current $\left(\mathrm{i}_{\mathrm{C}}\right.$ ) was reset to zero, and the transformer leakage inductance maintains zero current in phase $\mathrm{C}$ and continual current conduction in phase A and B.

- In mode 2, Y-connection in the secondary is the cause circulating current. However, in mode 1 , simply leakage inductance is the cause of the circulating current.

- All three phases are under freewheeling condition, which causes all transformer voltage to be $0 \mathrm{~V}$. Therefore, no power is being transmitted to load.

- All the rectifier diodes are forward biased. Circulating current in the primary reflects to secondary through transformers, and forces more current through some of rectifier diodes than others. The difference between the reflected circulating current and output current, $\mathrm{I}_{\mathrm{OUT}}$, freewheels through $\mathrm{D}_{5}$ and $\mathrm{D}_{6}$. Rectified output voltage, $\mathrm{V}_{\mathrm{RECT}}$, is $0 \mathrm{~V}$. 
4) V6 regulated converter mode 1 - Cycle 1, Stage 4: switch vector (1100X1)

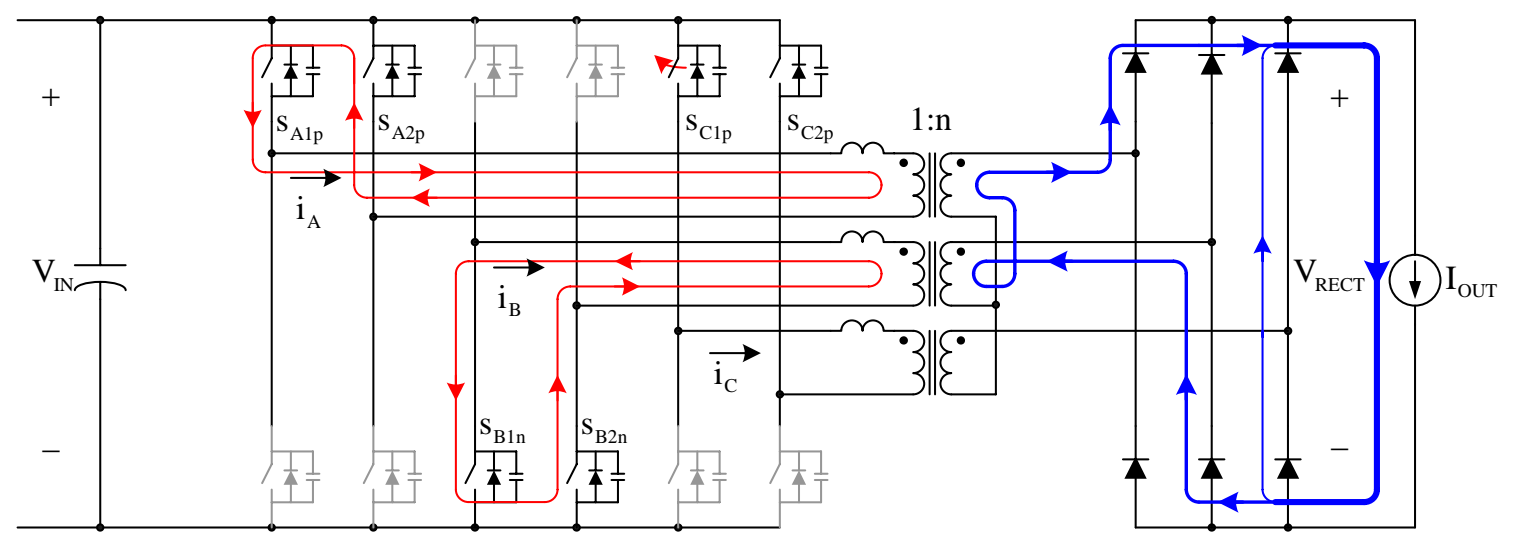

Figure 3.49 - V6 equivalent circuit: regulated converter mode 1 - cycle 1 stage 4

- At the beginning of the stage, a leading leg switch $\left(\mathrm{s}_{\mathrm{C} 1 \mathrm{p}}\right)$ turns off. The phase current $\left(\mathrm{i}_{\mathrm{C}}\right)$ is zero or near-zero, and zero-current switching (ZCS) turn-off is achieved.

- $\quad$ The stage condition remains the same as previous stage. 
5) V6 regulated converter mode 1 - Cycle 2, Stage 1: switch vector (110001)

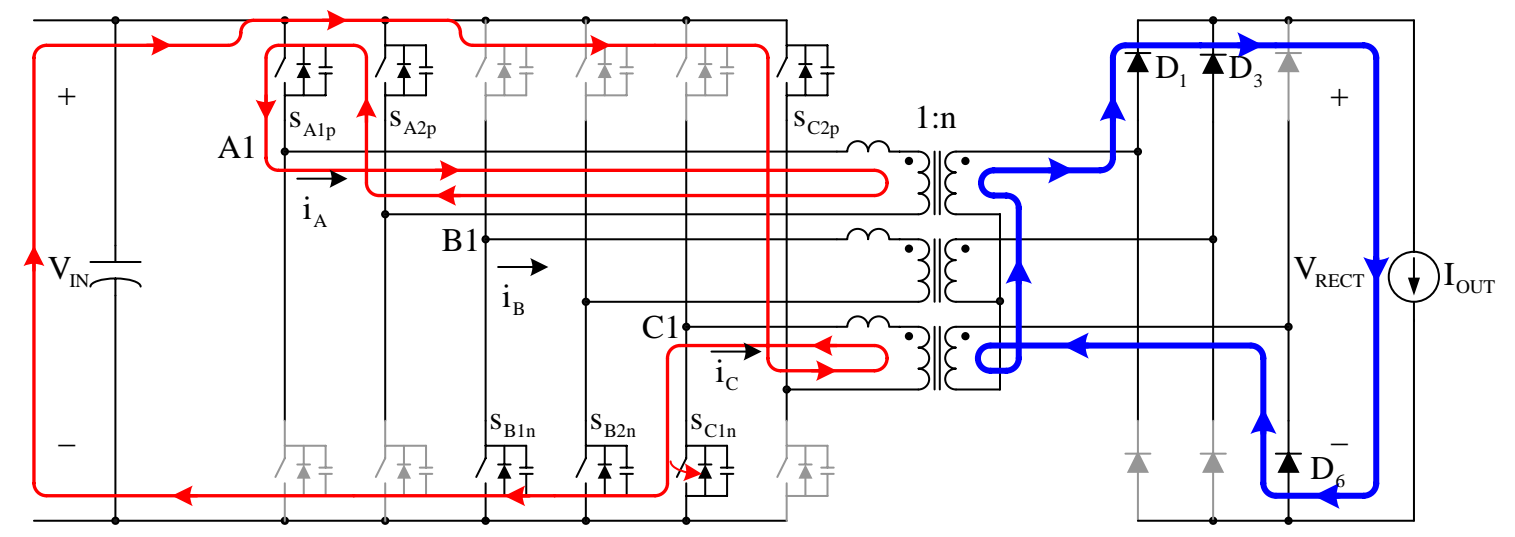

Figure 3.50 - V6 equivalent circuit: regulated converter mode 1 - cycle 2 stage 1

- At the beginning of the stage, a leading leg switch $\left(\mathrm{s}_{\mathrm{C} 1 \mathrm{n}}\right)$ turns on. As switch turns on, the phase current $\left(\mathrm{i}_{\mathrm{C}}\right)$ rapidly rises to match reflected load current, and phase midpoint voltage $\left(\mathrm{v}_{\mathrm{C} 1}\right)$ rapidly drops to zero. The leading leg switch turn-on takes place under hard-switching.

- When the leading leg switch $\left(\mathrm{s}_{\mathrm{C} 1 \mathrm{n}}\right)$ is turn on, the input voltage $\left(\mathrm{V}_{\mathrm{IN}}\right)$ is applied across the transformer leakage inductance of all phases. It causes the circulating current in phase $B\left(i_{B}\right)$ is reset to zero, and phase $A$ and $C$ current ( $i_{A}$ and $i_{C}$ ) rise and fall to match the reflected load current $\left(\mathrm{I}_{\mathrm{OUT}} / \mathrm{n}\right)$ and $\left(-\mathrm{I}_{\mathrm{OUT}} / \mathrm{n}\right)$, respectively.

- Phase $C$ applies negative input voltage $\left(-V_{\text {IN }}\right)$ to the phase transformer $\left(T_{C}\right)$ and transfers power to the load.

- $\quad D_{1}, D_{4}$ and $D_{6}$ are forward biased and conducting, and rectified output, $V_{\mathrm{RECT}}$, is $\mathrm{n} \cdot \mathrm{V}_{\mathrm{IN}}$.

- This stage is equivalent to the stage 1 of cycle 1 . The only difference is that the voltage status and current flow has shifted from phase to next phase. Each cycle is identical in operating principle. 


\subsubsection{V6 regulated converter mode 1 summary}

- Regulated converter mode 1 is present when phase-shift modulation angle is between $0^{\circ}$ and $60^{\circ}$. During this mode, at most one phase transfer input voltage to output side.

- When one phase is transferring input voltage to output side, rectified output voltage is $n \cdot V_{\text {IN }}$. When no phase is transferring, rectified output voltage is $0 \mathrm{~V}$. Rectangular waveform of given two voltages is produced, and phase-shift modulation controls the width of rectangle and regulates output voltage.

- ZVS turn-on is achieved on lagging leg switches. The ZVS is achieved using energy in both the leakage and output filter inductance. Therefore, ZVS can be easily achieved even during light load condition.

- $\quad$ Lagging leg switch turn-off takes place under hard-switching.

- $\quad$ Leading leg switch turn-on takes place under hard-switching.

- ZCS turn-off is achieved on leading leg switches. ZCS is achieved through resetting the phase current to zero with other phase.

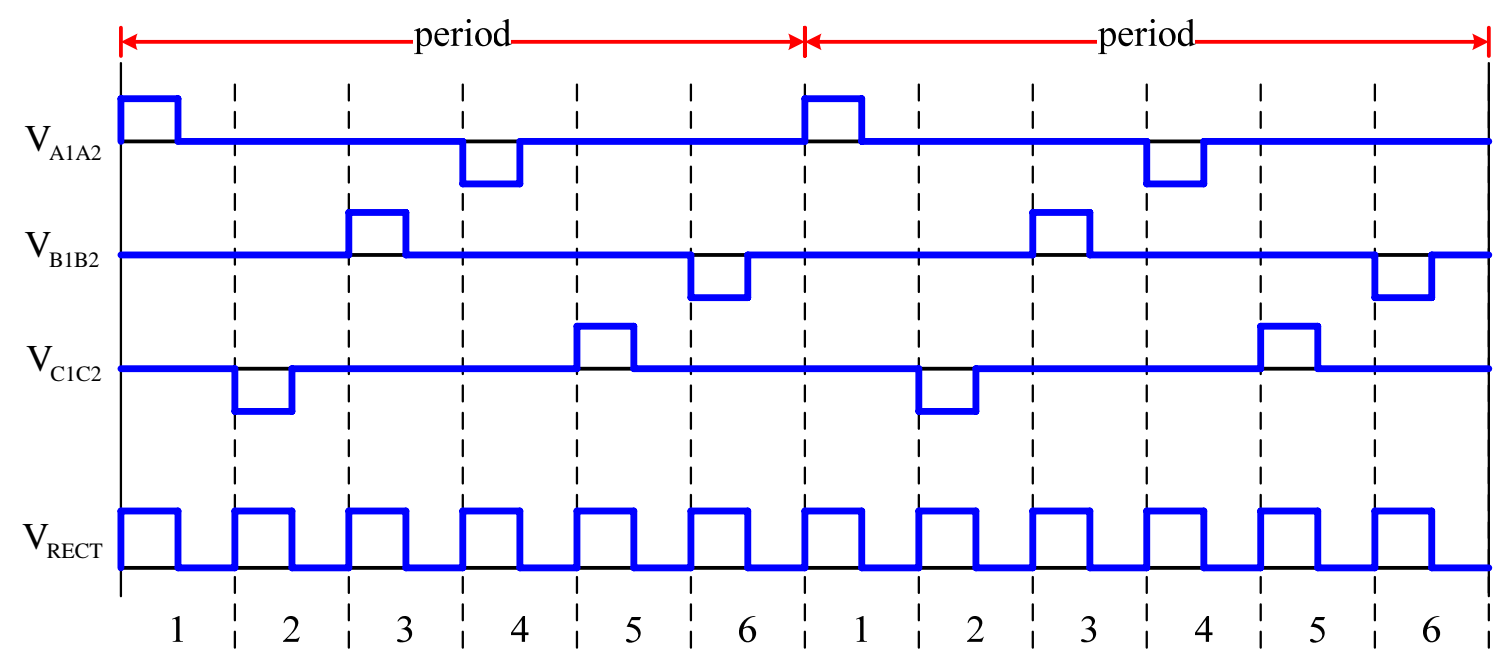

Figure 3.51 - V6 waveforms of three-phase output voltages and rectifier output voltage, $\mathrm{V}_{\mathrm{RECT}}$, in regulated converter mode 1 


\subsection{Chapter 3 summary}

In this chapter, the basic operations of multiphase dc-dc converters are examined and described in detail. The multiphase converters' interleaving control and paralleled phases enable higher power handling capabilities, higher power densities, lower components stresses, etc. Strenuous requirements, such as a high voltage conversion ratio and high current handling capabilities, severely limit employment of single-phase converters; however, the advantages of the multiphase converters become crucially important to meet the requirements when it comes to low-voltage, high-current fuel cell application.

Among the surveyed multiphase topologies, two of the multi-phase converters, V3 and V6, appear to be capable of achieving the requirements with soft-switching capabilities. In addition to all the benefit of the multiphase converters, proper selections of converter topology enable soft-switching and beneficial utilization of the converter parasitic components. Additionally, both V3 and V6 achieve soft-switching without any additional components. It is attractive for high-power applications because of the potential efficiency improvement without size, weight and/or cost penalty. 


\section{Performance Evaluation V3 and V6}

In chapter 3, the basic operation of V3 and V6 converters are theoretically analyzed. In this chapter, hardware prototypes are built and tested to compare the performance of V3 and V6 converters. Figure 4.1 shows pictures of V3 and V6 converter prototypes. An approximate size of each converter is 11 inches by 15.5 inches.
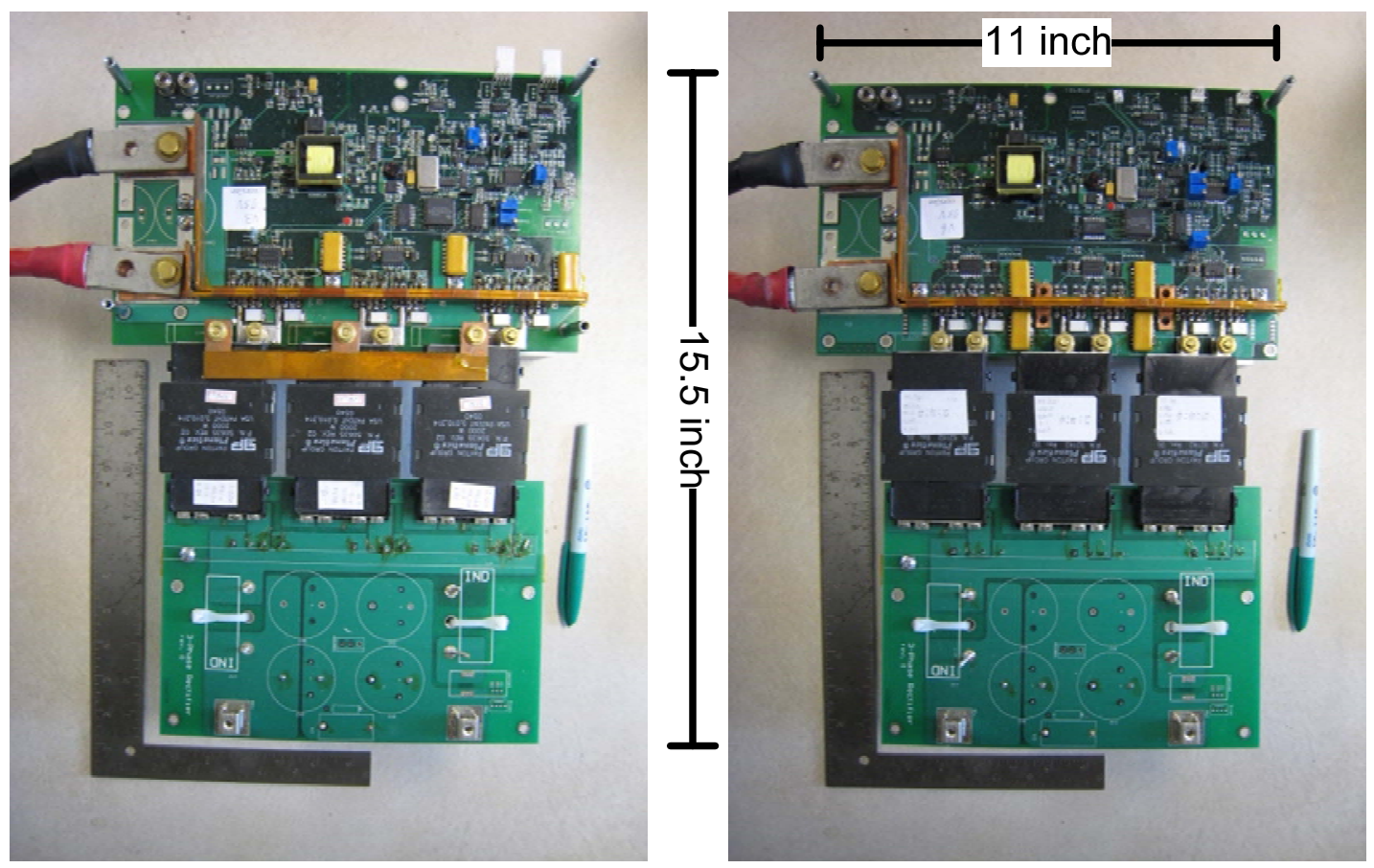

Figure 4.1 - V3 (Left) and V6 (Right) converter prototypes

Figure 4.2 illustrates the building blocks of the prototype, which include an input filter, auxiliary power supplies, a three-phase controller, sensing circuits, gate drivers, a three-phase power stage, three high-frequency transformers, a three-phase rectifier and a LC filter. This particular image is based on V3 converter; however, V6 shares similar building blocks. 


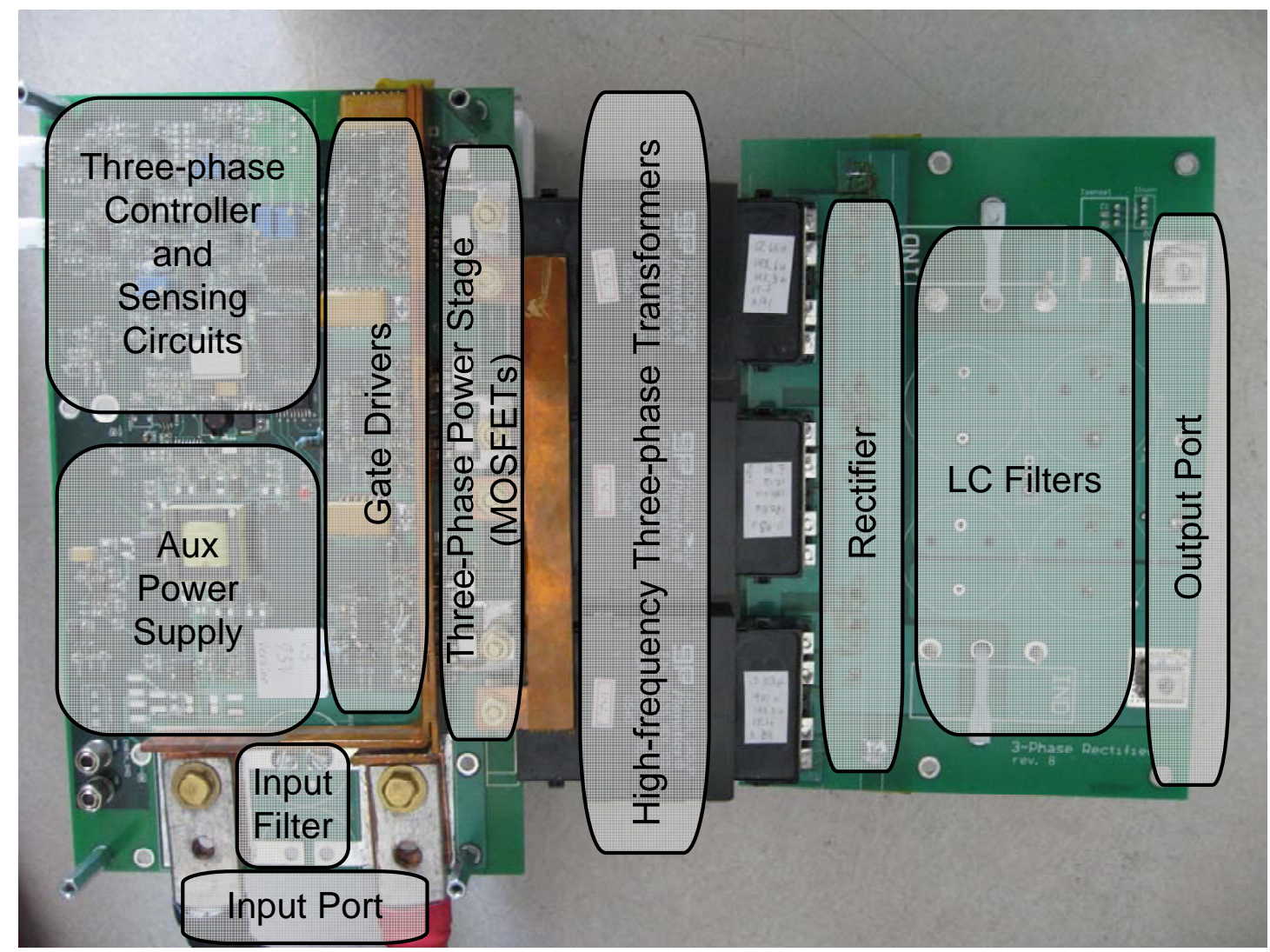

Figure 4.2 - Three-phase converter building blocks (V3)

\subsection{Transformer Setting Comparison}

Among the four possible three-phase transformer configurations, $\Delta-\Delta, \Delta-\mathrm{Y}, \mathrm{Y}-\mathrm{Y}$ and $\mathrm{Y}-\Delta$, V3 utilizes the Y-Y configuration and V6 utilizes the $\Delta-\mathrm{Y}$ configuration. The $\Delta-\Delta$ and the $\mathrm{Y}-\mathrm{Y}$ transformer configurations provide the same conversion ratio as the turns ratio, since primary and secondary configuration is the same. In other words, assuming turns ratio is one to one, 1 unit of input voltage results in 1 unit of output voltage. On the other hand, when the primary configuration differs from the secondary, such as the $\Delta-Y$ or the Y- $\Delta$, the conversion ratio is not the same as the turns ratio. For an instance, it is well known that when three-phase sinusoidal inputs are applied to $\Delta$-Y or $\mathrm{Y}-\Delta$ configuration, outputs are increased or decreased by a factor of square root of 3 , respectively.

However, instead of the sinusoidal inputs, if rectangular waveforms are used with $\Delta$ $\mathrm{Y}$ or $\mathrm{Y}-\Delta$ configuration, the output voltages are increased or decreased by a factor of 2 , 
rather than square root of 3 . In the case of $\Delta$-Y connection, if positive 1 per unit (pu) voltage is applied to one transformer input and negative 1 pu voltage is applied to the other, then 2 pu voltage is induced on the secondary output. For an example, if $\mathrm{V}_{\mathrm{A} 1 \mathrm{~A} 2}=1$ pu and $\mathrm{V}_{\mathrm{B} 1 \mathrm{~B} 2}=-1 \mathrm{pu}$, then the sum of induced secondary transformer output is $\mathrm{V}_{\mathrm{XY}}=2 \cdot \mathrm{n}$ $\mathrm{pu}$, which is twice the single-phase or $\mathrm{Y}-\mathrm{Y}$ transformer output. Figure 4.3 illustrates the $\mathrm{Y}-\mathrm{Y}$ and the $\Delta-\mathrm{Y}$ transformer configurations.
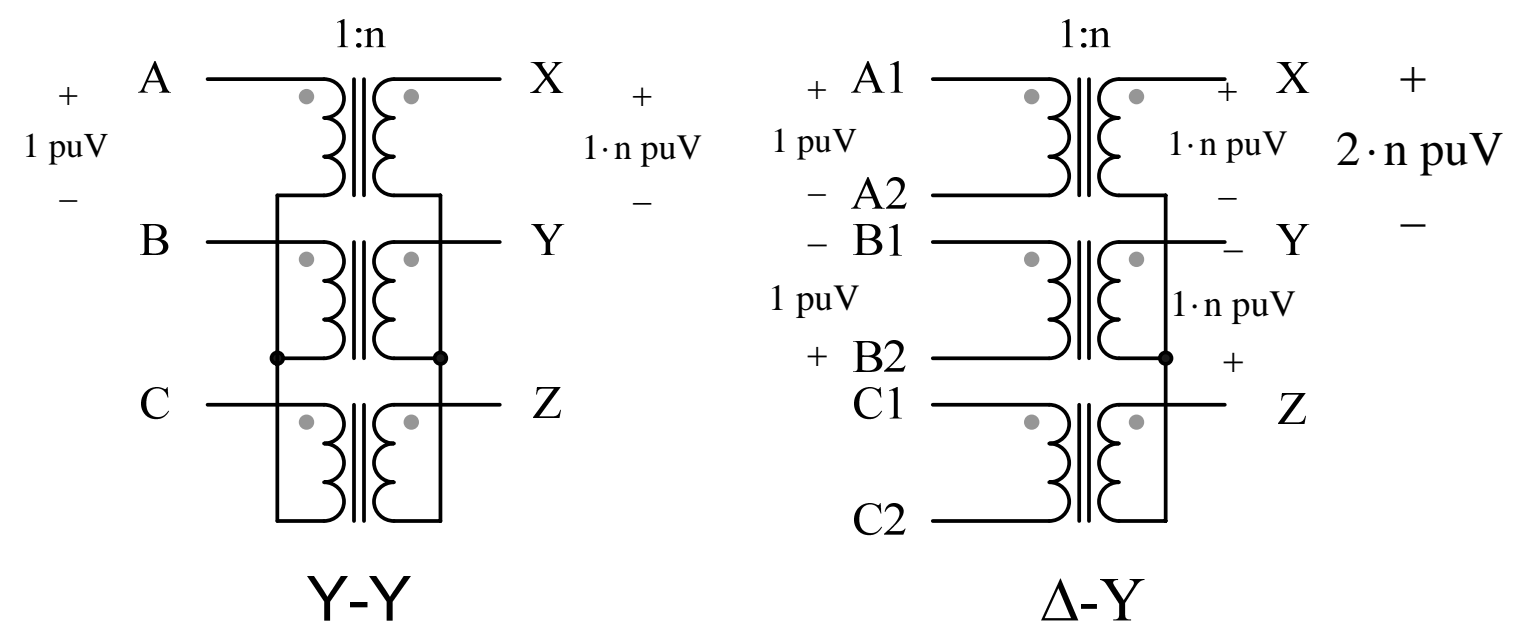

Figure 4.3 - Y-Y and $\Delta-\mathrm{Y}$ transformer configurations

Fuel cell applications require a high conversion ratio, from $20 \sim 60 \mathrm{~V}$ input to $400 \mathrm{~V}$ output, and the high conversion ratio calls for a high transformer turns ratio. For an instance with $25 \mathrm{~V}$ input and $400 \mathrm{~V}$ output, 1:16 conversion ratio and the same transformer turns ratio are needed in the $\mathrm{Y}-\mathrm{Y}$ or the $\Delta-\Delta$ transformer configuration. In contrast, the $\Delta-Y$ transformer configuration shows a voltage doubling effect, and it effectively reduces the turns ratio by half, which cuts down on the transformer turns ratio from 1:16 to 1:8. Table 4.1 shows typical transformer turns ratios required with the $\mathrm{Y}-\mathrm{Y}$ or the $\Delta-Y$ transformer configuration for a given input voltage and a desired output voltage.

In order to produce the same output voltage with the same input voltage, the $\mathrm{Y}-\mathrm{Y}$ transformer configuration must have a higher turns ratio than the $\Delta-Y$ transformer configuration. One consequence of the high turns ratio is a higher leakage inductance. Although the leakage inductance is needed for soft-switching, an excessive leakage 
inductance is undesirable, since it tends to reduce effective duty cycles and increase conduction losses. Especially, the increase of the conduction losses is objectionable in high-current applications, where the conduction loss is responsible for the majority of losses. In three-phase converters, the flexibility to adopt appropriate three-phase transformer configurations and the turns ratio gives a freedom to optimize designs and produce desired outputs. Therefore, one of design constraints is to make trade-offs between the transformer turn count and the leakage inductance.

Table 4.1 - Transformer turns ratio for V3 and V6

\begin{tabular}{|c|c|c|c|}
\hline \multirow{2}{*}{ Input Voltage } & Transformer & \multicolumn{2}{|c|}{ Output Voltage } \\
\cline { 3 - 4 } & Configuration & $200 \mathrm{~V}$ & $400 \mathrm{~V}$ \\
\hline $25 \mathrm{~V}$ & $\mathrm{Y}-\mathrm{Y}(\mathrm{V} 3)$ & $1: 8$ & $1: 16$ \\
\cline { 2 - 4 } & $\Delta-\mathrm{Y}(\mathrm{V} 6)$ & $1: 4$ & $1: 8$ \\
\hline $50 \mathrm{~V}$ & $\mathrm{Y}-\mathrm{Y}(\mathrm{V} 3)$ & $1: 4$ & $1: 8$ \\
\cline { 2 - 4 } & $\Delta-\mathrm{Y}(\mathrm{V} 6)$ & $1: 2(2: 4)$ & $1: 4(2: 8)$ \\
\hline
\end{tabular}

In the case of $50 \mathrm{~V}$ input of V6, turn count in hardware implementation are doubled, which is shown in brackets. In V6, input voltage is imposed across one transformer, where as in V3, input voltage is imposed across two transformers. A small turns ratio leads to a small magnetizing inductance, and a high input voltage with the small magnetizing inductance causes excessive magnetizing current. Therefore, the turn count of the V6 transformers are increased to magnetizing inductance and to reduce magnetizing currents. 


\subsection{High-frequency Ripple Operation}

An interleaving control scheme produces high operating frequencies while keeping switching frequencies low. Figure 4.4 shows an example waveform of the highfrequency ripple operation with V6 converter. Channel 1, 2 and 3 represent the gate signal of each phases, and channel 4 represent output inductor current. Control signals are interleaved $120^{\circ}$ apart and operate at approximately $50 \mathrm{kHz}$. As the result of the interleaving control, the inductor ripple current is approximately $300 \mathrm{kHz}$, which is much higher than the switching frequency. The high operating frequency of multiphase converters reduces the current and the voltage ripples in input and output, which lead to size, weight and cost reduction of passive components.

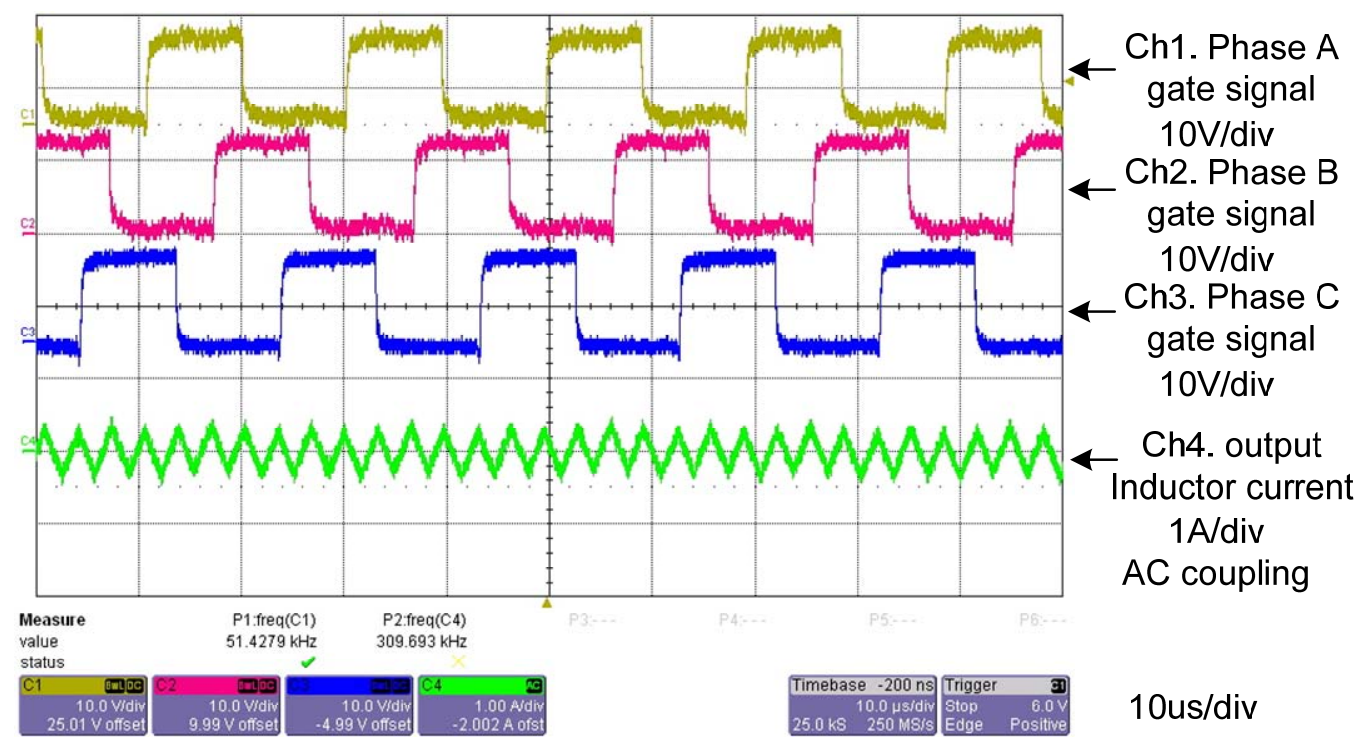

Figure 4.4 - High-frequency ripple operation with the three-phase interleaving control scheme of V6 


\subsubsection{High-frequency operation in the regulated converter mode}

One of the advantages of the multiphase converters is that the effective operating frequency is higher than actual switching frequency. For an instance, when switching frequency is $50 \mathrm{kHz}$, the effective operating frequency of V3 and V6 converter are 150 $\mathrm{kHz}$ and $300 \mathrm{kHz}$, respectively. The low switching frequency keeps switching stresses on individual device low, and the high operating frequency reduces size, weight and cost of passive components.

Figure 4.5 shows V3 high-frequency operation in the regulated converter mode with $20 \%$ duty cycle. Figure 4.6 and Figure 4.7 show V6 high-frequency operation in the regulated converter mode 1 with $30^{\circ}$ modulation angle and the mode 2 with $90^{\circ}$ modulation angle, respectively. In each figure, channel 1 and 2 respectively represent phase A upper and lower gate signals for V3 and leading and lagging leg gate signals for V6. Channel 3 represents rectified three-phase output at $V_{\text {RECT }}$, and channel 4 represents output inductor current. Channel 4 is ac coupled instead of dc coupling for a closer look at the ripple current.

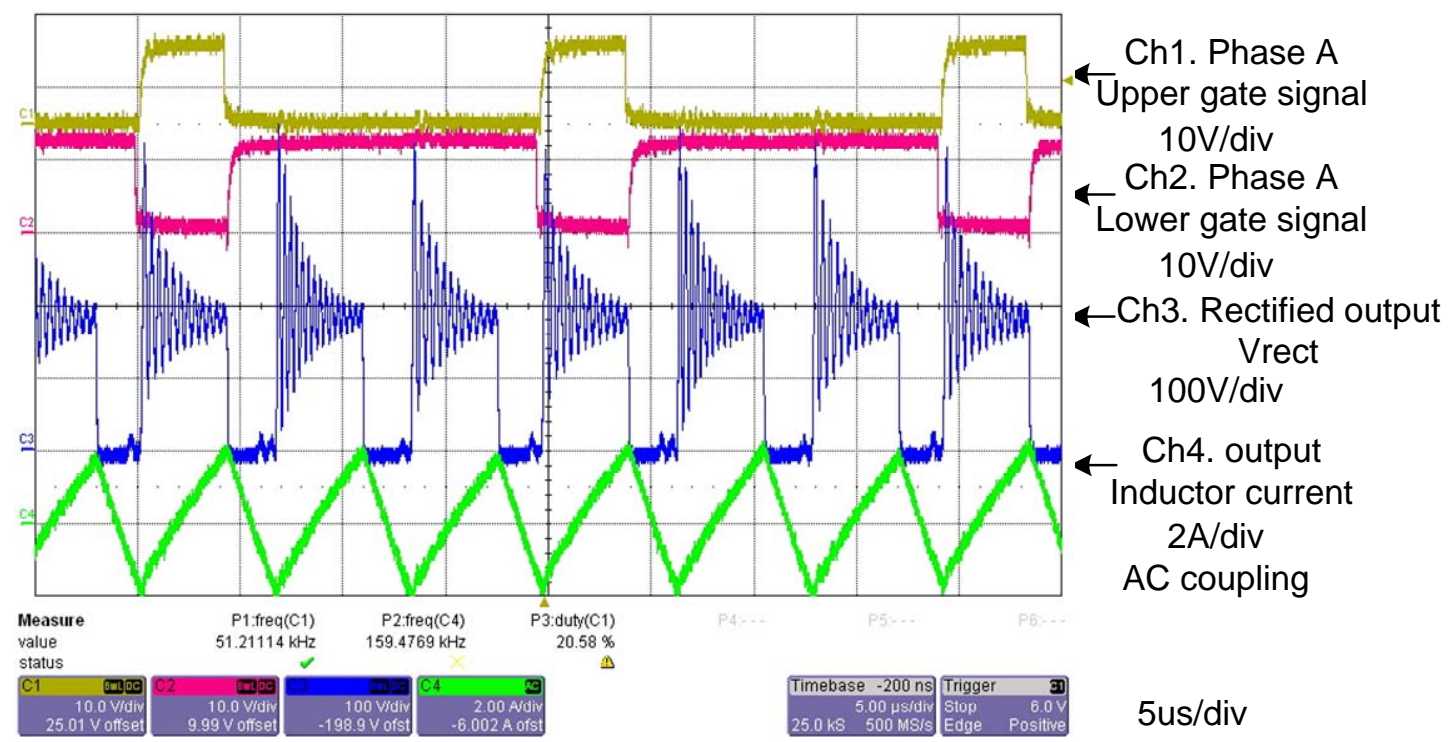

Figure 4.5 - V3 high-frequency operation in regulated converter mode 


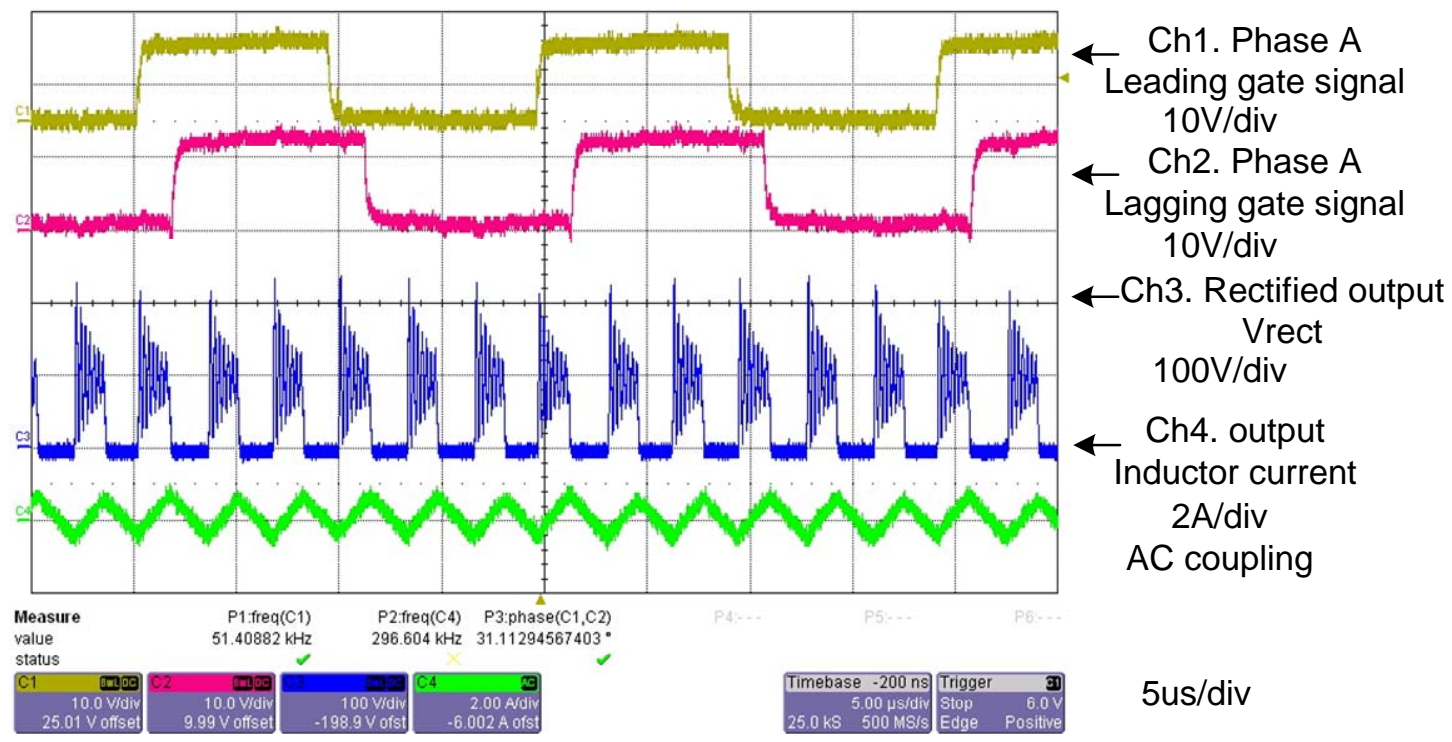

Figure 4.6 - V6 high-frequency operation in regulated converter mode 1

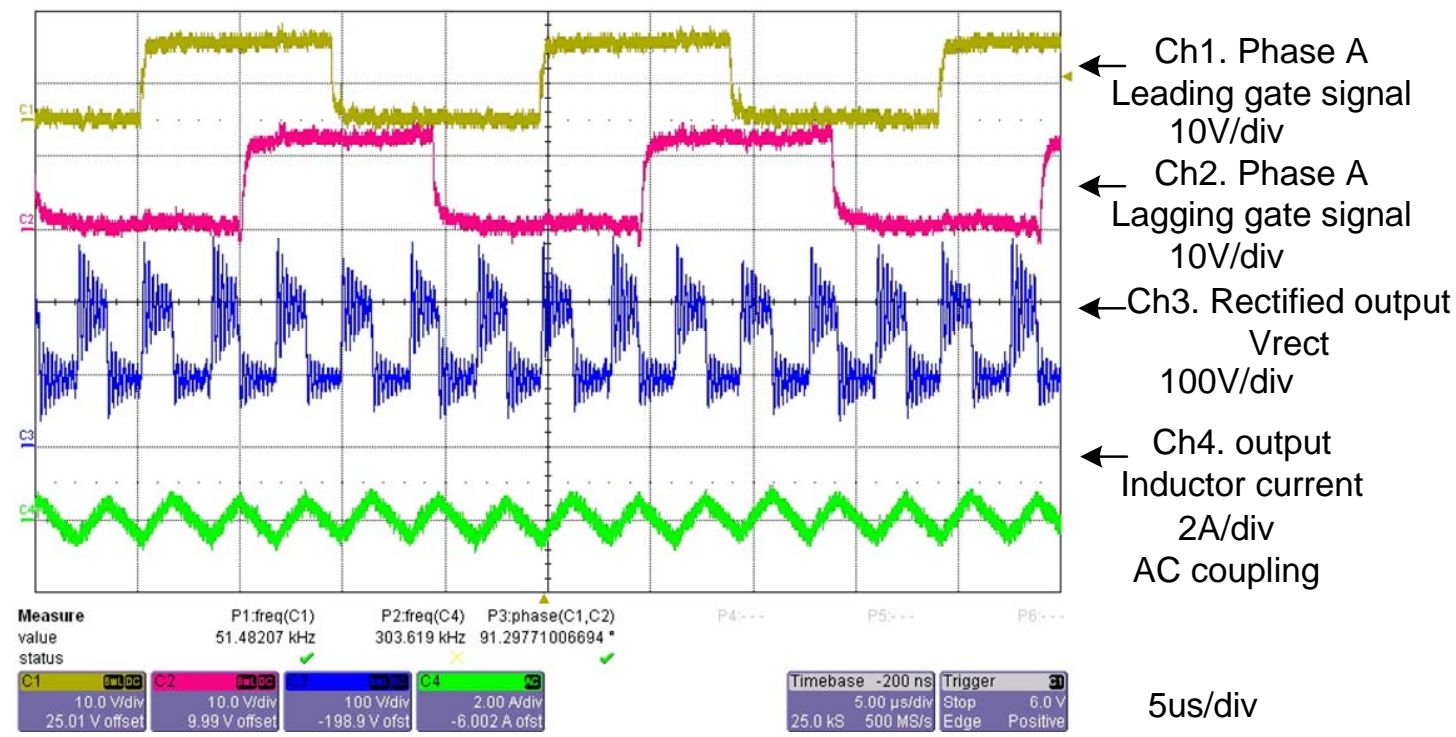

Figure 4.7 - V6 high-frequency operation in regulated converter mode 2

First, high effective operating conditions can be observed in the waveforms. The switching in both V3 and V6 is $50 \mathrm{kHz}$, and their effective operating frequencies are 150 $\mathrm{kHz}$ and $300 \mathrm{kHz}$ for V3 and V6, respectively.

Second, the amplitude of the ripple currents in V6 is significantly lower than V3. The current ripple in V3 is approximately 4 A peak-to-peaks. For the same load condition and the same filter inductance value, the current ripple in V6 is approximately 1 A peak- 
to-peaks. V6 current ripple amplitude is about one-fourth of V3 due to high operating frequencies and lower amplitudes of rectified waveform.

In V3's regulated converter mode, the rectified waveform move up and down between $0 \mathrm{~V}$ and $200 \mathrm{~V}$. In V6's regulated converter mode 1, the rectified waveform move up and down between $0 \mathrm{~V}$ and $100 \mathrm{~V}$, and in the mode 2, the rectified waveform move up and down between $100 \mathrm{~V}$ and $200 \mathrm{~V}$. In other words, V3 exhibits waveform amplitude about 200 V peak-to-peaks, while V6 exhibits amplitude about half of V3 at $100 \mathrm{~V}$ peak-to-peaks.

Two times faster operating frequency and one-half of $\mathrm{V}_{\text {RECT }}$ amplitude produce about one-fourth of current ripple amplitude, and the lower current ripple reuires smaller inductors for filtering. 


\subsubsection{High-frequency operation in the dc transformer mode}

Both V3 and V6 feature the dc transformer mode, which output voltages remain constant multiples of input voltage regardless of duty cycle or phase-shift modulation angle. Figure 4.8 and Figure 4.9 illustrate the high-frequency operating in the dc transformer mode in V3 with $50 \%$ duty cycle and in V6 with $150^{\circ}$ modulation angle, respectively.

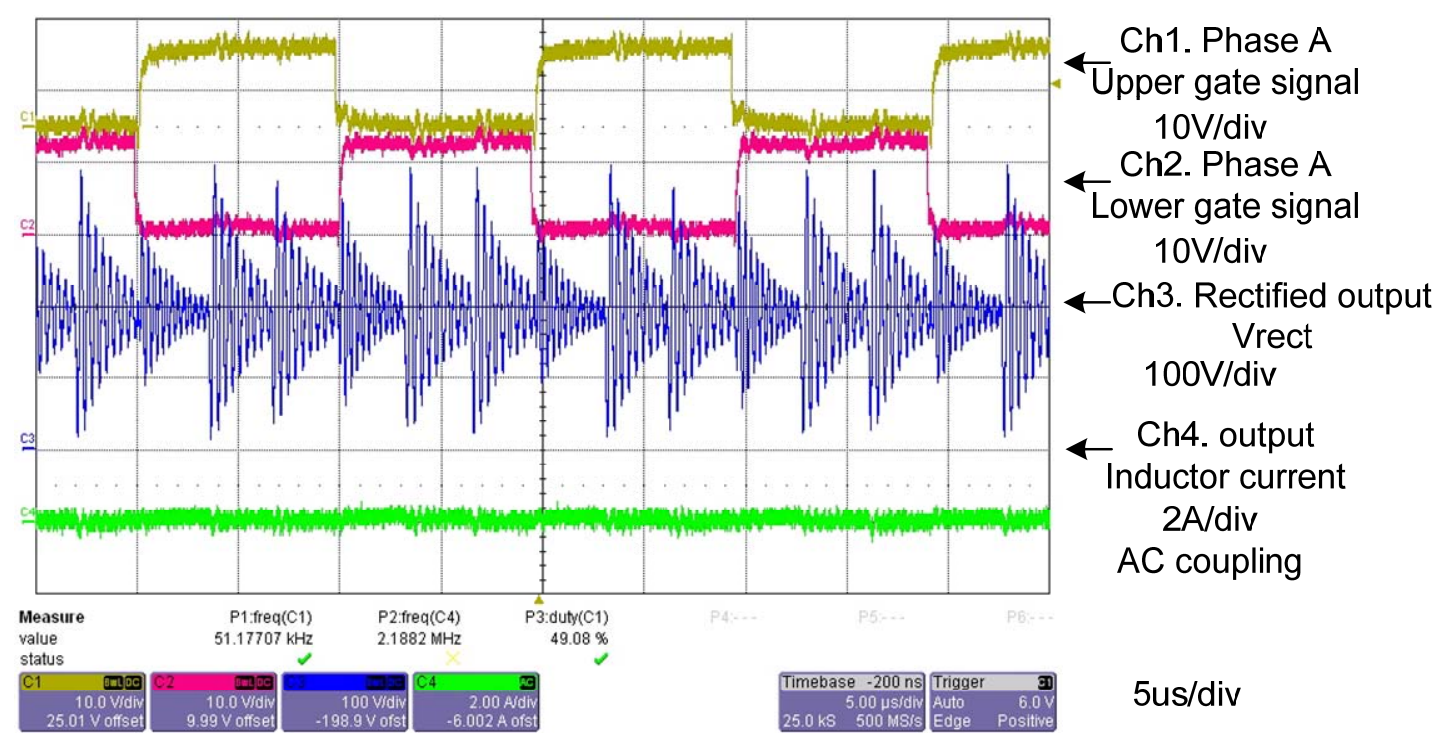

Figure 4.8 - V3 high-frequency operation in dc transformer converter mode

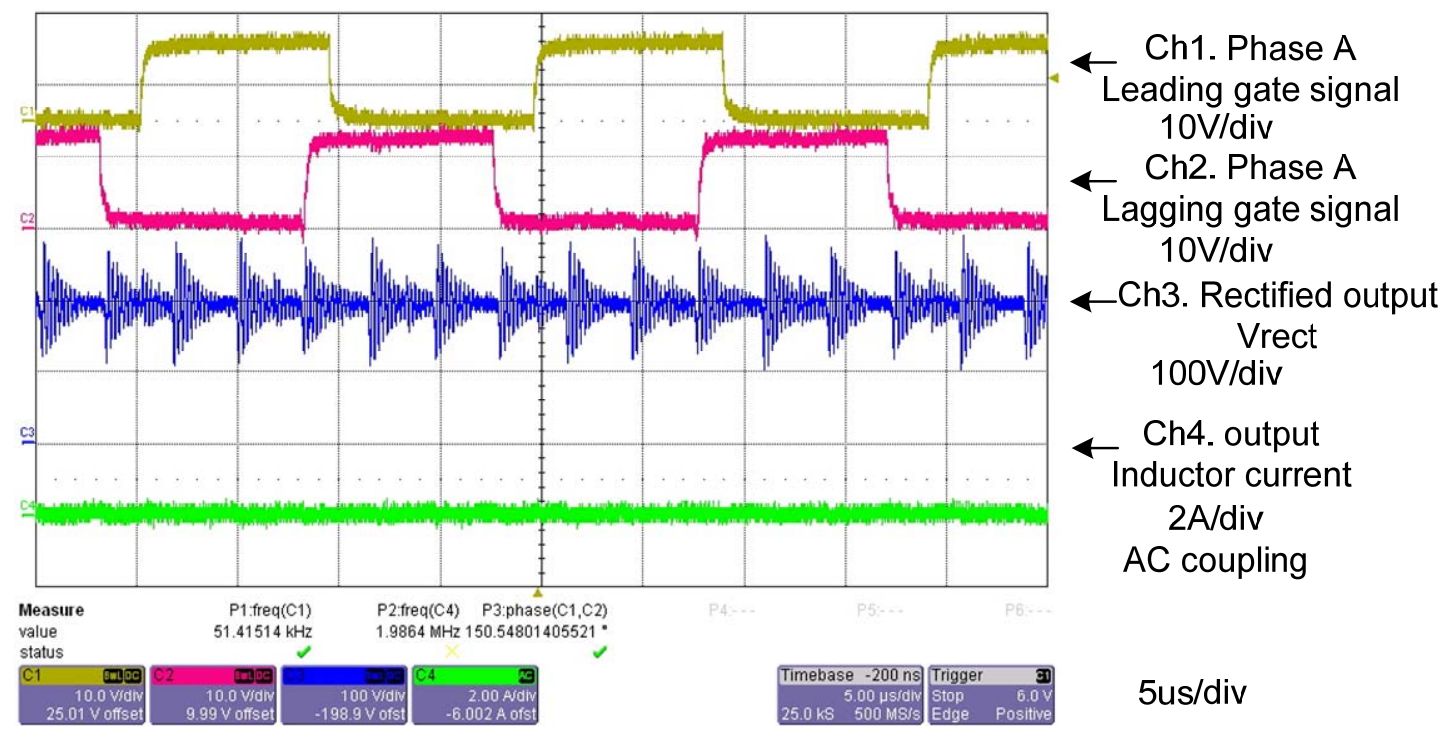

Figure 4.9 - V6 high-frequency operation in dc transformer converter mode 
The rectified waveforms show $200 \mathrm{~V}$ dc output with parasitic ringing on the top of dc output. V3 shows about $350 \mathrm{~V}$ peak-to-peaks ringing, and V6 shows about $170 \mathrm{~V}$ peakto-peaks ringing. One obvious reason for the ringing could be due to switching noises; however, soft-switching lessens effect of hard commutation on ringing. A bigger cause of the parasitic ringing is loss of duty cycle. As mentioned in the operating principles of V3 and V6 in chapter 3, rectified output momentary drops to lower voltages during switching transition, which is called loss of duty cycle. This short momentary voltage drop excites parasitic elements and causes the high frequency ringing. The amplitudeof voltage drop is about one half of $\mathrm{V}_{\text {OUT }}$ in V3 and is about one fourth of $\mathrm{V}_{\text {OUT }}$ in V6.

The high amplitude of the parasitic ringing may damage rectifying diodes, and the diodes may require snubbers for protection. However, no snubbers are used in experiments.

Without the parasitic ringing, the rectified output is constant, and the output inductor current is flat. The parasitic ringing is very high frequency and has negligible effects on inductor currents. 


\subsection{Soft-switching Condition Comparison}

Although the conduction losses from high-current condition are responsible for the majority of power losses in low-voltage, high-power fuel cell applications, switching losses are also responsible for significant power losses in high-frequency converters. In order to achieve high efficiency, soft-switching is required. In the previous chapter, V3 and V6 are analyzed and soft-switching conditions are identified. To verify the finding, prototype converters are tested and related waveforms are captured.

\subsubsection{V3 soft-switching waveforms}

V3 is capable of zero-voltage switching (ZVS) by discharging the device output capacitance with energy stored in leakage inductance and output filter inductor and let the phase current flow in the body diode before turning on the device.

V3 converter has two distinctive operating conditions, dc transformer mode and regulated converter mode. Figure 4.10 to Figure 4.12 are waveforms of the converter operating under dc transformer mode $(1 / 3<\mathrm{D}<2 / 3)$ and Figure 4.13 to Figure 4.15 are waveforms under regulated mode $(0<D<1 / 3$ and $2 / 3<D<1)$.

Each mode is tested under two different loading conditions, heavy and light load. Heavy load refers to $56 \Omega$ load, which corresponds to approximately $3 \mathrm{~kW}$ in $400 \mathrm{~V}$ output, and light load refers to approximately $10 \%$ of heavy load, $500 \Omega$. $50 \mathrm{~V}$ dc is used as input voltage. Duty cycle for dc transformer mode and regulated mode are 0.5 and 0.3 , respectively. Test conditions are summarized in Table 4.2. 
Table 4.2 - V3 test condition chart

\begin{tabular}{|c|c|c|c|c|c|c|}
\hline $\begin{array}{c}\text { Mode } \\
\text { (Duty cycle) }\end{array}$ & $\begin{array}{c}\mathrm{V}_{\text {IN }} \\
(\mathrm{V})\end{array}$ & $\begin{array}{c}\mathrm{I}_{\mathrm{IN}} \\
(\mathrm{A})\end{array}$ & $\begin{array}{c}\mathrm{V}_{\text {OUT }} \\
(\mathrm{V})\end{array}$ & $\begin{array}{c}\mathrm{I}_{\mathrm{OUT}} \\
(\mathrm{A})\end{array}$ & $\begin{array}{c}\mathrm{P}_{\text {OUT }} / \mathrm{P}_{\text {IN }} \\
\approx \mathrm{Eff}\end{array}$ & Notes \\
\hline $\begin{array}{c}\text { Dc transformer } \\
\text { mode } \\
(50 \%)\end{array}$ & 50.0 & 60.9 & 390.5 & 7.5 & $\begin{array}{c}2928 / 3045 \\
\approx 96.2 \%\end{array}$ & $\begin{array}{c}\text { Heavy load } \\
\text { Figure 4.10 }\end{array}$ \\
\cline { 2 - 7 } & 50.2 & 7.4 & 403.6 & 0.83 & $\begin{array}{c}335 / 372 \\
\approx 90.1 \%\end{array}$ & $\begin{array}{c}\text { Light Load } \\
\text { Figure 4.12 }\end{array}$ \\
\hline $\begin{array}{c}\text { Regulated } \\
\text { converter mode } \\
(30 \%)\end{array}$ & 50.1 & 49.0 & 347.8 & 6.7 & $\begin{array}{c}2330 / 2455 \\
\approx 95.0 \%\end{array}$ & $\begin{array}{c}\text { Heavy load } \\
\text { Figure 4.13 }\end{array}$ \\
\cline { 2 - 7 } & 50.1 & 7.1 & 395.3 & 0.81 & $\begin{array}{c}320 / 355 \\
\approx 90.0 \%\end{array}$ & $\begin{array}{c}\text { Light load } \\
\text { Figure 4.15 }\end{array}$ \\
\hline
\end{tabular}

Notes: values in the table are rounded to the nearest $1 / 10^{\text {th }}$ of value, and it does not accurately represent efficiency. Rather, it is intended to show test conditions.

Two types of waveforms are captures for V3. First type captures upper leg and lower leg soft switching states. Channel 1 and 3 represent upper device gate signal $\left(\mathrm{V}_{\mathrm{GS}}\right)$ and device voltage $\left(\mathrm{V}_{\mathrm{DS}}\right)$, respectively. Likewise, channel 2 and 4 represent lower device gate signal $\left(\mathrm{V}_{\mathrm{GS}}\right)$ and device voltage $\left(\mathrm{V}_{\mathrm{DS}}\right)$, respectively. This type of figure is marked with single cross $(\dagger)$.

Second type of waveforms captures phase currents along with gate signal and device. Phase current helps to explain the manner that is used achieve zero-voltage switching (ZVS). Channel 1 and 2 represent upper device gate signals $\left(\mathrm{V}_{\mathrm{GS}}\right)$ and device voltage $\left(\mathrm{V}_{\mathrm{DS}}\right.$ ), respectively. Channel 3, channel 4 and function4 (F4) represent current through phase $A, B$ and $C\left(i_{A}, i_{B}\right.$, and $\left.i_{C}\right)$, respectively. Phase currents are measured in transformer secondary side. Transformer turns ratio of 1:8 is used. Therefore, $5 \mathrm{~A} / \mathrm{div}$ in secondary corresponds to $40 \mathrm{~A} / \mathrm{div}$ in the primary. This type is marked with double cross $(\dagger \dagger)$. 


\subsubsection{V3 soft-switching waveforms: dc transformer mode}

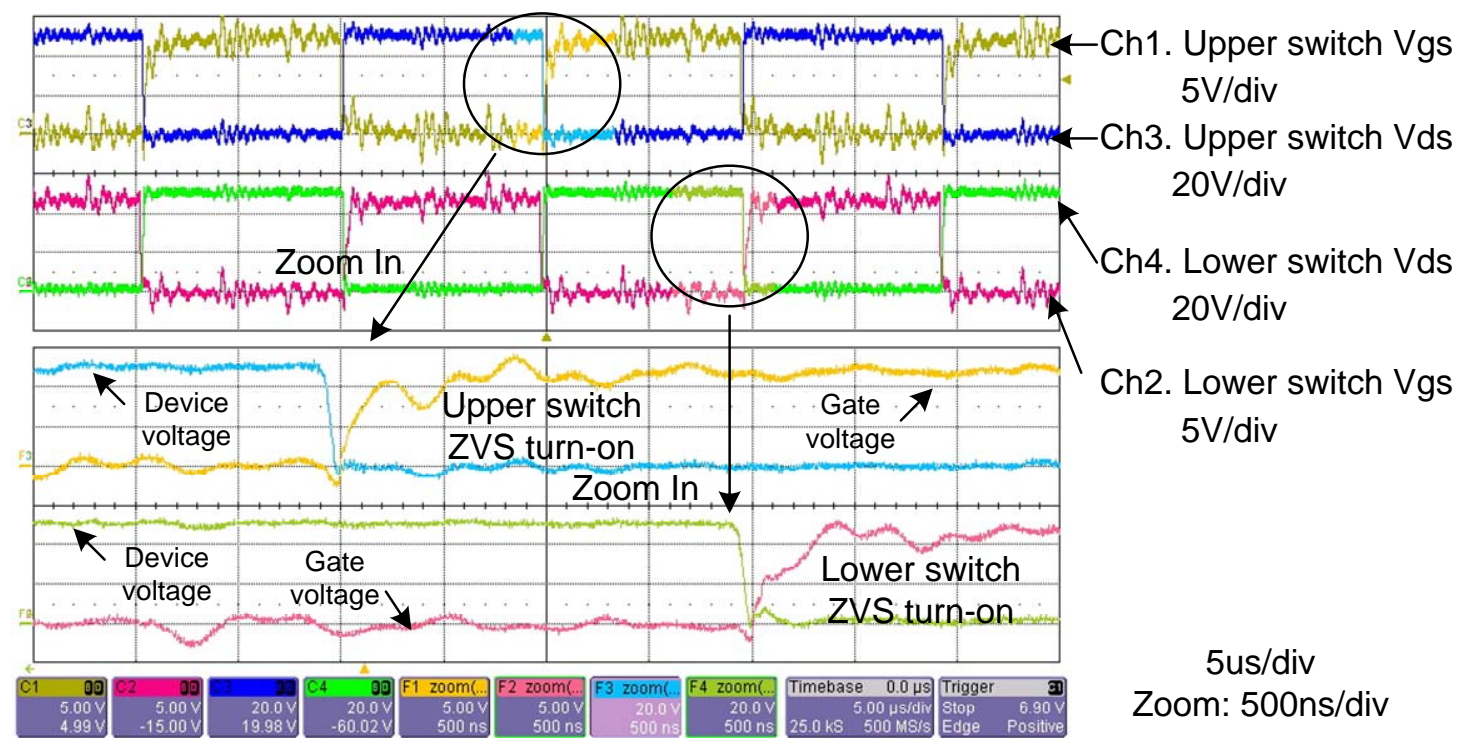

Figure 4.10 - V3 soft switching status: 50\% duty, heavy load (†)

Figure 4.10 captures V3 soft switching status during 50\% duty cycle and heavy load. As shown in the zoomed waveform, device voltage drops to zero before gate voltage rises and device turns on. Both upper and lower switches achieve zero voltage switching (ZVS). 


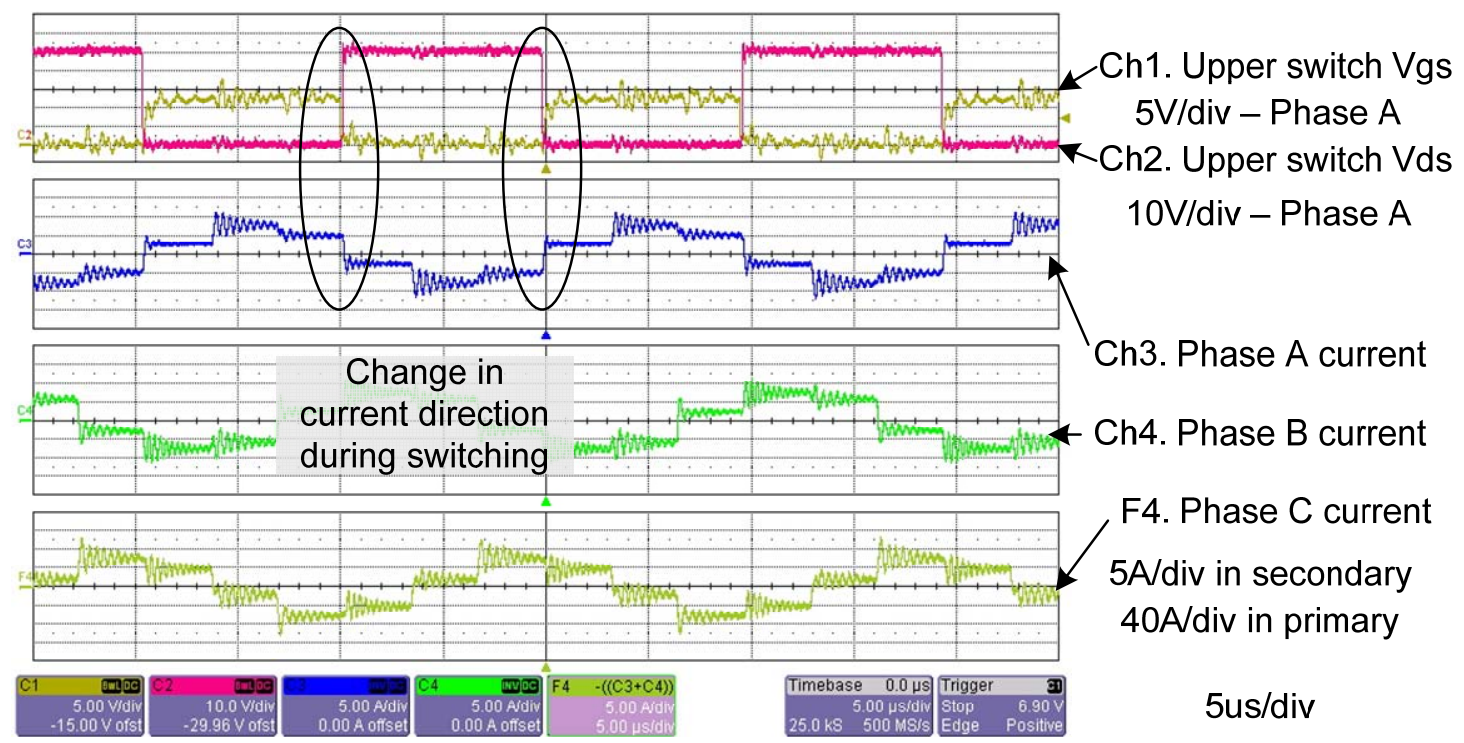

Figure 4.11 - V3 phase currents: 50\% duty, heavy load (††)

Figure 4.11 captures V3 phase currents during 50\% duty cycle and heavy load. First grid shows upper switch gate signal and device voltage, and second grid shows corresponding phase current. Third and fourth grid shows currents in other phases.

Circled parts in Figure 4.11 shows change in current direction during upper device turn on and off. Change in current direction signifies resonance between transformer leakage inductance and device output capacitance. In other words, energy stored in the transformer leakage inductance is utilized to achieve ZVS. 


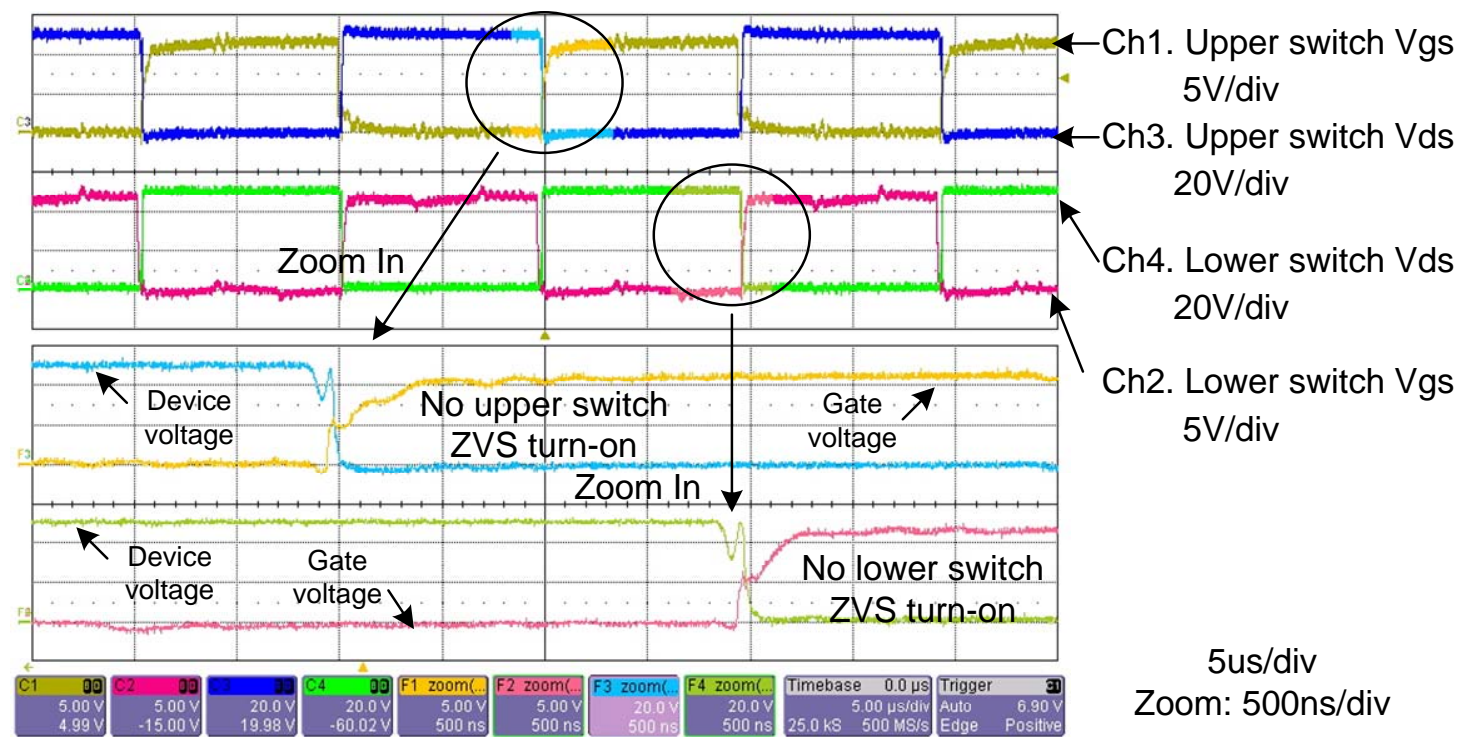

Figure 4.12 - V3 soft switching status: 50\% duty, light load (†)

Figure 4.12 captures V3 soft switching status during 50\% duty cycle and light load. As shown in the zoomed waveform, device voltage initially drops toward zero, but it resonates back to original value. Once gate voltage rises and device turns on, the device rapidly drops to zero, which means it is a hard commutation. It is due to the fact the energy stored in the leakage inductance is not enough to discharge the device output capacitance, and it fails to achieve ZVS. 


\subsubsection{V3 soft-switching waveforms: regulated converter mode}

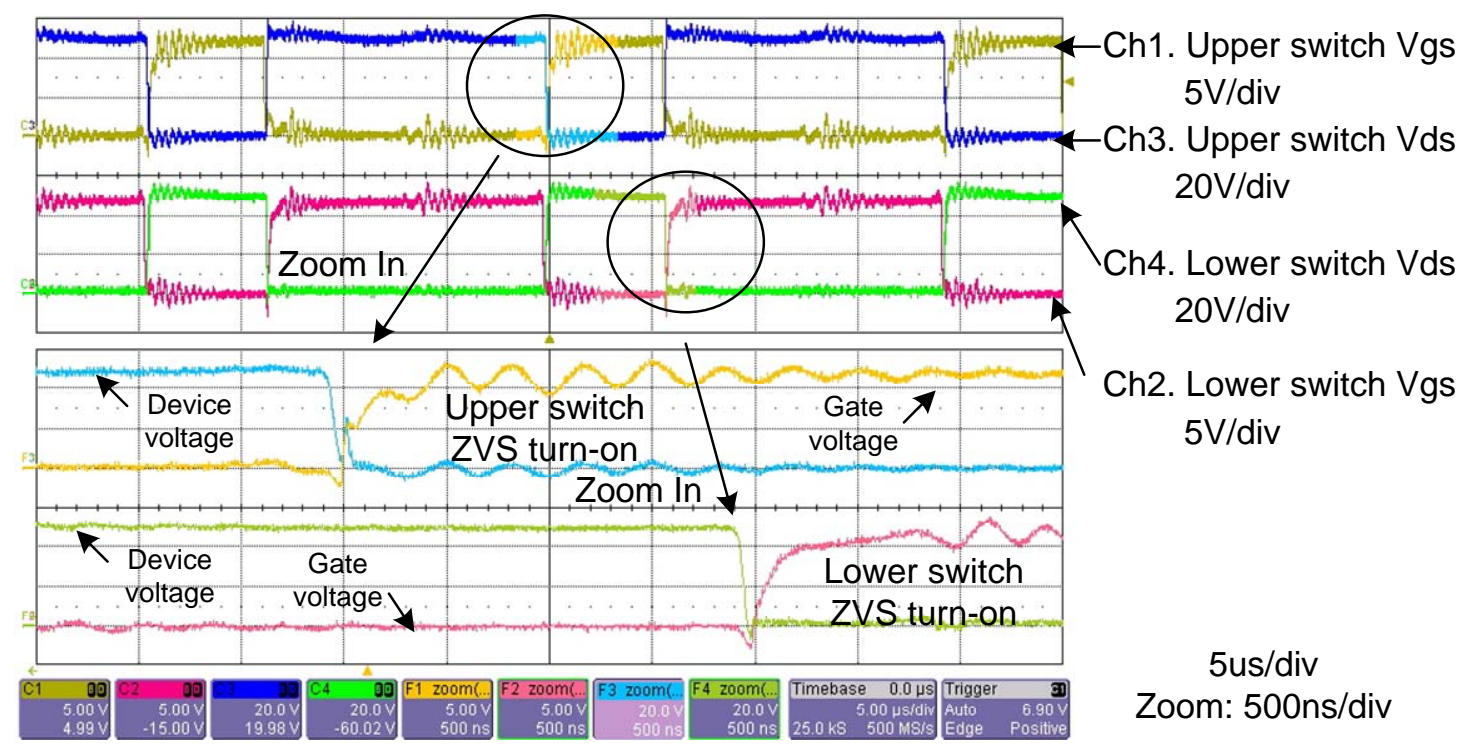

Figure 4.13 - V3 soft switching status: 30\% duty, heavy load (†)

Figure 4.13 captures V3 soft switching status during 30\% duty cycle and heavy load. As shown in the zoomed waveform, device voltage drops to zero before gate voltage rises and device turns on. Both upper and lower switches achieve zero voltage switching (ZVS). 


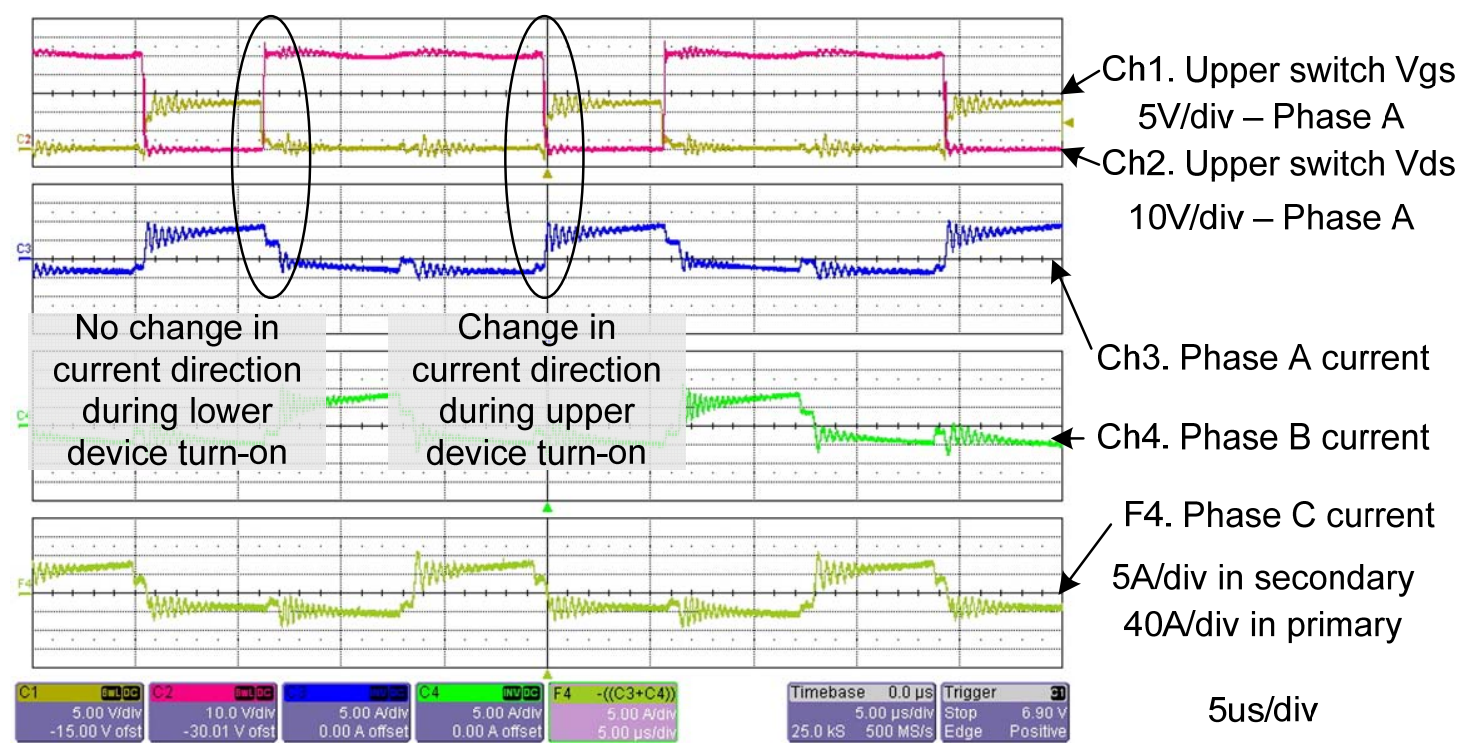

Figure 4.14 - V3 phase currents: 30\% duty, heavy load $(\dagger \dagger)$

Figure 4.14 captures V3 phase currents during 30\% duty cycle and heavy load. First grid shows upper switch gate signal and device voltage, and second grid shows corresponding phase current. Third and fourth grid shows currents in other phases.

Between two circled parts in Figure 4.14, left circle corresponds to lower device turn on. Unlike previous case in 50\% duty cycle, the phase current after device switching remains at the same polarity with relatively the same magnitude as before device switching. This signifies that energy stored in the output inductor is utilized to achieve ZVS.

Right circle in Figure 4.14 corresponds to upper device turn on. This shows change in current direction, which energy stored in the transformer leakage inductance is utilized to achieve ZVS. 


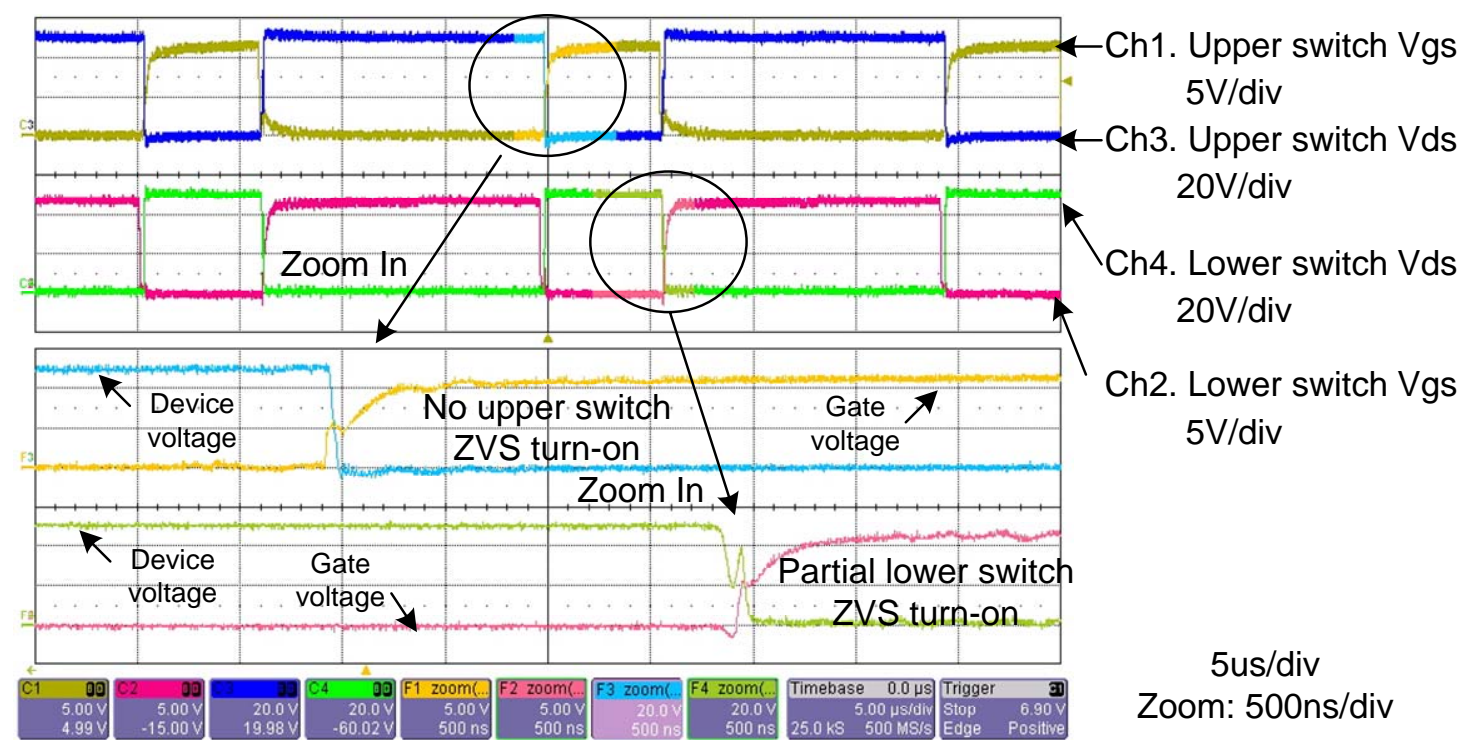

Figure 4.15 - V3 soft switching status: 30\% duty, light load (†)

Figure 4.15 captures V3 soft switching status during 30\% duty cycle and light load. As shown in the zoomed waveform, upper device voltage operated under hard commutation due to light load and lack of energy stored in the leakage inductance. Lower device achieves partial ZVS using energy in the output inductor. However, again due to very low load current, only partial ZVS could be achieved.

\subsubsection{V6 soft-switching waveforms}

V6 is capable of zero-voltage, zero-current switching (ZVZCS). Lagging leg achieves zero-voltage switching as the same manner as V3. Leading leg achieves zerocurrent switching when adjacent phase resets the phase current to zero before switch turns on or off.

V6 converter has three distinctive operating conditions, dc transformer mode and regulated converter mode 2 and 1. Figure 4.16 to Figure 4.18 are waveforms of converter operating under dc transformer mode $\left(120^{\circ}<\alpha<180^{\circ}\right)$, Figure 4.19 to Figure 4.21 are waveforms of converter operating under regulated converter mode $2\left(60^{\circ}<\alpha<120^{\circ}\right)$, and Figure 4.22 to Figure 4.24 are waveforms of converter operating under regulated converter mode $1\left(0^{\circ}<\alpha<60^{\circ}\right)$. 
Each mode is tested under two different loading conditions, heavy and light load. Heavy load refers to $56 \Omega$ load, which corresponds to approximately $3 \mathrm{~kW}$ in $400 \mathrm{~V}$ output, and light load refers to approximately $10 \%$ of heavy load, $500 \Omega$. $50 \mathrm{~V}$ dc is used as input voltage. Phase-shift modulation angle for dc transformer mode and regulated mode 2 and 1 are $150^{\circ}, 110^{\circ}$ and $50^{\circ}$, respectively. Test conditions are summarized in Table 4.3.

Two types of waveforms are captures for V6. First type captures leading leg soft switching states. Channel 1 and 3 represent leading leg gate signal $\left(\mathrm{V}_{\mathrm{GS}}\right)$ and device voltage $\left(\mathrm{V}_{\mathrm{DS}}\right)$, respectively. Channel 2 represents lagging leg gate signal $\left(\mathrm{V}_{\mathrm{GS}}\right)$, and channel 4 represent phase current. Phase currents are measured in transformer secondary side. Transformer turn ratio of 2:8 is used. Therefore, $5 \mathrm{~A} / \mathrm{div}$ in secondary corresponds to $20 \mathrm{~A} / \mathrm{div}$ in the primary. This type of figure is marked with single sharp sign (\#).

Second type captures lagging leg soft switching states. Channel 1 represents leading leg gate signal $\left(\mathrm{V}_{\mathrm{GS}}\right)$. Channel 2 and 3 represent lagging leg gate signal $\left(\mathrm{V}_{\mathrm{GS}}\right)$ and device voltage $\left(\mathrm{V}_{\mathrm{DS}}\right)$, respectively. Channel 4 represents phase current. Phase currents are measured in transformer secondary side. Transformer turn ratio of 2:8 is used. Therefore, $5 \mathrm{~A} / \mathrm{div}$ in secondary corresponds to $20 \mathrm{~A} / \mathrm{div}$ in the primary. This type of figure is marked with double sharp sign (\#\#). 
Table 4.3 - V6 test condition chart

\begin{tabular}{|c|c|c|c|c|c|c|}
\hline $\begin{array}{c}\text { Mode } \\
\text { (Mod. Angle) }\end{array}$ & $\begin{array}{l}\mathrm{V}_{\mathrm{IN}} \\
(\mathrm{V})\end{array}$ & $\begin{array}{l}\mathrm{I}_{\mathrm{IN}} \\
(\mathrm{A})\end{array}$ & $\begin{array}{l}\mathrm{V}_{\text {OUT }} \\
(\mathrm{V})\end{array}$ & $\begin{array}{l}\text { I } \\
\text { (A) }\end{array}$ & $\begin{array}{l}\mathrm{P}_{\mathrm{OUT}} / \mathrm{P}_{\mathrm{IN}} \\
\quad \approx \mathrm{Eff}\end{array}$ & Notes \\
\hline $\begin{array}{c}\text { Dc transformer } \\
\text { mode }\end{array}$ & 50.1 & 61.2 & 392.8 & 7.6 & $\begin{array}{l}2985 / 3066 \\
\approx 97.32 \%\end{array}$ & $\begin{array}{l}\text { Heavy load } \\
\text { Figure } 4.16\end{array}$ \\
\hline$\left(150^{\circ}\right)$ & 50.1 & 7.3 & 398.9 & 0.82 & $\begin{array}{l}327 / 366 \\
\approx 89.4 \%\end{array}$ & $\begin{array}{l}\text { Light Load } \\
\text { Figure } 4.18\end{array}$ \\
\hline $\begin{array}{c}\text { Regulated } \\
\text { converter mode }\end{array}$ & 50.0 & 50.3 & 349.7 & 6.7 & $\begin{array}{c}2342 / 2515 \\
\approx 93.1 \%\end{array}$ & $\begin{array}{l}\text { Heavy load } \\
\text { Figure } 4.19\end{array}$ \\
\hline $\begin{array}{c}2 \\
\left(110^{\circ}\right)\end{array}$ & 50.1 & 6.3 & 361.0 & 0.74 & $\begin{array}{l}267 / 315 \\
\approx 84.6 \%\end{array}$ & $\begin{array}{l}\text { Light load } \\
\text { Figure } 4.21\end{array}$ \\
\hline $\begin{array}{c}\text { Regulated } \\
\text { converter mode }\end{array}$ & 50.0 & 10.4 & 153.6 & 3.0 & $\begin{array}{l}461 / 520 \\
\approx 88.6 \%\end{array}$ & $\begin{array}{l}\text { Heavy load } \\
\text { Figure } 4.22\end{array}$ \\
\hline $\begin{array}{c}1 \\
\left(50^{\circ}\right)\end{array}$ & 50.0 & 1.7 & 191.1 & 0.39 & $\begin{aligned} & 75 / 85 \\
\approx & 87.7 \%\end{aligned}$ & $\begin{array}{l}\text { Light load } \\
\text { Figure } 4.24\end{array}$ \\
\hline
\end{tabular}

Notes: values in the table are rounded to the nearest $1 / 10^{\text {th }}$ of value, and it does not accurately represent efficiency. Rather, it is intended to show test conditions. 


\subsubsection{V6 soft-switching waveforms: dc transformer mode}

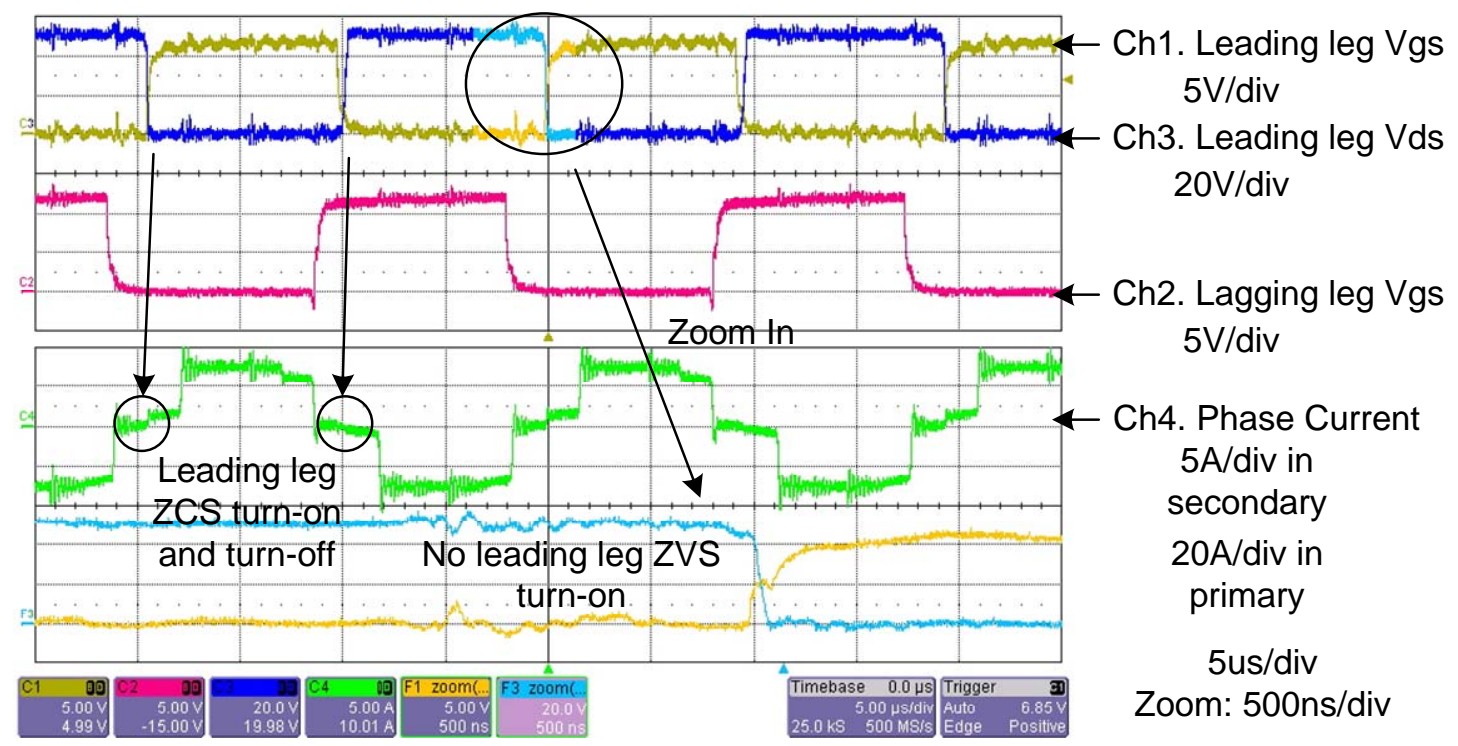

Figure 4.16 - V6 soft switching status: dc transformer mode $\left(150^{\circ}\right)$, leading leg, heavy load(\#)

Figure 4.16 captures V6 soft-switching status of leading leg during dc transformer mode with $150^{\circ}$ modulation angle and heavy load. This waveform illustrates zerocurrent switching (ZCS) of leading leg during turn on and off. During leading leg turn on and off sequence, phase current is at zero, as pointed out with two small circles. Typically, ZCS is associated with only turn-off sequence; however, this particular mode offers ZCS even during turn-on sequence.

As far as leading leg zero-voltage switching (ZVS), nature of ZCS condition causes lack of energy in leakage inductance to discharge device voltage to zero. Therefore, ZVS can not be achieved. 


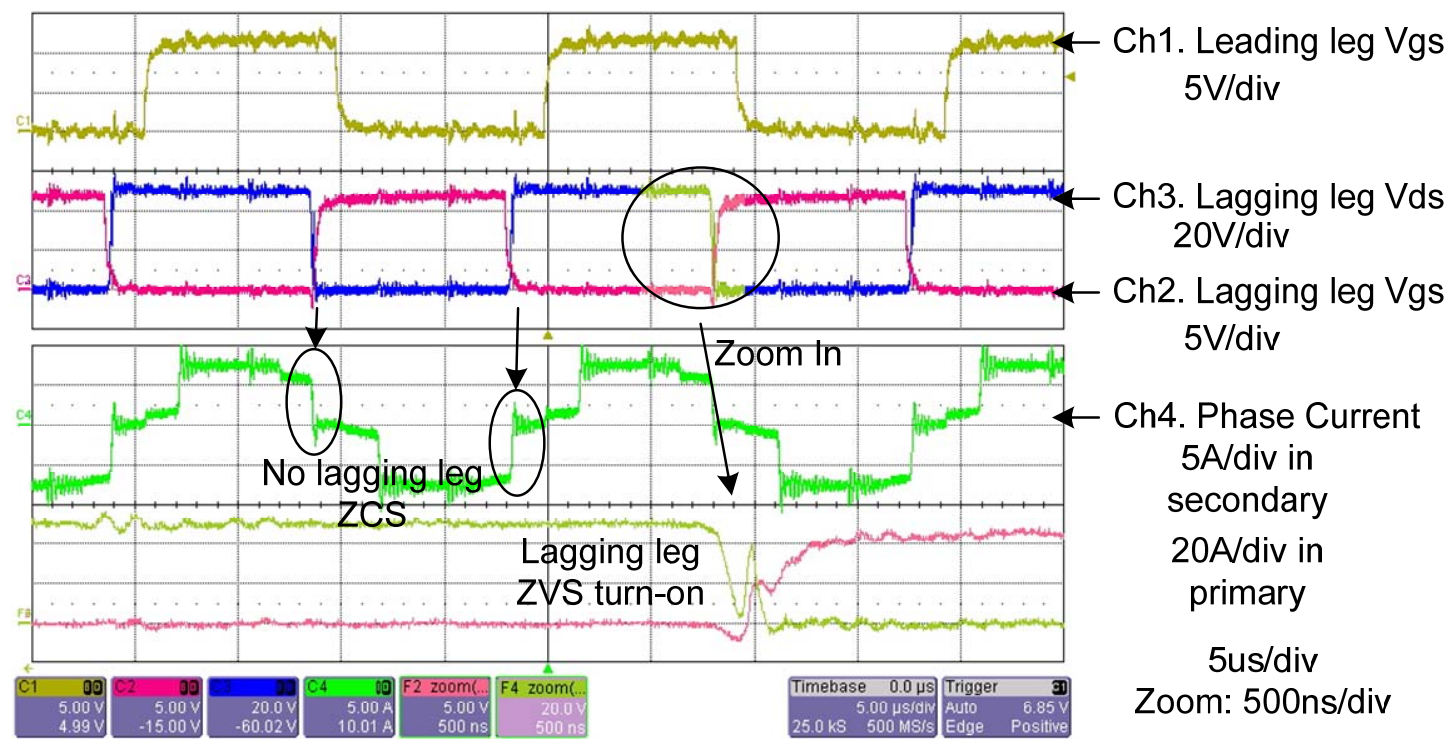

Figure 4.17 - V6 soft switching status: dc transformer mode (150), lagging leg, heavy load(\#\#)

Figure 4.17 captures V6 soft-switching status of lagging leg during dc transformer mode with $150^{\circ}$ modulation angle and heavy load. This waveform illustrates zerovoltage switching (ZVS) of lagging leg during turn on. As shown in the zoomed waveform, device voltage drops to zero before gate voltage rises and device turns on. Due to incorrect timing of the device turn-on, the device voltage swings back to dc rail voltage and ZVS is momentary lost; however, correct turn on timing can ensure ZVS and zero losses.

The waveform also shows phase current. Phase current rapidly approaches zero when a switch in legging leg is turned off, and it inform that resonance between transformer leakage inductance and device output capacitance causes ZVS. Phase current also informs that non-zero current value in phase current during switch turn off indicates ZCS turn-off can not be achieved. 


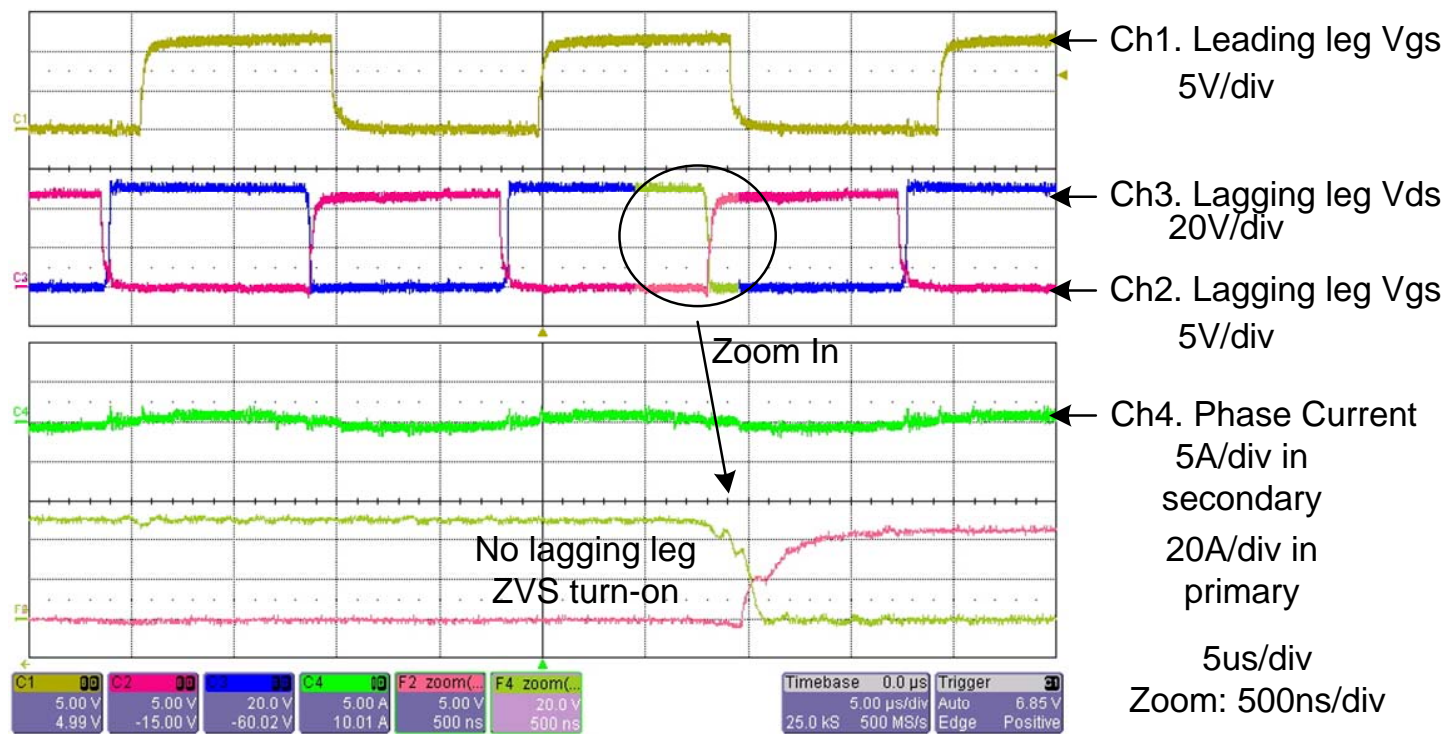

Figure 4.18 - V6 soft switching status: dc transformer mode $\left(150^{\circ}\right)$, lagging leg, light load(\#\#)

Figure 4.18 captures V6 soft-switching status of lagging leg during dc transformer mode with $150^{\circ}$ modulation angle and light load. Zoomed waveform shows partial lagging leg ZVS turn-on. During light load, insufficient of energy in the transformer leakage inductance only achieves partial ZVS. 


\subsubsection{V6 soft-switching waveforms: regulated converter mode 2}

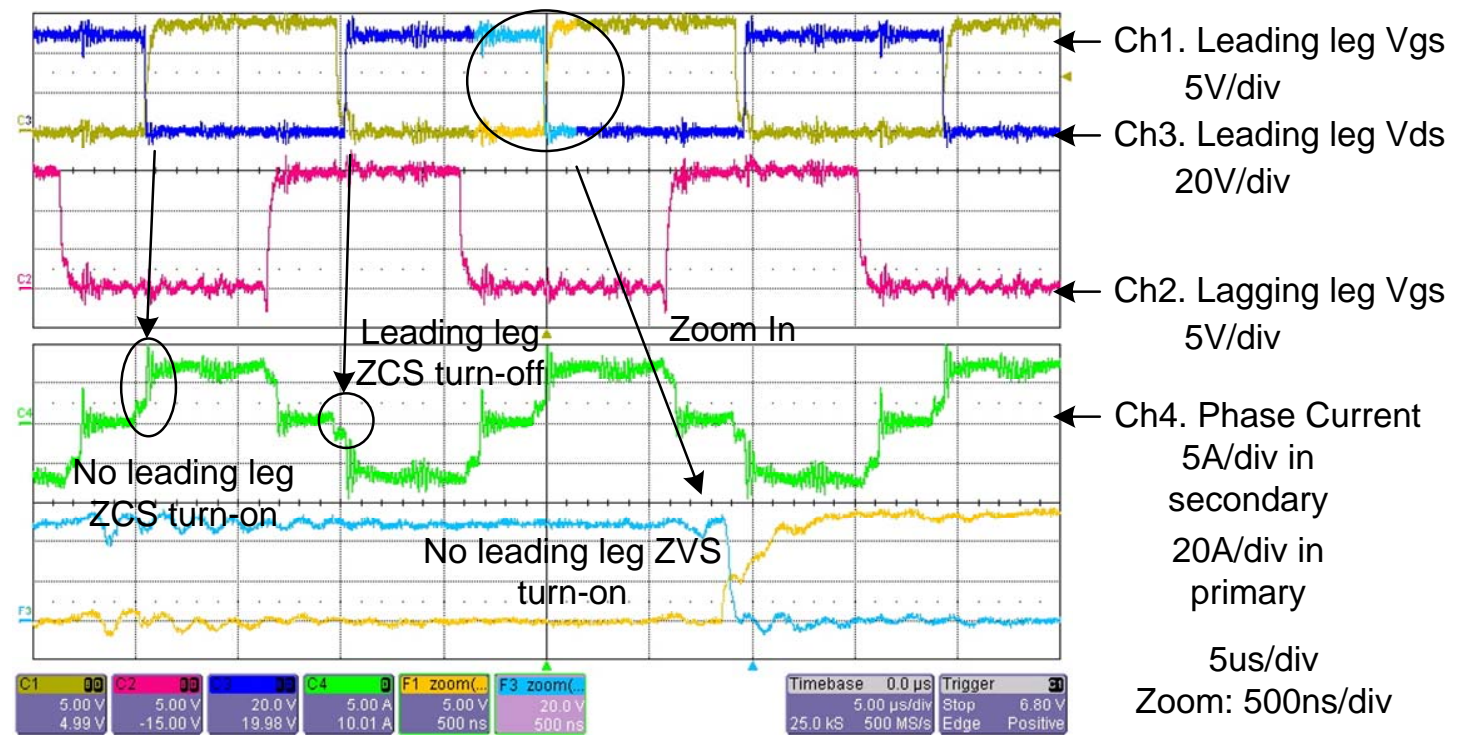

Figure 4.19 - V6 soft-switching status: regulated converter mode $2\left(110^{\circ}\right)$, leading leg, heavy load(\#)

Figure 4.19 captures V6 soft-switching status of leading leg during regulated converter mode 2 with $110^{\circ}$ modulation angle and heavy load. The waveform illustrates zero-current switching (ZCS) of leading leg during turn-off. Like previous case in $150^{\circ}$ modulation angle, the phase current is zero during leading leg turn-off. But unlike previous case, the phase current changes during turn-on. Therefore, ZCS is achieved during turn-off, but not with turn-on. 


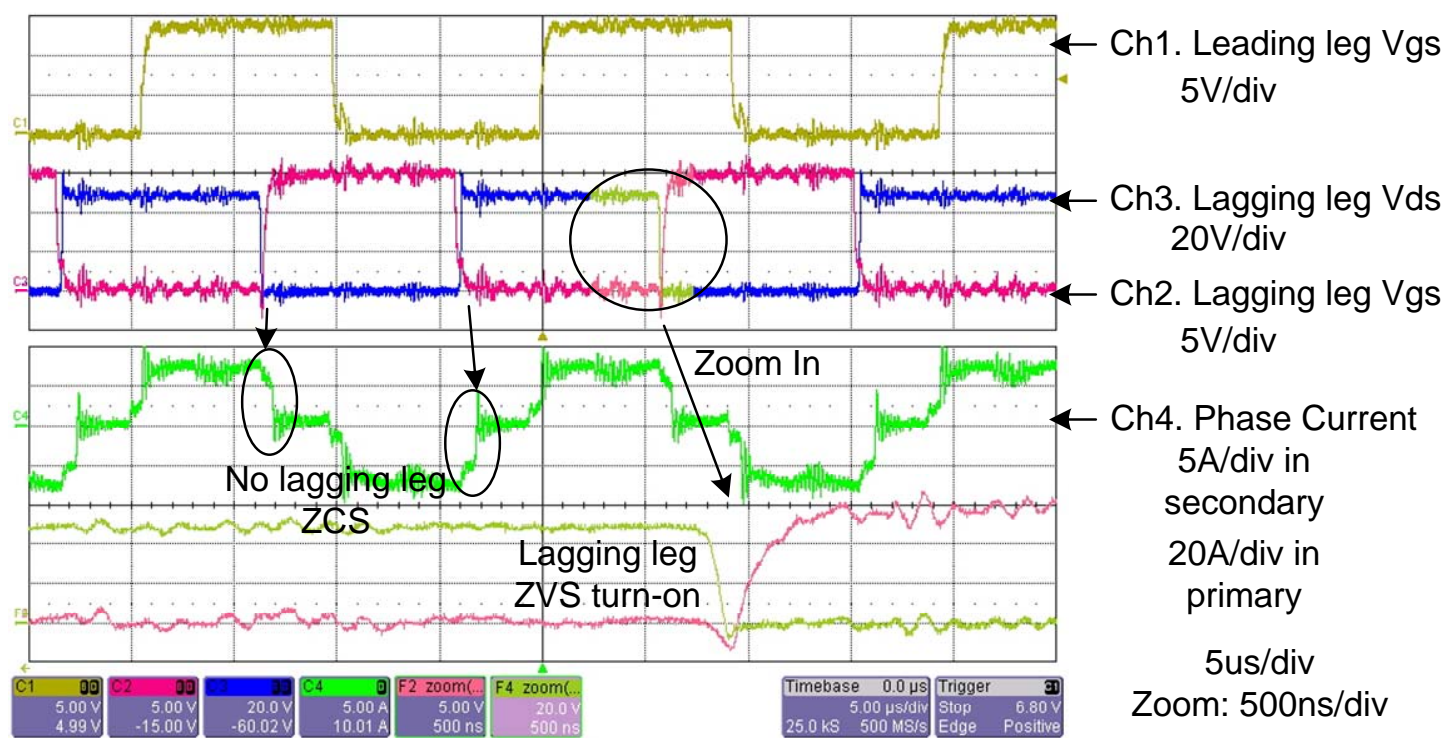

Figure 4.20 - V6 soft-switching status: regulated converter mode $2\left(110^{\circ}\right)$,, lagging leg, heavy load(\#\#)

Figure 4.20 captures V6 soft-switching status of lagging leg during regulated converter mode 2 with $110^{\circ}$ modulation angle and heavy load. The waveform illustrates zero-voltage switching (ZVS) of lagging leg during turn on. As shown in the zoomed waveform, device voltage drops to zero before gate voltage rises and device turns on. Unlike previous case in $150^{\circ}$ modulation angle, ZVS in this mode is achieved with energy in the output filter inductor, instead of transformer leakage inductance. It is indicated when a lagging leg switch is turned off, phase current remains at the same polarity with relatively the same magnitude. 


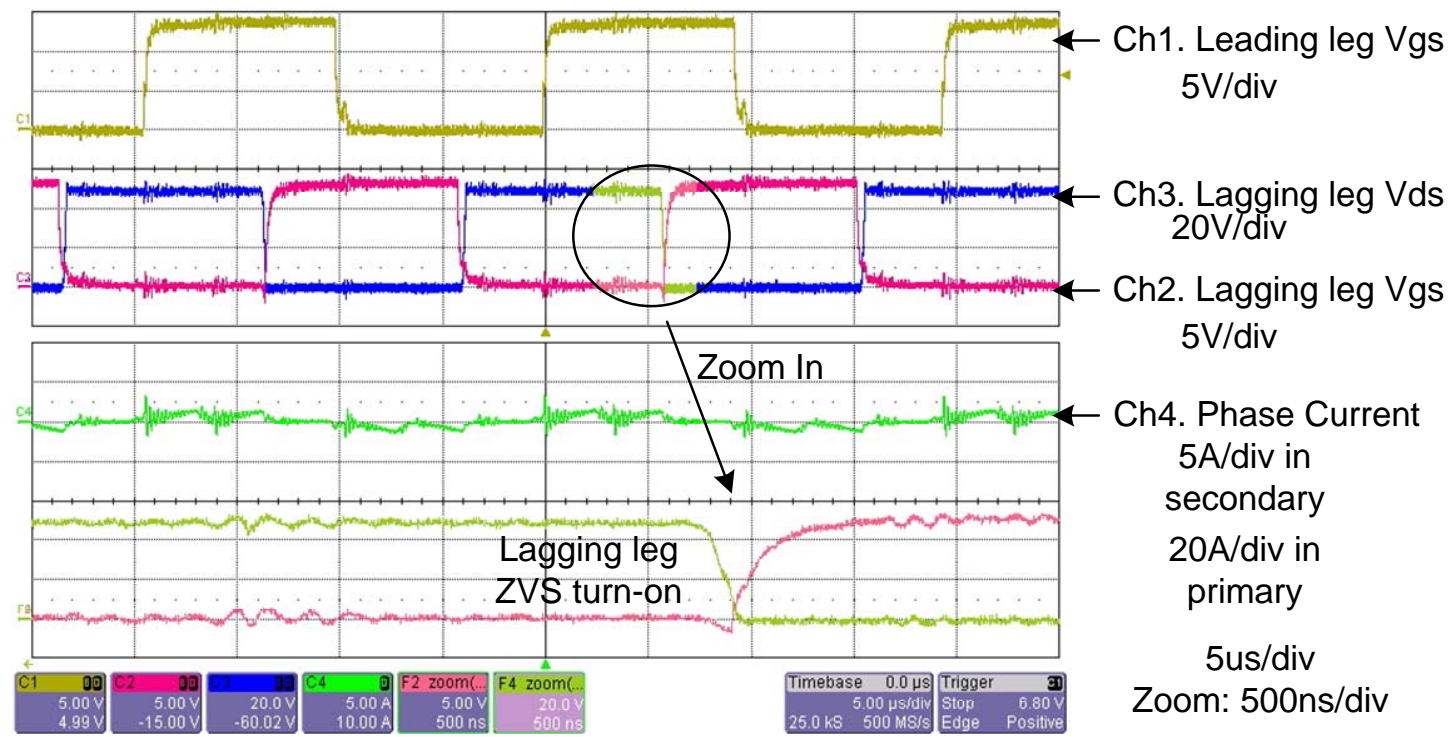

Figure 4.21 - V6 soft-switching status: regulated converter mode $2\left(110^{\circ}\right)$,, lagging leg, light load(\#\#)

Lagging leg continues to achieve ZVS even during light load, as shown in Figure 4.21. Usage of energy in output filter inductor enables ZVS even in the light load. In comparison to Figure 4.18 of dc transformer mode, lagging leg is not able to achieve ZVS during light load, since energy in transformer leakage inductance is used to achieve ZVS. 


\subsubsection{V6 soft-switching waveforms: regulated converter mode 1}

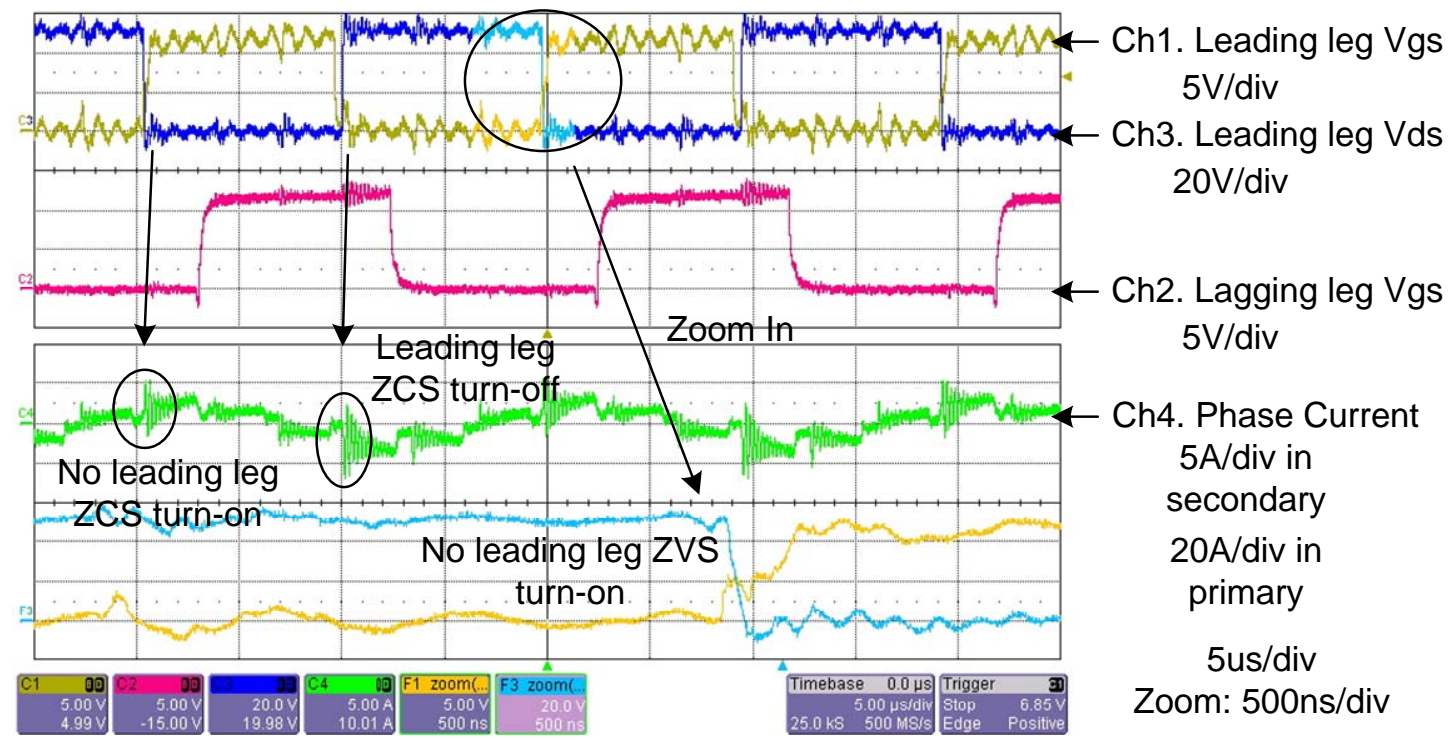

Figure 4.22 - V6 soft-switching status: regulated converter mode $1\left(50^{\circ}\right)$, leading leg, heavy load(\#)

Figure 4.22 capcutre V6 soft-switching status of leading leg during regulated converter mode 2 with $50^{\circ}$ modulation angle and heavy load. The soft-switching mechanism is identical to the regulated converter mode 2. Refer to section 4.3.2.2.

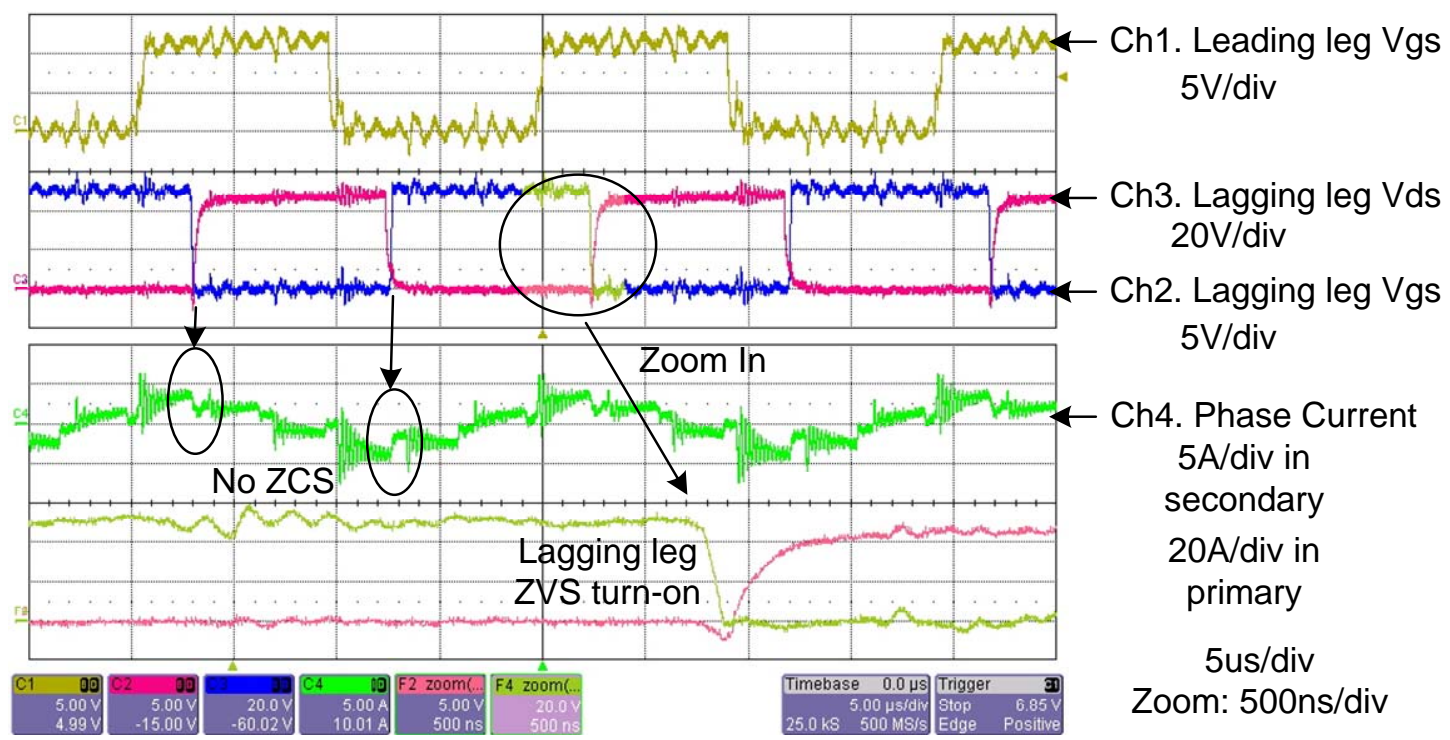

Figure 4.23 - V6 soft-switching status: regulated converter mode $1\left(50^{\circ}\right)$, lagging leg, heavy load(\#\#) 
Figure 4.23 captures V6 soft-switching status of lagging leg during regulated converter mode 1 with $50^{\circ}$ modulation angle and heavy load. Again, the soft-switching mechanism is identical to the regulated converter mode 2. Refer to section 4.3.2.2.

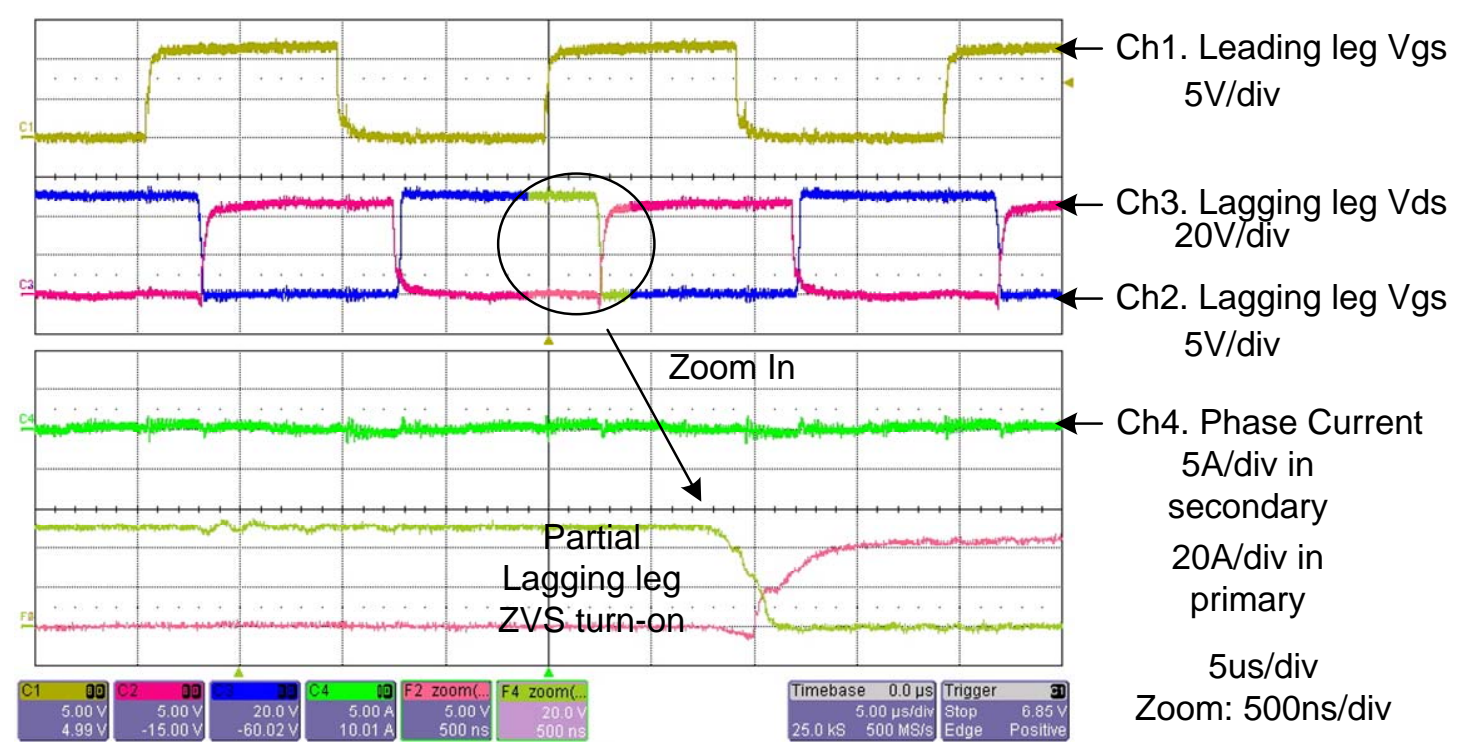

Figure 4.24 - V6 soft-switching status: regulated converter mode $1\left(50^{\circ}\right)$, lagging leg, light load(\#\#)

Figure 4.24 captures V6 soft-switching status of lagging leg during regulated converter mode 1 with $50^{\circ}$ modulation angle and light load. Lagging leg continues to achieve ZVS even during light load; however, due to insufficient load current causes only partial ZVS. Again, the soft-switching mechanism is identical to the regulated converter mode 2. Refer to section 4.3.2.2. 


\subsubsection{Soft-switching condition summary}

Table 4.4 and Table 4.5 summarize soft-switching condition of V3 and V6 converter, respectively.

Table 4.4 - V3 soft switching condition

\begin{tabular}{|c|c|c|c|}
\hline \multicolumn{2}{|c|}{ V3 soft switching condition } \\
\hline Mode (Duty Cycle) & Switching condition & Upper switch & Lower Switch \\
\hline \multirow{2}{*}{$\begin{array}{c}\text { Dc transformer mode } \\
(1 / 3<\mathrm{D}<2 / 3)\end{array}$} & Turn-on & ZVS* & ZVS* \\
\cline { 2 - 4 } & Turn-off & None & None \\
\hline $\begin{array}{c}\text { Regulated converter mode } \\
(0<\mathrm{D}<1 / 3)\end{array}$ & Turn-on & ZVS* & ZVS** \\
\cline { 2 - 4 } & Turn-off & None & None \\
\hline $\begin{array}{c}\text { Regulated converter mode } \\
(2 / 3<\mathrm{D}<1)\end{array}$ & Turn-on & ZVS** & ZVS* \\
\cline { 2 - 4 } & Turn-off & None & None \\
\hline
\end{tabular}

Table 4.5 - V6 soft-switching condition

\begin{tabular}{|c|c|c|c|}
\hline \multicolumn{4}{|c}{ V6 soft switching condition } \\
\hline Mode (Phase-Shift Angle) & Switching condition & Leading leg & Lagging leg \\
\hline $\begin{array}{c}\text { Dc transformer mode } \\
\left(120^{\circ}<\alpha<180^{\circ}\right)\end{array}$ & Turn-on & ZCS & ZVS* \\
\cline { 2 - 4 } & Turn-off & ZCS & None \\
\hline $\begin{array}{c}\text { Regulated converter mode } 2 \\
\left(60^{\circ}<\alpha<120^{\circ}\right)\end{array}$ & Turn-on & None & ZVS** \\
\cline { 2 - 4 } & Turn-off & ZCS & None \\
\hline $\begin{array}{c}\text { Regulated converter mode } 1 \\
\left(0^{\circ}<\alpha<60^{\circ}\right)\end{array}$ & Turn-on & None & ZVS** \\
\cline { 2 - 4 } & Turn-off & ZCS & None \\
\hline
\end{tabular}

Single asterisk $(*)$ means zero-voltage switching (ZVS) is achieved using energy from transformer leakage inductance. Therefore, ZVS condition is lost during light load condition. Double asterisk ${ }^{* *}$ ) means ZVS is achieved using energy from output filter inductor. Therefore, ZVS condition is quite well maintained even during light load condition. 
Neither converter needs additional circuitry for soft switching. Especially, V6 achieves ZCS without any additional reset circuitry.

\subsection{Conduction Loss Comparison}

In low-voltage, high-power fuel cell application, conduction losses from high-current condition is responsible for majority of power losses. Therefore, key to improve the efficiency is to reduce conduction losses in the high-current primary side.

\subsubsection{Conduction loss in dc transformer mode}

Figure 4.25 and Figure 4.26 capture phase current in dc transformer mode of V3 and V6, respectively. Upper grid represents duty cycle or phase-shift modulation angle, and lower grid represents three phase current.

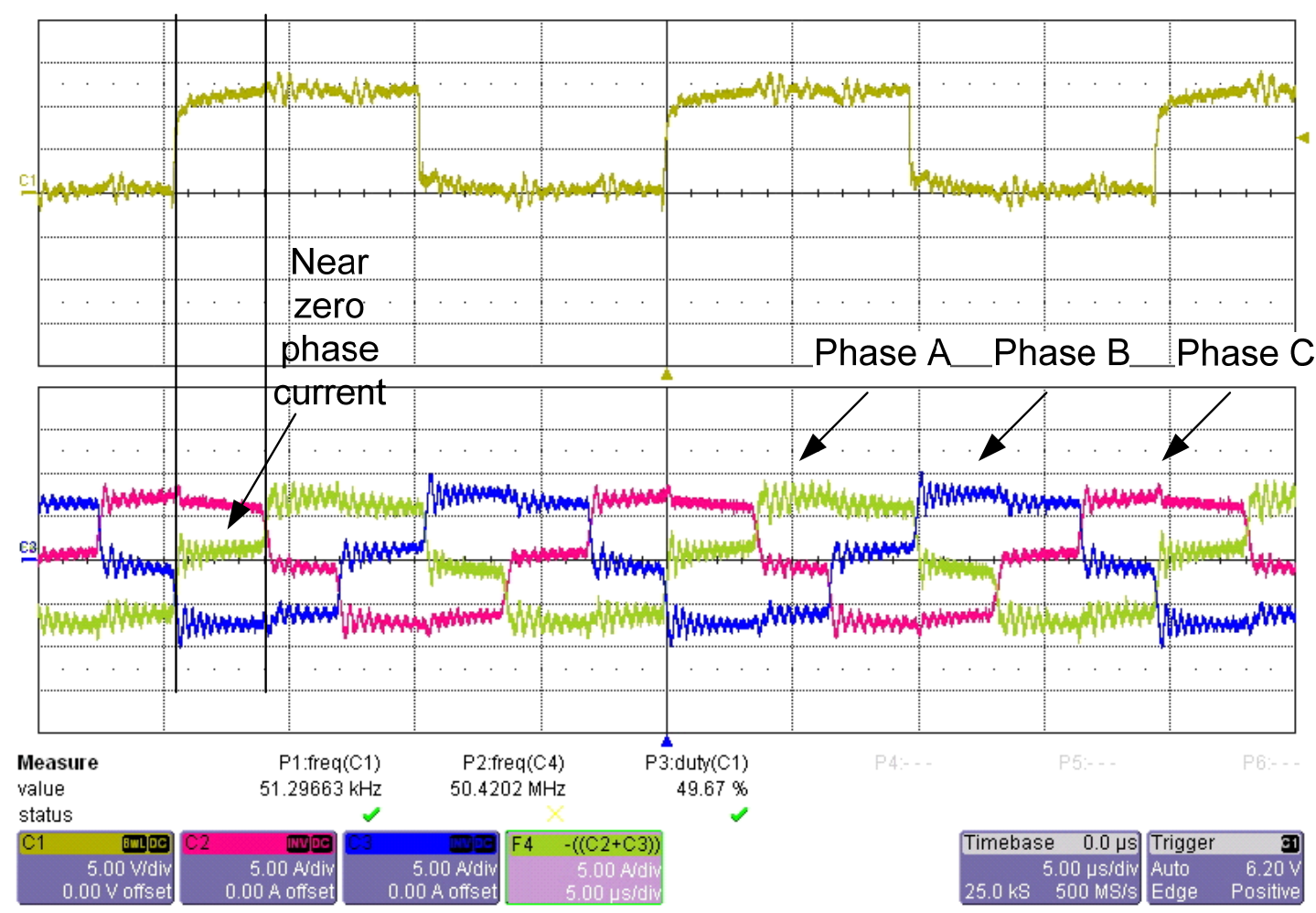

Figure 4.25 - V3 phase current in dc transformer mode 


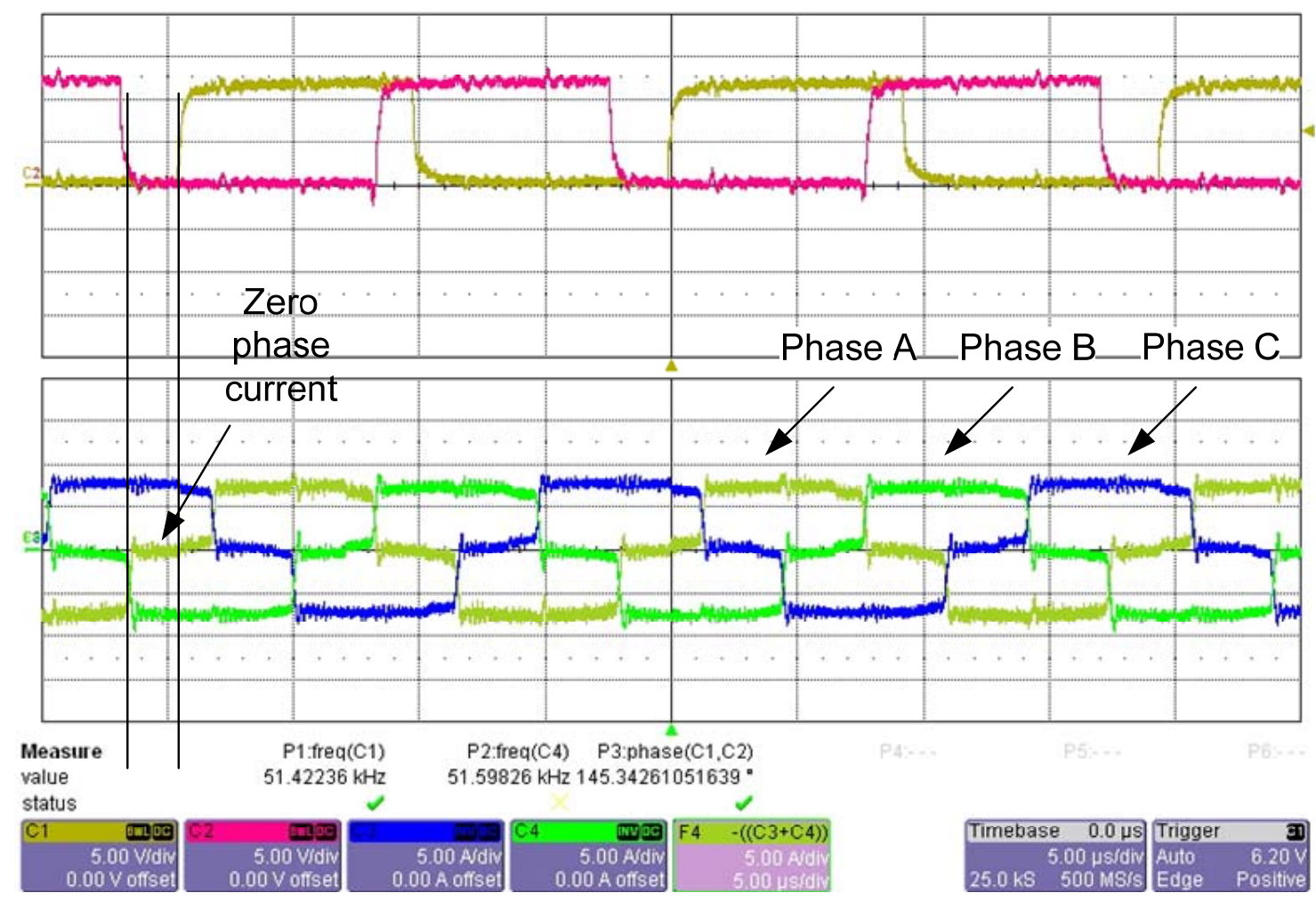

Figure 4.26 - V6 phase current in dc transformer mode

In dc transformer mode, power is constantly delivered to the load without freewheeling period. Each phase shares power delivery during a period, as described in chapter 3. For the majority of the period, only two of three phases deliver power, and Figure 4.27 and Figure 4.28 illustrate the condition. In Figure 4.27, switches are in (101) vector state, and phase $\mathrm{B}$ and $\mathrm{C}$ are responsible for majority of power delivery, while phase A delivers a negligible amount of power. Figure 4.25 illustrates that phase A current is near zero during (101) period.

Similarly, V6 only delivers majority of power through only two phases during dc transformer mode. In Figure 4.28, switches are in (100110) vector state, phase B and C deliver the majority of power, while phase A current is near zero. 


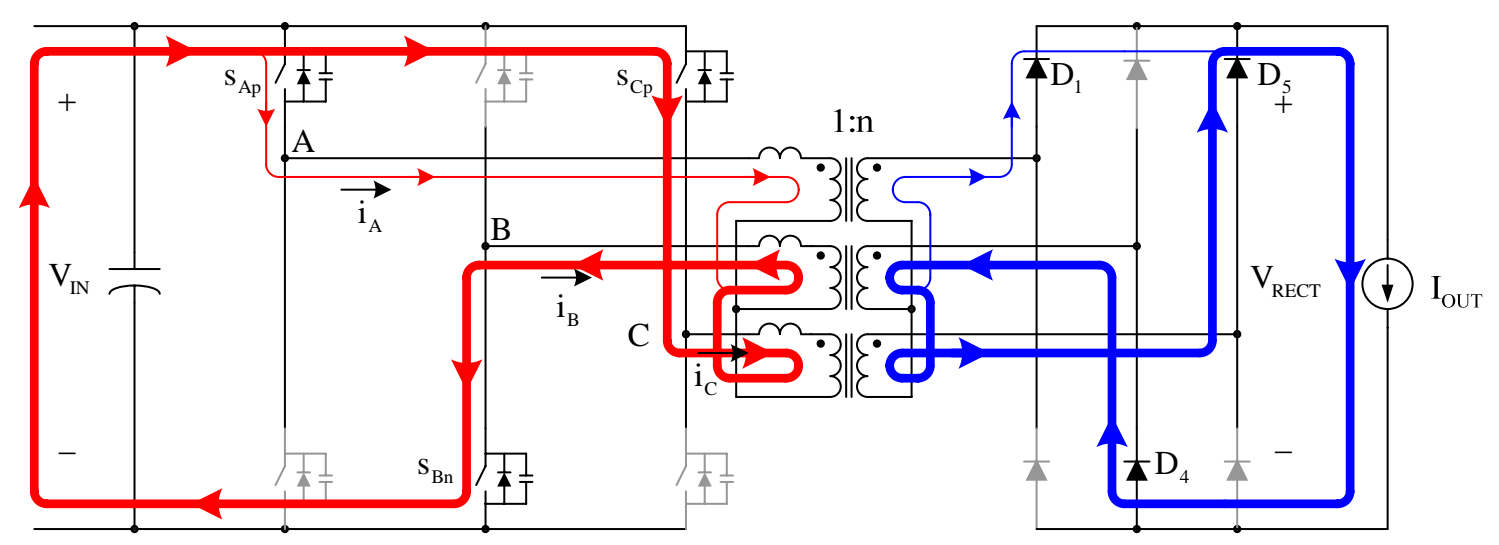

Figure 4.27 - V3 conduction path during power delivery

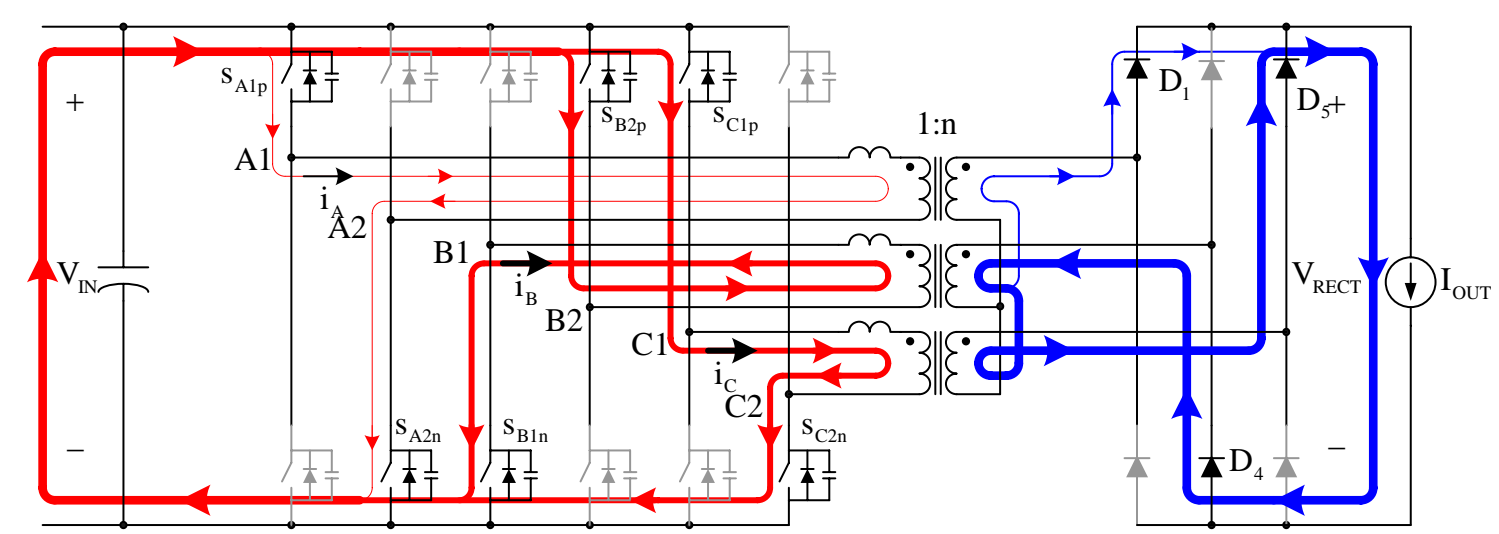

Figure 4.28 - V6 conduction path during power delivery

In V3, conduction path in a phase includes two MOSFETS and two transformers. Similarly, conduction path in a phase include two MOSFETs and one transformer in V6. Let $\mathrm{R}$ equals to the total resistance in conduction path of a phase, then total conduction loss in each converter is

V3:

$\mathrm{P}_{\text {loss-V3 }}=\mathrm{I}^{2} \cdot \mathrm{R}=\left(\mathrm{I}_{\mathrm{OUT}} / \mathrm{n}\right)^{2} \cdot \mathrm{R}$

V6:

$\mathrm{P}_{\text {loss-V6 }}=2 \cdot\left(\mathrm{I}^{2} \cdot \mathrm{R}\right)=2 \cdot\left(\left(\mathrm{I}_{\text {OUT }} / \mathrm{n}\right) / 2\right)^{2} \cdot \mathrm{R} \approx 1 / 2 \cdot \mathrm{P}_{\text {loss-V3 }}$ 
Turn ratio in V6 is half of V3. Therefore, the reflected load current per phase is half as well. However, current goes through two phases in V6. Overall, the total conduction loss in V6 is about half of V3 in dc transformer mode.

\subsubsection{Conduction loss in regulated converter mode}

Figure 4.29 and Figure 4.30 capture phase current in regulated converter mode of V3 and V6, respectively. Upper grid represents duty cycle or phase-shift modulation angle, and lower grid represents three phase current.

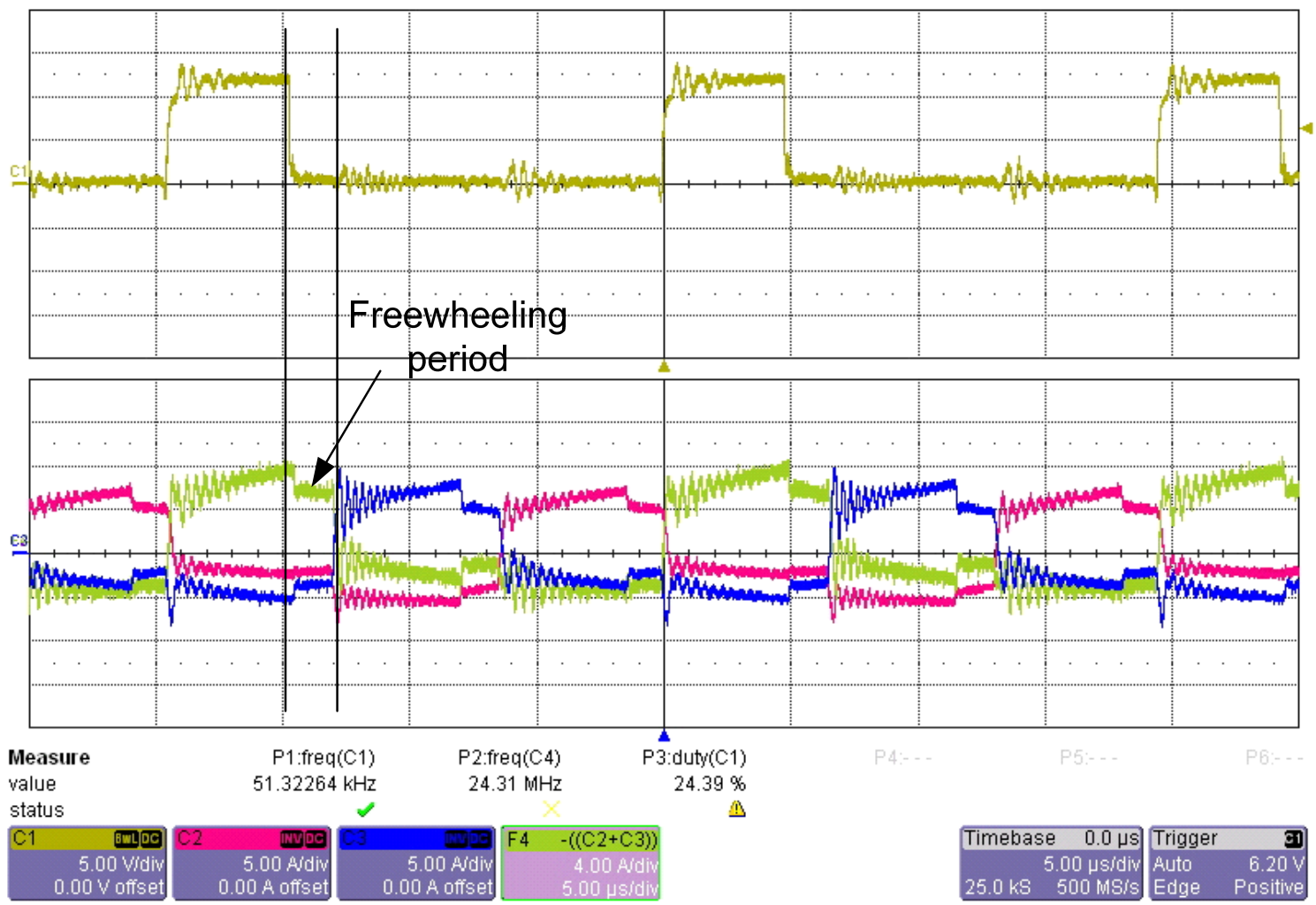

Figure 4.29 - V3 phase current in regulated converter mode 


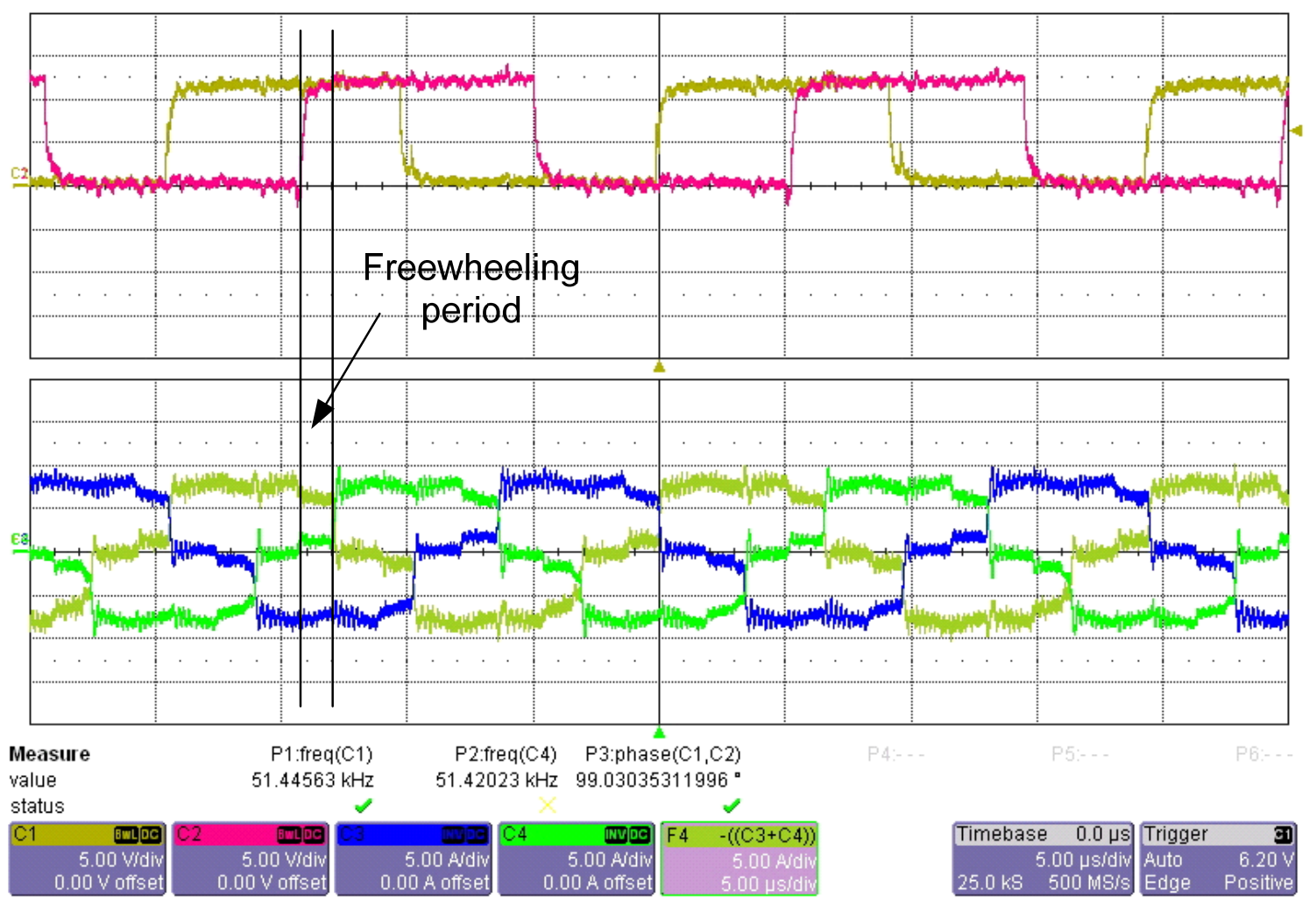

Figure 4.30 - V6 phase current in regulated converter mode

In regulated converter mode, power is delivered to the load for portions of a period, and phase currents freewheel during other portions of a period. Each phase shares power delivery during a period, as described in chapter 3 .

In Figure 4.29, the V3 phase current is distributed in all three phases; however, all three phases contributes to the circulating current during freewheeling period. In Figure 4.30, the V6 phase current is distributed in only two phases for the majority of period. However, only one phase contributes to the circulating current during freewheeling period. Figure 4.31 and Figure 4.32 illustrate the condition. In Figure 4.31, switches are in (000) vector state, and the circulating current flows in all three phases. Similarly, Figure 4.32 illustrates circulating current during (100011) vector state. In this condition, phase A is delivering power to the load, while current circulates in phase B. 


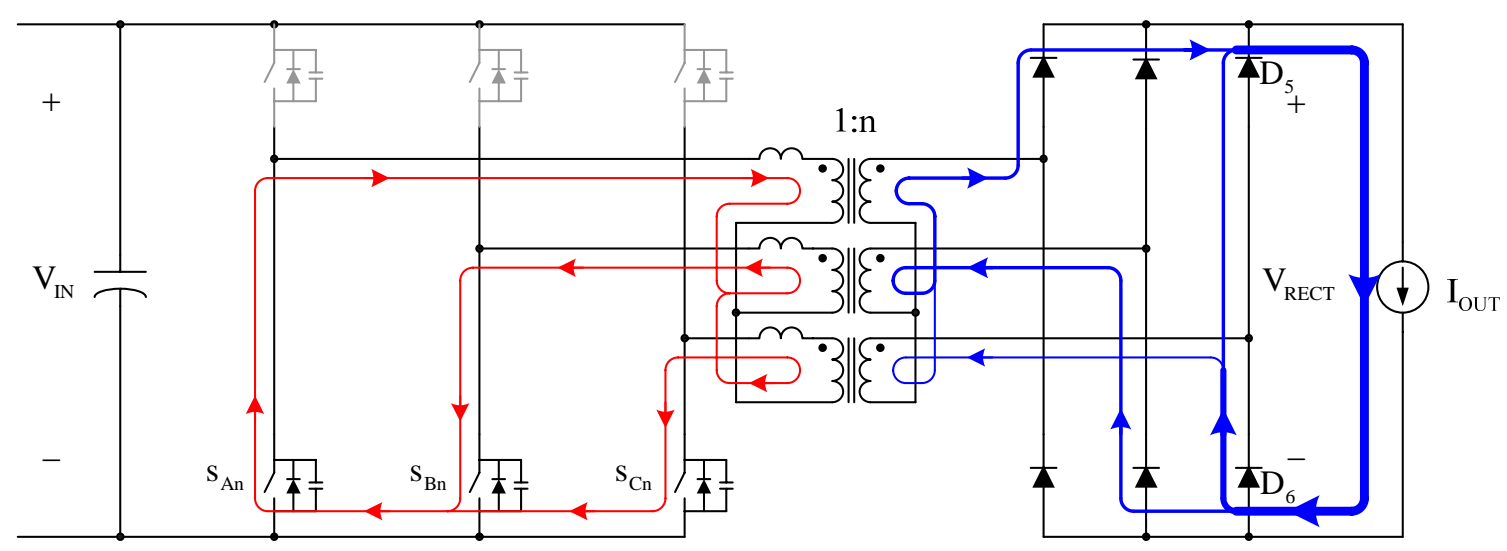

Figure 4.31 - V3 conduction path during freewheeling period

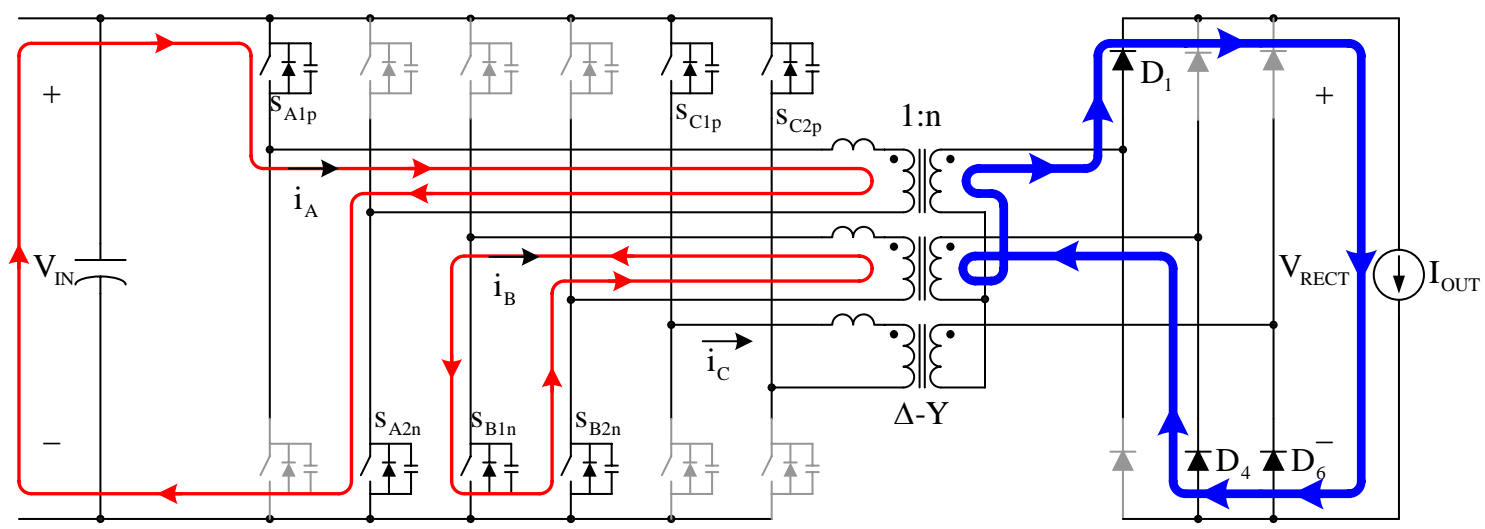

Figure 4.32 - V6 conduction path during freewheeling period

Conduction loss during freewheeling period is summarized below:

V3:

$$
\begin{aligned}
\mathrm{P}_{\text {loss-V3 }} & =\mathrm{I}_{\mathrm{A}}{ }^{2} \cdot(\mathrm{R} / 2)+\mathrm{I}_{\mathrm{B}}{ }^{2} \cdot(\mathrm{R} / 2)+\mathrm{I}_{\mathrm{C}}{ }^{2} \cdot(\mathrm{R} / 2) \\
& =\left(\mathrm{I}_{\text {OUT }} / \mathrm{n}\right)^{2} \cdot(\mathrm{R} / 2)+\left(\left(\mathrm{I}_{\text {OUT }} / \mathrm{n}\right) / 2\right)^{2} \cdot(\mathrm{R} / 2)+\left(\left(\mathrm{I}_{\text {OUT }} / \mathrm{n}\right) / 2\right)^{2} \cdot(\mathrm{R} / 2) \\
& =3 / 4 \cdot\left(\mathrm{I}_{\text {OUT }} / \mathrm{n}\right)^{2} \cdot \mathrm{R}
\end{aligned}
$$

V6:

$$
\begin{aligned}
\mathrm{P}_{\text {loss-V } 6} & =\mathrm{I}_{\mathrm{A}}{ }^{2} \cdot \mathrm{R}+\mathrm{I}_{\mathrm{B}}{ }^{2} \cdot \mathrm{R}+\mathrm{I}_{\mathrm{C}}{ }^{2} \cdot \mathrm{R} \\
& =\left(\left(\mathrm{I}_{\text {OUT }} / \mathrm{n}\right) / 2\right)^{2} \cdot \mathrm{R}+\left(\left(\mathrm{I}_{\text {OUT }} / \mathrm{n}\right) / 2\right)^{2} \cdot \mathrm{R}+0 \\
& =1 / 2 \cdot\left(\mathrm{I}_{\text {OUT }} / \mathrm{n}\right)^{2} \cdot \mathrm{R}
\end{aligned}
$$




\subsubsection{Conduction loss summary}

For low-voltage, high-power fuel cell applications, the primary side power losses have a major impact on efficiency. Key to improve the efficiency in high-current condition is to reduce conduction losses. To reduce conduction losses, low-voltage MOSFETs with very low $\mathrm{R}_{\mathrm{DS} \text {-ON }}$ value is chosen. Also multiphase topology is employed to reduce rms current through individual components.

In dc transformer mode, only two of three phases transfer power to the load at any instant, even though average current and power delivery per phase is the same. In regulated converter mode, V6 continues to only utilize two of three phases. However, V3 shares power delivery in all three phases. 


\subsection{Efficiency Comparison}

V3 and V6 prototypes are evaluated for their efficiency. V3 requires six MOSFETs, while V6 requires twelve MOSFETs. Higher number of MOSFETs in V6 offers lower impedance path than V6. In order to match the number of MOSFETs and average impedance of primary side, two MOSFETs are paralleled in V3. In other words, V3 uses two $4.7 \mathrm{~m} \Omega, 75 \mathrm{~V}$ devices in parallel and V6 uses single $4.7 \mathrm{~m} \Omega, 75 \mathrm{~V}$ device. The switching frequency is $50 \mathrm{kHz}$ for both cases.

\subsubsection{Dc transformer mode efficiency}

Figure 4.33 compares efficiency measurement result between two converters in dc transformer mode. The results indicate that the V3 converter maintains efficiency above $95 \%$ from sub-1 $\mathrm{kW}$ to $5.5 \mathrm{~kW}$ and peaks at $96.8 \%$ at $1.8 \mathrm{~kW}$. The V6 converter demonstrates the efficiency above $96 \%$ from $1.3 \mathrm{~kW}$ to $5.7 \mathrm{~kW}$. The peak efficiency of V6 converter is $97.2 \%$ at $2.5 \mathrm{~kW}$. Both converter show excellent efficiency; however, V3 converter shows a lower efficiency than V6. Lower efficiency is presumed to be caused by higher leakage inductance in V3. High leakage inductance causes higher overall rms current, and greater loss of duty cycle. Additionally, V6 exhibits better softswitching mechanism in dc transformer mode, which could contribute to higher efficiency.

The efficiency profile indicates that light-load efficiencies in both converters are almost the same because both converters lose ZVS during light load condition, and switching losses dominates. In contrast, after efficiency peak, the conduction losses become the dominant loss factor during heavy-load condition.

The converters are tested with $50 \mathrm{~V}$ input, approximately $400 \mathrm{~V}$ output, $50 \%$ duty cycle for V3 and $165^{\circ}$ modulation angle for V6. 


\section{Efficiency \\ (dc transformer mode)}

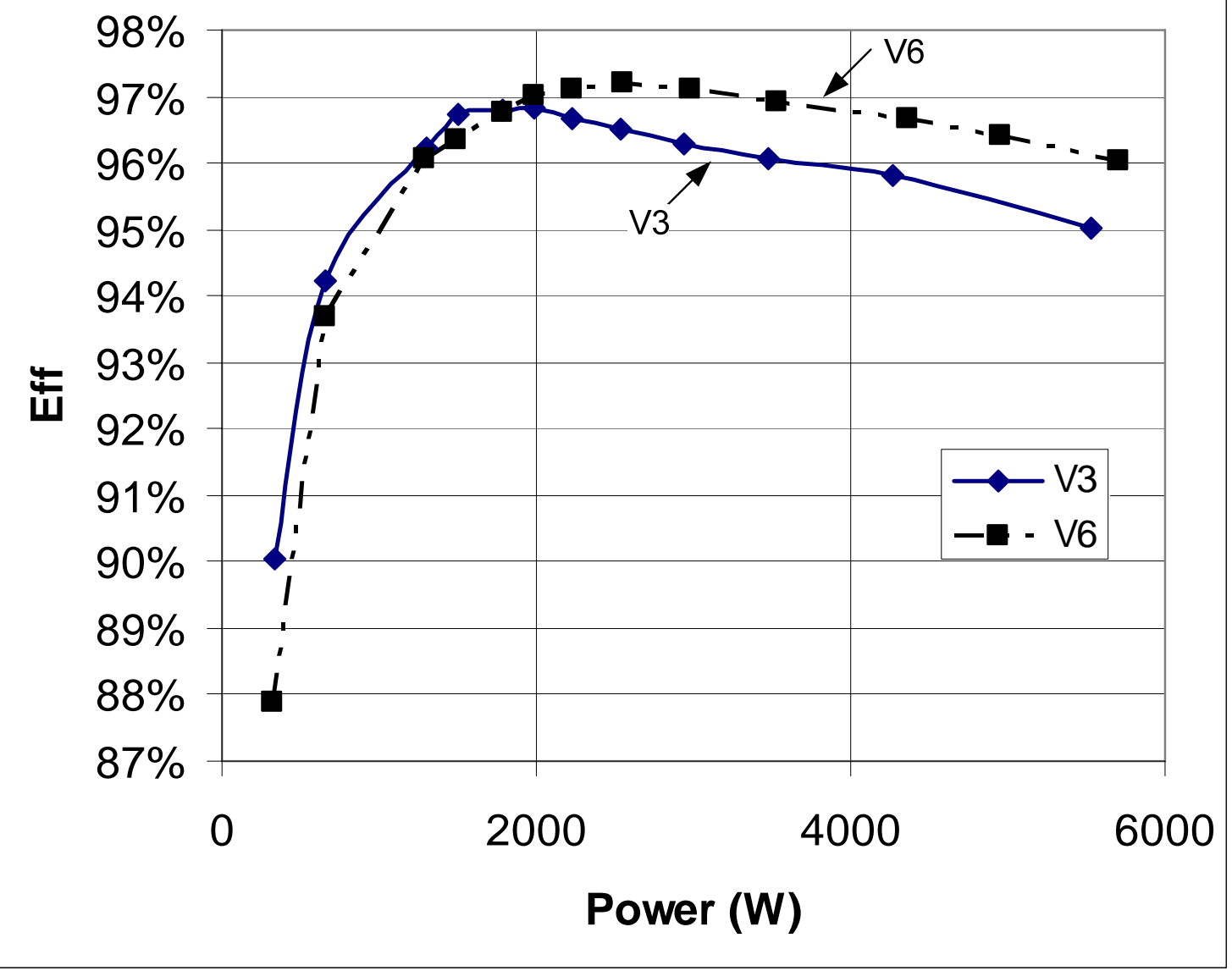

Figure 4.33 - Prototype converter efficiency in dc transformer mode

\subsubsection{Regulated converter mode efficiency}

Figure 4.34 compares efficiency measurement result between two converters in regulated converter mode. The efficiency during regulated converter mode is lower than the efficiency during dc transformer mode. This is expected since the circulating current during freewheeling period causes significant conduction losses without delivering power to the load. 
The V3 converter maintains efficiency above $94.5 \%$ from $2 \mathrm{~kW}$ to $4.8 \mathrm{~kW}$ and reaches $95 \%$ from $2.5 \mathrm{~kW}$ to $3 \mathrm{~kW}$. The efficiency at $2.5 \mathrm{~kW}$ during dc transformer mode is $96.5 \%$, and efficiency drops approximately $1.5 \%$ during regulated converter mode. The V6 converter demonstrates the efficiency above $93 \%$ from $1.5 \mathrm{~kW}$ to $4.5 \mathrm{~kW}$. The efficiency during dc transformer mode peaks at $97.2 \%$ under $2.5 \mathrm{~kW}$ loads. The efficiency during regulated converter mode drops to $93.5 \%$ at $2.5 \mathrm{~kW}$. It is $3.7 \%$ efficiency drop, or near $90 \mathrm{~W}$ losses.

Efficiency drop in V3 converter is moderate and is within expected range; however, 3.7\% efficiency drop in V6 converter is quite large and unexpected. As a result, V3 converter exhibits better efficiency during regulated converter mode.

Majority of additional losses are because of freewheeling in the primary during regulated converter mode. During freewheeling period, large amount of current circulates in the primary side of transformer and incurs additional losses without delivering power. Both converters suffer from conduction losses during freewheeling, and actual losses from freewheeling should be similar.

In addition to the losses from freewheeling, V6 suffers from higher losses than V3, and several reasons can be speculated for lower efficiency in V6. One major reason can be hypothesize to higher switching losses in V6. In MOSFET applications, turn-off losses are negligible, while turn-on losses are significantly higher than turn-off losses. In dc transformer mode, V6 achieved soft-switching on all switches during turn-on sequence; however, V6 leading leg turn-on sequence loses zero-current switching (ZCS) during regulated converter mode. Due to hard commutation on leading leg, significant amount of switching losses may occur during regulated converter mode. In comparison, V3 converter maintains ZVS turn-on in both regulated converter mode and dc transformer mode.

Although V6 suffer from higher losses, higher switching losses can not be blamed for all the additional losses, and other factors may contribute. For example, turn on and turn off speed of gate drive is optimized for dc transformer mode; however, the optimization might not be optimal for regulated converter mode. Additionally, circuit layout and phase parameter mismatch may cause problem and lower efficiency in regulated converter mode. Although lower efficiency is observed, exact causes are inconclusive. 
The converters are tested with $50 \mathrm{~V}$ input, approximately $350 \mathrm{~V}$ output, $30 \%$ duty cycle for V3 and $105^{\circ}$ modulation angle for V6.

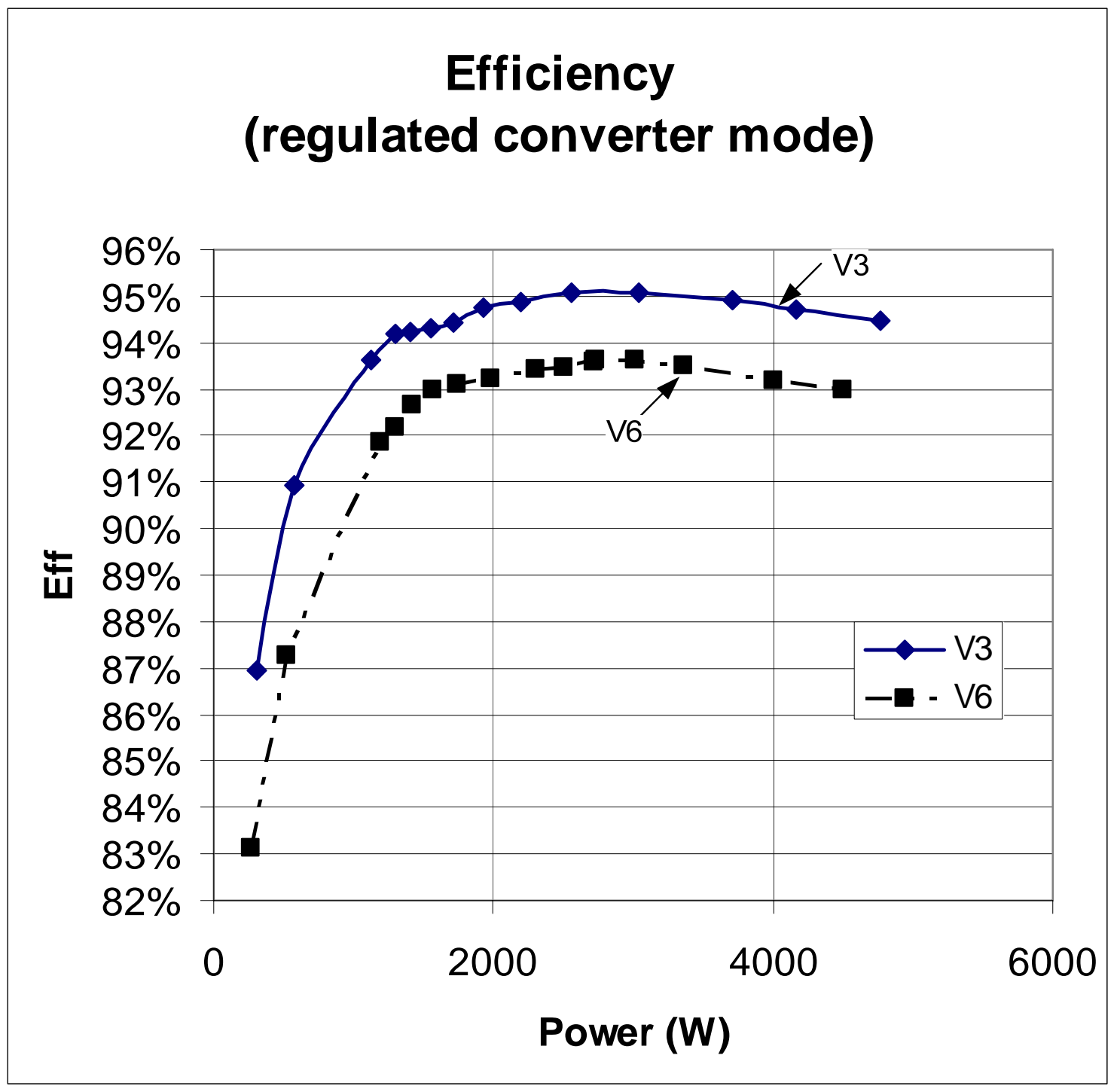

Figure 4.34 - Prototype converter efficiency in regulated converter mode 


\section{Conclusion AND Future ReSEARCh DiRECTION}

The main objectives of the thesis are to find and to evaluate suitable dc-dc converters for low-voltage, high-power fuel cell applications, particularly the dc-dc converters in distributed power applications, such as standalone and utility grid-tie applications. Among different advanced dc-dc converters, soft-switching capable, multiphase converters are the main focus of the research. The multiphase structures allow the current sharing among phases to reduce device current stresses, and interleaving control schemes reduce the ripple currents in passive components. The soft-switching mechanisms allow the reduction of switching losses and are significant to achieve highefficiency power conversions.

Two multiphase converters, V3 and V6, are evaluated and proved to provide high conversion ratios under high-current conditions with excellent efficiencies, which are required for low-voltage, high-power fuel cell applications. In the low-voltage, highpower applications, the majority of losses can be attributed to the high conduction losses from high current operating conditions. High efficiency is obtained with lowering conduction losses by lowering the ohmic resistances of current paths and reducing RMS currents. Power semiconductor devices are properly selected to minimize ohmic resistance, and prototypes are carefully constructed to reduce parasitic elements. Additionally, the intrinsic operating characteristics of the multiphase converters ensure current sharing between phases to reduce RMS current per phase. In order to further improve efficiency, both converters provide soft-switching mechanisms for even higher efficiency. The soft-switching is achieved without any additional circuitry, which is highly attractive for high-power converters.

Efficiency is considered to be the most important performance index in all the energy related application. V3 converter achieved peak efficiency of 96.8\% and V6 achieved peak efficiency of 97.2\%. V6 demonstrated a higher efficiency than V3 during dc transformer mode, thus V6 is recommended for two stage power conversion, such as stand-alone and utility grid-tied applications. In such applications, intermediate outputs from the dc-dc converters can be loosely regulated, since subsequent dc-ac inverters 
tightly regulate final outputs. In medium to heavy load, the converters are recommended to run in the dc transformer mode, where efficiency is the highest. During light load conditions, the efficiency is sacrificed to achieve output regulation.

While V6 shows a higher efficiency under the dc transformer mode, V3 demonstrates a higher efficiency during regulated converter mode, thus V3 is recommended for single stage power conversion, such as battery charging. In such applications, the dc-dc converters are responsible for final outputs, thus the converters are required to run in the regulated converter mode in most loading conditions. In such conditions, V3 exhibits a higher efficiency for the majority of operating condition.

V3 and V6 converters are multiphase isolated dc-dc converters which proved to be suitable for the low-voltage, high-power fuel cell applications. These multiphase converters are also suitable for other low-voltage applications, such as photovoltaic power conditioning systems and battery-power uninterruptible power systems.

\subsection{Direction of Future Research}

The research presented in this thesis summarizes two multiphase isolated dc-dc converters; however, it is not a comprehensive analysis of multiphase converters. There are still many aspects of researches to be done. Such are listed below.

- Further topology research

o Literature survey is conducted only within dc-dc converter topologies. There may be some potential dc-ac inverter topologies that have distinctive features for low-voltage, high-power dc-dc converter applications.

o Different secondary options, such as synchronized rectifications, current triplers, and/or hybridge rectifiers, can be applied for V3 and V6.

o Coupled three-phase transformers, instead of three single-phase transformers, can be utilized

o Both V3 and V6 are buck-type topologies, but boost-type topology can be also adopted for V3 and V6. It is worth of comparing the efficiency and cost between voltage-source and current-source type of V3 and V6. 
- Control scheme study

o V3 utilizes asymmetrical duty cycle control and V6 utilize phase-shift modulation control. V6 may be able to adopt hybrid of the asymmetrical duty cycle and the phase-shift modulation control to achieve better softswitching.

o Suitable control techniques for different fuel cell applications can be dervied.

o The thesis is mainly focused in large-signal analysis. Small-signal analysis is also needed. 


\section{REFERENCES}

[1] EG\&G Technical Services, Fuel Cell Handbook, Seventh Sixth Edition, DE-AM2699FT40575, November 2004.

[2] US DOE National Energy Technology Laboratory, 2005 Office of Fossil Energy Fuel Cell Program Annual Report, September 2005.

[3] Energy Information Administration, "International Energy Annual 2004," 1.8 World Consumption of Primary Energy by Energy Type and Selected Country Groups (Quadrillion Btu), 1980-2004. 31 July 2006. 1 March 2007. $<$ http://www.eia.doe.gov/pub/international/iealf/table18.xls>

[4] Fuel Cell Technologies, LTD., "Technical Specification/Operators Manual for the 5kW SOFC Simulator,” 14 April 2005.

[5] Lai, Jih-Sheng, "A High-Efficiency Low-Cost DC-DC Converter for SOFC," Presentation on SECA Core Technology Program Review Meeting, May 11-13, 2004, Boston, Massachusetts.

[6] G. Fontes, C. Turpin, R. Saisset, T. Meynard, and S. Astier, "Interactions Between Fuel Cells and Power Converters Influence of Current Harmonics on a Fuel Cell Stack," Proc. of IEEE Power Electronics Specialists Conference, Aachen, Germany, June 2004, pp. 4729 - 4735.

[7] Gemmen, R. S., "Analysis for the effect of inverter ripple current on fuel cell operating condition,” J. Fluids Eng., vol. 125, no. 3, 2003, pp. 576-585.

[8] Moon, S. R.; J. S. Lai; S. Y. Park; C. Liu, "Impact of SOFC fuel Cell Source Impedance on Low Frequency AC Ripple ," Power Electronics Specialists Conference, 2006. 37th IEEE, Vol., Iss., 18-22 June 2006 Pages: 1- 6

[9] Erickson, Robert W. and Dragan Maksimovic, Fundamentals of Power Electronics, 2nd ed.; Norwell, Mass.: Kluwer Academic, c 2001. xxi, 883 p. ISBN: 0792372700 (alk. paper); LCCN: 00052569

[10] Lee, F.C., "High-frequency quasi-resonant converter technologies," Proceedings of the IEEE , vol.76, no.4pp.377-390, Apr 1988 
[11] Aydemir, M.T.; Bendre, A.; Venkataramanan, G., "A critical evaluation of high power hard and soft switched isolated DC-DC converters," Industry Applications Conference, 2002. 37th IAS Annual Meeting. Conference Record of the , vol.2, no.pp. 1338- 1345 vol.2, 2002

[12] Sabate, J.A.; Vlatkovic, V.; Ridley, R.B.; Lee, F.C.; Cho, B.H., "Design considerations for high-voltage high-power full-bridge zero-voltage-switched PWM converter," Applied Power Electronics Conference and Exposition, 1990. APEC '90, Conference Proceedings 1990., Fifth Annual, vol., no.pp.275-284, 11-16 Mar 1990

[13] Lotfi, A.W.; Chen, Q.; Lee, F.C., "Nonlinear optimisation tool for the full-bridge zero-voltage-switched DC-DC convertor," Electric Power Applications, IEE Proceedings B [see also IEE Proceedings-Electric Power Applications], vol.140, no.5pp.289-296, Sep 1993

[14] Cho, J.G.; Sabate, J.A.; Lee, F.C., "Novel full bridge zero-voltage-transition PWM DC/DC converter for high power applications," Applied Power Electronics Conference and Exposition, 1994. APEC '94. Conference Proceedings 1994., Ninth Annual , vol., no.pp.143-149 vol.1, 13-17 Feb 1994

[15] Cho, J.G.; Baek, J.W.; Yoo, D.W.; Lee, H.S.; Rim, G.H., "Novel zero-voltage and zero-current-switching (ZVZCS) full bridge PWM converter using transformer auxiliary winding," Power Electronics Specialists Conference, 1997. PESC '97 Record., 28th Annual IEEE , vol.1, no.pp.227-232 vol.1, 22-27 Jun 1997

[16] Jung-Goo Cho; Sabate, J.A.; Guichao Hua; Lee, F.C., "Zero-voltage and zerocurrent-switching full bridge PWM converter for high-power applications," Power Electronics, IEEE Transactions on , vol.11, no.4pp.622-628, Jul 1996

[17] Cho, J.G.; Baek, J.W.; Jeong, C.Y.; Yoo, D.W.; Lee, H.S.; Rim, G.H., "Novel zerovoltage and zero-current-switching (ZVZCS) full bridge PWM converter using a simple auxiliary circuit," Applied Power Electronics Conference and Exposition, 1998. APEC '98. Conference Proceedings 1998., Thirteenth Annual , vol.2, no.pp.834-839 vol.2, 15-19 Feb 1998

[18] Baek, J.W.; Cho, J.G.; Yoo, D.W.; Rim, G.H.; Kim, H.G., "An improved zero voltage and zero current switching full bridge PWM converter with secondary 
active clamp," Power Electronics Specialists Conference, 1998. PESC 98 Record. 29th Annual IEEE , vol.2, no.pp.948-954 vol.2, 17-22 May 1998

[19] Prasad, A.R.; Ziogas, P.D.; Manias, S., "Analysis and design of a three-phase offline DC-DC converter with high frequency isolation," Industry Applications Society Annual Meeting, 1988., Conference Record of the 1988 IEEE , vol., no.pp.813-820 vol.1, 2-7 Oct 1988

[20] Prasad, A.R.; Ziogas, P.D.; Manias, S., "A three-phase resonant PWM DC-DC converter," Power Electronics Specialists Conference, 1991. PESC '91 Record., 22nd Annual IEEE , vol., no.pp.463-473, 24-27 Jun 1991

[21] Bhat, A.K.S.; Zheng, L., "A three-phase series-parallel resonant converter-analysis, design, simulation and experimental results," Industry Applications Conference, 1995. Thirtieth IAS Annual Meeting, IAS '95., Conference Record of the 1995 IEEE , vol.3, no.pp.2373-2380 vol.3, 8-12 Oct 1995

[22] Jacobs, J.; Averberg, A.; De Doncker, R., "A novel three-phase DC/DC converter for high-power applications," Power Electronics Specialists Conference, 2004. PESC 04. 2004 IEEE 35th Annual, vol.3, no.pp. 1861- 1867 Vol.3, 20-25 June 2004

[23] Zhou, J.; Xu, M.; Lee, F.C., "A novel current-tripler DC/DC converter," Power Electronics Specialist Conference, 2003. PESC '03. 2003 IEEE 34th Annual, vol.3, no.pp. 1373- 1378 vol.3, 15-19 June 2003

[24] Oliveira, D.S., Jr.; Barbi, I., "A three-phase version of the hybridge rectifier associated to the three-phase ZVS DC/DC converter with asymmetrical duty cycle," Industrial Electronics, 2003. ISIE '03. 2003 IEEE International Symposium on , vol.1, no.pp. 516- 520 vol. 1, 9-11 June 2003

[25] Oliveira, D.S., Jr.; Barbi, I., "A three-phase ZVS PWM DC/DC converter with asymmetrical duty cycle for high power applications," Power Electronics Specialist Conference, 2003. PESC '03. 2003 IEEE 34th Annual, vol.2, no.pp. 616- 621 vol.2, 15-19 June 2003

[26] Liu, C.; Johnson, A.; Lai, J.-S., "A novel three-phase high-power soft switched DC/DC converter for low voltage fuel cell applications," Applied Power Electronics 
Conference and Exposition, 2004. APEC '04. Nineteenth Annual IEEE, vol.3, no.pp. 1365- 1371 Vol.3, 2004

[27] Oliveira, S.V.G.; Barbi, I., "A three-phase step-up DC-DC converter with a threephase high frequency transformer," Industrial Electronics, 2005. ISIE 2005. Proceedings of the IEEE International Symposium on , vol.2, no.pp. 571- 576 vol. 2, 20-23 June 2005

[28] Liu, C, A. Johnson, J. S. Lai, "A novel phase-shifting circuit using digital first-infirst-out (FIFO) for multiphase power converter interleaved control," Computers in Power Electronics, 2004. 2004 IEEE Workshop. 15-18 Aug. 2004. 


\section{VITA}

Seung-Ryul Moon, son of Young-Chul Moon and Hyun-Sook Kim, was born in Seoul, Republic of Korea on the 7th day of September, 1981. He was raised mostly in the suburban of Seoul until the age of 15, and in summer of 1996, he moved to the United States of America to study abroad.

He received the B.S. degree in Computer Engineering from Virginia Polytechnic Institute and State University (Virginia Tech) at Blacksburg, Virginia in 2000. In fall 2000, he joined the Future Energy Electronics Center (FEEC) at Virginia Tech as a research assistant. During his staying at Virginia Tech, he engaged in research in the areas of high-frequency power converter topologies, soft-switching techniques, modeling and control of power converters, power converter for fuel cell applications, and distributed power systems. 